\title{
Crowdsourcing Neighbourhood Delineations in Wellington, New Zealand
}

\section{Hayden Rickard}

A thesis submitted to Victoria University of Wellington in partial fulfilment of the requirements for the degree of Master of Science in Geographic Information Science

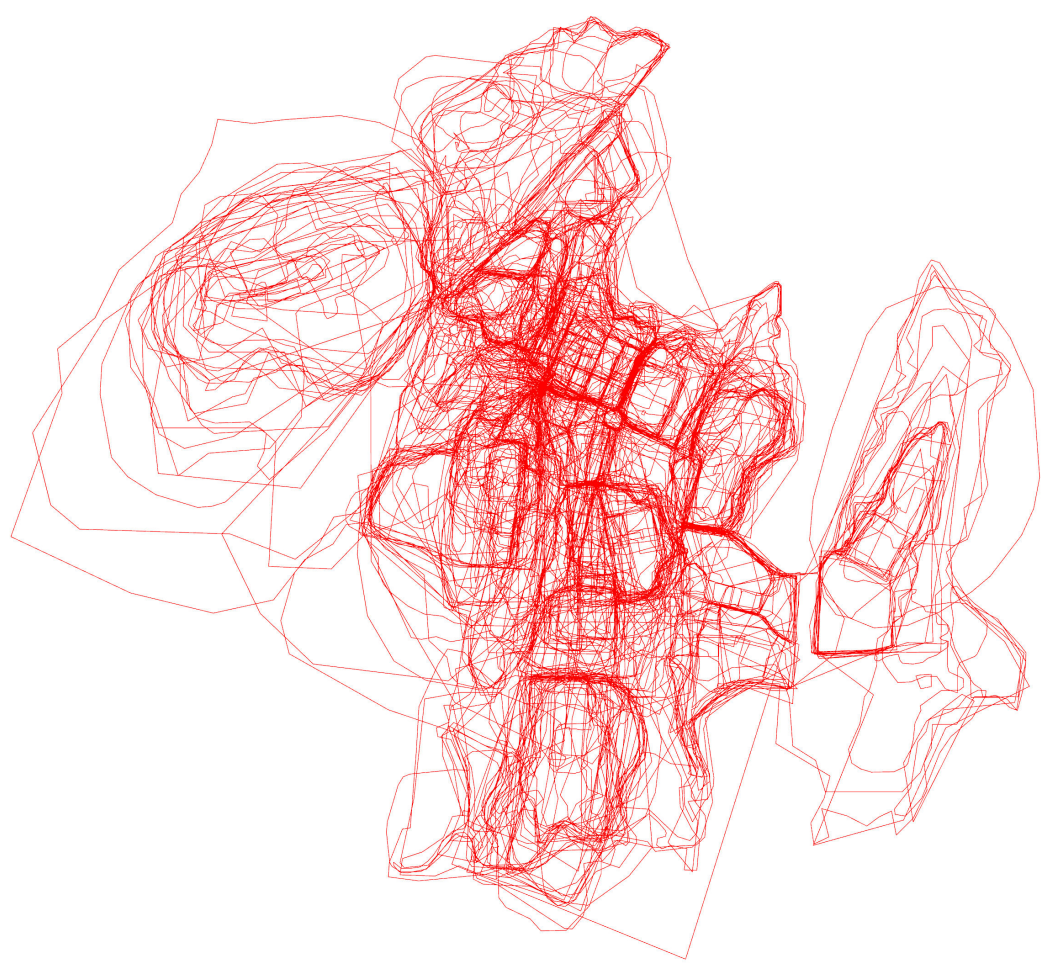

School of Geography, Environment, and Earth Sciences

Victoria University of Wellington

2020

\section{Supervisors:}

Dr. Mairéad de Róiste

Professor David O'Sullivan 


\begin{abstract}
Neighbourhoods are important in our everyday lives, but physical definitions of neighbourhoods are often ambiguous. Official representations of neighbourhood boundaries used to present geographic outcomes poorly reflect individuals' perceptions of their neighbourhoods. Existing methods of collecting neighbourhood delineations commonly consist of small sample sizes or stratified surveys on residents of individual neighbourhoods. By reducing effort and potentially increasing response rates, a crowdsourcing approach may be effective in collecting neighbourhood delineations across an entire city.

This thesis presents results from a web-based application used to crowdsource neighbourhood delineations from residents of Wellington City, Aotearoa-New Zealand. Over eight hundred responses were analysed to investigate how personal characteristics impact neighbourhood boundaries, determine areas of shared neighbourhood geographies based on overlapping demarcations, and examine how participants neighbourhood delineations compare to official representations of neighbourhoods. Case studies of a range of geographic features are provided to explore how they impact neighbourhood delineations.

This thesis found transport choices significantly impact perceived neighbourhood area; neighbourhood areas differ markedly in terms of consensus about their boundaries; and there are both similarities and discrepancies between official and perceived neighbourhood boundaries. A variety of geographic features were found to function as different perceptual elements in informing neighbourhood delineations. Crowdsourcing was a practical method to collect neighbourhood perceptions with possible implications for official neighbourhood boundaries. Finally, recommendations for future research aiming to crowdsource neighbourhood delineations were made with a combination of quantitative and qualitative methods being of high value.
\end{abstract}




\section{ACKNOWLEDGEMENTS}

First, I would like to thank my supervisors: Dr. Mairéad de Róiste and Professor David O'Sullivan.

This thesis would not have been possible without your guidance, support, and skill in reining me in when my ideas became too grand. I particularly enjoyed using both of you as a diverse test sample of two Irish academics with children when chatting about the questionnaire. Thank you as well to Andy Rae for the help installing packages, setting up environments, and for the great yarns.

Thank you to my partner, Ella. Your support and capacity to listen me rant about the deep intricacies of Wellington's neighbourhoods over the past year has been phenomenal. Also, thank you to Neil. You were a great motivator and provided lots of entertainment, even if you did regularly yell and wake me up at 6am. A big thank you to all my thesis friends in CO102A: Aaron, Sylvie, Sarah, HanLing, Amelia, JoJo, Mel, and of course, Victor. I consider myself lucky to have met you all and hope to continue the 3pm quiz tradition. Tom, thank you for listening, even if you are an Arsenal supporter. I would also like to thank my parents, Graham and Sandra, for their backing throughout my thesis.

Finally, thank you to everyone that took the time out of their day to complete my survey. The amount of responses and positive feedback I received was astounding, and without your contributions I would not have been able to complete as much I did. 


\section{Contents}

$\begin{array}{ll}\text { Abstract } & \text { iii }\end{array}$

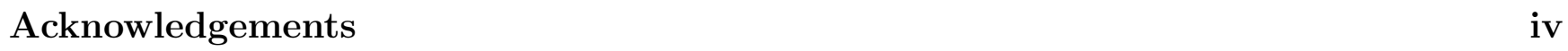

\begin{tabular}{ll}
\hline Table of Contents & v \\
\hline
\end{tabular}

$\begin{array}{ll}\text { List of Figures } & \text { ix }\end{array}$

\begin{tabular}{lr}
\hline List of Tables & xii
\end{tabular}

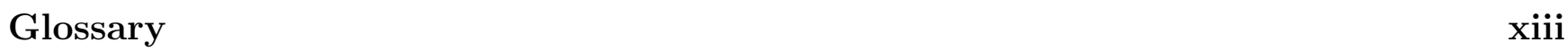

\begin{tabular}{lll}
\hline 1 & Introduction & 1
\end{tabular}

1.1 Background . . . . . . . . . . . . . . . . . . . . . . 1

1.2 Problem . . . . . . . . . . . . . . . . . . . . . . . 2

1.3 Research Questions . . . . . . . . . . . . . . . . . . . . . 3

1.4 Thesis Structure . . . . . . . . . . . . . . . . . . . . . . . . . . . . 4

\begin{tabular}{|lrr}
\hline 2 & Literature Review & 6
\end{tabular}

2.1 Introduction . . . . . . . . . . . . . . . . . . . . . . . . . . . . . . . . . 6

2.2 The Neighbourhood $\ldots \ldots \ldots$. . . . . . . . . . . . . . . . . . . . . . . . . . . . 6

$2.2 .1 \quad$ Representing Neighbourhoods using Predefined Boundaries . . . . . . . . . . 6

$2.2 .2 \quad$ Other Approaches of Representing Neighbourhoods . . . . . . . . . . . . . . 8

2.2 .3 Perceived Neighbourhoods . . . . . . . . . . . . . . . . . . . . . 9

2.3 Crowdsourcing Neighbourhood Delineations . . . . . . . . . . . . . . . . . . . . . . 12

$2.3 .1 \quad$ Volunteered Geographic Information (VGI) . . . . . . . . . . . . . . . . . . 13

2.3 .2 Geographical Citizen Science (GCS) . . . . . . . . . . . . . . . . . . 15

2.3 .3 Public Participation GIS (PPGIS) . . . . . . . . . . . . . . . . . . . . 15

2.3 .4 Placing a Crowdsourcing Approach . . . . . . . . . . . . . . . . . . . 16

2.3 .5 Limitations of Crowdsourcing . . . . . . . . . . . . . . . . . . 17

2.4 Summary . . . . . . . . . . . . . . . . . . . . . . . . . . . 18 
$\begin{array}{lll}3 & \text { Methodology } & 20\end{array}$

3.1 Introduction . . . . . . . . . . . . . . . . . . . . . . . . . 20

3.2 Area of Interest: Wellington City, New Zealand . . . . . . . . . . . . . . . . 21

3.3 Questionnaire Development . . . . . . . . . . . . . . . . . . . . . . 21

3.3 .1 Neighbourhood Factors . . . . . . . . . . . . . . . . . . . . . 22

3.3 .2 Demographic Information $\ldots \ldots \ldots \ldots \ldots \ldots$

3.3 .3 Children . . . . . . . . . . . . . . . . . . . . . . . . . . 24

3.3 .4 Transport Decisions . . . . . . . . . . . . . . . . . . . 24

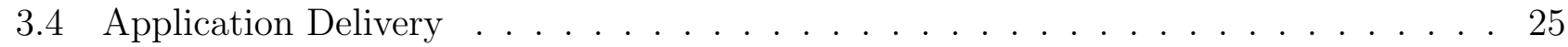

3.4 .1 Bostonography: Hoods Project _ . . . . . . . . . . . . . 25

3.4 .2 Wellyhoods App . . . . . . . . . . . . . . . . . . 26

3.4 .3 User Testing . . . . . . . . . . . . . . . . . . . . . . . . . . . . . . . . 28

$3.4 .4 \quad$ Application Launch . . . . . . . . . . . . . . . . . . . . . . . . . . . . . . . . . 29

3.5 Analysis $\ldots \ldots \ldots \ldots \ldots \ldots$

3.5 .1 Data Cleaning . . . . . . . . . . . . . . . . . . . . . 31

3.5 .2 Statistical Analysis $\ldots \ldots \ldots \ldots \ldots$

3.5 .3 Neighbourhood Consensus . . . . . . . . . . . . . . . . . . . . . 34

3.5 .4 Comparisons to Official Boundaries . . . . . . . . . . . . . . . . 38

3.6 Summary . . . . . . . . . . . . . . . . . . . . . . . . . . . . 41

\begin{tabular}{|lll}
4 & Results & 42
\end{tabular}

4.1 Introduction . . . . . . . . . . . . . . . . . . . . . . . . . . . . . . 42

4.1 .1 Geographic Distribution . . . . . . . . . . . . . . . . . . . . . 42

4.2 Personal Characteristic Analysis $\ldots \ldots \ldots \ldots \ldots$. . . . . . . . . . . . . 44

4.2 .1 Age and Gender . . . . . . . . . . . . . . . . . . . . 44

4.2 .2 Neighbourhood Factors . . . . . . . . . . . . . . . . . . . . . 45

4.2 .3 Children . . . . . . . . . . . . . . . . . . . . . . . . . . . 48

4.2 .4 Transport Decisions $\ldots \ldots \ldots \ldots$. . . . . . . . . . . . . . . . . . 48

4.2 .5 Neighbourhood Dimensions Correlations … . . . . . . . . . . 52

4.3 Neighbourhood Consensus $\ldots \ldots \ldots \ldots \ldots$

4.3 .1 Hexagon Grids $\ldots \ldots \ldots \ldots$

4.3 .2 Neighbourhood Connectivity . . . . . . . . . . . . . . . . . . 58

4.3 .3 Focal Point Clustering . . . . . . . . . . . . . . . . . . . 63

4.4 Comparisons to Official Boundaries $\ldots \ldots \ldots \ldots \ldots$. . . . . . . . . . . 67

4.4 .1 Neighbourhood Dimensions $\ldots \ldots \ldots 7$. . . . . . . . . . . . 67

4.4 .2 Congruence . . . . . . . . . . . . . . . . . . . . . . . . . . . . . . . . . 69

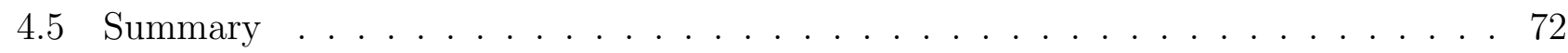


$\begin{array}{lll}5 & \text { Case Studies } & 73\end{array}$

5.1 Introduction . . . . . . . . . . . . . . . . . . . . . . . 73

5.2 Man-made Features . . . . . . . . . . . . . . . . . . . . . . . . . . . . . . 74

5.2 .1 Cambridge and Kent Terraces . . . . . . . . . . . . . . . . . . . . . . 74

5.2 .2 Cuba Street . . . . . . . . . . . . . . . . . . . 77

5.2 .3 Brooklyn Wind Turbine . . . . . . . . . . . . . . . . . . . 80

5.2 .4 Karori Tunnel . . . . . . . . . . . . . . . . . . . . . . . . . . 84

5.2 .5 Mt Victoria Lookout . . . . . . . . . . . . . . . . . . . . . . . . . . . . . . . 87

5.2 .6 Wellington Airport . . . . . . . . . . . . . . . . . . . . . 90

5.3 Natural Features $\ldots \ldots \ldots$. . . . . . . . . . . . . . . . . . . . . . . 93

5.3 .1 Wellington Botanic Gardens . . . . . . . . . . . . . . . . . . . . 93

5.3 .2 Wakefield Park and the Green Belt . . . . . . . . . . . . . . . . . . . . . . . 96

5.3 .3 Taputeranga Island . . . . . . . . . . . . . . . . . . . . . . . . . . . . . . . . 99

5.3 .4 Shorelines . . . . . . . . . . . . . . . . . . . . . . 102

5.3 .5 Hutt River . . . . . . . . . . . . . . . . . . . . . . 107

5.4 Summary . . . . . . . . . . . . . . . . . . . . . 109

\begin{tabular}{lll}
\hline 6 & Discussion & 111
\end{tabular}

6.1 Introduction . . . . . . . . . . . . . . . . . . . . . . . . . . 111

6.2 Personal Characteristics . . . . . . . . . . . . . . . . . . . . . 111

6.2 .1 Overall Dataset . . . . . . . . . . . . . . . . . . . . . . 112

6.2 .2 Age and Gender . . . . . . . . . . . . . . . . . . . . . . . . 112

6.2 .3 Neighbourhood Factors . . . . . . . . . . . . . . . . . . . . . . 113

6.2 .4 Transport . . . . . . . . . . . . . . . . . . . . . 114

6.2 .5 Suitability of Neighbourhood Dimensions . . . . . . . . . . . . . . . . . 116

6.3 Neighbourhood Consensus ． . . . . . . . . . . . . . . . . . . . . . . . 117

6.3 .1 Hexagon Grids . . . . . . . . . . . . . . . . . . 117

6.3 .2 Neighbourhood Connectivity . . . . . . . . . . . . . . . . . 118

6.4 Official Boundaries Comparisons . . . . . . . . . . . . . . . . . . . . . . . 119

6.4 .1 Neighbourhood Dimensions . . . . . . . . . . . . . . . . . . 120

6.4 .2 Congruence . . . . . . . . . . . . . . . . . . . . . 121

6.4 .3 Perspective for Official Boundaries . . . . . . . . . . . . . . . . . . . . 121

6.5 Lynch's Five Elements . . . . . . . . . . . . . . . . . . . . . . . . . . . . . . . . . . 123

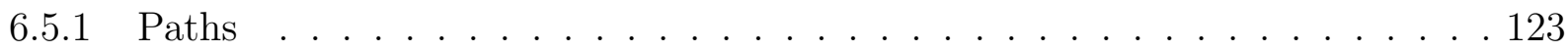

6.5 .2 Edges . . . . . . . . . . . . . . . . . . . . . 124

6.5 .3 Districts . . . . . . . . . . . . . . . . . . . . 124

6.5 .4 Nodes . . . . . . . . . . . . . . . . . . . . 126 
6.5 .5 Landmarks . . . . . . . . . . . . . . . . . . . . . . . . 128

6.5 .6 Limitations . . . . . . . . . . . . . . . . . . . . . . . . . . . . . . 129

6.6 Viability of the Crowdsourcing Approach . . . . . . . . . . . . . . . . . . 130

6.6 .1 Neighbourhood Survey: Wellington City . . . . . . . . . . . . . . . . 131

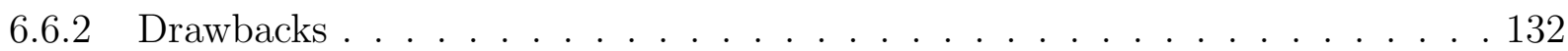

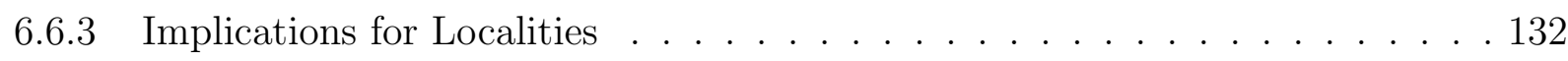

6.7 Summary . . . . . . . . . . . . . . . . . . . . . . . . . . . 134

$\begin{array}{lll}7 & \text { Conclusion } & 135\end{array}$

7.1 Answering the Research Questions. . . . . . . . . . . . . . . . . . . . . 135

7.2 Future Research Directions . . . . . . . . . . . . . . . . . . . . . . . . 138

7.3 Final Remarks . . . . . . . . . . . . . . . . . . . . . . . . . . . . . . . . 139

\begin{tabular}{ll}
\hline References & 140
\end{tabular}

\begin{tabular}{ll}
\hline Appendix 1: Questionnaire & 151
\end{tabular}

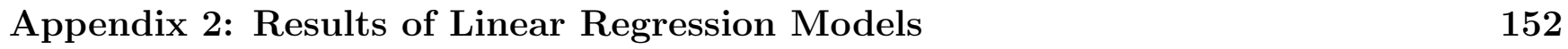




\section{List of Figures}

Figure 2.1 26,518 GeoNet Felt Reports to a 5.4 Magnitude Earthquake on 25/01/2020 . 14

Figure 2.2 Placing Crowdsourcing Approaches in the context of Application Motivation and Contributor Expertise . . . . . . . . . . . . . . . . . . 17

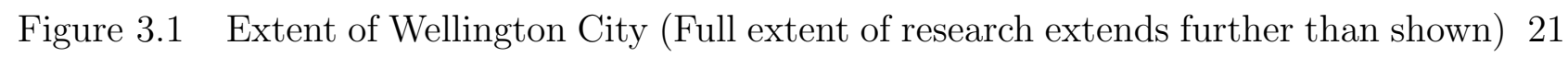

Figure $3.2 \quad$ Landing Page of the Bostonography Hoods Project . . . . . . . . . . . . . . 26

Figure $3.3 \quad$ Wellyhoods Data Collection Process: Steps 1 and 2 . . . . . . . . . . . . . . 27

Figure 3.4 $\quad$ Basemaps of Bostonography's Hoods Project and Wellyhoods App . . . . . . 28

Figure 3.5 $\quad$ Poster advertising the Wellyhoods app . . . . . . . . . . . . . . . . . . . . . 30

Figure 3.6 Example excluded PNBs . . . . . . . . . . . . . . . . . . . . . . . . . . . . . 31

Figure $3.7 \quad$ Example PNBs with Low and High Compactness . . . . . . . . . . . . . . . 33

Figure $3.8 \quad$ Distribution of PNB Area before and after $\log$ transformation . . . . . . . . 34

Figure $3.9 \quad$ Example Hexagon Cluster . . . . . . . . . . . . . . . . . . . . . . . . . . . . 35

Figure 3.10 Comparison between Mean and Median Centre Methods . . . . . . . . . . . 37

Figure 3.11 Example of Shopping Hub Median Centroid Buffer in Brooklyn . . . . . . . 38

Figure 3.12 Localities in Wellington City (Full extent of research extends further than

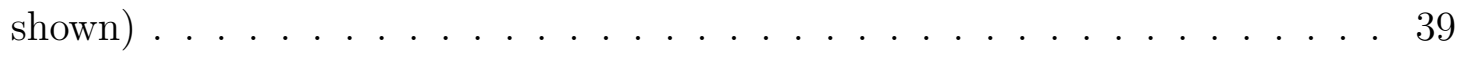

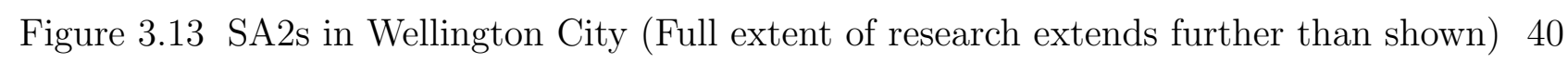

Figure 3.14 Example PNBs and overlapping Locality boundaries . . . . . . . . . . . . . 41

Figure $4.1 \quad$ Geographic Distribution of all PNBs and FPs . . . . . . . . . . . . . . . . . 43

Figure 4.2 Geographic Distribution of PNBs and FPs in Wellington City . . . . . . . . 43

Figure $4.3 \quad$ Interface of the Neighbourhood Data Explorer App . . . . . . . . . . . . . . 44

Figure $4.4 \quad$ Years Lived in Neighbourhood: Area Boxplots . . . . . . . . . . . . . . . . . 46

Figure $4.5 \quad$ Neighbourhood Type: Area Boxplots . . . . . . . . . . . . . . . . . . . . . . 47

Figure 4.6 Days Spent Using a Car in an Average Week: PNB Area Boxplots. . . . . . 50

Figure 4.7 Days Spent Cycling in an Average Week: PNB Area Boxplots . . . . . . . . 51

Figure 4.8 Days Spent Walking in an Average Week: Area Boxplots . . . . . . . . . . . 52

Figure $4.9 \quad$ Neighbourhood Density by Hexagon . . . . . . . . . . . . . . . . . . . . . . 54

Figure 4.10 Neighbourhood Consensus: Unique Neighbourhood Names . . . . . . . . . . 55

Figure 4.11 Neighbourhood Consensus: Common Neighbourhood Names . . . . . . . . . 56 
Figure 4.12 Karori Neighbourhood Consensus using Unique and Common Names . . . . 57

Figure 4.13 Community Defined Neighbourhoods . . . . . . . . . . . . . . . . . . . . . . 58

Figure 4.14 Neighbourhood Connectivity . . . . . . . . . . . . . . . . . . . . . . . . . . . 59

Figure 4.15 Neighbourhood Connectivity: Weighted by Number of Intersections . . . . . 60

Figure 4.16 Neighbourhood Connectivity: Weighted by Intersection Area . . . . . . . . . 61

Figure 4.17 Neighbourhood Connectivity Weighted by Interaction Area: Karori and

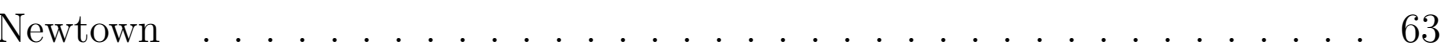

Figure 4.18 FP Density Based Clusters (DBSCAN) . . . . . . . . . . . . . . . . . . . . . 64

Figure 4.19 FPs and Shopping Hub: Brooklyn . . . . . . . . . . . . . . . . . . . . . . . . 64

Figure 4.20 FPs and Shopping Hub: Lyall Bay . . . . . . . . . . . . . . . . . . . . . . . 65

Figure 4.21 Neighbourhood Consensus (Common Name) and FPs for Newtown . . . . . 66

Figure 4.22 Example CDN and Locality Polygons for Aro Valley . . . . . . . . . . . . . 68

Figure 4.23 SA2 and Locality Boundaries for Newtown . . . . . . . . . . . . . . . . . . . 70

Figure 4.24 Lowest and Highest Congruence PNB and Locality Boundaries . . . . . . . . 71

Figure 4.25 PNBs and Locality Boundary: Petone . . . . . . . . . . . . . . . . . . . . . 72

Figure 5.1 Cambridge and Kent Terrace . . . . . . . . . . . . . . . . . . . . . . . . . 75

Figure 5.2 Te Aro and Mt Victoria PNBs, and Cambridge and Kent Terraces . . . . . . 76

Figure 5.3 Proportion of Mt Victoria and Te Aro PNB Borders in a 50 metre Buffer of Cambridge and Kent Terraces . . . . . . . . . . . . . . . . 76

Figure $5.4 \quad$ Cambridge and Kent Terrace, and Neighbourhood Consensus. . . . . . . . . 77

Figure 5.5 The Bucket Fountain in Action . . . . . . . . . . . . . . . . . . . . . . . . . 78

Figure 5.6 Cuba Street PNBs and FPs . . . . . . . . . . . . . . . . . . . . . . . . . . . . 79

Figure 5.7 FPs within 25 metres of Cuba Street . . . . . . . . . . . . . . . . . . . . . . 80

Figure $5.8 \quad$ Brooklyn Wind Turbine and Navigation Street Sign . . . . . . . . . . . . . . 81

Figure 5.9 $\quad$ Brooklyn PNBs and FPs . . . . . . . . . . . . . . . . . . . . . . . . . . . . . 82

Figure 5.10 Distance Between Brooklyn Wind Turbine and Main Intersection . . . . . . 83

Figure 5.11 Brooklyn PNBs with and without the wind turbine included . . . . . . . . . 84

Figure 5.12 Eastern Entrance of the Karori Tunnel . . . . . . . . . . . . . . . . . . . . . 85

Figure 5.13 Karori and Kelburn PNBs . . . . . . . . . . . . . . . . . . . . . . . . . . . . 86

Figure 5.14 Karori and Kelburn Neighbourhood Consensus . . . . . . . . . . . . . . . . . 87

Figure 5.15 View from Mt Victoria Lookout and Walkway Signs . . . . . . . . . . . . . . 88

Figure 5.16 PNBs of Mt Victoria, Hataitai, and Roseneath . . . . . . . . . . . . . . . . . 89

Figure 5.17 Mt Victoria PNBs with and without the lookout included. . . . . . . . . . . 90

Figure 5.18 Wellington Airport . . . . . . . . . . . . . . . . . . . . . . . . . . . . . . 91

Figure 5.19 Wellington Airport Extent and Surrounding PNBs . . . . . . . . . . . . . . 92

Figure 5.20 Wellington Airport and Surrounding Neighbourhood Consensus . . . . . . . 93 
Figure 5.21 Wellington Botanic Gardens … . . . . . . . . . . . . . . . . . . 94

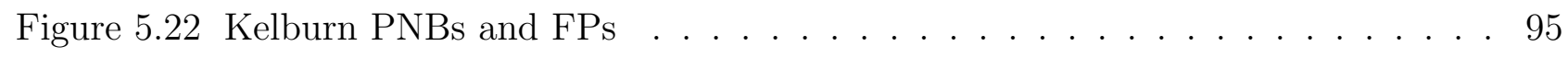

Figure 5.23 Kelburn and Botanic Gardens Consensus: Common Names . . . . . . . . . . 96

Figure 5.24 Wakefield Park . . . . . . . . . . . . . . . . . . . . . . 97

Figure 5.25 Extent of Wakefield Park and Green Belt . . . . . . . . . . . . . . . . . 97

Figure 5.26 Island Bay and Berhampore PNBs Overlaid with Wakefield Park and Green

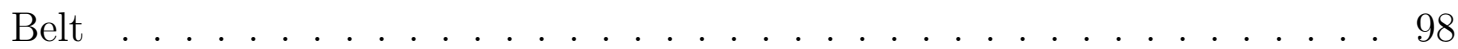

Figure 5.27 Wakefield Park Consensus … . . . . . . . . . . . . . . . . . . . . 99

Figure 5.28 Taputeranga Island seen from Island Bay's Shoreline . . . . . . . . . . . . . 100

Figure 5.29 Island Bay PNBs and FPs . . . . . . . . . . . . . . . . . . . . . . 101

Figure 5.30 Island Bay PNBs with and without Taputeranga Island included . . . . . . 102

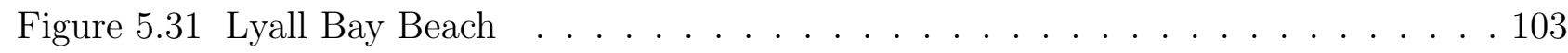

Figure 5.32 Lyall Bay PNBs and FPs. . . . . . . . . . . . . . . . . . . . . . . 104

Figure 5.33 Petone seen from above … . . . . . . . . . . . . . . . . 105

Figure 5.34 Petone PNBs and FPs . . . . . . . . . . . . . . . . . . . 106

Figure 5.35 The Hutt River . . . . . . . . . . . . . . . . . . . . . . . . . . . 107

Figure 5.36 Extent of the Hutt River . . . . . . . . . . . . . . . . . . . . . 107

Figure 5.37 Totara Park PNBs and FPs … . . . . . . . . . . . . . . . . . . 108

Figure 5.38 Totara Park Consensus . . . . . . . . . . . . . . . . . . . . . . . . . . . . 109

Figure 6.1 Multiple Type PNBs and Locality Boundaries: Newtown/Berhampore . . . . 114

Figure 6.2 Car Use in an Average Week PNBs: Zero Days and Daily . . . . . . . . . . 115

Figure 6.3 Number of Participants: Walk by Car Usage (Days) . . . . . . . . . . . . . 116

Figure 6.4 CDN and Locality Boundaries: Brooklyn . . . . . . . . . . . . . . . . . . 122

Figure 6.5 Wellington Airport Extent and Rongotai Locality and SA2 Boundaries . . . 126

Figure 6.6 Traffic Sign showing Brooklyn Shops . . . . . . . . . . . . . . . . . . . . 127

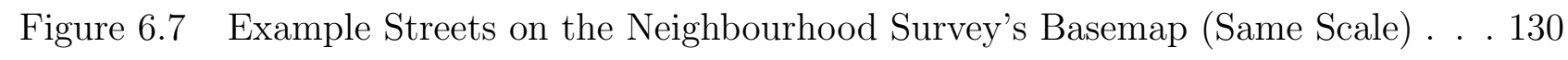

Figure 6.8 Localities Change Request Document . . . . . . . . . . . . . . . . . . . 133 


\section{List of Tables}

Table $4.1 \quad$ Summary Statistics for Age and Gender . . . . . . . . . . . . . . . . . . . . . 45

Table 4.2 Summary Statistics for Neighbourhood Factors . . . . . . . . . . . . . . . . . 46

Table 4.3 Summary Statistics for Status of Children . . . . . . . . . . . . . . . . . . . . 48

Table 4.4 Summary Statistics for Transport Decisions . . . . . . . . . . . . . . . . . . . 49

Table 4.5 Pearson's Correlation Matrix for Neighbourhood Dimensions . . . . . . . . . 53

Table 4.6 Summary Statistics for Spatial Join Between FPs and Consensus Hexagons . 66

\begin{tabular}{lll}
\hline Table 4.7 & Summary Statistics for Area and Perimeter of Four Neighbourhood Datasets & 67
\end{tabular}

Table 4.8 Summary Statistics for Compactness and Vertices of Four Neighbourhood Datasets . . . . . . . . . . . . . . . . . . . . 68

Table 4.9 Summary Statistics for Congruence Between Four Comparison Datasets . . . 69

Table 5.1 $\quad$ Lynch's (1960) Five Elements . . . . . . . . . . . . . . . . . . . . . . . . . . 74

Table $5.2 \quad$ Case Studies and Lynch's (1960) Five Elements . . . . . . . . . . . . . . . . . 110 


\section{GLOSSARY}

CBD: Central Business District

CDN: Community Defined Neighbourhood

FP: Focal Point

GCS: Geographical Citizen Science

GIS: Geographic Information Systems/Science

OSM: OpenStreetMap

PNB: Perceived Neighbourhood Boundary

PPGIS: Public Participation GIS

VGI: Volunteered Geographic Information 


\section{Chapter 1}

\section{Introduction}

\section{$1.1 \quad$ Background}

Neighbourhoods are a fundamental part of our lives. We attach sentiment and meaning to our neighbourhoods as they add social cohesion and a sense of community to our lives (Forrest \& Kearns, 2001). Neighbourhoods fulfil a range of functions in our day-to-day lives, such as providing opportunities for socialising, shopping, running errands, and dining. Individuals' uniquely experience and interact with their neighbourhoods; consequently, the ways individuals perceive the physical boundary of their neighbourhood are fluid, subjective, and ever-changing (Lupton, 2003). While official representations of neighbourhood boundaries exist, individuals' personal neighbourhood delineations are an invaluable data source able to provide a unique perspective into complex neighbourhood geographies (Coulton, Korbin, Chan, \& Su, 2001).

The neighbourhoods we live in have a demonstrated effect on personal health outcomes and are the most commonly used unit of scale in which geographic outcomes are presented (Diez Roux, 2001). Neighbourhoods are an important scale for health research as they inform health outcomes and policy (Kawachi \& Berkman, 2003). Representing neighbourhoods as a set of fixed, contiguous, geographic units is almost ubiquitous in geographic health research as they provide homogeneous and comparable units of scale (Mujahid \& Diez Roux, 2010). Personal health outcomes affected by the neighbourhoods individuals live in include rates of obesity (Black \& Machinko, 2008), exposure to air pollution (Clougherty \& Kubzansky, 2009), and accessibility of primary healthcare (Apparicio, Abdelmajid, Riva, \& Shearmur, 2008), supermarkets and convenience stores (Pearce, Hiscock, Blakely, \& Witten, 2008), and alcohol, tobacco, and fast food retailers (Schneider \& Gruber, 2013).

It is important for collections of individuals' neighbourhood delineations to take place. Even though research on neighbourhood definitions has been performed for decades, there is a lack of consensus 
for the physical and operational definitions of neighbourhood (Haney \& Knowles, 1978; Kearns \& Parkinson, 2001; Galster, 2001). Neighbourhood perceptions are largely subjective and vary from person-to-person, even those with with common demographics and in dense, urban areas (Lupton, 2003). Personal characteristics and contextual factors also have a pronounced impact on how we perceive our neighbourhoods (Coulton, Jennings, \& Chan, 2013). Understanding differences in the ways individuals perceive their neighbourhoods can provide clarity into the physical and operational definitions of neighbourhood with implications for the diverse areas of research in which neighbourhoods are deployed.

\subsection{Problem}

Even though a long history of neighbourhood research exists, neighbourhoods are still notoriously difficult to define (Galster, 2001). The study context often determines how 'neighbourhood' is defined operationally, resulting in a wide variety of interpretations used in research (Weiss, Ompad, Galea, \& Vlahov, 2007). Other terms are also used to operationalize neighbourhoods, such as 'the built environment' or 'suburb', adding confusion and difficulty to comparisons made among neighbourhood research (Spielman \& Yoo, 2009). Physical boundaries of neighbourhoods are no exception to this caveat. Individuals uniquely experience and interact with their neighbourhoods, and neighbourhood perceptions are shaped in relation to other neighbourhoods (Lupton, 2003). Consequently, there is a large amount of variation exists in how individuals define their neighbourhood boundaries, even among individuals living in close proximity and sharing personal characteristics (Coulton et al., 2001). Further context regarding the operational and physical definitions of neighbourhoods is required.

Neighbourhoods are the most common scale used to present geographic health outcomes (Diez Roux, 2001). Due to being easily accessible and comparable, and allowing for the integration of other indicators, such as socioeconomic status and urban density, official boundaries in the form of census units are often used to represent spatial boundaries of neighbourhoods to disseminate geographic outcomes. Census units take the form of meshblocks and statistical areas level 2 (SA2s) in New Zealand (Pearce, 2006), census tracts in the United States (Tailor et al., 2019), and wards in the United Kingdom (Richardson \& Mitchell, 2010). However, it has been repeatedly established that census units poorly reflect residents' perceptions of and experiences with their neighbourhoods (Weiss et al., 2007; Coulton et al., 2013; Alidoust, Bosman, Holden, Shearer, \& Shutter, 2017). The sheer variety in ways in which individuals perceive their neighbourhood boundaries is impossible to capture through a single set of fixed census units. Differences between census units and individuals' neighbourhood delineations can cause problems for spatial analysis and produce biased results (Duncan et al., 2014). The ability of individuals to provide a unique 
perspective of their neighbourhoods is a powerful source of data, but capturing responses can be problematic.

Surveying neighbourhood delineations is not a new concept. Traditionally, two data collection approaches are commonly used. The first involves recruiting small samples of participants to draw the boundary of their neighbourhood on paper maps which are then manually digitized into a GIS framework (Jenks \& Dempsey, 2007; Lohmann \& McMurran, 2009; Alidoust et al., 2017). Second, stratified surveys of residents living in neighbourhoods meeting desired criteria, such as socioeconomic status or urban density, are performed in which participants record their neighbourhood boundary through a digital mapping tool (Charreire et al., 2016; Coulton, Chan, \& Mikelbank, 2011; Chaix et al., 2012). Both approaches have shown success, but have limitations. Using paper maps to record neighbourhood observations commonly results in small sample sizes of participants and produces error as a result of the digitization process. The amount of effort required to employ a survey using either approach is substantial. Finally, both approaches only capture neighbourhood delineations from residents of individual neighbourhoods disconnected from bordering neighbourhoods. As a result, interactions between neighbourhoods across a city-wide scale remains unexplored in the relevant literature.

\subsection{Research Questions}

This thesis proposes a crowdsourcing methodology as an alternative approach of collecting neighbourhood delineations as it can potentially address limitations faced by traditional methods. Crowdsourcing applications use the general public (the crowd) as a means to collectively solve a problem or provide data on a phenomenon (Brabham, 2013). Official organisations, such as government departments, local councils, and private companies, often struggle to replicate the amount and quality of data on phenomena that the collective effort of the crowd can produce. Through advancements in web-based technology, such as smartphones, web browsers, and cloud data storage, crowdsourcing data collection methods are flexible and can take place at greater frequencies (Papadopoulou \& Giaoutzi, 2014). For spatial data, crowdsourcing can create high quality datasets by accessing a wide variety of contributors, is cost-effective, and produces unique data sources, such as live traffic feeds and walking tracks (Heipke, 2010).

A range of projects have demonstrated success in harnessing the power of a crowdsourcing approach to produce a collective picture of a phenomenon. OpenStreetMap (OSM) is a structured community of contributors producing worldwide map databases of similar quality to those of authoritative organisation's in urban areas (Dorn, Törnros, \& Zipf, 2015) 1 . Geograph is a project aiming to

\footnotetext{
$1 \longdiv { \text { https://www.openstreetmap.org/ } }$
} 
crowdsource geographically accurate photographs of every square kilometre in Britain and Ireland. Since beginning in 2005, over six million photographs covering $84.4 \%$ of the total area have been received ${ }^{2}$, In New Zealand, GeoNet's Felt It? earthquake reporting tool collects and displays individuals' reactions after an earthquake ${ }^{3}$. All three examples are made possible by the collective effort of individuals who contribute their time, effort, and personal knowledge. They are also enabled by web-based tools and technologies allowing individuals from a range of backgrounds to easily contribute. Additionally, they all openly provide the data collected back to the community adding an element of reciprocity.

For neighbourhood delineations, a crowdsourcing approach has the potential to reach many demographically diverse individuals from a variety of neighbourhoods across a city. Because a crowdsourcing data collection method does not require face-to-face interviews or stratified surveys of neighbourhood residents, only a minimal amount of effort is required to survey neighbourhood delineations. Crowdsourcing also allows for flexibility in the design of the application used to survey individuals.

This thesis poses the following research questions:

\section{How do personal characteristics impact neighbourhood delineation?}

2. What can collective individual neighbourhood definitions tell us about complex neighbourhood geographies?

\section{How do crowdsourced neighbourhood boundaries compare to official boundaries?}

\section{What impact do geographic features have on neighbourhood perceptions?}

5. Is a crowdsourcing methodology viable for collecting neighbourhood delineations?

\subsection{Thesis Structure}

This thesis has 7 chapters. Chapter 2 reviews the literature surrounding the importance of neighbourhoods and ways neighbourhoods are represented geographically. A research gap is identified based on limitations of traditional methods used to survey individuals' neighbourhood delineations. The main concepts of a methodology leveraging crowdsourcing to gather neighbourhood data are presented: volunteered geographic information (VGI), geographical citizen science (GSC), and public participation GIS (PPGIS). Finally, limitations of using a crowdsourcing methodology are given and the implications for the methodology are discussed.

\footnotetext{
2 https://www.geograph.org.uk/

3 https://felt.geonet.org.nz/
} 
The methodology is outlined in Chapter 3 in three phases. Phase 1 describes the design of a questionnaire to collect neighbourhood delineations and personal characteristics from residents of Wellington City. In Phase 2, the method of delivery for the web-based application is described, involving the design, launch, and promotion of the application. Finally, Phase 3 details data cleaning and analyses performed using the crowdsourced neighbourhood dataset.

Chapter 4 presents results of the analysis performed on the crowdsourced neighbourhood dataset. Outcomes from statistical analysis investigating how personal characteristics impact neighbourhood delineation are presented. Areas of high and low neighbourhood consensus are identified, models of neighbourhood connectivity are posed, and neighbourhood focal points are clustered and related to different features of neighbourhoods. Finally, crowdsourced neighbourhood boundaries are compared to official boundaries based on four neighbourhood dimensions and congruence.

Chapter 5 provides case studies of geographic features and their impact on neighbourhood perceptions. Two groups of features are presented: man-made and natural features. Each geographic feature and the neighbourhood it resides in is described, outcomes from analysis showing the impact of the feature on neighbourhood delineation are given, and the feature is placed into one or more of Lynch's (1960) elements of urban mental maps.

Chapter 6 discusses the key findings and explores their connection to the current literature. The effectiveness of using a crowdsourcing methodology to gather neighbourhood data is also evaluated.

Chapter 7 concludes the thesis by outlining key findings, use the thesis to provide answers to the research questions, and identifies opportunities for future research. 


\section{Chapter 2}

\section{Literature Review}

\section{$2.1 \quad$ Introduction}

The neighbourhood is an increasingly important aspect of understanding our urban environments. Physical neighbourhood geographies are subjective, ever-changing, and complex making a consensus on neighbourhood definitions difficult. This chapter presents the context, and methods by which neighbourhoods are represented. Multiple factors (including geographic features and personal characteristics), that impact how we perceive our neighbourhood boundaries are detailed. Traditional approaches of collecting neighbourhood delineations are discussed, and a limitation is identified in both the sample sizes they achieve and the time and effort required to execute these approaches. A crowdsourcing approach to collect perceived neighbourhoods is then explored. The benefits and drawbacks of three applications of crowdsourcing, each suitable to survey neighbourhood delineations are given in Section 2.3. The limitations of a crowdsourcing approach are also discussed, providing direction for this thesis' methodology to effectively crowdsource perceived neighbourhoods from the general public and ensure appropriate data quality.

\subsection{The Neighbourhood}

\subsubsection{Representing Neighbourhoods using Predefined Boundaries}

No clear consensus exists regarding the physical boundary of neighbourhoods. The most common approach by researchers is to use predefined boundaries of similar sizes to represent neighbourhoods. These often take the form of administrative areas, census units, or postcode zones (Pearce, 2006; Apparicio et al., 2008; Richardson \& Mitchell, 2010; Tailor et al., 2019). Fixed Euclidean or network distance buffers around participant's home addresses have also seen use (Charreire et al., 2016; Stewart et al., 2015). Predefined boundaries are easy for researchers to access and make comparisons between, and are fundamental to integrate other indicators, such as population counts 
or deprivation levels (Weiss et al., 2007).

Personal definitions of neighbourhoods are complex, subjective, and influenced by various personal and contextual factors (Lupton, 2003). Consequently, representing neighbourhoods using predefined boundaries is problematic. It has been repeatedly established that predefined boundaries do not accurately reflect individuals' perceptions of the physical aspects of their neighbourhoods (Coulton et al., 2013; Perchoux, Chaix, Brondeel, \& Kestens, 2016; Alidoust et al., 2017). The discrepancy between how individuals perceive the spatial boundaries of their neighbourhoods and official boundaries used to represent neighbourhoods causes problems for spatial analyses and produces biased estimates of outcomes at the neighbourhood level (Spielman \& Yoo, 2009). For example, Vallée, Le Roux, Chaix, Kestens, \& Chauvin (2015) observed a discrepancy in the number of accessible primary healthcare resources between predefined neighbourhood boundaries and individuals' neighbourhood definitions.

Using predefined boundaries to present geographic outcomes at the neighbourhood level has further limitations. Results are subject to the Modifiable Area Unit Problem (MAUP), which describes statistical bias arising from analysing spatial data in units of different levels and scales (Openshaw, 1981). Locations and temporal patterns experienced by individuals in respect to their neighbourhood are poorly captured by predefined boundaries. This is defined as the Uncertain Geographic Context Problem (UGCoP), and it creates inconsistent results when contextual effects of neighbourhoods on geographic outcomes are examined (Kwan, 2012). The 'local trap' describes the notion that the only scale that matters in presenting geographic outcomes is the local scale (Purcell \& Brown, 2005; Cummins, 2007). The 'local trap' is persistent in research presenting results at the neighbourhood level and questions if the local scale is always the correct scale to perform analysis at. Using individuals' perceived neighbourhoods does not remove these limitations, but might reduce the impacts of these problems by providing a community perspective to predefined boundaries.

Examining consensus among common neighbourhood areas can identify unrepresentative areas of predefined boundaries and provide insight into complex neighbourhood geographies (Galster, 1986). Prior studies have only examined neighbourhood consensus in the context of individual neighbourhoods isolated from other neighbourhoods (Coulton et al., 2001; Minnery, Knight, Byrne, \& Spencer, 2009). This approach does not present an accurate picture of collective neighbourhood geographies, as they are formed in relation to both internal and external features and places (Lupton, 2003). Both interactions between bordering neighbourhoods and comparisons between neighbourhoods observing varying patterns of consensus are not able to be presented using this approach. Examining neighbourhood consensus within and between a network of neighbourhoods across a city can potentially produce a novel picture of neighbourhood geographies and offer an alternative perspective to predefined boundaries. 


\subsubsection{Other Approaches of Representing Neighbourhoods}

Representing neighbourhoods using predefined boundaries is not the only approach. In the past decade, big data sources have become available as 'digital footprints', as defined by Thatcher (2014). Digital footprints refer to information passively produced by human actions on social media platforms that contain a location component, such as Twitter, Instagram, and Flickr. Big datasets are produced by georeferencing geo-tagged posts and photos passively generated by sources of digital footprints (Thatcher, 2014). Spatial clustering of digital footprints has been used to detect significant groupings and areas of consensus (Anselin \& Williams, 2016; Jenkins, Croitoru, Crooks, \& Stefanidis, 2016; Brindley, Goulding, \& Wilson, 2018). Subsequently, neighbourhood areas can be inferred. However, producers of digital footprints may be unrepresentative of the general population. Ballatore and De Sabbata (2018) compared demographics of Twitter users and Wikipedia contributors to local census data to explain spatial variation of urban place representation. They found that information received from data sources that feed into digital footprints was predominantly created by young, wealthy, and educated individuals unrepresentative of surrounding populations.

Computational methods have been used to attempt and generate more representative neighbourhood boundaries. Examples of methods used include clustering existing census units in relation to a range of socio-economic factors (Santos, Chor, \& Werneck, 2010), using zone definitions considering factors weighted by importance, such as geographic contiguity, population equality, and homogeneity (Zhao \& Exeter, 2016), categorising areas based on different geodemographics (Harris, Sleight, \& Webber, 2005; Singleton \& Spielman, 2014), and using existing census units as the foundation of zonal systems through extensive random sampling (Clapp \& Wang, 2006; Flowerdew, Manley, \& Sabel, 2008). While these methods have strong use cases, perspectives of residents who live in the neighbourhoods they are aiming to represent are not taken into account. These residents can provide reliable, high quality spatial data about their neighbourhood that is difficult to capture through traditional means (Knigge \& Cope, 2006; Coulton et al., 2013).

Related to neighbourhoods, activity spaces are defined by the set of locations an individual regularly visits in their day-to-day life for different reasons, including work, leisure, education, or shopping (Horton \& Reynolds, 1971; Golledge, 1997). From these locations, an area that individuals spend most of their time in can be inferred and used in analysis. While not a replacement for neighbourhoods, activity spaces provide a different picture of how social exposures impact individuals' perceptions of their spatial environments (Jones \& Pebley, 2014). When combined with temporal information from GPS tracking or a personal travel diary, a "space-time cube" can be created providing a 3D view of an individual's daily activity, with the third dimension capturing time (Kwan, 2004; Farber, Morang, \& Widener, 2014). Perchoux et al. (2016) compared activity spaces and individuals' neighbourhood delineations in regard to different environmental 
exposures. They found activity spaces had lower levels of environmental exposures than individuals' neighbourhood delineations, indicating a discrepancy between the two approaches. More context regarding how individuals perceive the physical extents of their neighbourhoods is needed to further our understanding of the suitability of different neighbourhood representations.

\subsubsection{Perceived Neighbourhoods}

Predefined boundaries are not accurate representations of how individuals perceive their neighbourhood (Coulton et al., 2013; Alidoust et al., 2017). Perhaps a better approach is to represent neighbourhoods using delineations provided by the residents living within them. However, numerous studies have shown that individuals have unique experiences with their neighbourhoods, causing personal neighbourhood perceptions to be largely subjective, even when living near each other and possessing similar personal characteristics (Lupton, 2003; Coulton et al., 2001; Orford \& Leigh, 2014).

\section{Mental Maps}

Most individuals' perceived neighbourhood boundaries (PNBs) are spatial regions with undetermined, vague boundaries (Montello, Goodchild, Gottsegen, \& Fohl, 2003). Effective methods are required to elicit PNBs from individuals. Understanding how individuals think about their urban environments spatially in the form of mental maps can provide context. Mental maps are fluid representations of our day-to-day lives and are heavily based on personal experiences with our environments (Sulsters, 2005; Gould \& White, 1974). We use our mental maps for a range of both implicit and explicit purposes, including navigation, orientation, and quick decision making. Kevin Lynch's influential work The Image of the City (1960) describes how we interpret our urban environments and use the information we receive to form mental maps. Lynch argues we use our mental maps for navigation of our cities and identified five fundamental elements used by individuals to construct mental maps of urban areas:

- Paths: linear and continuous channels in which people travel. Paths arrange space in mental maps and are the predominant element in individuals' mental maps. Examples include streets, footpaths, canals, trails, train tracks.

- Edges: breaks in continuity between two areas. Edges can be real or perceived. Examples include roads, buildings, rivers, shorelines, railroads.

- Districts: two dimensional, recognisable areas which individuals move between. Districts have common identifying features and are always recognisable from the inside. Examples include a city's central business district, cultural area, neighbourhoods of different status. 
- Nodes: accessible focal points of areas. Nodes offer a perspective of the other four elements. Examples include town squares and plazas, shopping centres.

- Landmarks: memorable points of reference used in navigation. Landmarks are unable to be entered by the observer, and can either be local and personal, or distant and prominent. Examples include churches, mountains, murals, shops, buildings, the sun.

Lynch's (1960) five elements are predominantly geographic features, such as roads, rivers, and railway tracks. Borders of PNBs are also impacted by geographic features, with road networks being the most influential for the delineation of PNBs (Minnery et al., 2009). A study in Claremont, California collected PNBs from neighbourhoods inside and outside the corridor of a major freeway before and after its construction (Lohmann \& McMurran, 2009). The area of PNBs in the freeway corridor shrunk from 0.61 to 0.36 square miles following its construction, while PNBs outside of the freeway corridor grew from 0.50 to 0.89 square miles. In this sense, the freeway functioned as an edge for residents of neighbourhoods inside the freeway corridor as its construction cut off these neighbourhoods from outside areas, consequently reducing PNB size. However, for residents of neighbourhoods outside of the freeway corridor, the freeway functioned as a path by providing a connection to nearby areas and increasing PNB area (Lohmann \& McMurran, 2009). This indicates that the relationship between geographic features and PNBs may be complicated and difficult to determine. Lynch's (1960) five elements provides a framework to categorise and interpret the impact geographic features have on neighbourhood delineation.

Each of the five elements play an important role in neighbourhood perceptions. Alidoust et al. (2017) investigated how Lynch's (1960) five elements impacted the spatial dimensions of 54 older participants' perceived neighbourhoods through a mixture of qualitative interviews and selfreported PNBs. All five elements were found to repeatedly shape participants' PNBs, with nodes being the most common, as almost all the participants referred to one or more nodes when describing experiences with their neighbourhoods (Alidoust et al., 2017). However, in their research, the locations of participants' nodes were inferred from qualitative interviews, as the only spatial element of participants' neighbourhoods captured were their PNBs. This presents an opportunity for a deeper exploration of popular locations for neighbourhood nodes by collecting another spatial aspect of individuals' neighbourhoods: focal points (FPs). FPs are expected to be a spatial representation of a node in participants' neighbourhoods, and in collecting them, this thesis can explore popular locations of nodes and examine if a similar level of subjectivity between PNBs and FPs is observed. 


\section{Impact of Personal Characteristics}

The size of individuals' PNBs is impacted by various personal characteristics. Age has been repeatedly found to be a significant predictor of PNB size, with younger individuals delineating larger neighbourhoods than their older counterparts (Guest \& Lee, 1984; Coulton et al., 2013; Pebley \& Sastry, 2009; Charreire et al., 2016; Minnery et al., 2009; Orford \& Leigh, 2014). Findings on effects of gender on PNB size have been mixed, with no significant gender differences being found in some studies (Haney \& Knowles, 1978; Pebley \& Sastry, 2009; Coulton et al., 2013; Kresek, 2018). However, two studies found women delineate significantly smaller neighbourhoods than men (Guest \& Lee, 1984; Charreire et al., 2016), and another found the opposite effect (Orford \& Leigh, 2014). Findings are also mixed for the relationship between length of residence in a neighbourhood and PNB area. A significant, positive relationship has been reported by some studies (Charreire et al., 2016; Coulton et al., 2013; Pebley \& Sastry, 2009), while other studies have reported a negative (Guest \& Lee, 1984; Sastry, Pebley, \& Zonta, 2002) or no significant relationship (Haney \& Knowles, 1978; Kresek, 2018).

The inconsistency in findings on relationships between personal characteristics and neighbourhood delineations has been linked to differences in study design and data collection of PNBs, such as the medium used by participants to record their PNB and whether a definition of 'neighbourhood' was provided to participants (Coulton et al., 2013; Charreire et al., 2016). Further collections of neighbourhood delineations are required to examine observed inconsistencies. Additionally, an agreed-upon, standardised method of surveying neighbourhood perceptions would potentially reduce bias produced by inconsistent study design.

The focus of examining the relationship between personal characteristics and PNBs has been predominantly on area. However, other spatial dimensions of PNBs can potentially add value to our understanding of complex neighbourhood geographies. Kresek (2018) examined the impact of personal characteristics on two neighbourhood dimensions other than area: perimeter and compactness. A significant relationship between age and PNB perimeter was observed, but not between age and PNB area, indicating that perimeter provided insights that area did not (Kresek, 2018). Replication of these findings is worthwhile to further our understanding of the interaction between personal characteristics and PNBs, and to test if neighbourhood dimensions other than area can provide meaningful insights into understanding of neighbourhood boundaries

\section{Collecting Perceived Neighbourhoods}

Traditionally, two approaches have been used to collect individuals' perceived neighbourhoods. The first involves recruiting small numbers of individuals to draw their PNB on paper maps, and then manually digitizing the responses into a GIS environment (Jenks \& Dempsey, 2007; Lohmann \& 
McMurran, 2009; Campbell, Henly, Elliott, \& Irwin, 2009; Robinson \& Oreskovic, 2013; Crawford et al., 2014; Stewart et al., 2015; Alidoust et al., 2017). This approach is limited by the amount of time and effort it takes to recruit and interview participants, and process their PNBs. As a result, only small samples of participants living in a single neighbourhood have been mainly used to draw conclusions from. Additionally, a degree of error occurs during the process of digitizing hand-drawn PNBs.

The second approach uses technological advancements in GIS software to collect individuals' PNBs on a wide scale. As part of the SPOTLIGHT project which investigates determinants of obesity, Charreire et al. (2016) sampled PNBs from 6037 participants from 60 neighbourhoods across 5 different European cities. Coulton et al. (2011) collected neighbourhood definitions on paper maps from 6224 participants living in 10 American cities to investigate the effectiveness of local community change initiatives. To explore individuals' mobility patterns, Chaix et al. (2012) developed a survey tool to collect participants' activity spaces and PNBs. It was applied as part of the RECORD (Residential Environment and Coronary Heart Disease) cohort study to repeatedly survey neighbourhood delineations from 5542 participants in Paris, France (Perchoux et al., 2016). While this approach has demonstrated success in collecting PNBs from large amounts of individuals, it is limited by the decision to survey participants living neighbourhoods that fit contextual criteria, such as socioeconomic status and urban density. Consequently, this does not provide a picture of how contiguous neighbourhoods interact across an entire city. Additionally, a substantial amount of effort is required to employ this approach. The limitations of both these approaches presents an opportunity to employ a crowdsourcing approach for the collection of perceived neighbourhoods to potentially address these issues.

\subsection{Crowdsourcing Neighbourhood Delineations}

Individuals' neighbourhood perceptions are fundamental in providing a unique perspective to complex neighbourhood geographies. Traditional methods of surveying neighbourhood delineations from individuals tend to be expensive, time consuming, and often receive small sample sizes. This section discusses how a crowdsourcing approach can potentially be used to augment the process of collecting neighbourhood delineations. Three applications of crowdsourcing are potentially appropriate to frame a crowdsourcing approach: volunteered geographic information (VGI), geographical citizen science (GCS), and public participation GIS (PPGIS). Each application uses similar methods to collect spatial data from individuals and can be difficult to distinguish from each other (See et al., 2016). Following a summary of each of VGI, GCS, and PPGIS, a crowdsourcing approach of surveying neighbourhood delineations is placed on two relevant axes alongside each application. Limitations of crowdsourcing are also discussed. 


\subsubsection{Volunteered Geographic Information (VGI)}

Until the mid-2000s, spatial data was primarily collected, produced, and maintained by authoritative organisations, such as government agencies, local councils, and private companies. Comparatively, Volunteered Geographic Information (VGI) is spatial data created by the general public (Goodchild, 2007). Most individuals who provide VGI often have little to no previous experience or education, yet their participation is essential in the success of VGI (Haklay, 2010). High quality VGI can be provided by individuals in respect to things they have local knowledge of, such as scenic driving routes (Alivand \& Hochmair, 2013), cycling tracks (Conrow, Wentz, Nelson, \& Pettit, 2018), and creation of maps following a natural disaster (Zook, Graham, Shelton, \& Gorman, 2010). In urban areas, VGI has powered maps of comparable quality to those produced by government mapping agencies (Haklay, 2010; Dorn et al., 2015). Technology and tools that enable collection of VGI have become more advanced and accessible as VGI has become more popular. Geographic information is being produced through VGI data collection applications at prolific rates that are increasing as advancements in technology are made (Sui, Elwood, \& Goodchild, 2013). Procedures are required to process, validate, and make use of the enormous amount of VGI available.

A common way VGI is collected is through active methods involving individuals using a website or smartphone app to record an observation of a phenomenon or edit existing data (Haklay, 2013). An active data collection method uses individuals' personal experiences with their environments to provide insight that is difficult to replicate through traditional data collection methods. An example of an active VGI initiative in New Zealand is GNS Science's GeoNet earthquake reporting tool, Felt It?, which records and displays individuals' reactions following an earthquake (Figure 2.1). Felt It? is easy to use and receives huge amounts of submissions after a major earthquake shakes the country. GeoNet also provides the VGI collected using Felt It? back to the general public. For a survey of neighbourhood delineations, an active VGI data collection approach may see success by prompting residents to think about their neighbourhood spatially. 


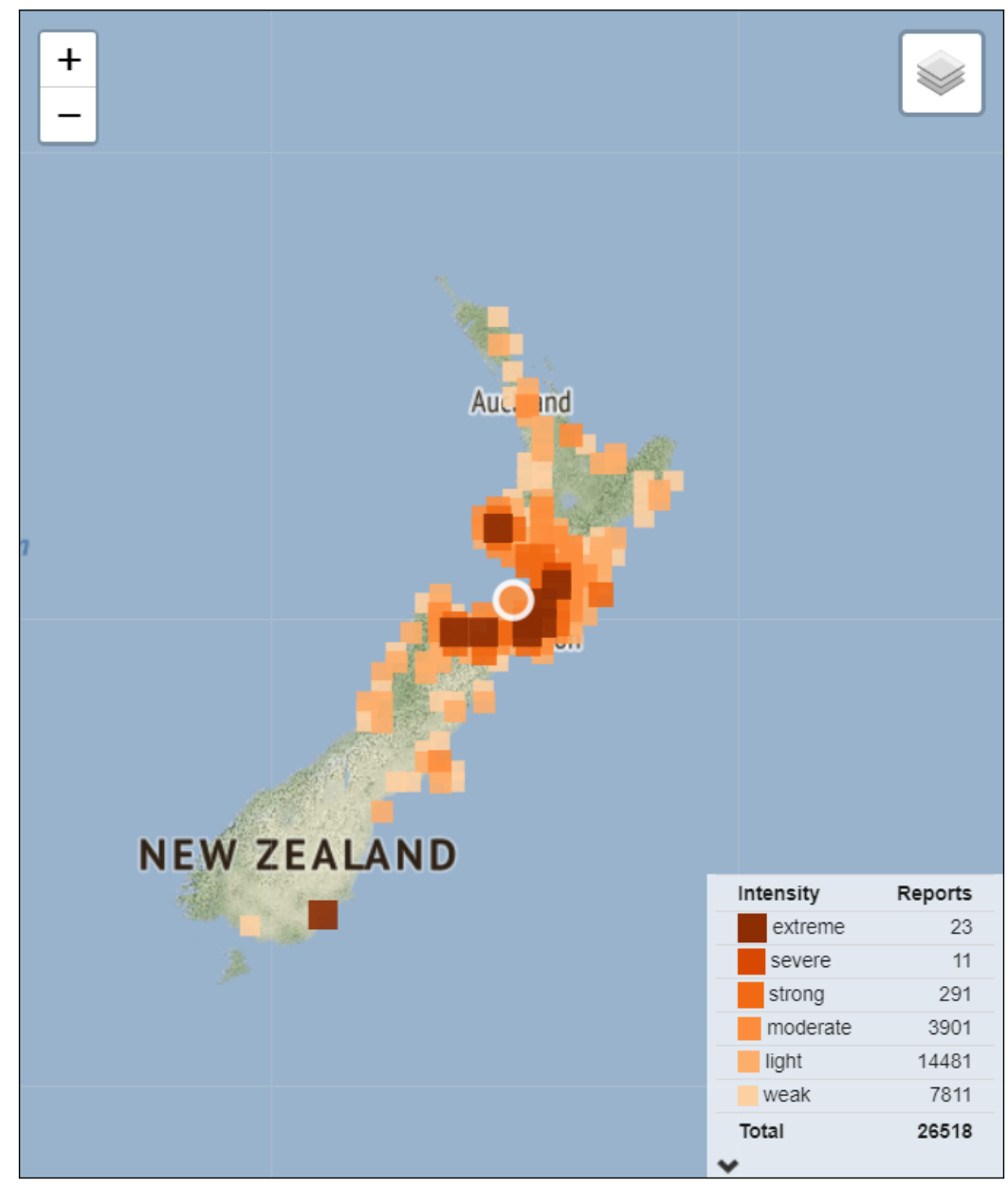

Figure 2.1: 26,518 Felt Reports to a 5.4 Magnitude Earthquake on 25/01/2020. Retrieved from: https://www.geonet.org.nz/earthquake/2020p066075

The majority of literature surrounding VGI refers to two fields of research unrelated to a survey of neighbourhood delineations from the general public. First, structured communities (such as OpenStreetMap (OSM) or Wikimapia) working towards a common goal are frequently discussed (Haklay, 2013; Neis \& Zipf, 2012). Structured communities contain implications not applicable to a survey of neighbourhood delineations, such as participation inequalities causing a small number of contributors to produce the majority of VGI (Nielsen, 2006; Haklay, 2016) and using a community reputation system to assure data quality and validation (Goodchild \& Li, 2012). Second, passive data collection methods of VGI are prominent in the literature, involving using GPS capabilities of individuals' smartphones as sensors (Haklay, 2013) or mass-harvesting digital footprints of georeferenced social media posts (Thatcher, 2014; See et al., 2016). Issues surrounding the legality of the right to access information produced by passive VGI data collection methods also exist (Mooney et al., 2017). 


\subsubsection{Geographical Citizen Science (GCS)}

Initiatives that use individuals to provide data and perform analysis on a scientific phenomenon are referred to as citizen science (Silvertown, 2009; Bonney at al., 2009). Geographical Citizen Science (GCS) is a version of citizen science where data collection primarily has a geographic component (Haklay, 2013). GCS has been enabled in recent years by web-based GIS advancements allowing individuals to easily record observations through smartphone apps. An example of an application of GCS in New Zealand is the annual Great Kerurū Count (The Great Kerurū Count, 2018). Over a 9-day period, the general public is encouraged to report sightings of New Zealand's beloved native wood pigeon, Kerurū, through either a simple app that works on both smartphones and tablets, or a website. Participation in the Great Kerurū Count has increased considerably from 3335 observations in 2016 to 8879 in 2018 (The Great Kerurū Count, 2018). This growth can be attributed to increasing awareness of the initiative over the years, and the framing of participation as a fun activity that can make a difference.

Residents living in neighbourhoods can provide a unique perspective that government organisations maintaining official neighbourhood boundaries struggle to replicate (Coulton et al., 2013). A GCS approach to collecting neighbourhood delineation could be considered an appropriate framing as neighbourhood residents' can be used by briefly turning them into citizen scientists and experts of their neighbourhood. However, what can be considered a GCS initiative are unclear (Haklay, 2013). Neighbourhood perceptions are personal, community driven observations: an area that GCS might be unsuitable for because GCS is underpinned by scientific framework and practices (Haklay, 2013).

\subsubsection{Public Participation GIS (PPGIS)}

Public Participation GIS (PPGIS) refers to the use of GIS tools and technology to enable and encourage the general public to engage with and contribute to organisational planning and design processes (Sieber, 2006). PPGIS aims to empower marginalised individuals, such as those with visual impairments, to contribute to and improve local decision making processes (Elwood, 2006). Factors that elicit effective PPGIS include ensuring there are little to no knowledge or skills required to participate with the technology, focusing on the user during the design process, and introducing as few barriers as possible to participation (Haklay \& Tobón, 2003; Meng \& Malczewski, 2010). It is also important to distinguish who the 'public' is when designing a PPGIS initiative to ensure that the information received is appropriate to the context (Schlossberg \& Shuford, 2005). PPGIS has seen applications in a variety of fields, such as urban planning (Bugs, 2012) and environmental reporting (Brown \& Reed, 2009). Output produced by PPGIS initiatives can also be of high quality, as long as individuals involved are familiar with the area of interest (Brown, 2012). 
Three aspects of PPGIS are not applicable to a limited survey of neighbourhood delineations. First, a core component of PPGIS is empowering marginalised individuals, to contribute to and change involvement with GIS procedures at a local scale (Elwood, 2006). Second, the process used to employ a PPGIS initiative, as well as the community empowerment are more important than the output produced. Finally, applications of PPGIS are ongoing initiatives repeatedly consulting and engaging with the community of participants.

\subsubsection{Placing a Crowdsourcing Approach}

Citizens are an increasingly significant source of geographic information that is difficult to capture using traditional means, and a wide range of applications of methods to collect citizen-produced data exist (See et al., 2016). VGI, GCS, and PPGIS are three applications relevant to a crowdsourcing approach of surveying neighbourhood perceptions. Each have aspects that can be drawn upon to produce a high quality dataset of neighbourhood delineations by creating a web-based application able to be completed by individuals with varying technical skills and reach a large number of demographically diverse individuals living in different neighbourhoods.

Given the overlap between each of the relevant applications, Figure 2.2 is an attempt to place VGI, GCS, PPGIS, and a crowdsourcing approach of collecting neighbourhood delineations on two axes: Application Motivation (data driven versus process driven) and Contributor Expertise (amateur versus expert). VGI applications focus more on the data produced than the means of data collection and contributors have varying levels of expertise. GCS contributors are local experts of the phenomenon they provide data on and GCS initiatives are mainly driven by the data provided, although the process in which citizens are motivated to contribute is fundamental to their success. PPGIS is driven by the process with a lack on emphasis on the data produced, and encourages marginalised, amateur contributors to contribute information and partake in decision making processes. For a crowdsourcing approach of collecting neighbourhood delineations, the main motivator of the application is the data produced, but the process is still important as to reach a large amount of participants who provide data voluntarily. These participants are also experts of their neighbourhood, but are likely to have varying technical skills. A variant of a GCS data collection application practising usability factors of PPGIS and employing methods of ensuring VGI data quality is likely to be successful in crowdsourcing neighbourhood delineations from the general public. 


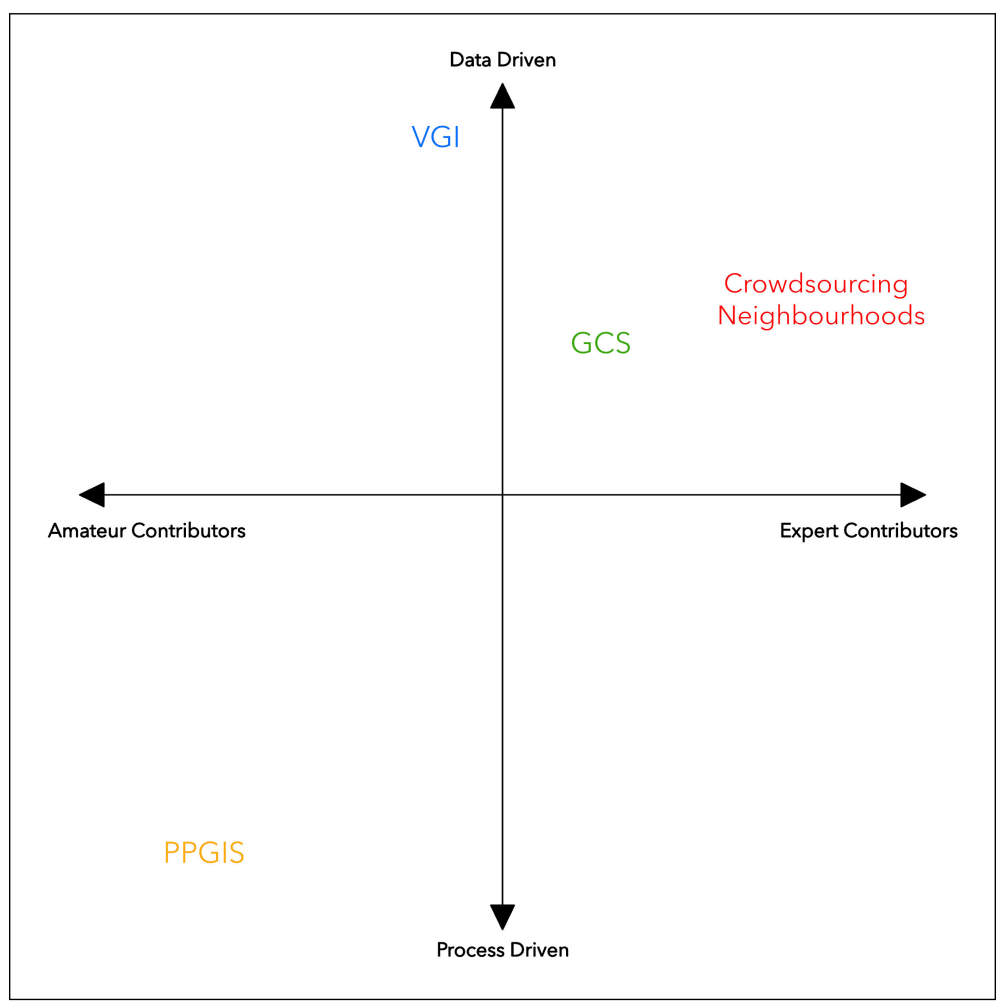

Figure 2.2: Placing Crowdsourcing Approaches in the context of Application Motivation and Contributor Expertise. Credit: Author's Own

\subsubsection{Limitations of Crowdsourcing}

Lack of completeness, usability, assurance, and positional accuracy are all issues of data collected through crowdsourcing. Without appropriate methods to ensure data quality, crowdsourced datasets often possess lower quality and credibility than official data sources (Flanagin \& Metzger, 2008; Basiri, Haklay, Foody, \& Mooney, 2019). This reduces trust in crowdsourced datasets when compared to official data sources (Bishr \& Janowicz, 2010). Metadata and documentation are often not provided with crowdsourced datasets, which are essential for ensuring the accuracy and usefulness of the data. Without these, there is little way to effectively assess the quality of crowdsourced datasets (Kalantari, Rajabifard, Olfat, \& Williamson, 2014). Issues of data quality also arise when poor platform usability causes contributors to struggle to effectively use the platform or understand their task (Schmidt, Klettner, \& Steinmann, 2013).

Various methods can be employed to ensure data quality of crowdsourced datasets. Comparing the data to traditional data sources can be used to check the positional accuracy and completeness of the data, and subsequently ensure its quality (Haklay, 2010; Dorn et al., 2015). Metadata is fundamental in identifying the quality of crowdsourced datasets. Introducing systems to encourage metadata creation or crowdsourcing metadata itself for existing crowdsourced data can help 
(Kalantari et al., 2014; Bastin, Schade, \& Mooney, 2018). Models that quantify trust in crowdsourced data through various personal and positional indicators can also improve data quality (Severinsen, de Róiste, Reitsma, \& Hartato, 2019). For crowdsourcing neighbourhood delineations from the general public, ensuring data quality through one or more quality assurance methods is vital.

The success of crowdsourcing relies on participation from the general public. Low participation increases bias and results in poor representation of the area of interest (Heipke, 2010). Low participation stems from a lack of awareness of the data collection platform platform, privacy concerns, and the time required to contribute data (Schmidt et al., 2013). Incentive mechanisms in the form of financial rewards, gamification, social, and reputation systems have been shown to motivate individuals to contribute to crowdsourcing platforms (Katmada, Satsiou, \& Kompatsiaris, 2016). For neighbourhood delineations, participation is an important consideration, since representing neighbourhoods accurately in analysis requires ample sample sizes distributed over the area of the interest.

While a crowdsourcing approach can easily reach wide subsets of the population via the internet, some individuals will not be reached. Social, technological, and economic obstacles can prevent some individuals from operating or accessing the required technology to contribute data (Sui et al., 2013; Cavallo, Lynch, \& Scull, 2014). Individuals facing participation barriers will not be accounted for in output produced from crowdsourcing, unless efforts are made to include them.

Bias is unavoidable for crowdsourced datasets (Basiri et al., 2019). A problematic form of bias is self-selection bias arising when participant recruitment is based on individuals choosing to participate (Heckman, 1977; Bethlehem, 2008). Bias created from a self-selected sample reduces the ability to draw significant inferences about a population, and inferences made are less credible than if a completely random sample of a population was taken (Basiri et al., 2019). Self-selection bias also causes the spatial distribution of crowdsourced data to be biased when responses are concentrated around some locations more than others, such as urban versus rural areas (Hecht \& Stephens, 2015; Zhang \& Zhu, 2018). Self-selection bias is problematic for crowdsourcing neighbourhood delineations as some neighbourhoods may be poorly represented, producing a limited picture of how these neighbourhoods are perceived by their residents.

\subsection{Summary}

The literature outlined in this chapter explored the importance of neighbourhoods and how they are commonly represented geographically. Neighbourhoods are represented through a range of methods, all of which need to factor in perspectives of residents to be effective and draw accurate 
conclusions. Numerous factors influence neighbourhood perceptions making it difficult to reach a common consensus for determining complex neighbourhood geographies. Traditional methods used to survey neighbourhood delineations are limited. The time and effort required to run the collections is substantial, small sample sizes are often achieved, and only residents living in individual, isolated neighbourhoods are surveyed.

A crowdsourcing approach may be an excellent way to collect perceived neighbourhoods from the general public, given that crowdsourcing: allows for data collection through a website designed with ease of use in mind; can access a wide subset of the population; and is cost effective and straightforward to implement. It is also less time consuming and can reach more individuals than traditional methods of surveying neighbourhood delineations. Three applications of a crowdsourcing approach were reviewed: collecting VGI, GCS, and PPGIS. Each had aspects appropriate for crowdsourcing neighbourhood delineations, but none were fully suitable for this purpose. An approach drawing on the relevant components of each was identified as a potentially effective way to collect perceived neighbourhoods. Drawbacks of a crowdsourcing approach important to consider, including issues of data quality, participation, and production of biased datasets. 


\section{Chapter 3}

\section{Methodology}

\subsection{Introduction}

This chapter overviews the application (app) used to crowdsource neighbourhood data in Wellington City, Aotearoa-New Zealand. This thesis was granted ethics approval by Victoria University of Wellington's human ethics committee (reference number: 0000027406) and comprised of three phases:

1: Questionnaire Development - development of survey questions related to participants' neighbourhoods, demographics, children, and transport decisions.

2: Application Delivery - construction and deployment of a web-based app used to crowdsource neighbourhood delineations in Wellington City. The functionality and design of the app is detailed, as well as its implementation, and participant recruitment.

3: Data Cleaning and Analysis - the crowdsourced neighbourhood dataset was cleaned for analysis. A range of analyses were then performed, including production of descriptive statistics and statistical tests, geographic measures of consensus, focal point clustering, and comparisons between PNBs and official boundaries. 


\subsection{Area of Interest: Wellington City, New Zealand}

This thesis crowdsourced neighbourhood delineations from residents of Wellington City in AotearoaNew Zealand. Wellington is the capital city of New Zealand, and as of the 2013 census, the Greater Wellington Region has a population of 471,315 (Statistics New Zealand, 2013). Wellington is a hilly, rugged, coastal city that is affected by strong winds (Figure 3.1). Wellington City was chosen as the area of interest to crowdsource neighbourhood data from as it contains a mix of different population densities, rural and urban areas, and geographic features. It is a moderately sized city, meaning appropriate sample sizes for different neighbourhoods are achievable. Finally, Wellington City and its neighbourhoods are well known to the researchers.

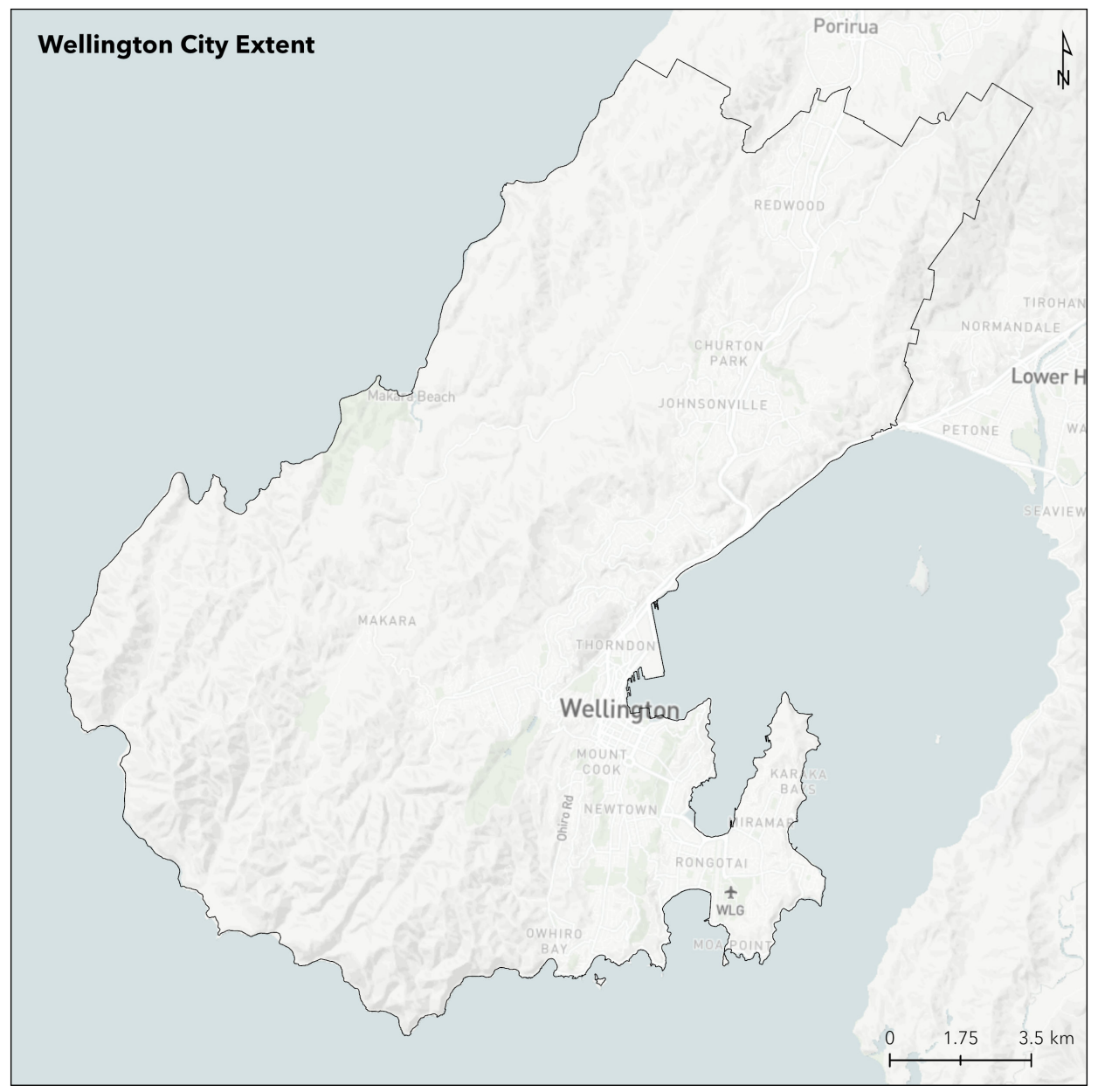

Figure 3.1: Extent of Wellington City (Full extent of research extends further than shown)

\subsection{Questionnaire Development}

The questionnaire comprises of 4 categories:

- Neighbourhood Factors: information about the participant's neighbourhood. 
- Demographic Information: general information about the participant. Two demographic variables were collected: age and gender.

- Children: information about participant's children.

- Transport: questions related to access to transport and transport decisions.

Asking too much from participants can reduce survey completions (Dillman, Smyth, \& Christian, 2014). This thesis' methodology aimed to ensure the questionnaire could be easily completed on a range of smartphones as it was expected this would be a common method. Additionally, the questionnaire was designed to be anonymous. Participant's personal details, such as name, contact information, and location, were not asked. The full questionnaire is provided in Appendix 1.

\subsubsection{Neighbourhood Factors}

\section{Boundary}

This thesis collected perceived neighbourhood boundaries (PNBs) from participants. PNBs are important as they represent the physical area of the participant's neighbourhood. Prior studies that collected PNBs have used stratified surveys of individual neighbourhoods in or between cities (Jenks \& Dempsey, 2007; Coulton et al., 2013; Charreire et al., 2016). A crowdsourcing methodology can collect PNBs across an entire city, enabling the exploration of interactions between bordering neighbourhoods.

\section{Focal Point}

In most surveys of neighbourhood perceptions, neighbourhood boundaries are often the only geographic element collected (Coulton et al., 2013; Jenks \& Dempsey, 2007; Alidoust et al., 2017). An exception to this include prior studies recording participants' home addresses (Charreire et al., 2016; Minnery et al., 2009). Other aspects of neighbourhood geographies can provide a different look into how individuals perceive their neighbourhoods. In the survey, participants are required to mark where they believe the Focal Point (FP) of their neighbourhood to be. This point is constrained to within the PNB. It is expected FPs may relate to the elements of urban mental maps of nodes (accessible foci of areas, such as town squares) and landmarks (memorable points of reference, such as mountains and churches) defined by Lynch (1960). By requiring participants to mark their neighbourhood FP, we collected another physical aspect of neighbourhoods and could test if FPs are related to nodes and landmarks. 


\section{Name}

Participants provided a name for the neighbourhood they drew. The participant could not proceed in the questionnaire without providing this data. This name is important to measure common areas across participants and to compare PNBs to official neighbourhood boundaries. Coulton et al. (2013) was a prior study surveying PNBs that made providing a neighbourhood name optional. Consequently, a large number of participants that did not provide a neighbourhood name were excluded from analysis. Requiring participants to provide a neighbourhood name avoids this limitation. The collection of neighbourhood names from participants also afforded the opportunity to explore variation in ways participants perceive their neighbourhoods.

\section{Length of Residence}

The length of residence in a neighbourhood on PNB area has had mixed impact. Significant positive effects (Charreire et al., 2016; Coulton et al., 2013; Pebley \& Sastry, 2009) and negative effects (Guest \& Lee, 1984; Sastry et al., 2002) between length of residence and PNB area have been observed. Non-significant effects have also been found (Haney \& Knowles, 1978; Kresek, 2018). Positive relationships have been explained by longer neighbourhood residency resulting in development of more social interactions and relationships in an individual's neighbourhood, as well as higher awareness of new locations in their neighbourhood that took time to discover (Charreire et al., 2016). The questionnaire asks participants how many years they have lived in the neighbourhood they drew. Length of residence (years) was captured as: 0, less than 1, 1 to 5 , 6 to 10 , and 10 or more years.

\subsubsection{Demographic Information}

Two demographics of participants were collected: age and gender. Age has been repeatedly shown to significantly impact PNB area, with younger individuals delineating smaller neighbourhoods than older individuals (Guest \& Lee, 1984; Coulton et al., 2013; Pebley \& Sastry, 2009; Charreire et al., 2016). As individuals age, it is hypothesised their mobility and opportunities for social interaction decrease reducing their activity spaces and PNB area (Charreire et al., 2016). Age (years) was recorded as: 0 to 10, 11 to 15,16 to 20, 21 to 30,31 to 40, 41 to 50, 51 to 60,61 to 70,70 or older.

Impacts of gender on PNB area has had mixed outcomes. Some prior studies found no significant gender differences (Haney \& Knowles, 1978; Pebley \& Sastry, 2009; Coulton et al., 2013; Kresek, 2018). Conversely, two studies found women delineated significantly smaller neighbourhoods than men (Guest \& Lee, 1984; Charreire et al., 2016). In this thesis, three options of gender 
were provided: Male, Female, or Other, please specify (with a text box provided to record their preference).

\subsubsection{Children}

Participants were asked if they had children as having children may impact their PNBs and FPs. The school or preschool attended by participant's children are likely to be important locations in the lives and neighbourhoods of participants. Having children has also mediated PNB area differences based on gender (Charreire et al., 2016). Neighbourhood FPs of participants with children are expected to be placed nearby the school their child attends making knowing their child's level of education valuable. Three questions related to participant's children were recorded:

1. Do you have children? (Yes/No)

2. Do they live in your household? (Yes/No)

3. What level of education do they attend? (Preschool, primary, intermediate, secondary and post-secondary)

\subsubsection{Transport Decisions}

Numerous studies have established the type of neighbourhood individuals live in has an impact on their transport decisions (Schwanen \& Mokhtarian, 2005; Chen, Gong, \& Paaswell, 2008). Individuals living in high-density, urban neighbourhoods with good public transport options tend to walk, cycle, or use public transport, while individuals living in low-density, rural environments with poor public transport links tend to drive (Ewing \& Cervero, 2010). However, the impact of transport decisions on perceived neighbourhood delineation remains unexplored. Prior studies have focused on participant demographics, such as age, gender, ethnicity, and contextual factors including socioeconomic status and residential density (Charreire et al., 2016; Coulton et al., 2013). Two aspects of transport decisions were questioned: access to a car (Yes/No) and preferred mode of transport. If participants had access to a car, they were asked if they were able to drive this car (Yes/No).

Options for preferred mode of transport included car, public transport, cycling, and walking. It can be difficult to tease apart the main mode of transport used by participants (Dillman et al., 2014). For example, asking participants to choose one of four modes of transport as their preferred choice is problematic: an individual may use public transport to commute to work but use their car for errands on the weekend. Participants were asked how many days in an average week they used each of the modes of transport, with options including zero, one, two to three, four to five, 
and daily. This approach provided participants with the option of reporting use of multiple modes of transport while still recording a preferred mode.

\subsection{Application Delivery}

A functional and easy to use application (app) was required to deliver the questionnaire to the general public and ensure individuals with a variety of technical skills could participate. This section describes development, testing, and distribution of the app. Initially, a range of existing data collection platforms were explored to see if they could provide the desired functionality to crowdsource neighbourhood delineations; including an ArcGIS Online app ${ }^{1}$, Maptionnaire ${ }^{2}$, and an ArcGIS GeoForm ${ }^{3}$. While these platforms could provide similar functionality to that desired, none could provide the level of flexibility in design and functionality of a custom-built app.

\subsubsection{Bostonography: Hoods Project}

The app developed for this thesis was based on a project called Hoods run by Bostonography which crowdsources neighbourhood delineations in Boston (USA) Inspired by Kevin Lynch's The Image of the City (1960), Bostonography is a website run by two self-proclaimed 'cartography nerds', Andy Woodruff and Tim Wallace. Woodruff and Wallace create interesting geographic visualisations representing different aspects of Boston. Hoods has been running from 2012, and as of March 2017 received over 2300 neighbourhood submissions (Woodruff, 2017). Figure 3.2 shows the landing page of Hoods. When providing neighbourhood data, users have the option to draw either a neighbourhood shape (i.e. a polygon) or mark a neighbourhood point. Information panes containing animated guides on how to provide data are also shown. Finally, users can view and interact with existing neighbourhood submissions. The Bostonography Hoods project is a static JavaScript web page built using a mixture of JavaScript, HTML, CSS, and PHP. The code used for Hoods is provided on GitHub5. Due to similarities between Hoods and what was desired for this thesis' methodology, it was an ideal starting point for developing an app to crowdsource neighbourhood delineations in Wellington City.

\footnotetext{
${ }^{1}$ https://www.esri.com/en-us/arcgis/products/arcgis-online/overview

2 https://maptionnaire.com/

${ }^{3}$ https://enterprise.arcgis.com/en/portal/latest/use/geoform.htm

${ }^{4}$ https://bostonography.com/hoods/

5 https://github.com/awoodruft/neighborhoods
} 


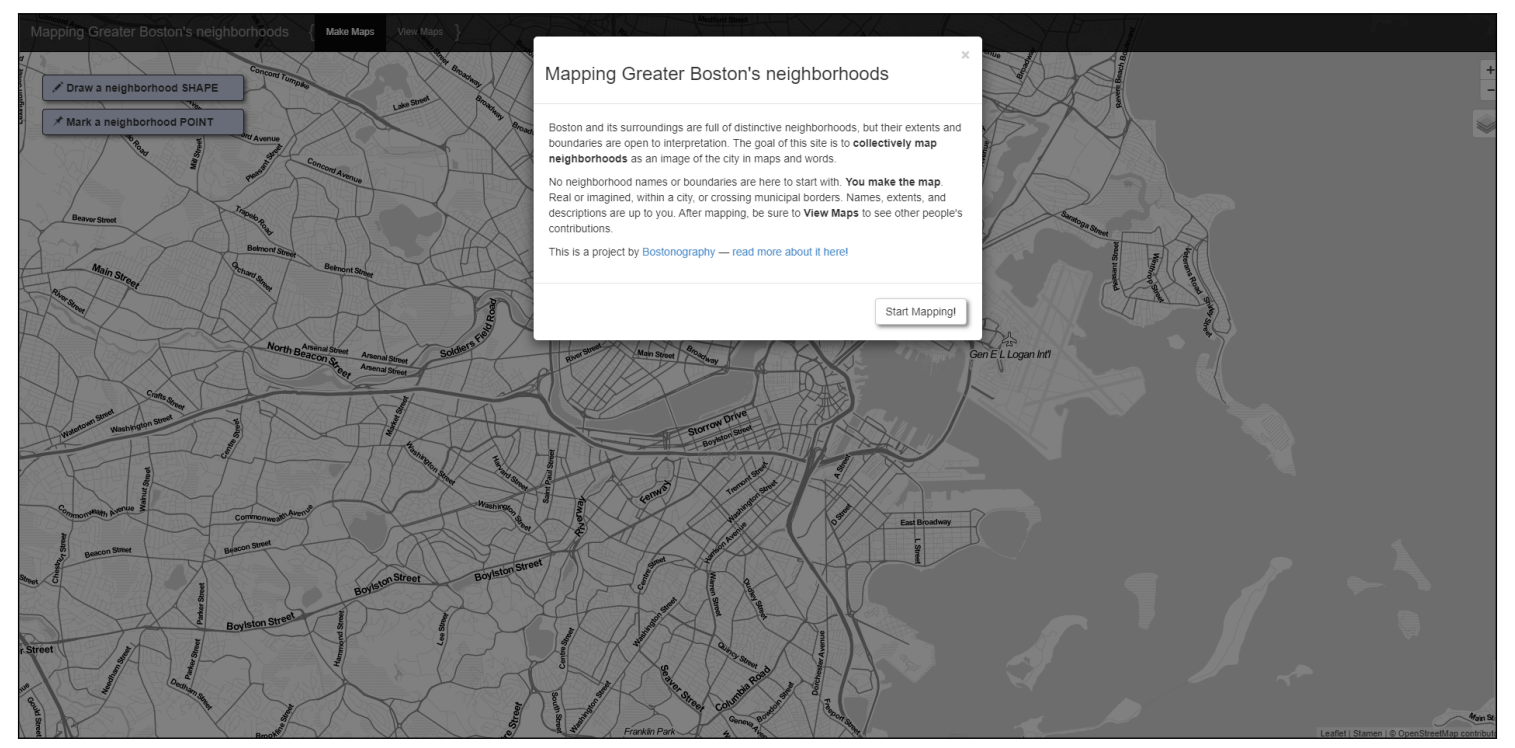

Figure 3.2: Landing Page of the Bostonography Hoods Project

\subsubsection{Wellyhoods App}

A simple and memorable URL (www.wellyhoods.com) was used to host the app to survey neighbourhood delineations from residents of Wellington City. Based on the Hoods project's source code, the data collection process of the Wellyhoods app was simplified to three steps:

1. Participants drew their PNB using freehand styling (rather than placing individual vertices) provided by Leaflet Draw ${ }^{6}$ (Figure 3.3 (a)).

2. Participants placed a marker on where they believed their neighbourhood FP to be (Figure $3.3(\mathrm{~b})$ ).

3. Participants complete the questionnaire (shown in full in Appendix 1).

Participants had the ability to change their boundary by dragging individual vertices in the polygon or edit their FP by dragging it to a new location. In between each step, participants were presented with an information pane containing a short animation and text dialogue guiding them through the data collection process.

\footnotetext{
${ }^{6}$ https://github.com/Leaflet/Leaflet.draw
} 


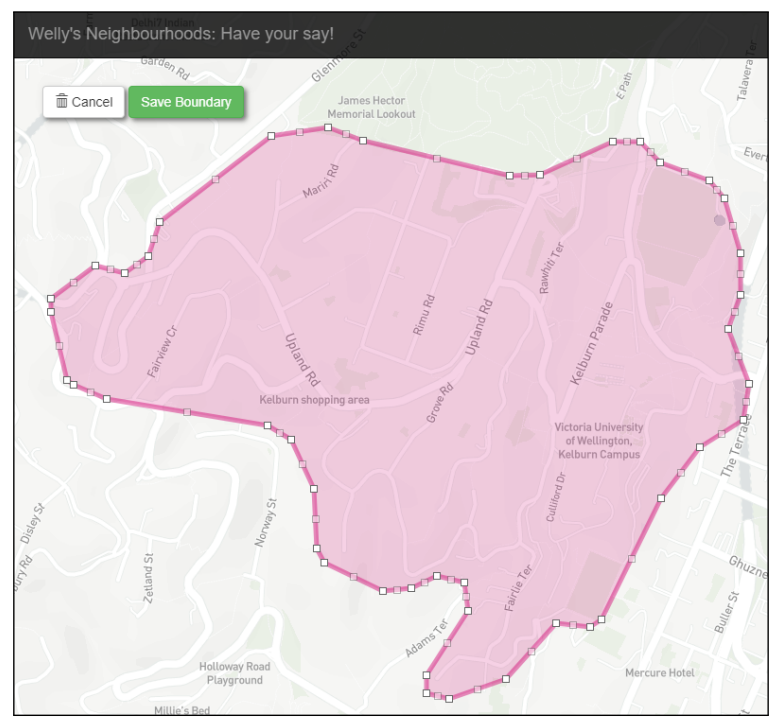

(a) Drawing a Neighbourhood Boundary

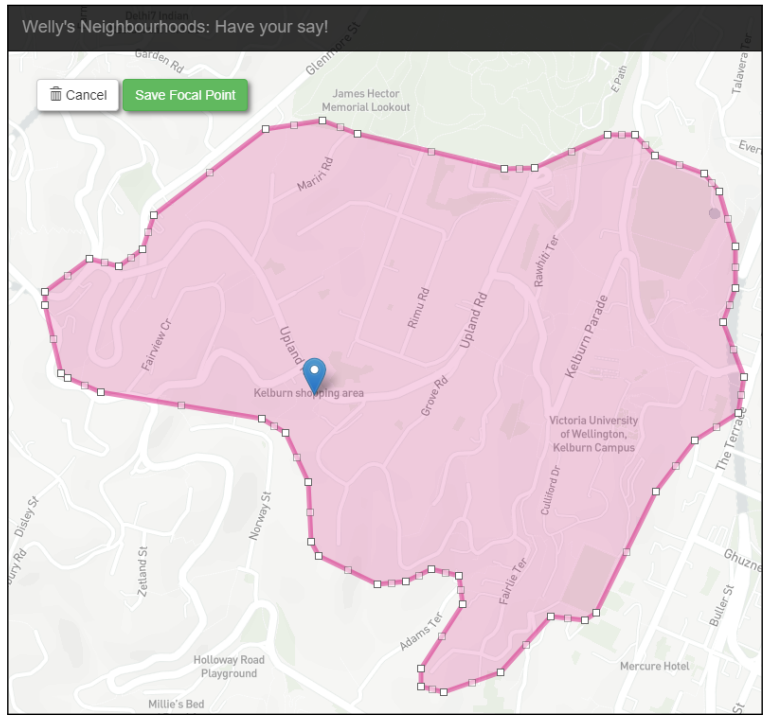

(b) Marking a Neighbourhood FP

Figure 3.3: Wellyhoods Data Collection Process: Steps 1 (a) and 2 (b)

Throughout data collection, neighbourhood or focal point definitions were not provided. This intentional absence aimed to capture personal interpretations of participants' neighbourhoods and communicate there is no wrong answer for what defines a neighbourhood. There was no limit on where participants could provide data, e.g. submissions located outside of the Wellington City boundary were not invalid. This decision reflected the focus on increasing the response rate as preventing individuals from participating may have caused them to not recommend the Wellyhoods app to their friends and family. Submissions out of geographic scope (e.g. submissions received in different cities in New Zealand or different countries) were excluded during data cleaning.

Other functionality and design changes made to the Wellyhoods app from Bostonography's Hoods project's source code were:

- Participants could not view existing responses, as viewing other PNBs and FPs may have biased data collection.

- Animations recorded for Wellington City shown in the information panes were presented rather than animations of Boston.

- To comply with Victoria University of Wellington Human Ethics approval, participants were presented with an information pane asking for informed consent to participate in the survey.

- Unnecessary buttons were removed, such as links to Bostonography's Twitter and GitHub accounts. 
- After completing the data collection process, participants were presented with links to share the Wellyhoods app on social media, and a text box to submit their email address for a copy of the completed thesis.

The default basemap was changed to remove labels of neighbourhood names and improve aesthetics. A custom basemap was developed for the app using the basemap style editor created by Mapbox:7. A comparison between the default basemap used in Bostonography's Hoods and the Wellyhoods app is shown in Figure 3.4. All labels of neighbourhoods were removed from the basemap to reduce implicit bias about the location of existing neighbourhoods. A lighter theme was also used which was aesthetically pleasing and improved usability by making features clearer. The option of changing the basemap to aerial imagery was also provided.

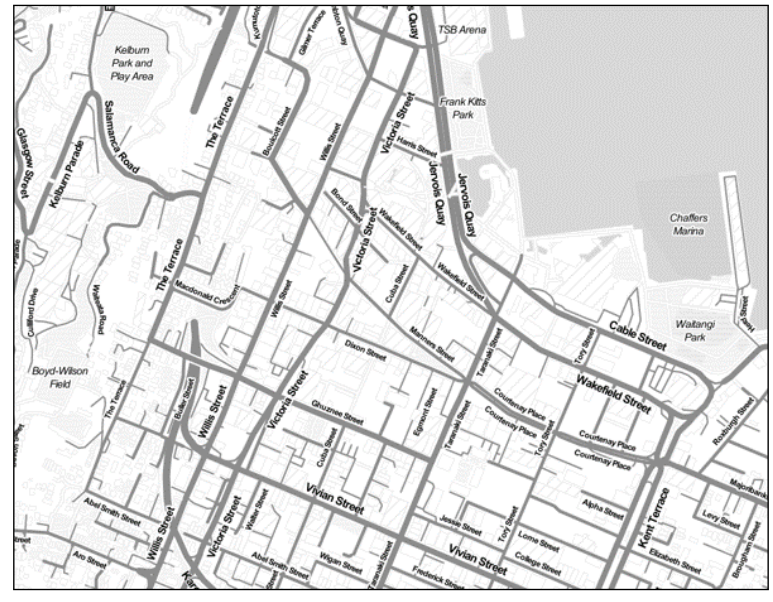

(a) Basemap Used in Bostonography's Hoods (Toner by Stamen)

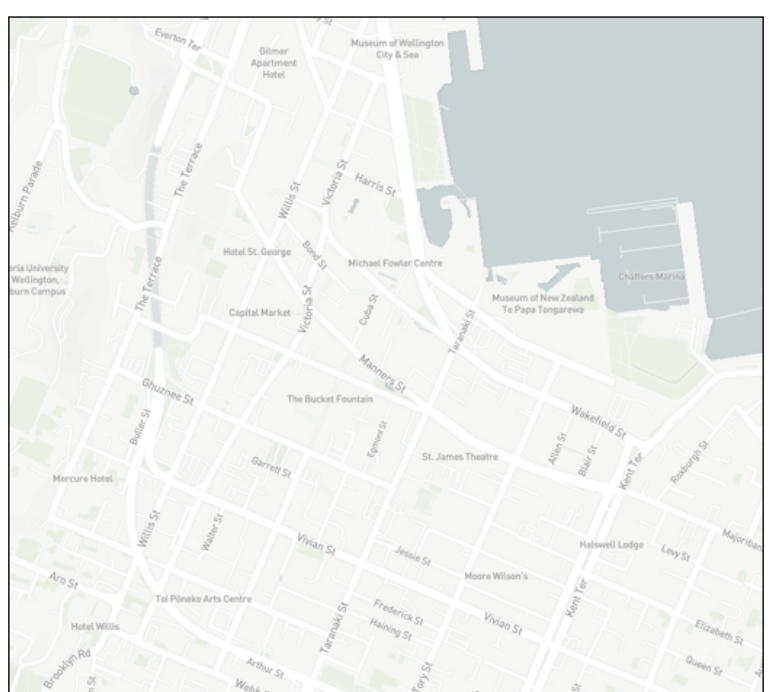

(b) Custom Basemap Used in Wellyhoods App

Figure 3.4: Basemaps of Bostonography's Hoods Project (a) and Wellyhoods App (b)

\subsubsection{User Testing}

The app was tested by 10 individuals. User testing is an important step in the application development process because it allows for feedback to be received from individuals who were not involved in the process (Tan, Liu, \& Beshu, 2009). The 10 individuals (friends, family, co-workers, and office-mates) were known to the researcher. They provided feedback and ideas for improvement. To prompt feedback on potential areas of improvement for the app, user testing individuals answered the following questions after completing the data collection process:

\footnotetext{
7 https://www.mapbox.com/
} 
1. "Was it clear at every stage what you were supposed to be doing? If not, where was it unclear?"

2. "Were the maps of Wellington appropriate? How did they help you find the locations? Where did you encounter problems?"

3. "What did you think Neighbourhood Focal Point meant?"

4. "Was the length of the questionnaire OK? Were there any questions you did not want to answer? Were there any questions that were unclear?"

5. "Would you recommend the app to your friends, family, and co-workers? Why?"

6. "Do you have any other feedback or improvements for the app?"

Feedback was taken into account following user testing and changes to the app were made in order to make it more user friendly. Difficulty navigating to their neighbourhood using the basemap without neighbourhood labels was experienced by user testing individuals. Green space and labels for neighbourhood features (e.g. schools, shopping centres, parks) were subsequently made more obvious to aid navigation. The questionnaire was also improved following user testing. The question regarding the level of education attended by participants' children was changed from single input to multiple input to reflect parents of children at different education levels.

\subsubsection{Application Launch}

The app was made available to the general public for three months, from the beginning of July 2019 to the end of September 2019. Throughout this period, the app was advertised using a range of methods. Posters advertising the app were placed in locations across Wellington City, including university campuses, major shopping areas, the CBD, cafes, and libraries (Figure 3.5). A phonereadable QR code was included for individuals with smartphones with QR reading capabilities to easily access the app. The posters were printed on A4 water resistant paper to survive wet and windy conditions. 


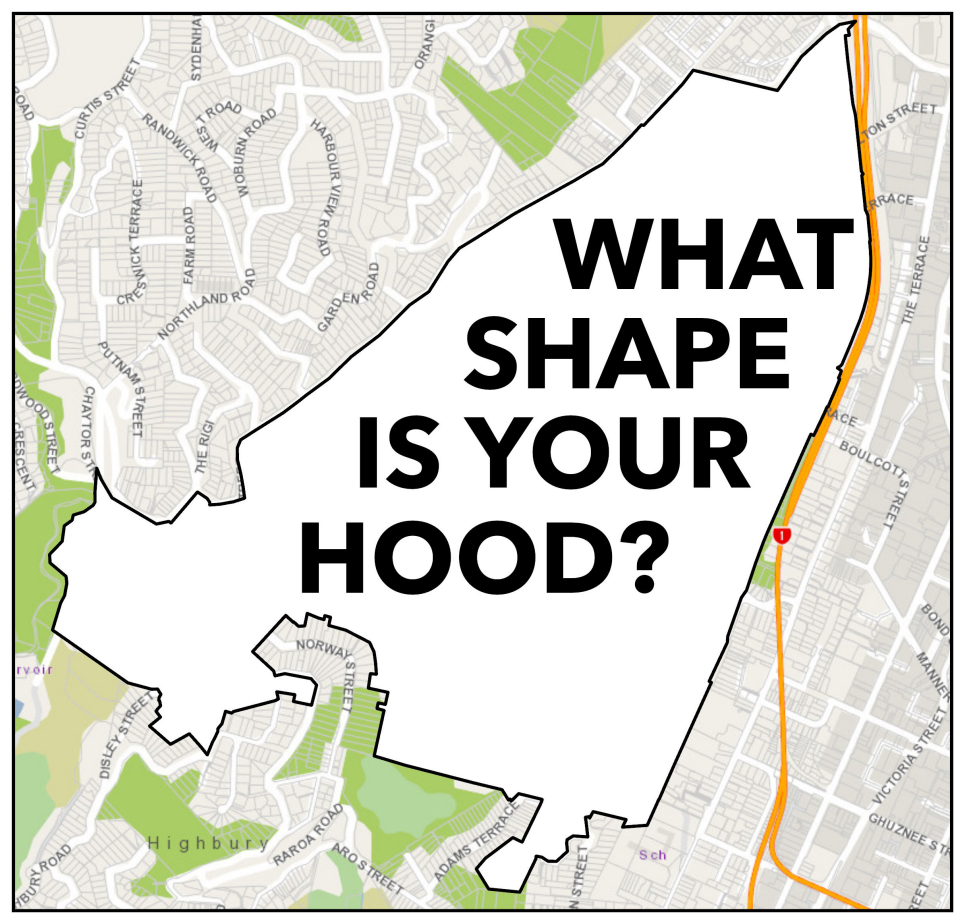

Have you ever thought about your neighbourhood's shape?
I am a Masters student at Victoria University of Wellington
gathering Wellingtonian's perceptions of their
neighbourhood and want your help!
Head to wWW.wellyhoods.com
or scan the QR code to have your say!
The exercise will only take 5 minutes
and no confidential data is collected.

Figure 3.5: Poster advertising the Wellyhoods app

Contacts in different organisations known to the author were contacted to take part in and share the app. Friends, family, and co-workers were also contacted. Participants and contacts were encouraged to share the app. This approach aimed to leverage a form of snowball sampling recruitment used in research methods performing qualitative interviews (Noy, 2008). This method of emailing individuals saw success as it required less effort from individuals to access the app as they only needed to click on a link compared to remembering a URL seen on a poster or scanning a QR code.

The app was shared on social media platforms: Facebook, Twitter, and LinkedIn. \$20 (NZD) was spent on a paid Facebook advertisement promoting the app to individuals in Wellington City. Similar to recruitment emails, this method was less effort for participants to access the app. 


\subsection{Analysis}

This section describes data cleaning and analysis performed on the crowdsourced neighbourhood dataset. All analysis was performed using a mixture of open source Python and R packages, and desktop QGIS software (version 3.8.1) was used to produce output maps.

\subsubsection{Data Cleaning}

Data cleaning was performed on the crowdsourced neighbourhood dataset to ensure it was usable in analysis. 32 responses to the survey were excluded as they were either jokes, errors, or nonsensical. Figure 3.6 shows two examples of excluded responses. In prior studies surveying neighbourhood perceptions, exclusion criteria of PNBs were not noted (Coulton et al., 2013; Jenks \& Dempsey, 2007). Charreire et al. (2016) is a notable exception who excluded any PNB larger than $40 \mathrm{~km}^{2}$ based on visual inspection of outliers. No high quality PNB among the crowdsourced neighbourhood dataset was larger than $30 \mathrm{~km}^{2}$, so no submissions were excluded due to size.

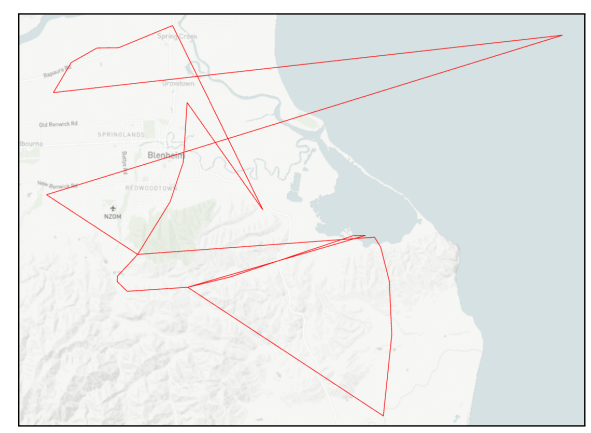

(a) "please delete - test only (sorry)"

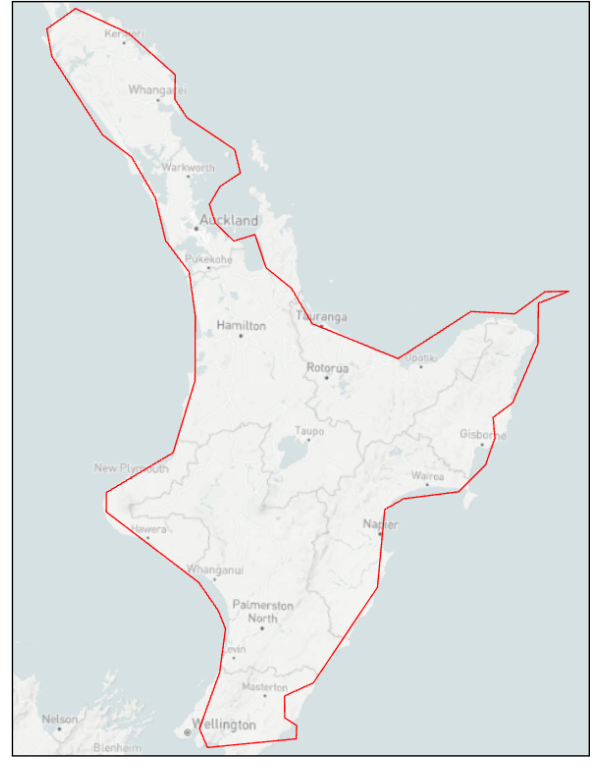

(b) "Te dika a maui"

Figure 3.6: Example excluded PNBs

The 11 to 15 and $70+$ age bands received response rates of 2 and 3 respectively. These sample sizes were too small to include in analysis, so were merged with the closest age band. The age band of 16 to 20 became 11 to 20 , and the age band of 61 to 70 became 61 or over. Neighbourhood names were also tidied to reflect participants' intentions and add consistency in analysis. For example, all instances of Mt Vic and Mount Victoria were changed to Mt Victoria. Spelling mistakes were also corrected, e.g. Kilbrnie was changed to Kilbirnie. 
Using the given neighbourhood name, another neighbourhood factor called Neighbourhood Type was added to each submission based on the 5 options listed below:

- Single: individual neighbourhood, e.g. Karori, Brooklyn, Te Aro.

- Multiple: more than one neighbourhood name, e.g. Kilbirnie/Miramar, Northland-KaroriKelburn, Northland and Central Wellington.

- Subset: part of a neighbourhood, e.g. Karori West, Newtown Central, Part of Miramar.

- Street: individual street, e.g. Majoribanks Street, Ohiro Road, Lambton Quay.

- Other: neighbourhoods not fitting into other categories, e.g. The good place, Hill side, My hood.

\subsubsection{Statistical Analysis}

This thesis explores how our personal characteristics impact neighbourhood delineation. Four neighbourhood dimensions were used to interpret PNBs: area (square kilometres), perimeter (kilometres), compactness, and number of vertices. Area, perimeter, and number of vertices were all derived from the neighbourhood boundaries using the field calculator in QGIS (version 3.8.1).

Compactness was defined using the Polsby-Popper method (PP). A PP score is the ratio between the area of a neighbourhood $\left(\mathrm{A}_{\mathrm{N}}\right)$ and a circle with the same perimeter of the neighbourhood $\left(\mathrm{P}_{\mathrm{N}}\right)$ (Polsby \& Popper, 1991). PP values range from 0 to 1 , with scores closer to 1 meaning a more compact neighbourhood. Figure 3.7 shows examples of PNBs with low (a) and high (b) PP values. The formula for calculating PP scores is given below:

$$
P P=4 \pi \times \frac{A_{N}}{P_{N}}
$$




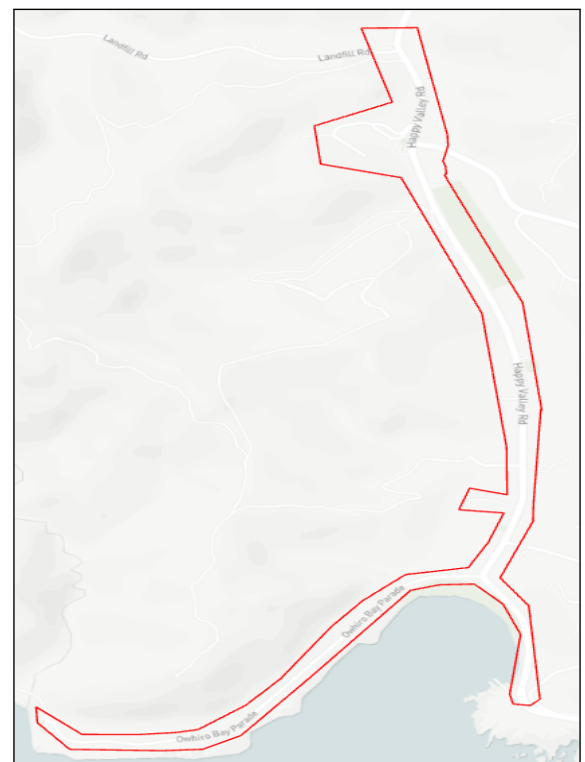

(a) Low Compactness PNB (0.063)

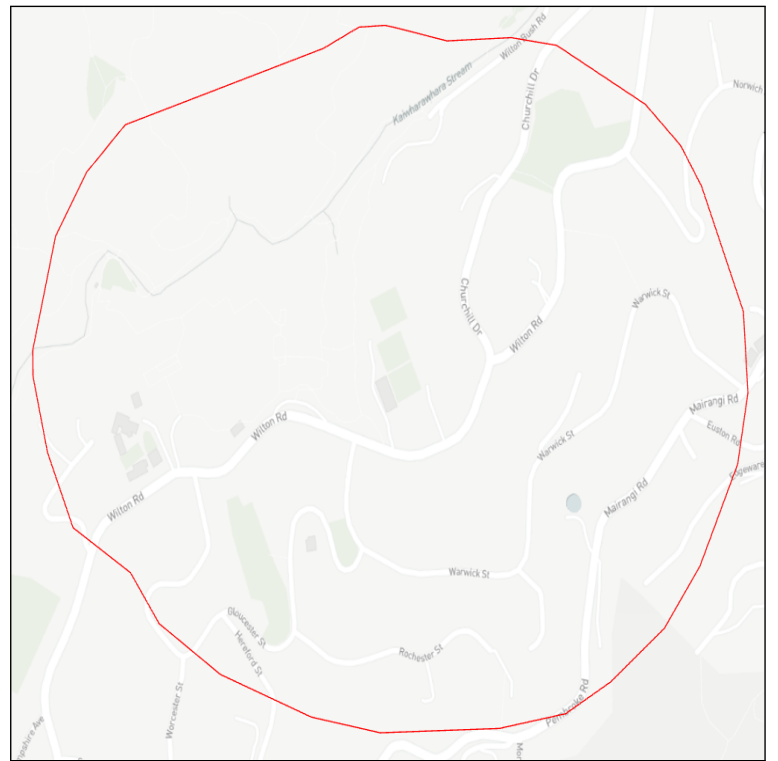

(b) High Compactness PNB (0.95)

Figure 3.7: Example PNBs with Low (a) and High (b) Compactness

Summary statistics for the four neighbourhood dimensions were produced for participants' personal characteristics. Assumptions of linear regression were checked for each of the four neighbourhood dimensions to ensure linear regression models were appropriate for the data. Diagnostic plots for the neighbourhood dimensions were produced to check the assumptions required for linear regression. The distributions of area, perimeter, and number of vertices were all heavily skewed to the right, and compactness was normally distributed. Log transformations were performed on area, perimeter, and number of vertices and were normally distributed afterwards. Figure 3.8 shows the distributions of PNB area before (a) and after the log transformation (b). Following the log transformations, the assumptions of linearity, independence, and equal variance were met for the four neighbourhood dimensions. As the assumptions for linear regression were met, four linear regression models were fit for each of the four neighbourhood dimensions and personal characteristics of participants. Pearson's correlation coefficients were also calculated between the four neighbourhood dimensions. 


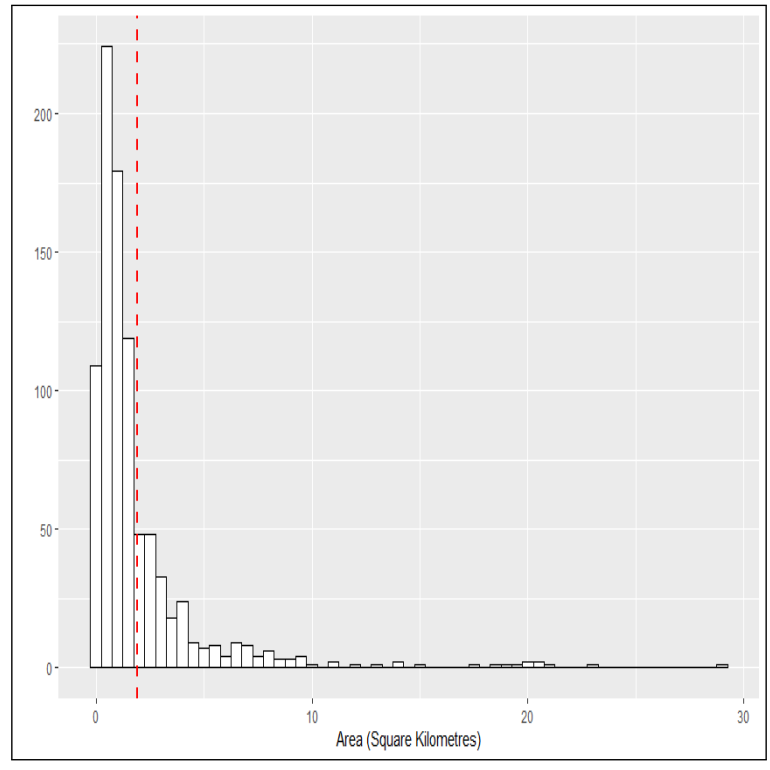

(a) Distribution of PNB Area (Skewness of 4.3)

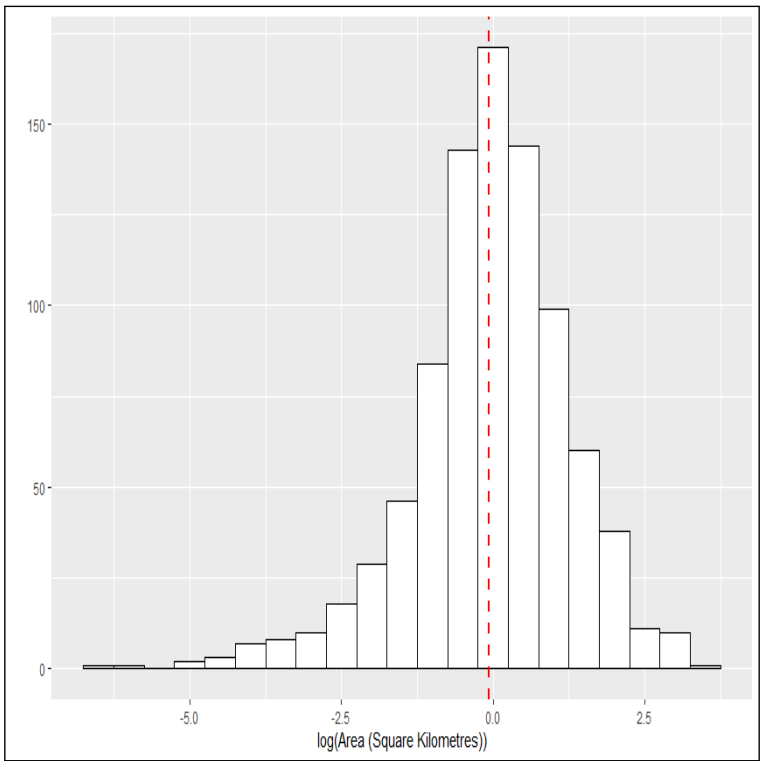

(b) Distribution of PNB Area after log transformation (Skewness of -0.76)

Figure 3.8: Distribution of PNB Area before (a) and after log transformation (b)

\subsubsection{Neighbourhood Consensus}

\section{Hexagon Grids}

This thesis investigates neighbourhood areas of high and low consensus based on overlapping PNBs. Calculating levels of consensus for common neighbourhood areas was done by adopting a method used by Woodruff (2017) involving four steps:

1. Produce a grid of hexagons over the area of interest (extent covered by PNBs). The size of the hexagons can vary based on need, but in this metholodology were $3000 \mathrm{~m}^{2}$ or 68 metres across. This is large enough to cover a section of a street and a few houses. Figure 3.9 shows an example a hexagon cluster.

2. For each hexagon, calculate the total number of PNBs intersecting with it and the number of PNBs intersections sharing the most common neighbourhood name.

3. Remove any hexagon that received less than 5 total PNB intersections.

4. Produce a consensus ratio in each hexagon by dividing the count of PNB intersections sharing the most common name by the total number of intersections. For example, for one hexagon intersecting with 50 PNBs and out of these PNBs, 30 were named Karori, then consensus for the hexagon being part of Karori would be $60 \%$ (30/50). 


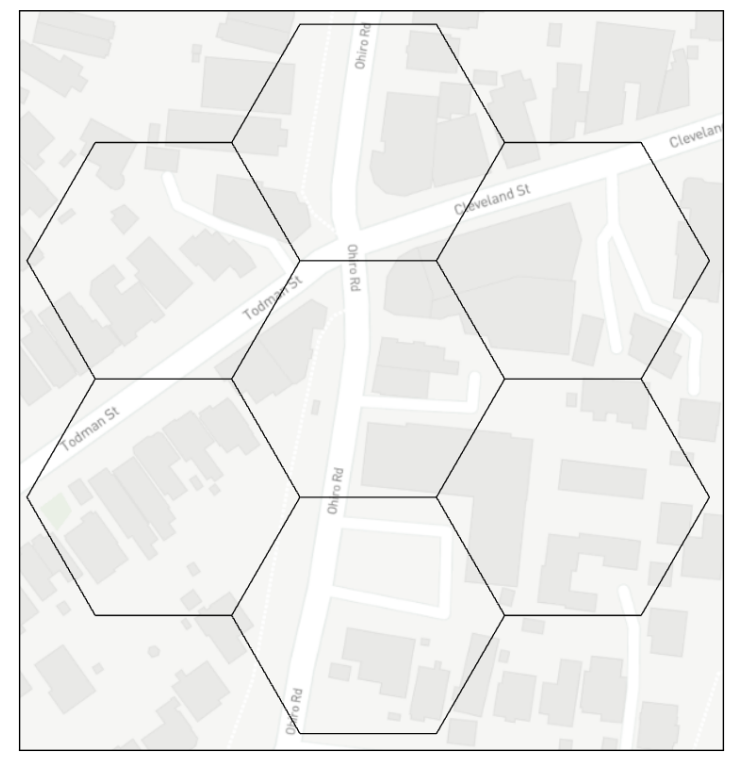

Figure 3.9: Example Hexagon Cluster

The neighbourhood name provided by participants was used to compare neighbourhood areas. However, considerable variation in neighbourhood names was observed, making it difficult to establish consensus in some cases. For example, one hexagon in Wellington's CBD had 25 PNBs with unique neighbourhood names intersecting it, listed below:

(Part of) Te Aro, CBD, CBD and outer burbs, CBD to edge, CBD Victoria Street, Central west wellington, Cuba Quarter, Home to work, Kelburn/Te Aro, Lower Cuba, Mount Cook extending into Te Aro, Mt Victoria and Newtown via walkways, parks and reserves, Mt Cook/Te Aro, Mt

Cook/CBD, My hood, My Te Aro Bubble, Northland and Wellington, Te Aro, Te Aro/Kelburn/Newtown, Town, Wellington, Wellington CBD, Wellington Central, Wellington Central/Cuba, Wellington inner city, Work - Gym - Home

To account for the variation in provided neighbourhood names, two methods of measuring consensus were used as described below: unique and common. Both methods used were case insensitive, for example Wellington Central and wellington central counted as submissions for the same neighbourhood.

- Unique Names: neighbourhood names were treated separately. For example Te Aro, My Te Aro Bubble, and Mt Cook/Te Aro all counted as submissions for different neighbourhoods.

- Common Names: neighbourhood names containing shared names were treated commonly. For example Te Aro, My Te Aro Bubble, and Mt Cook/Te Aro all counted as submissions for the same neighbourhood (Te Aro). Additionally, neighbourhoods with multiple names were 
able to count for submissions for multiple neighbourhoods. For example, Mt Cook/Te Aro counted as submissions for both Mt Cook and Te Aro.

To represent collective neighbourhood areas, a set Community Defined Neighbourhoods (CDNs) were created by merging each hexagon sharing a common name.

\section{Neighbourhood Connectivity}

Models of neighbourhood connectivity were produced by comparing the spatial extents of all PNBs with each other. If one PNB intersected with another PNB, a connection between the two neighbourhoods was assumed. Connectivity was also weighted by two measures:

1. Number of Intersections: connectivity between neighbourhoods A and B is weighted by the count of the number of times PNBs of neighbourhood A intersected PNBs of neighbourhood B. To reduce the effect of one neighbourhood receiving more intersections than another, the count of number of intersections was normalised by dividing the count by the total number of submissions for neighbourhoods A and B.

2. Mean Intersection Area: connectivity between neighbourhoods A and B was weighted by the mean intersection area between the PNBs observed for neighbourhoods A and B. This was normalised by dividing each intersection area by the total area of the two neighbourhood PNBs.

Only the PNBs located in Wellington City were used because low sample sizes of PNBs observed for neighbourhoods outside of Wellington City would have produced biased neighbourhood connections. PNBs with the neighbourhood types of street and other were not used as they did not have comparable neighbourhood names to measure connectivity between neighbourhoods. As neighbourhood names were used to calculate connectivity, the same problem of variation in neighbourhood names that existed when measuring consensus was present. The method of treating neighbourhood names commonly was used for neighbourhood connectivity outputs.

\section{Defining Shopping Hubs}

To investigate if FP clusters were related to shopping hubs, a spatial definition for what constitutes a 'shopping hub' was required. To achieve this, the locations of all amenities relevant to a shopping hub (cafes, restaurants, fast food stores and takeaways, pubs, convenience stores, supermarkets, libraries, doctor's offices, and pharmacies) in Wellington City were exported from OpenStreetMap (OSM).

A spatial join was then performed between the relevant amenities and CDNs to give a neighbourhood name to each amenity. Next, the median centre was found for each group of amenities in a 
neighbourhood. The median centre was used rather than the mean centre because median centre limited the effect of outlier amenities dragging shopping hub location away from most neighbourhood amenities. An example of the difference between using mean and median centre methods is shown in Figure 3.10 .

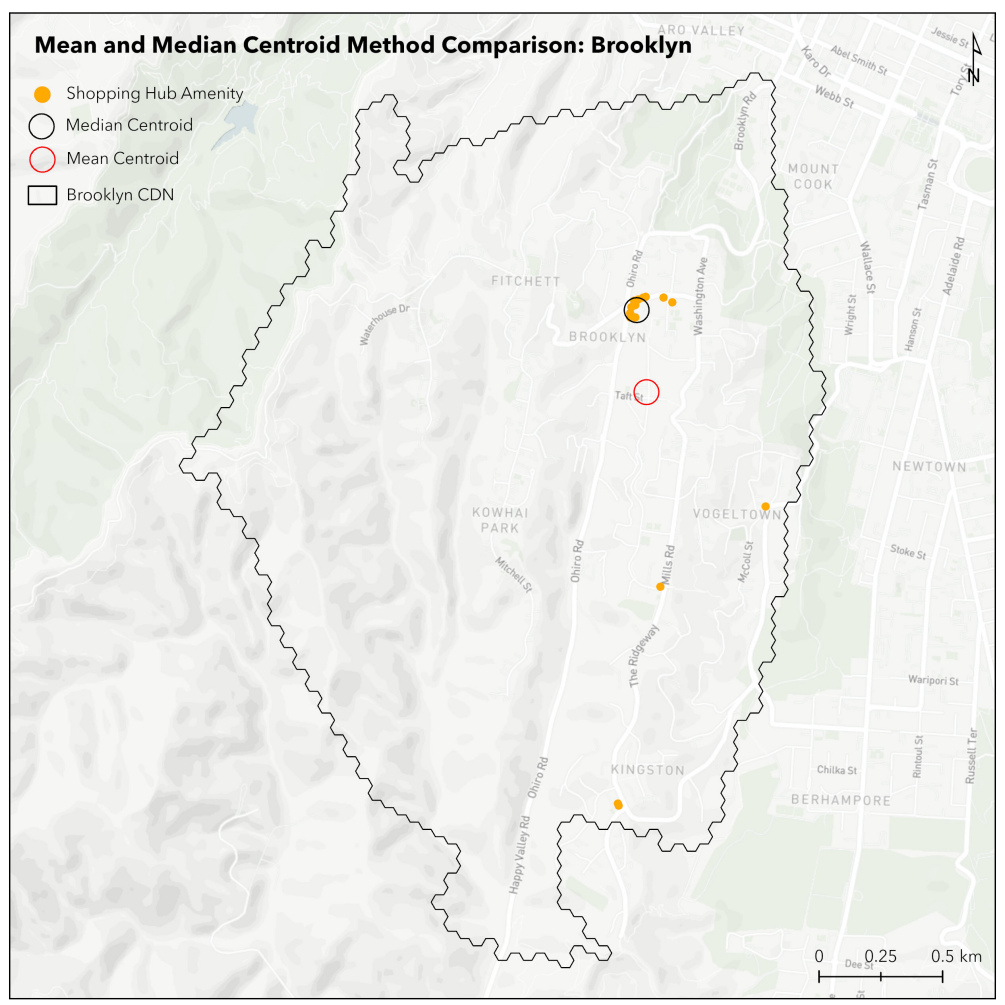

Figure 3.10: Comparison between Mean and Median Centre Methods

Median centre locations in each neighbourhood were then buffered by 150 metres to produce an area representing neighbourhood shopping hubs. A 150 metre buffer was chosen as it was appropriate for what could be considered a walking distance from one end of a shopping hub to another (300 metres in total). Also, from visual inspection across neighbourhoods, a 150 metre buffer captured most of the amenities relevant to a neighbourhood shopping hub without being too large. An example of a buffered neighbourhood shopping hub in Brooklyn is shown in Figure 3.11 . 


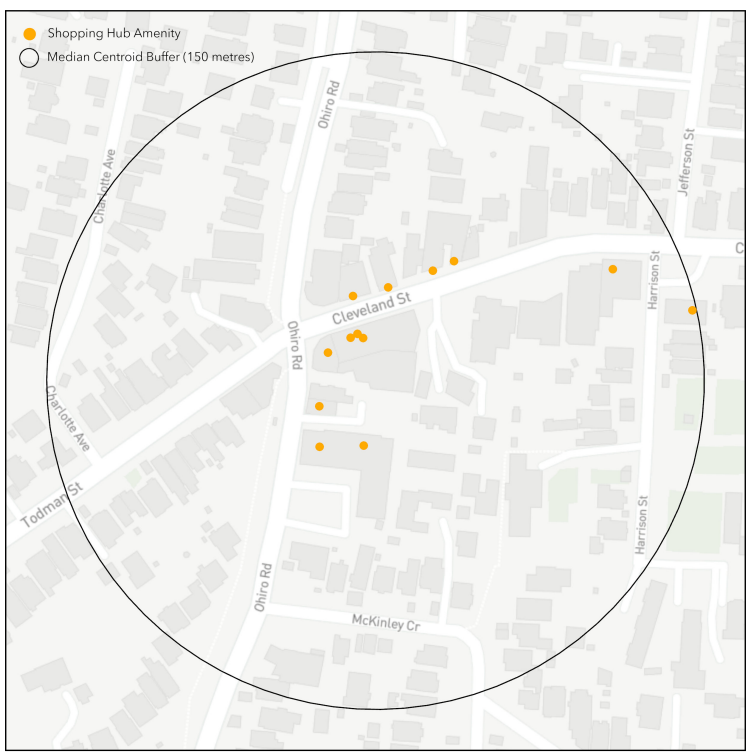

Figure 3.11: Example of Shopping Hub Median Centroid Buffer in Brooklyn

\subsubsection{Comparisons to Official Boundaries}

The crowdsourced neighbourhood dataset was compared to two datasets of official neighbourhood boundaries: localities and statistical areas 2 (SA2). Localities are official boundaries in New Zealand most similar to neighbourhoods. Localities are not census units, but are maintained by Fire and Emergency New Zealand (FENZ) to support emergency response, addressing models, and provide property information. Localities in Wellington City have an average area of $5.14 \mathrm{~km}^{2} \mathrm{but}$ vary greatly in size, ranging between 0.26 and $89.42 \mathrm{~km}^{2}$. Figure 3.12 shows all 57 localities found within Wellington City. Localities are not openly accessible to the public, but were requested and provided by FENZ. 


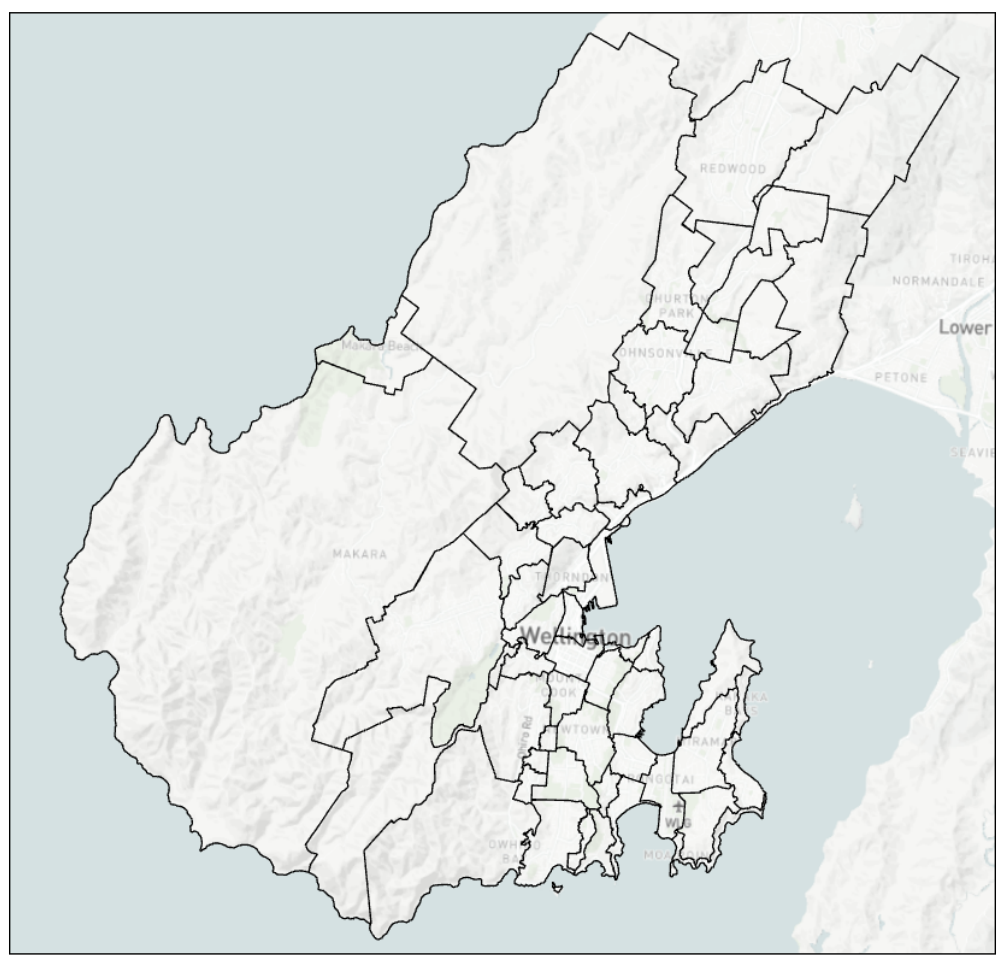

Figure 3.12: Localities in Wellington City (Full extent of research extends further than shown)

SA2s are a census unit produced and maintained by Statistics New Zealand (StatsNZ). SA2s are used to disseminate results of the census and surveys run by StatsNZ at a neighbourhood level. In some cases, an individual SA2 represents a neighbourhood entirely, but for larger neighbourhoods multiple SA2s are used. On average, SA2s represent between 2000 to 4000 people. As a result, SA2s are considerably larger in rural areas than urban areas as populations in rural areas are less dense. SA2s are smaller than localities, with an average area of $3.72 \mathrm{~km}^{2}$. Variation in size also exists in SA2s, with minimum and maximum areas of $0.29 \mathrm{~km}^{2}$ and $177.54 \mathrm{~km}^{2}$ respectively. There are 78 SA2s in Wellington City shown in Figure 3.13. SA2s were accessed from StatsNZ's open data portal 8

\footnotetext{
${ }^{8}$ https://datafinder.stats.govt.nz/
} 


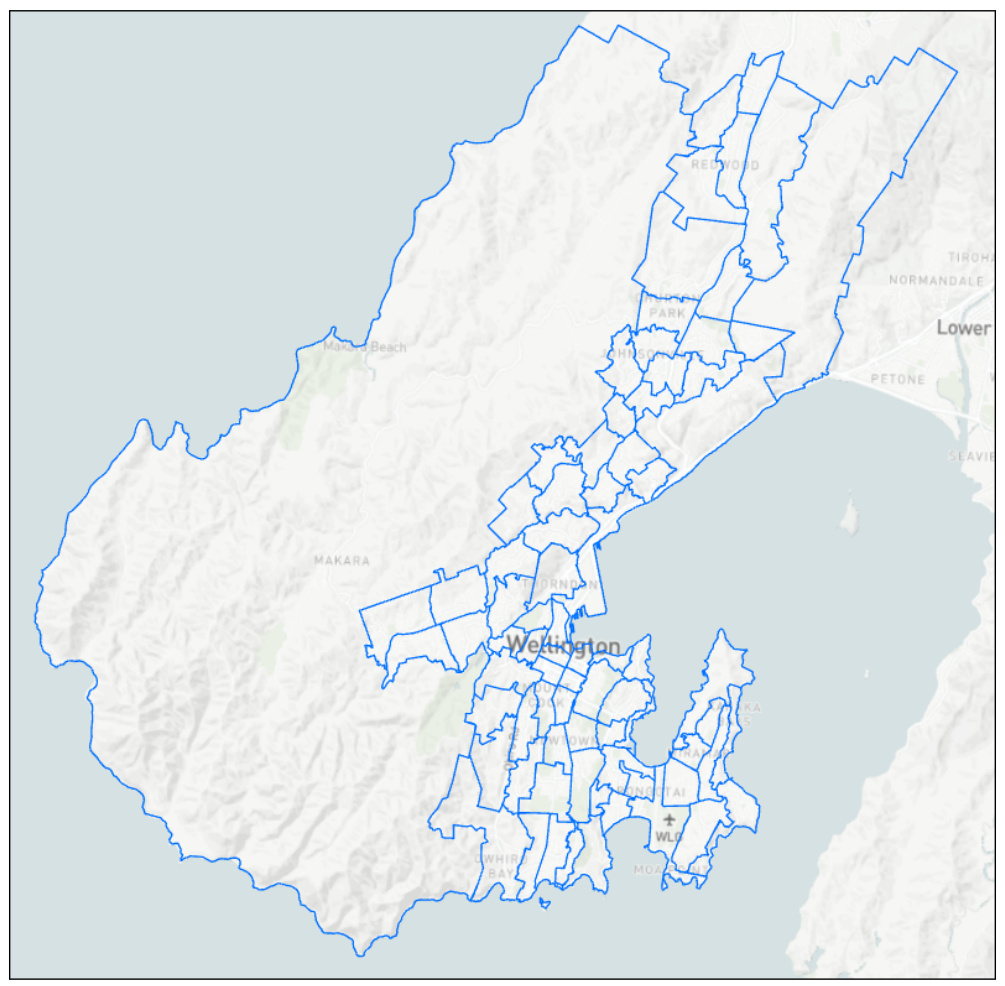

Figure 3.13: SA2s in Wellington City (Full extent of research extends further than shown)

Four neighbourhood datasets were compared: PNBs, CDNs, localities, and SA2s. Only localities and SA2s intersecting a CDN were included in analysis. The same four neighbourhood dimensions (area, perimeter, compactness, and number of vertices) used in statistical testing were calculated for each of the four comparison neighbourhood datasets and used to produce summary statistics.

Congruence was compared across the four comparison neighbourhood datasets. For two overlapping boundaries $\mathrm{X}$ and $\mathrm{Y}$, congruence is the ratio between the intersection and the union of $\mathrm{X}$ and Y (Galster, 1986). Congruence values range from 0 to 1, with 0 meaning two completely dissimilar boundaries and 1 meaning they are completely alike. The formula for calculating congruence is:

$$
\text { Congruence }=(X \cap Y) /(X \cup Y)
$$

When measuring congruence between the four comparison neighbourhood datasets, varying amounts and sizes of intersections were observed. Figure 3.14 shows two cases of PNBs intersecting with different amounts of localities, and intersections with varying areas. Measuring congruence between the complete neighbourhood datasets is problematic, as a large amount of smaller intersections produced highly skewed congruence values when averaged. Congruence was therefore measured for only the intersection with the largest area between individual neighbourhood polygons of the four comparison datasets. 


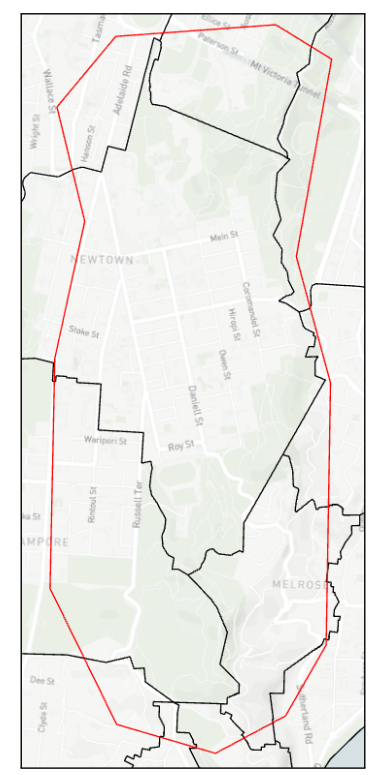

(a) PNB and overlapping Locality Boundaries (11 intersections)

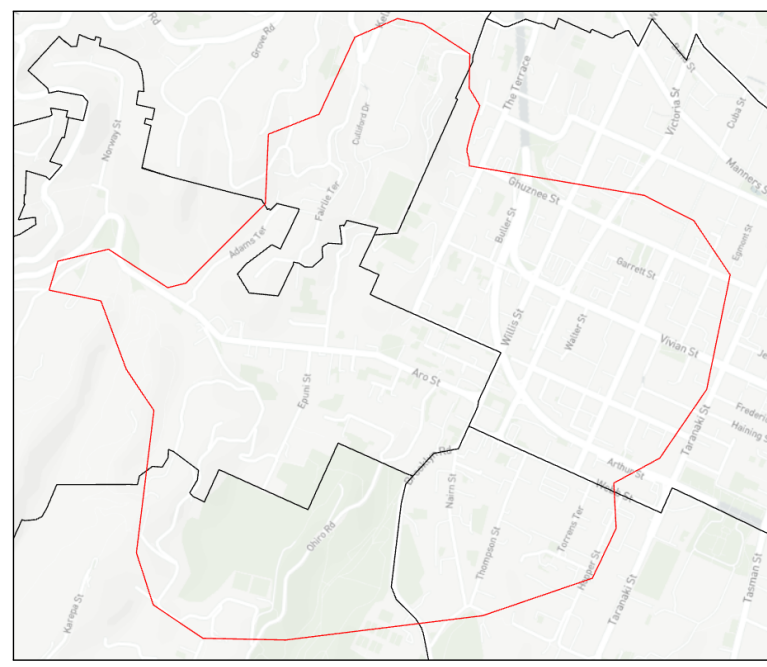

(b) PNB and overlapping Locality Boundaries (5 intersections)

Figure 3.14: Example PNBs and overlapping Locality boundaries

\subsection{Summary}

This chapter outlined the three components of the methods used for developing a questionnaire and an application to crowdsource neighbourhood data, along with analysis performed. First, a questionnaire developed to crowdsource neighbourhood data and personal characteristics from participants was discussed. Second, the development and distribution of the app was described. Last, the data cleaning and spatial and statistical analyses methods performed on the crowdsourced neighbourhood dataset were outlined. 


\section{Chapter 4}

\section{Results}

\subsection{Introduction}

This chapter presents the results of the crowdsourced neighbourhood survey in Wellington City and subsequent spatial analyses performed. Results of statistical analysis between four neighbourhood dimensions (area, perimeter, compactness, and number of vertices) and participant's personal characteristics are shown. Hexagon grids are used to explore areas of high and low neighbourhood consensus, outputs from a novel model representing neighbourhood connectivity are presented, and density-based clustering of Focal Points (FPs) are performed and related to different neighbourhood features. Finally, results from comparisons between crowdsourced neighbourhood boundaries and official boundaries (localities and statistical area $2(\mathrm{SA} 2 \mathrm{~s}))$ are presented.

\subsubsection{Geographic Distribution}

918 responses were received in the three month data collection period. 32 of these were considered

joke or error responses and were removed from the sample. The final sample included 886 responses contributed from across the Greater Wellington Region. Figure 4.1 presents the geographic distribution for all 886 Perceived Neighbourhood Boundaries (PNBs) and FPs. While some responses extended to locations far from Wellington City such as the Kapiti Coast and Wairarapa, most responses were clustered around Wellington City. 748 PNBs intersected with the Wellington City extent. Spatial analyses performed in this chapter will focus on responses received in Wellington City to minimise the effect of spatial bias produced from small sample sizes of PNBs and FPs. 


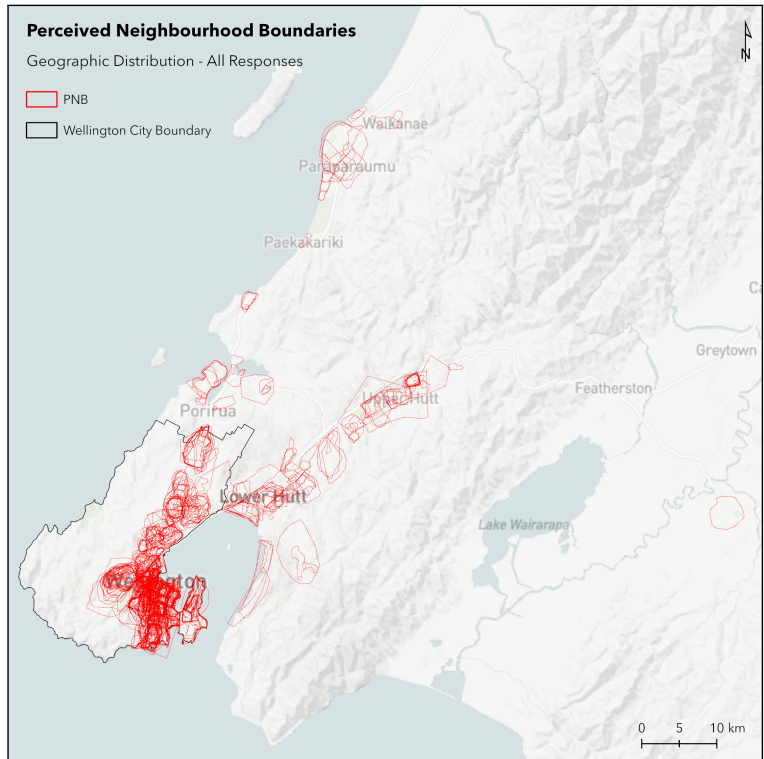

(a) PNBs

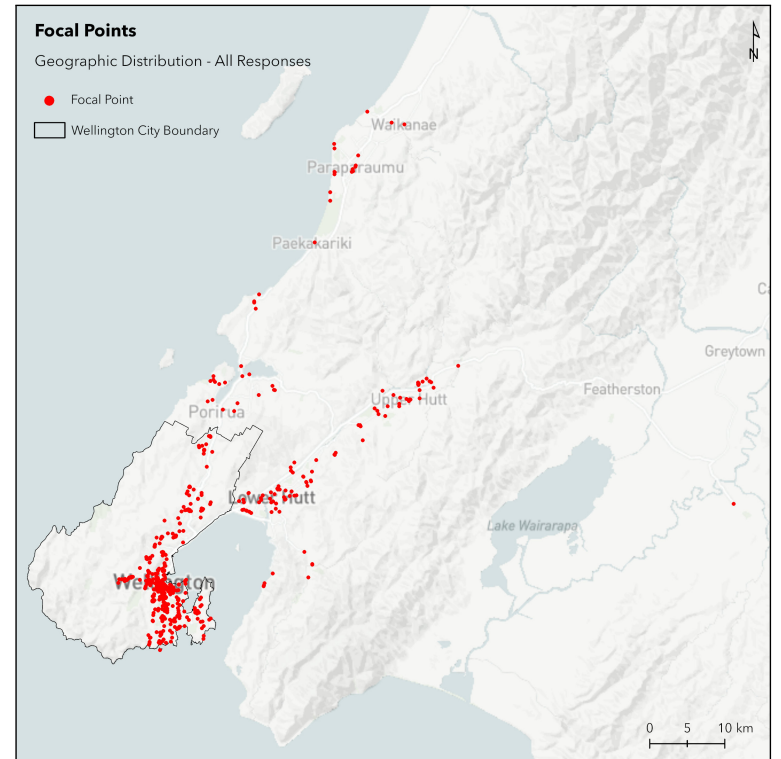

(b) FPs

Figure 4.1: Geographic Distribution of all PNBs (a) and FPs (b)

Figure 4.2 shows PNBs (a) and FPs (b) in Wellington City. From visual inspection, large amounts of overlap among neighbourhood boundaries are identifiable. Clear variation between and within neighbourhoods can also be observed. Road networks are visible in Wellington's CBD where a pronounced gridded effect can be seen.

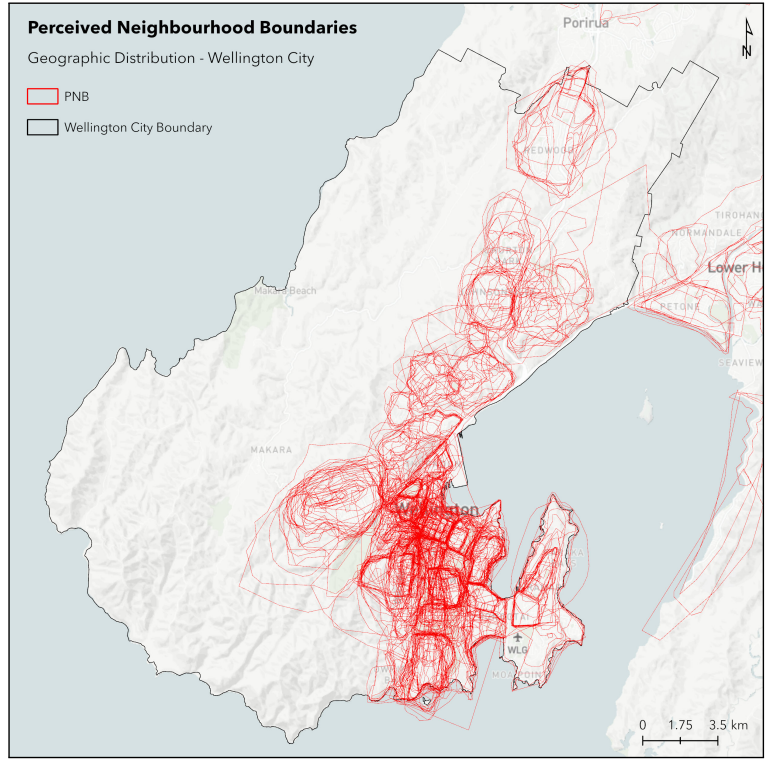

(a) PNBs

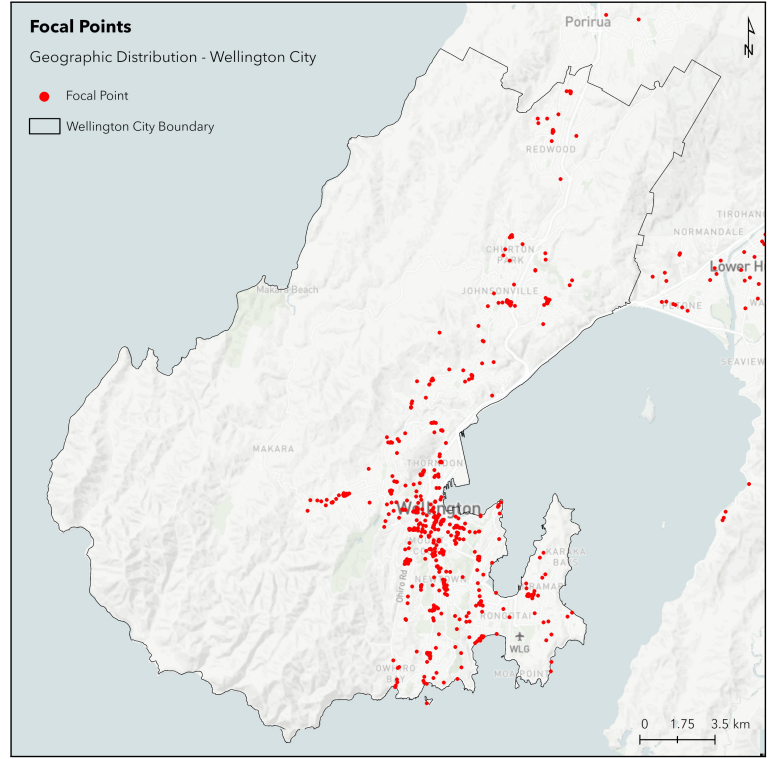

(b) FPs

Figure 4.2: Geographic Distribution of PNBs (a) and FPs (b) in Wellington City 
The highly clustered nature of the crowdsourced neighbourhood dataset makes static maps a poor method of presentation. An $\mathrm{R}$ Shiny app was created to let individuals explore the data in a more interactive medium (Figure 4.3). This app allows users to navigate the crowdsourced neighbourhood data in a web-based mapping interface, apply filters to PNBs and FPs, and overlay locality and SA2 boundaries. It is available at https://wellyhoods.shinyapps.io/explorer.

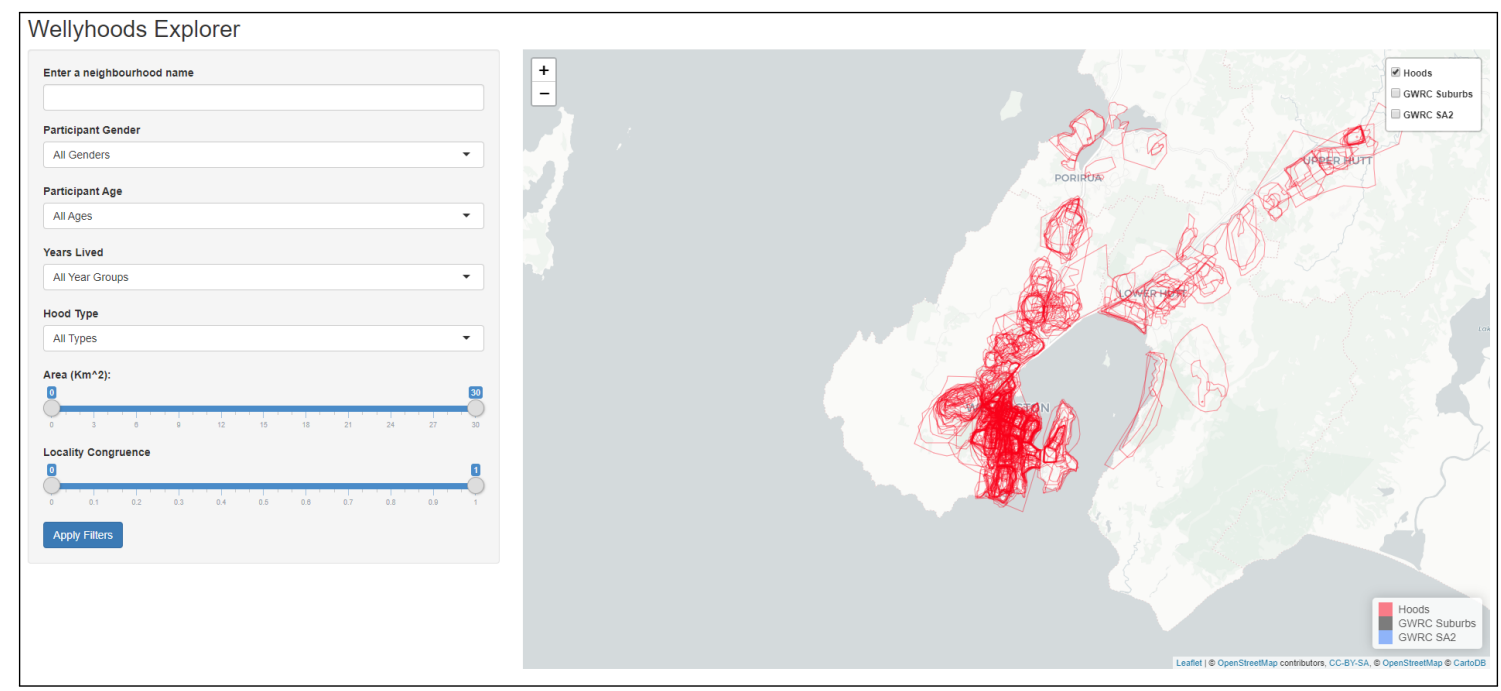

Figure 4.3: Interface of the Neighbourhood Data Explorer App

\subsection{Personal Characteristic Analysis}

Our personal characteristics have demonstrated relationships on our neighbourhood perceptions (Coulton et al., 2013; Charreire et al., 2016). However, given the complex and subjective nature of neighbourhood geographies, these relationships are often unclear. This section describes the personal characteristics of the study sample and their impact on neighbourhood delineation. Four groups of participants' personal characteristics are analysed: age and gender, neighbourhood factors, children, and transport decisions. Summary statistics and results of statistical analysis for four neighbourhood dimensions are presented (area, perimeter, compactness, and number of vertices). Appendix 2 shows results of statistical analysis performed in this section.

\subsubsection{Age and Gender}

Table 4.1 presents counts of each of the subgroups for age and gender received in the sample. Most participants were male $(53.5 \%)$ and in the $21-30$ age bracket $(43.13 \%)$. The high representation of this younger age bracket is likely due to smartphone and technology usage, and promotion methods (posters at universities, Facebook advertisements) being more salient to younger individuals. Although participants were predominantly younger, a large number of older participants also took 
part in the survey $(18.06 \%$ (160) were 41 or older $)$.

\begin{tabular}{|c|c|c|c|c|c|c|c|c|c|c|c|c|c|c|c|}
\hline & & \multirow[b]{2}{*}{ Count } & \multirow[b]{2}{*}{ Proportion } & \multicolumn{3}{|c|}{ Area $\left(\mathrm{Km}^{2}\right)$} & \multicolumn{3}{|c|}{ Perimeter $(\mathrm{Km})$} & \multicolumn{3}{|c|}{ Compactness } & \multicolumn{3}{|c|}{ Vertices } \\
\hline & & & & Mean & Median & SD & Mean & Median & SD & Mean & Median & SD & Mean & Median & SD \\
\hline \multirow[t]{4}{*}{ Gender } & Male & 474 & 53.5 & 1.82 & 1.03 & 2.63 & 5.26 & 4.64 & 3.2 & 0.63 & 0.64 & 0.16 & 23.62 & 22 & 11.18 \\
\hline & Female & 391 & 44.13 & 2.06 & 0.99 & 3.33 & 5.43 & 4.58 & 3.59 & 0.64 & 0.66 & 0.17 & 22.41 & 19 & 11.12 \\
\hline & Other & 15 & 1.69 & 1.5 & 0.86 & 1.75 & 4.62 & 4.06 & 2.65 & 0.67 & 0.67 & 0.19 & 19.27 & 20 & 4.03 \\
\hline & Missing & 6 & 0.68 & & & & & & & & & & & & \\
\hline \multirow[t]{7}{*}{ Age } & 11 to 20 & 124 & 14.00 & 2.09 & 1.09 & 3.06 & 5.56 & 4.70 & 3.43 & 0.63 & 0.64 & 0.16 & 22.11 & 20 & 8.64 \\
\hline & 21 to 30 & 391 & 44.13 & 1.69 & 0.93 & 2.8 & 5.03 & 4.34 & 3.21 & 0.62 & 0.64 & 0.16 & 23.84 & 21 & 11.95 \\
\hline & 31 to 40 & 208 & 23.48 & 2.15 & 1.07 & 3.25 & 5.62 & 4.78 & 3.57 & 0.64 & 0.65 & 0.17 & 22.23 & 20 & 10.52 \\
\hline & 41 to 50 & 110 & 12.42 & 2.06 & 1.21 & 2.82 & 5.50 & 4.78 & 3.15 & 0.67 & 0.68 & 0.18 & 22.79 & 20 & 10.7 \\
\hline & 51 to 60 & 35 & 3.95 & 2.01 & 1.10 & 2.85 & 5.28 & 4.62 & 4.1 & 0.67 & 0.69 & 0.16 & 21.54 & 19 & 10.9 \\
\hline & $61+$ & 15 & 1.69 & 1.81 & 1.16 & 2.22 & 5.16 & 4.27 & 3.21 & 0.67 & 0.68 & 0.14 & 25.69 & 21.5 & 16.05 \\
\hline & Missing & 2 & 0.23 & & & & & & & & & & & & \\
\hline
\end{tabular}

Table 4.1: Summary Statistics for Age and Gender

Table 4.1 also presents summary statistics of the four neighbour dimensions (area, perimeter, compactness, and number of vertices) for the age and gender subgroups of participants. No significant differences between the age and gender groups of participants were observed for the four neighbourhood dimensions (Appendix 2). On average, male participants delineated smaller neighbourhoods $\left(1.82 \mathrm{~km}^{2}\right)$ than female participants $\left(2.06 \mathrm{~km}^{2}\right)$. However, the median PNB areas for male and female participants were much smaller and did not differ greatly, at $1.03 \mathrm{~km}^{2}$ and $0.99 \mathrm{~km}^{2}$ respectively. This disparity between mean and median values is likely the result of outliers causing mean values to be skewed upwards. Participants who indicated their gender as Other (15 participants) delineated much smaller neighbourhoods than male and female participants with an average of $1.50 \mathrm{~km}^{2}$, a median of $0.86 \mathrm{~km}^{2}$, and a standard deviation of $1.75 \mathrm{~km}^{2}$. However, this was a much smaller sample group than males and females. No clear trends were observed among participants' age groups. One exception is the 21 to 30 age group delineated smaller neighbourhoods (median area of $0.93 \mathrm{~km}^{2}$ ) than the other age groups combined (average median value of $1.13 \mathrm{~km}^{2}$ ).

\subsubsection{Neighbourhood Factors}

Most participants had lived in the neighbourhood they provided information on for 5 years or less (66.25\%, 587 participants) (Table 4.2). This may reflect the younger age of participants who may move houses or flats regularly. A large number of participants also lived in the neighbourhood they provided data on for more than 10 years $(21.78 \%)$.

Table 4.2 also shows summary statistics of the four neighbourhood dimensions for the subgroups of length of residence and neighbourhood type. A median area of $1.40 \mathrm{~km}^{2}$ was observed for participants who have lived in their neighbourhood for more than 10 years. This is much larger than the median area observed for individuals who lived in their neighbourhood than less than a 
year $\left(0.84 \mathrm{~km}^{2}\right)$. The mean and standard deviation values reflect this trend. Length of residence was found to be a significant predictor of PNB area (Appendix 2). Living in a neighbourhood for 6 to 10 years and 10 or more years were both significantly associated with a mean increase in PNB area (0.305 $\mathrm{km}^{2}$ and $0.464 \mathrm{~km}^{2}$ respectively), compared to living in a neighbourhood for less than a year. Boxplots of the relationship between years lived in a neighbourhood and PNB area exemplifies this difference (Figure 4.4). Significant trends following the same pattern as neighbourhood area were also observed for perimeter. Length of residence was not found to be a significant predictor for PNB compactness or the number of vertices.

\begin{tabular}{|c|c|c|c|c|c|c|c|c|c|c|c|c|c|c|c|}
\hline & & \multirow[b]{2}{*}{ Count } & \multirow[b]{2}{*}{ Proportion } & \multicolumn{3}{|c|}{ Area $\left(\mathrm{Km}^{2}\right)$} & \multicolumn{3}{|c|}{ Perimeter $(\mathrm{Km})$} & \multicolumn{3}{|c|}{ Compactness } & \multicolumn{3}{|c|}{ Vertices } \\
\hline & & & & Mean & Median & $\mathrm{SD}$ & Mean & Median & $\mathrm{SD}$ & Mean & Median & $\mathrm{SD}$ & Mean & Median & $\mathrm{SD}$ \\
\hline \multirow[t]{5}{*}{ Years Lived } & Less than 1 & 210 & 23.7 & 1.41 & 0.84 & 2.18 & 4.65 & 4.07 & 2.78 & 0.635 & 0.65 & 0.16 & 22.37 & 20.5 & 9.71 \\
\hline & 1 to 5 & 377 & 42.55 & 1.76 & 0.92 & 2.88 & 5.11 & 4.36 & 3.28 & 0.623 & 0.632 & 0.17 & 23.46 & 21 & 11.6 \\
\hline & 6 to 10 & 103 & 11.63 & 2.14 & 1.22 & 2.95 & 5.7 & 4.88 & 3.48 & 0.635 & 0.659 & 0.16 & 24.48 & 20 & 13.63 \\
\hline & More than 10 & 193 & 21.78 & 2.66 & 1.40 & 3.59 & 6.24 & 5.19 & 3.8 & 0.659 & 0.667 & 0.16 & 22.15 & 21 & 9.96 \\
\hline & Missing & 2 & 0.23 & & & & & & & & & & & & \\
\hline Neighbourhood & Single & 706 & 79.68 & 1.88 & 1.11 & 2.41 & 5.40 & 4.72 & 2.91 & 0.65 & 0.65 & 0.16 & 23.05 & 20.5 & 10.75 \\
\hline \multirow[t]{4}{*}{ Type } & Subset & 44 & 4.97 & 1.04 & 0.62 & 1.22 & 4.13 & 3.73 & 2.1 & 0.61 & 0.64 & 0.13 & 21.95 & 19.5 & 7.59 \\
\hline & Multiple & 56 & 6.32 & 2.92 & 1.41 & 4.81 & 7.30 & 5.98 & 4.97 & 0.52 & 0.55 & 0.2 & 27.95 & 23 & 18.14 \\
\hline & Street & 46 & 5.19 & 0.21 & 0.13 & 0.37 & 1.84 & 1.55 & 1.27 & 0.64 & 0.66 & 0.2 & 18.57 & 16.5 & 6.67 \\
\hline & Other & 34 & 3.84 & 4.49 & 0.58 & 7.32 & 6.57 & 3.43 & 6.75 & 0.65 & 0.69 & 0.19 & 21.62 & 22.5 & 8.62 \\
\hline
\end{tabular}

Table 4.2: Summary Statistics for Neighbourhood Factors

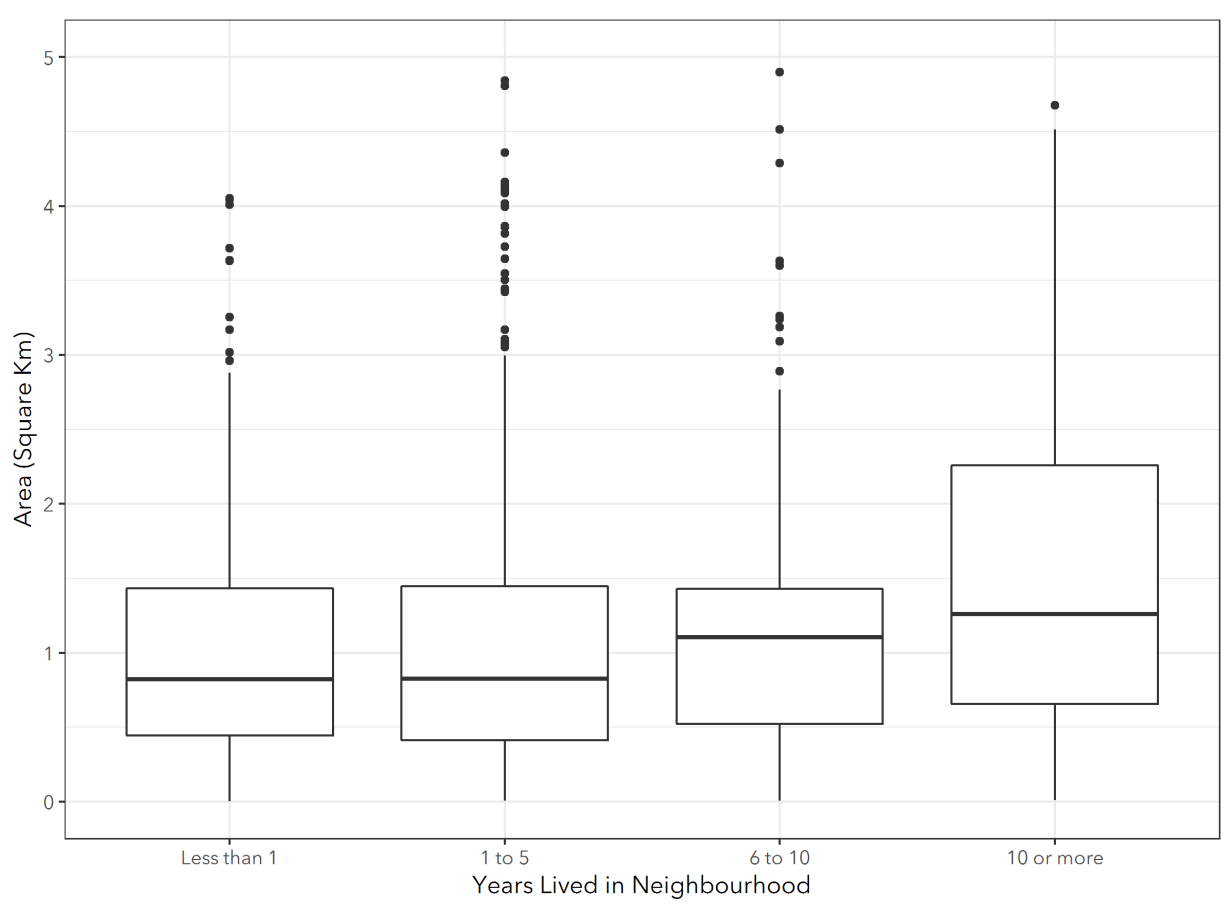

Figure 4.4: Years Lived in Neighbourhood: Area Boxplots

When completing the survey, a definition of neighbourhood was not provided to participants. Consequently, various types of neighbourhoods were received during the crowdsourced neighbourhood 
survey, shown in Table 4.2. Further detail and examples of the neighbourhood types are given in Section 3.5.1. Most participants provided neighbourhood data on a single neighbourhood (79.68\%). Other neighbourhood types were also common, including subset (4.97\%), multiple (6.32\%), and street $(5.19 \%)$. The variation in neighbourhood types supports the conclusion when no definition of neighbourhood is provided, individuals perceive their neighbourhoods in a wide variety of ways, all of which are valid interpretations.

Significant PNB area differences were observed between the different neighbourhood types (Figure 4.5. Appendix 2). The neighbourhood types of subset $\left(0.62 \mathrm{~km}^{2}\right)$ and street $\left(0.13 \mathrm{~km}^{2}\right)$ were significantly smaller than single neighbourhoods $\left(1.11 \mathrm{~km}^{2}\right)$. Multiple neighbourhoods were also significantly larger than the single neighbourhoods, with a median area of $1.41 \mathrm{~km}^{2}$. Consistent findings of neighbourhood type's impact on area were also observed for perimeter.

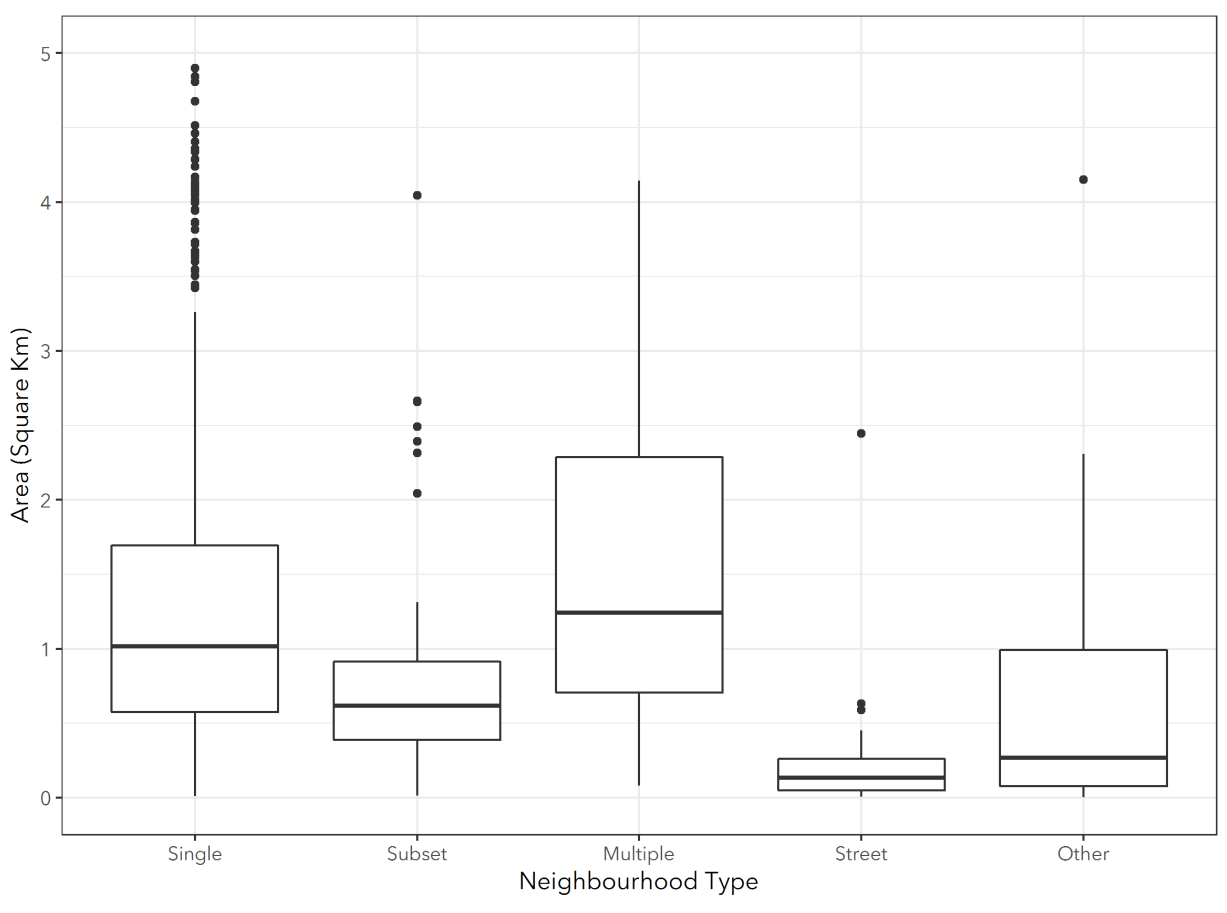

Figure 4.5: Neighbourhood Type: Area Boxplots

The multiple neighbourhood type caused a significant decrease of 0.112 in compactness when compared to the single neighbourhood type (Appendix 2). This could be attributed to participants' with a multiple neighbourhood type delineating an area roughly encompassing areas of both neighbourhoods of interest, rather than following geographic features, such as roads or shorelines, in a single neighbourhood. Variations in the number of vertices can also be observed between the neighbourhood types, with means of 18.57 and 27.95 observed for neighbourhood types of street and multiple respectively. 


\subsubsection{Children}

Summary statistics for the personal characteristics related to children are presented in Table 4.3. Most participants did not have children (75.06\%). This result may be due to younger composition of the sample size. For participants with children, their children were, in most cases, living at home $(89.86 \%)$. Preschool and primary were the most common levels of education for participants' children $(38.12 \%$ and $34.98 \%$ respectively). Again, this result likely reflects the younger composition of participants. No significant differences were found between the four neighbourhood dimensions and personal characteristics related to children (Appendix 2). Slightly larger neighbourhood areas were observed for participants with children (median of $1.22 \mathrm{~km}^{2}$ ) than participants without children (median of $1.01 \mathrm{~km}^{2}$ ).

\begin{tabular}{|c|c|c|c|c|c|c|c|c|c|c|c|c|c|c|c|}
\hline & & \multirow[b]{2}{*}{ Count } & \multirow[b]{2}{*}{ Proportion } & \multicolumn{3}{|c|}{ Area $\left(\mathrm{Km}^{2}\right)$} & \multicolumn{3}{|c|}{ Perimeter $(\mathrm{Km})$} & \multicolumn{3}{|c|}{ Compactness } & \multicolumn{3}{|c|}{ Vertices } \\
\hline & & & & Mean & Median & SD & Mean & Median & $\mathrm{SD}$ & Mean & Median & $\mathrm{SD}$ & Mean & Median & $\mathrm{SD}$ \\
\hline \multirow[t]{3}{*}{ Children } & Yes & 217 & 24.49 & 2.19 & 1.22 & 3.14 & 5.62 & 4.72 & 3.43 & 0.66 & 0.67 & 0.16 & 22.22 & 19 & 11.32 \\
\hline & No & 665 & 75.06 & 1.84 & 1.01 & 3.13 & 5.23 & 4.5 & 3.34 & 0.63 & 0.64 & 0.17 & 23.29 & 21 & 11.03 \\
\hline & Missing & 4 & 0.45 & & & & & & & & & & & & \\
\hline \multirow[t]{3}{*}{ At Home } & Yes & 195 & 89.86 & 2.29 & 1.23 & 3.25 & 5.76 & 4.89 & 3.49 & 0.65 & 0.65 & 0.15 & 21.96 & 19 & 10.64 \\
\hline & No & 23 & 10.6 & 1.22 & 0.62 & 2.88 & 4.18 & 3.82 & 2.5 & 0.70 & 0.77 & 0.2 & 23.22 & 17 & 16.24 \\
\hline & Missing & 3 & 1.38 & & & & & & & & & & & & \\
\hline \multirow[t]{6}{*}{ School Level } & Preschool & 85 & 38.12 & 1.99 & 1.3 & 2.08 & 5.65 & 4.97 & 2.96 & 0.64 & 0.64 & 0.14 & 20.22 & 18 & 8.46 \\
\hline & Primary & 78 & 34.98 & 2.46 & 1.25 & 3.96 & 5.96 & 4.88 & 3.94 & 0.63 & 0.65 & 0.15 & 22.58 & 20 & 9.78 \\
\hline & Intermediate & 11 & 4.93 & 1.95 & 1.39 & 1.65 & 5.53 & 4.95 & 2.24 & 0.73 & 0.72 & 0.11 & 21.45 & 21 & 8.84 \\
\hline & Secondary & 31 & 13.9 & 2.33 & 1.36 & 2.2 & 5.81 & 4.71 & 2.99 & 0.70 & 0.69 & 0.13 & 23.45 & 21 & 10.56 \\
\hline & Post-Secondary & 10 & 4.48 & 1.54 & 0.8 & 1.82 & 4.62 & 3.64 & 2.91 & 0.71 & 0.68 & 0.12 & 22.2 & 20 & 9.56 \\
\hline & Missing & 8 & 3.59 & & & & & & & & & & & & \\
\hline
\end{tabular}

Table 4.3: Summary Statistics for Status of Children

\subsubsection{Transport Decisions}

Most participants had access to a car (72.80\%), and out of these participants the majority could drive it (87.75\%) (Table 4.4). Almost a third (32.39\%) of participants did not have access to a car they could drive. Car access resulted in larger PNB areas, with median areas of $1.13 \mathrm{~km}^{2}$ and 0.86 $\mathrm{km}^{2}$ respectively observed for participants with and without car access. A consistent pattern was found for participants able to drive the car they had access to (median area of $1.15 \mathrm{~km}^{2}$ ) compared to participants unable to drive it (median area of $0.74 \mathrm{~km}^{2}$ ).

Having access to a car produced a mean increase of $0.289 \mathrm{~km}^{2}$ and $0.153 \mathrm{~km}$ for PNB area and perimeter respectively compared to not having access to one. However, having access to a car only significantly impacted PNB perimeter. An almost significant p-value of 0.05008 was observed for car access and PNB area. Due to the p-value being only just above the $5 \%$ significance threshold commonly used in statistical testing, and strong correlation between neighbourhood area and perimeter, we can still conclude having access to a car has a significant impact on PNB area. 


\begin{tabular}{|c|c|c|c|c|c|c|c|c|c|c|c|c|c|c|c|}
\hline & & \multirow[b]{2}{*}{ Count } & \multirow[b]{2}{*}{ Proportion } & \multicolumn{3}{|c|}{ Area $\left(\mathrm{Km}^{\wedge} 2\right)$} & \multicolumn{3}{|c|}{ Perimeter $(\mathrm{Km})$} & \multicolumn{3}{|c|}{ Complexity } & \multicolumn{3}{|c|}{ Vertices } \\
\hline & & & & Mean & Median & $\mathrm{SD}$ & Mean & Median & $\mathrm{SD}$ & Mean & Median & SD & Mean & Median & $\mathrm{SD}$ \\
\hline \multirow[t]{3}{*}{ Car Access } & Yes & 645 & 72.8 & 2.06 & 1.13 & 3.09 & 5.48 & 4.73 & 3.47 & 0.64 & 0.65 & 0.16 & 22.49 & 20 & 10.83 \\
\hline & No & 239 & 26.98 & 1.54 & 0.86 & 3.33 & 4.9 & 4.11 & 3.03 & 0.62 & 0.65 & 0.17 & 24.52 & 22 & 11.7 \\
\hline & Missing & 2 & 0.23 & & & & & & & & & & & & \\
\hline \multirow[t]{3}{*}{ Can Drive } & Yes & 566 & 87.75 & 2.1 & 1.15 & 3.14 & 5.53 & 4.75 & 3.51 & 0.64 & 0.65 & 0.16 & 22.37 & 20 & 10.66 \\
\hline & No & 48 & 7.44 & 1.74 & 0.74 & 3.34 & 4.79 & 4.09 & 3.52 & 0.65 & 0.66 & 0.15 & 22.71 & 19.5 & 12.79 \\
\hline & Missing & 31 & 4.81 & & & & & & & & & & & & \\
\hline \multirow[t]{6}{*}{ Car (Days) } & Zero & 194 & 21.9 & 1.24 & 0.74 & 2.07 & 4.41 & 3.85 & 2.71 & 0.62 & 0.65 & 0.17 & 23.03 & 21 & 10.57 \\
\hline & One & 160 & 18.06 & 1.43 & 1.07 & 1.61 & 4.8 & 4.57 & 2.47 & 0.63 & 0.64 & 0.16 & 24.89 & 23 & 11.81 \\
\hline & Two to Three & 219 & 24.72 & 1.81 & 1.1 & 3.17 & 5.25 & 4.8 & 2.8 & 0.64 & 0.65 & 0.16 & 23.23 & 21 & 11.06 \\
\hline & Four to Five & 93 & 10.5 & 2.39 & 1.3 & 3.17 & 6.07 & 5.14 & 3.9 & 0.63 & 0.63 & 0.16 & 22.41 & 21 & 9.37 \\
\hline & Daily & 208 & 23.48 & 2.7 & 1.35 & 4.06 & 6.14 & 4.95 & 4.16 & 0.65 & 0.65 & 0.16 & 21.04 & 19 & 9.98 \\
\hline & Missing & 12 & 1.35 & & & & & & & & & & & & \\
\hline \multirow{6}{*}{$\begin{array}{l}\text { Public Transport } \\
\text { (Days) }\end{array}$} & Zero & 267 & 30.14 & 1.81 & 0.92 & 3.03 & 5.15 & 4.37 & 3.51 & 0.63 & 0.64 & 0.17 & 21.7 & 19 & 10.7 \\
\hline & One & 152 & 17.16 & 1.74 & 0.92 & 2.53 & 5.22 & 4.33 & 3.42 & 0.63 & 0.65 & 0.18 & 23.18 & 20 & 11.95 \\
\hline & Two to Three & 165 & 18.62 & 1.91 & 1.05 & 2.72 & 5.32 & 4.82 & 3.11 & 0.64 & 0.64 & 0.15 & 24.64 & 23 & 10.67 \\
\hline & Four to Five & 203 & 22.91 & 2.18 & 1.1 & 3.33 & 5.58 & 4.73 & 3.4 & 0.64 & 0.67 & 0.17 & 23.21 & 21 & 10.88 \\
\hline & Daily & 81 & 9.14 & 2 & 1.14 & 2.88 & 5.39 & 4.91 & 3.3 & 0.64 & 0.65 & 0.17 & 23.48 & 21 & 12.07 \\
\hline & Missing & 18 & 2.03 & & & & & & & & & & & & \\
\hline \multirow[t]{6}{*}{ Cycle (Days) } & Zero & 641 & 72.35 & 1.85 & 0.98 & 3.07 & 5.23 & 4.48 & 3.34 & 0.64 & 0.65 & 0.16 & 22.36 & 20 & 10.1 \\
\hline & One & 62 & 7 & 2.3 & 1.34 & 3.49 & 5.59 & 5.15 & 3.22 & 0.67 & 0.70 & 0.14 & 22.23 & 20 & 9.43 \\
\hline & Two to Three & 68 & 7.67 & 2.31 & 1.31 & 3.49 & 6.08 & 4.98 & 3.87 & 0.62 & 0.64 & 0.18 & 27.53 & 23 & 17.29 \\
\hline & Four to Five & 29 & 3.27 & 2 & 1.01 & 4.19 & 5.26 & 4.46 & 3.61 & 0.62 & 0.64 & 0.15 & 23.66 & 19 & 11.04 \\
\hline & Daily & 27 & 3.05 & 1.24 & 0.87 & 2.2 & 4.5 & 4.14 & 2.72 & 0.56 & 0.57 & 0.18 & 24.67 & 21 & 15.31 \\
\hline & Missing & 59 & 6.66 & & & & & & & & & & & & \\
\hline \multirow[t]{6}{*}{ Walk (Days) } & Zero & 88 & 9.93 & 2.93 & 1.36 & 4.65 & 6.29 & 4.79 & 4.63 & 0.66 & 0.65 & 0.15 & 21.6 & 20 & 9.57 \\
\hline & One & 84 & 9.48 & 1.76 & 1.36 & 1.74 & 5.4 & 5.15 & 2.69 & 0.64 & 0.65 & 0.17 & 22.99 & 20.5 & 12.04 \\
\hline & Two to Three & 150 & 16.93 & 2.28 & 1.25 & 3.14 & 5.87 & 4.88 & 3.7 & 0.63 & 0.65 & 0.17 & 22.44 & 20 & 11.78 \\
\hline & Four to Five & 130 & 14.67 & 2.03 & 1.03 & 3.2 & 5.41 & 4.57 & 3.33 & 0.64 & 0.64 & 0.16 & 24.82 & 23 & 10.01 \\
\hline & Daily & 412 & 46.5 & 1.57 & 0.84 & 2.45 & 4.86 & 4.2 & 2.98 & 0.63 & 0.65 & 0.17 & 22.98 & 20 & 11.31 \\
\hline & Missing & 22 & 2.48 & & & & & & & & & & & & \\
\hline
\end{tabular}

Table 4.4: Summary Statistics for Transport Decisions

A similar number of participants do not use a car at all (21.9\%) to the number of participants who use a car daily $(23.48 \%)$ or those who use a car two to three days a week $(24.72 \%)$ (Table 4.4). Car usage had a significant impact on PNB area (Appendix 2). Using a car daily resulted in a significant, mean increase in PNB area of $0.605 \mathrm{~km}^{2}$ compared to not using one at all. A median PNB area of $1.35 \mathrm{~km}^{2}$ was observed for participants who used a car daily; almost double the median PNB area of participants with no usage $\left(0.74 \mathrm{~km}^{2}\right)$ (Figure 4.6). 


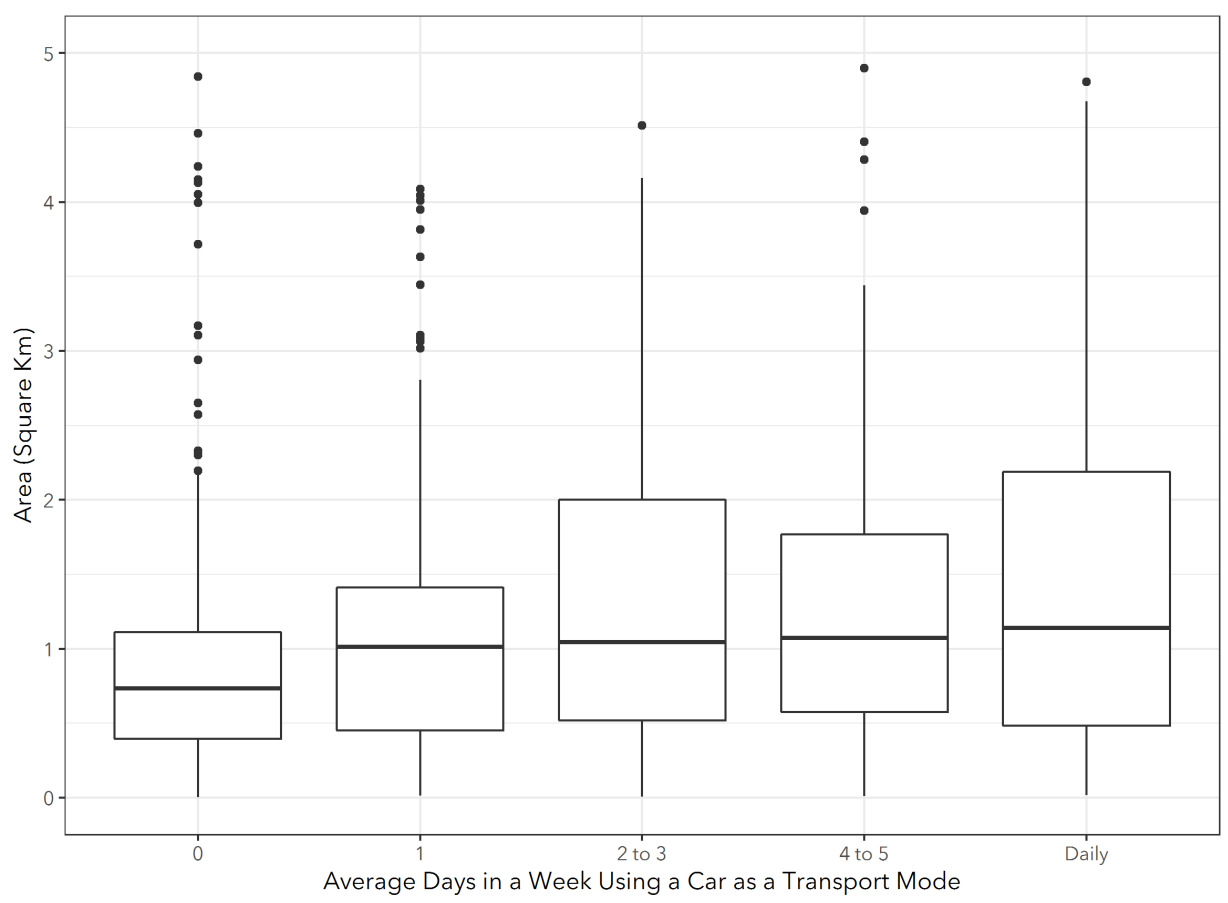

Figure 4.6: Days Spent Using a Car in an Average Week: PNB Area Boxplots

$67.83 \%$ of participants used public transport at least one day a week (Table 4.4). While more frequent public transport users delineated slightly larger neighbourhoods than non-frequent users, no significant relationships between use of public transport and any of the four neighbourhood dimensions were observed.

Cycling was less popular than other transport modes. Only $20.99 \%$ of participants cycled one or more days a week. An inconsistent relationship between cycling and perceived neighbourhood area was observed. Cycling daily caused a mean decrease in PNB area of $0.605 \mathrm{~km}^{2}$. However, cycling two to three days a week resulted in a mean increase in PNB area of $0.348 \mathrm{~km}^{2}$. (Figure 4.7). No significant differences between cycling one day or four to five days a week were observed. The small amounts of participants who cycled one or more days a week compared to participants who did not cycle at all may explain the inconsistent results. 


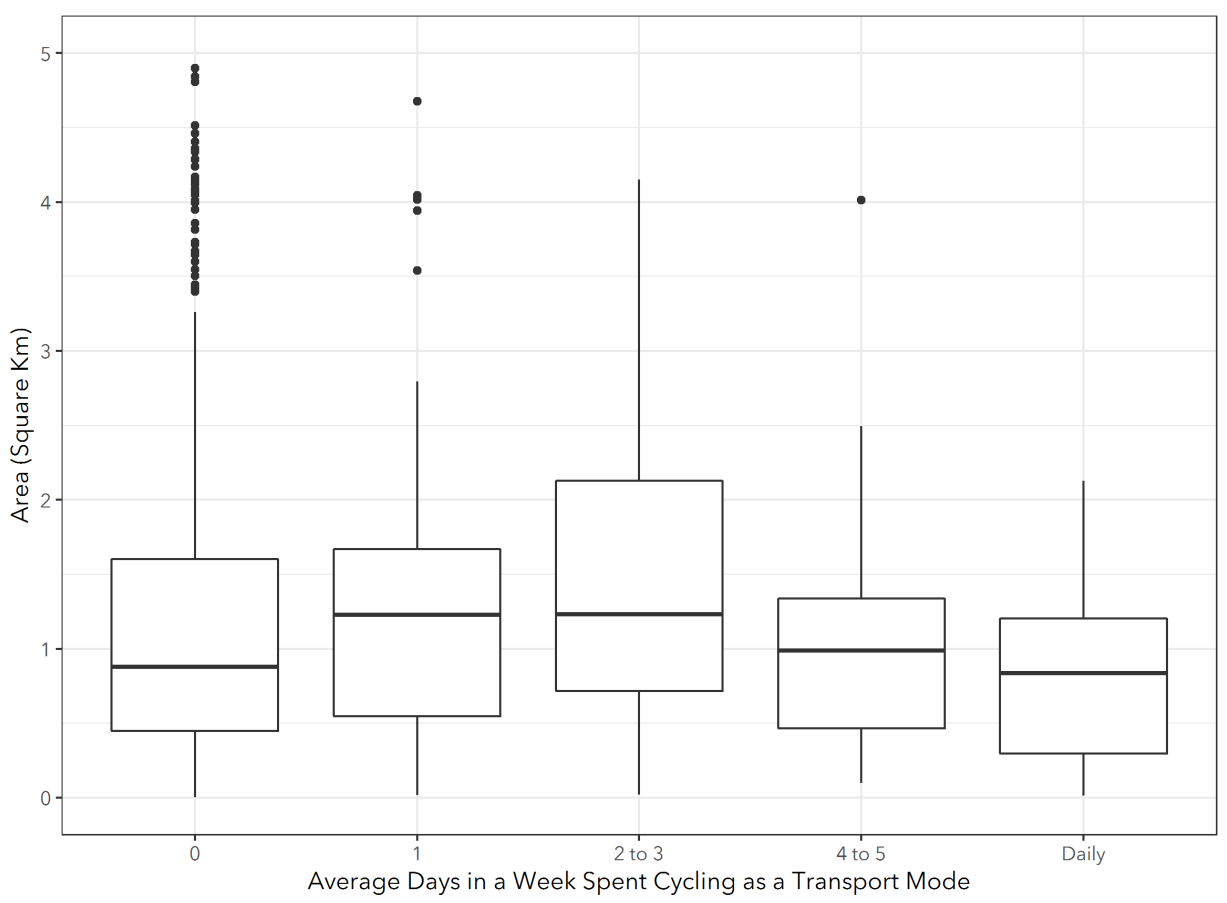

Figure 4.7: Days Spent Cycling in an Average Week: PNB Area Boxplots

Walking was the most popular transport choice. $46 \%$ of participants walked daily and only $9.93 \%$ of participants did not walk at all. This result could be attributed to the framing of the question in the questionnaire which did not specify the transport purpose and individuals tending to answer questions regarding their lifestyles more positively than is actually the case (Dillman et al., 2014). A significant relationship between walking and PNB area was observed (Appendix 2). Walking daily caused a mean decrease in PNB area of $0.388 \mathrm{~km}^{2}$ when compared to not walking at all (Figure 4.8). 


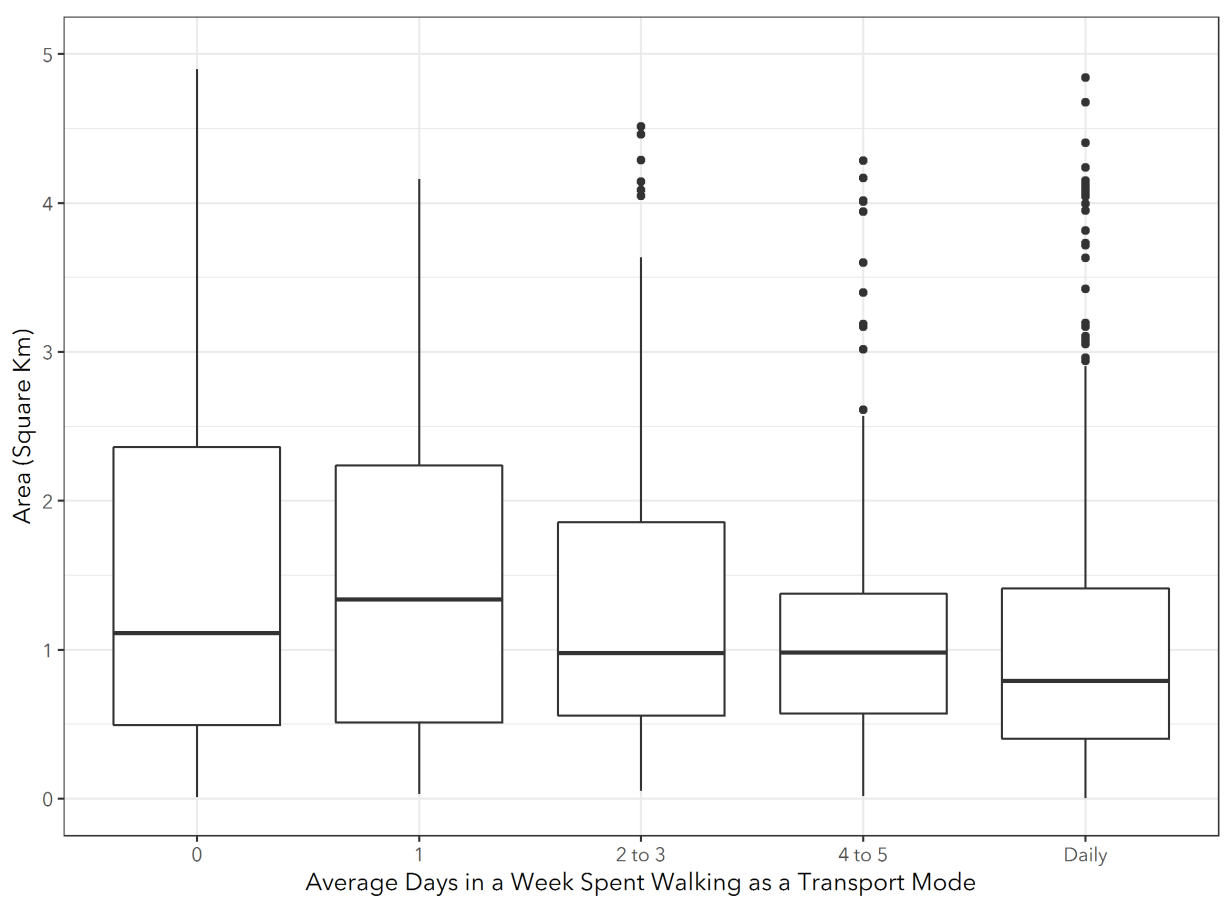

Figure 4.8: Days Spent Walking in an Average Week: Area Boxplots

An $\mathrm{R}^{2}$ value of 0.2482 was observed for the linear regression model of PNB area indicating $24.82 \%$ of the variance associated with the linear model can be explained by the predictor variables. This result is not poor for predicting highly variable human behaviour. The overall model for area was also found to be highly statistically significant with an observed F-Statistic value of 9.16. A similar $\mathrm{R}^{2}$ value was observed for the model of PNB perimeter (0.2377), but for models PNB compactness and number of vertices, the $\mathrm{R}^{2}$ values were considerably lower (0.028 and 0.025 respectively).

\subsubsection{Neighbourhood Dimensions Correlations}

Pearson's correlation coefficients were produced for each relationship between the four neighbourhood dimensions (Table 4.5). A highly significant, strong, positive relationship between PNB area and perimeter was observed (correlation coefficient 0.89). As the area of a PNB increases, so does the perimeter. This was expected as they are directly related and are influenced by each other. A significant, moderate, negative relationship between compactness and vertices was also found (correlation of -0.42). As a neighbourhood becomes more compact, it tends to have less vertices. This could be attributed to PNBs influenced by geographic features; for example roads and coastlines have more vertices but are less compact because they follow detailed features. 


\begin{tabular}{lllll}
\hline & Area & Perimeter & Compactness & Vertices \\
\hline Area & & $0.89^{* * *}$ & $0.089^{* *}$ & $0.068^{*}$ \\
Perimeter & $0.89^{* * *}$ & & $-0.124^{* * *}$ & $0.26^{* * *}$ \\
Complexity & $0.089^{* *}$ & $-0.124^{* * *}$ & & $-0.42^{* * *}$ \\
Vertices & $0.068^{*}$ & $0.26^{* * *}$ & $-0.42^{* * *}$ & \\
\hline
\end{tabular}

Table 4.5: Pearson's Correlation Matrix for Neighbourhood Dimensions $*=\mathrm{p}<0.05, * *=\mathrm{p}<0.01,{ }^{* * *}=\mathrm{p}<0.001$

\subsection{Neighbourhood Consensus}

How individuals perceive their neighbourhoods is formed in relation to both internal and external features (Lupton, 2003). Prior research has examined neighbourhood consensus by using PNBs received for single, disconnected neighbourhoods (Coulton et al., 2001; Minnery et al., 2009). A look into collective neighbourhood consensus across a city-wide scale remains unexplored in prior research. The crowdsourced neighbourhood dataset presents the opportunity for this thesis to investigate neighbourhood consensus in Wellington City and examine spatial interactions between neighbourhoods. Establishing a consensus in both neighbourhood location and name facilitates a wider exploration of shared neighbourhood areas. This section uses overlapping neighbourhood delineations in Wellington City to present areas of high and low neighbourhood consensus, models of neighbourhood connectivity, and clustering of FPs.

\subsubsection{Hexagon Grids}

PNBs located in Wellington's CBD and surrounding neighbourhoods were densely clustered. To interpret them further, hexagon grids were used. Figure 4.9 shows a density map of PNB intersections in each hexagon. The highest density of PNBs were observed in the CBD (maximum of 72 PNB interactions), and nearby neighbourhoods of Brooklyn, Mount Victoria, and Newtown. Other neighbourhoods received higher amounts of PNB intersections near their centre, reducing closer to the neighbourhood boundary.

Any hexagons with less than 5 PNB intersections were excluded from subsequent hexagon grids, shown in the 0-4 band of total intersections in Figure 4.9. This threshold acts as a level of measurable consensus and rules out poorer quality submissions (Woodruff, 2017). Areas excluded due to not meeting the 5-intersection threshold included Wellington Airport, Strathmore and bays to the south, and Makara Hills. Apart from Wellington Airport, this exclusion is likely the result of receiving negligible neighbourhood submissions from individuals living in these areas. Wellington 
Airport is located in between two neighbourhoods (Kilbirnie and Miramar), but received minimal submissions as it was not considered to be part of many participants' neighbourhoods.

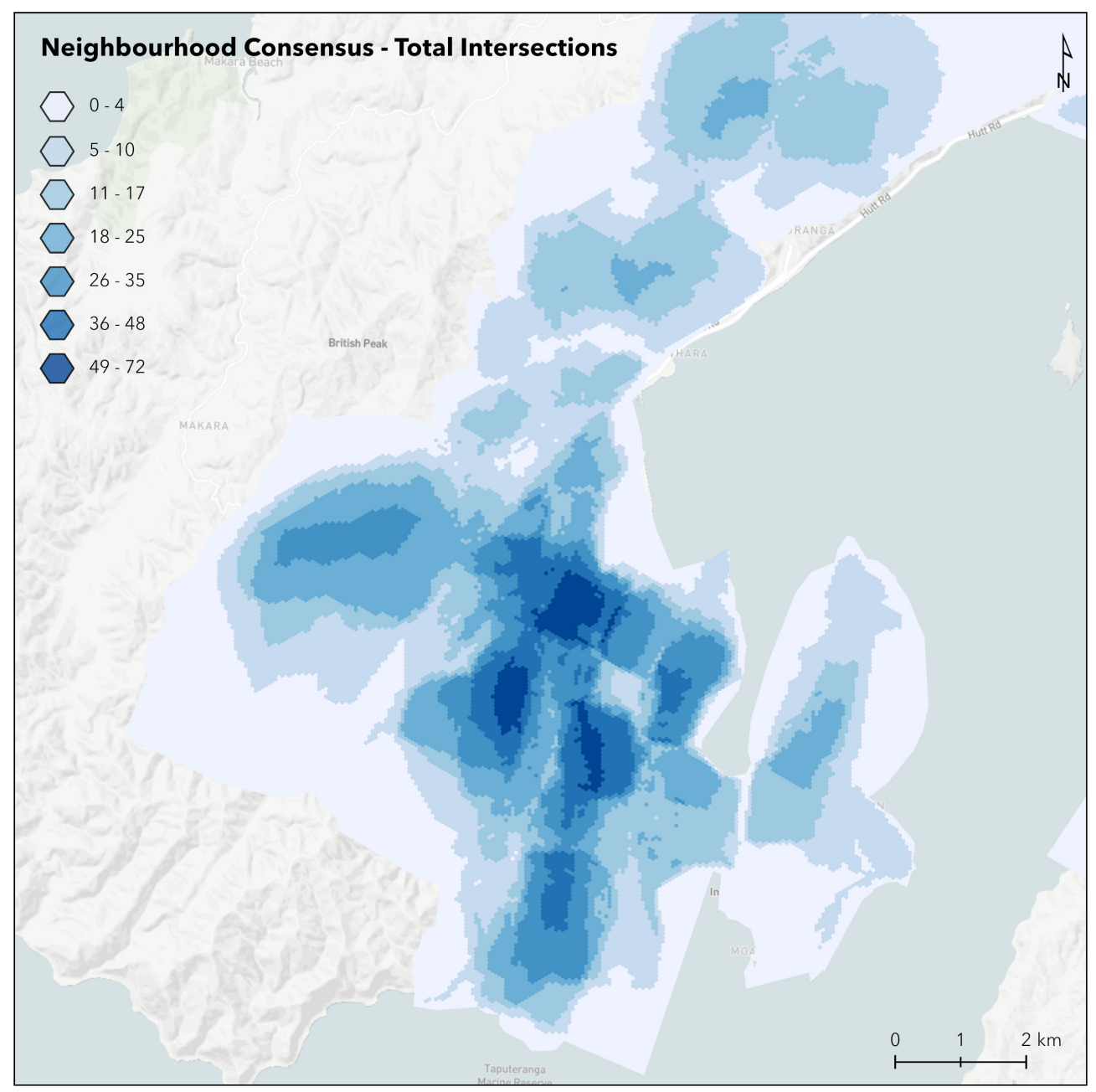

Figure 4.9: Neighbourhood Density by Hexagon

Figure 4.10 shows a hexagon grid of neighbourhood consensus using unique neighbourhood names. As explained in Section 3.5.3, the ratio between total PNB intersections and the number of neighbourhoods with a common name measures neighbourhood consensus. In Figure 4.10, neighbourhood names were treated uniquely. For example, Brooklyn and South Brooklyn counted as submissions for different neighbourhoods. From visual inspection, we can observe areas with high and low neighbourhood consensus. High consensus can be observed within larger neighbourhoods, such as Khandallah, Karori, Brooklyn, and Island Bay. Smaller neighbourhoods, such as Mount Cook and Berhampore received lower levels of consensus, because PNBs of larger, surrounding neighbourhoods often extended into these neighbourhoods. One exception to this was Roseneath, which observed high consensus due to it being predominantly by the ocean to the east. Low consensus can also be seen where boundaries of different neighbourhoods meet and for geographic features such as main roads, parks and green space, and tunnels. Gradients of consensus changes 
can also be observed when moving away from neighbourhood centres and reaching boundaries between different neighbourhoods.

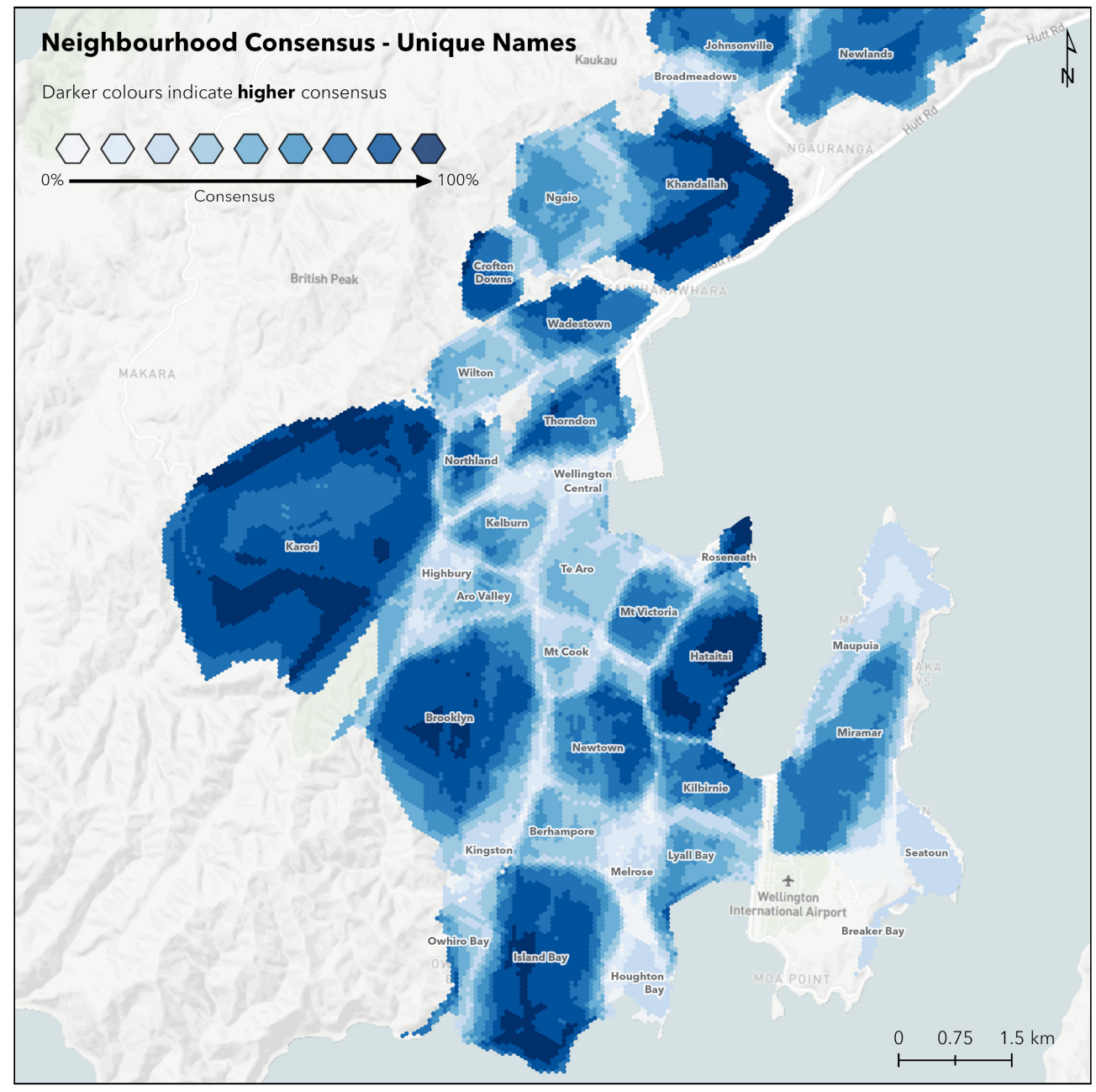

Figure 4.10: Neighbourhood Consensus: Unique Neighbourhood Names

In contrast to Figure 4.10, Figure 4.11 presents a hexagon grid of neighbourhood consensus, but neighbourhood names were treated commonly. For example, the neighbourhoods Brooklyn, South Brooklyn, and Brooklyn, Vogeltown, Mornington all counted as submissions for the same neighbourhood. Additionally, Brooklyn, Vogeltown, Mornington would also count for submissions for Vogeltown and Mornington. This is explained in further detail in Section 3.5.3. As a result of treating neighbourhood names commonly, consensus inside most neighbourhoods was higher. This is partially due to the neighbourhoods types of multiple and subset counting as submissions for the same neighbourhood, rather than separate neighbourhoods because they shared a name. The most noticeable changes in consensus can be observed for larger neighbourhoods that received more multiple and subset neighbourhood types, such as Karori, Brooklyn, and Newtown, with each having higher consensus when names were treated commonly. 


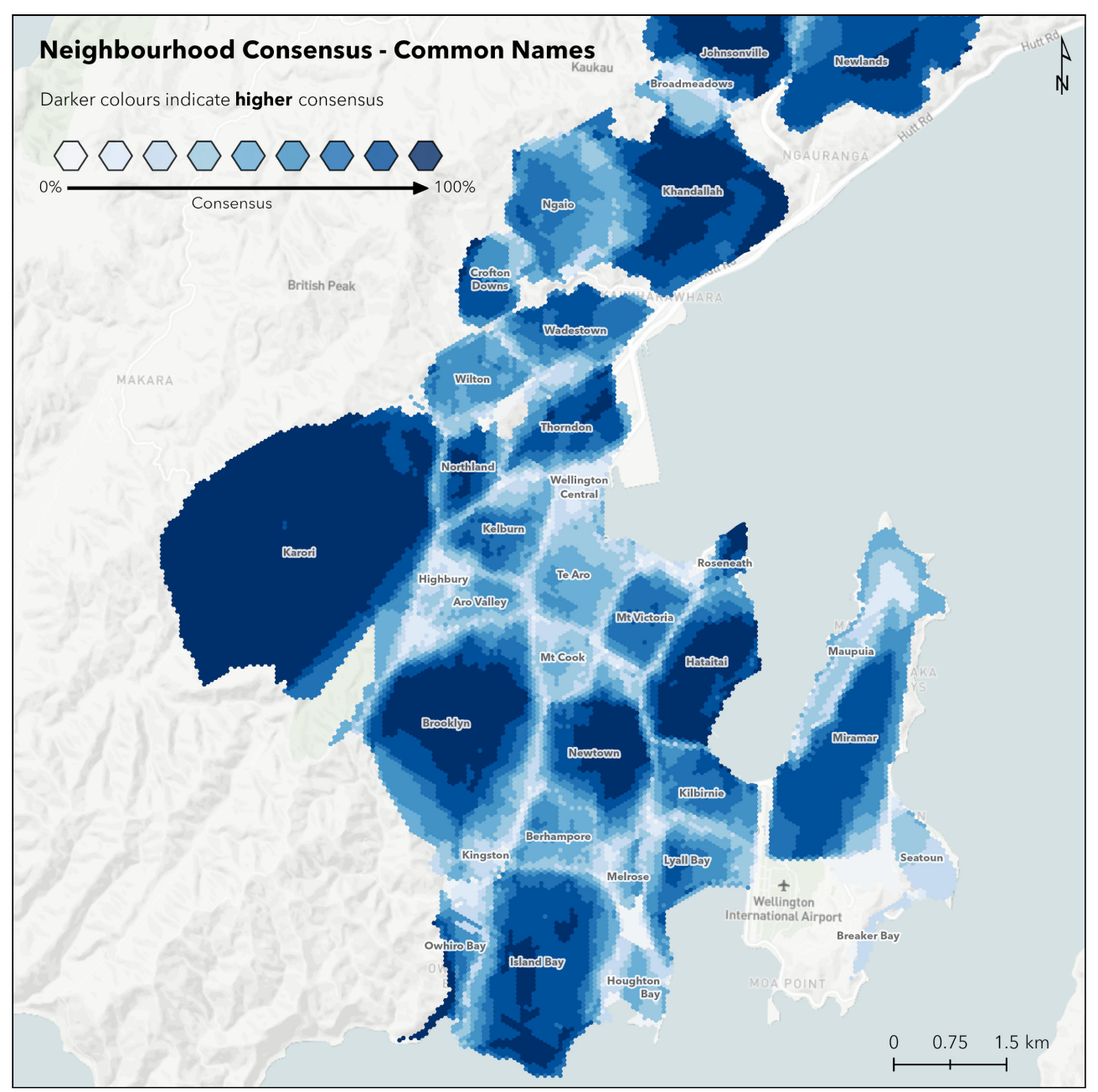

Figure 4.11: Neighbourhood Consensus: Common Neighbourhood Names

While most neighbourhoods had higher consensus when neighbourhood names were treated commonly rather than uniquely, some areas did not present much difference, such as Wellington's CBD (also referred to as Te Aro). This is likely due to two reasons. First, variation in neighbourhood names already existed, with common examples of neighbourhood names provided in Wellington's CBD including Te Aro, Wellington Central, CBD, and Cuba Street. Second, the neighbourhood types of multiple and subset, which cause variation between unique and common consensus methods were rare among submissions received in Wellington's CBD. Only 3.7\% (3 out of 82) of PNBs in Wellington's CBD had the neighbourhood type of multiple or subset.

The most noticeable difference in consensus between the unique and common methods was observed in Karori. Figure 4.12 shows consensus using unique (a) and common (b) names for Karori. When unique names are used, varying levels of consensus, and pockets of high and low consensus are present across Karori. Notably, the centre of Karori has lower neighbourhood consensus than most of the rest of the neighbourhood. This difference can be attributed to Karori being a large neighbourhood defined by participants in a range of ways. 10 subset neighbourhood types, such 
as Karori West and Karori - not the flash end, were received out of the 35 total submissions for Karori. As a result, consensus levels were higher when common neighbourhood names were used as the method as it considered Karori and Karori West to be the same, where unique neighbourhood names did not.

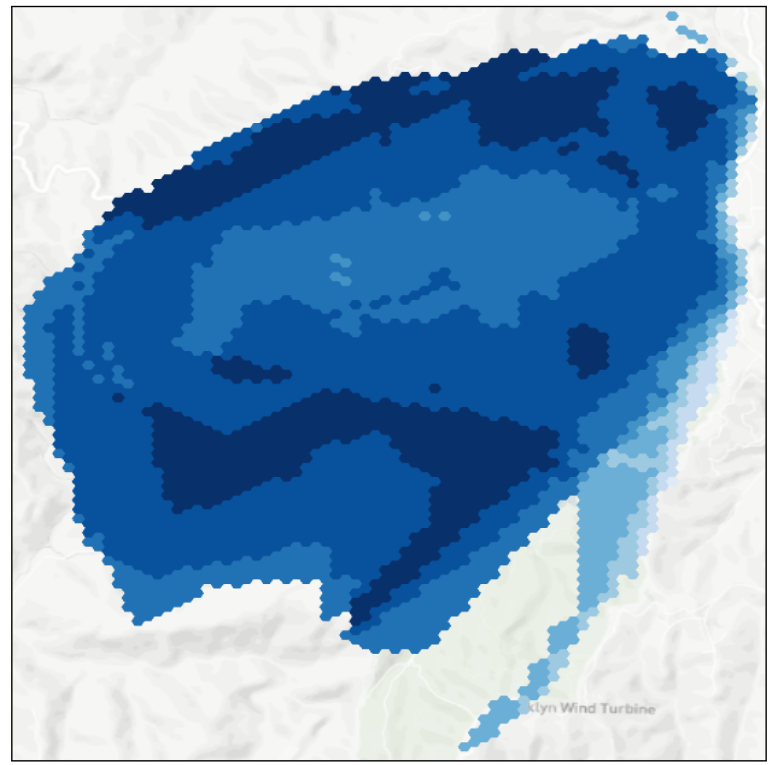

(a) Unique Neighbourhood Name: Karori

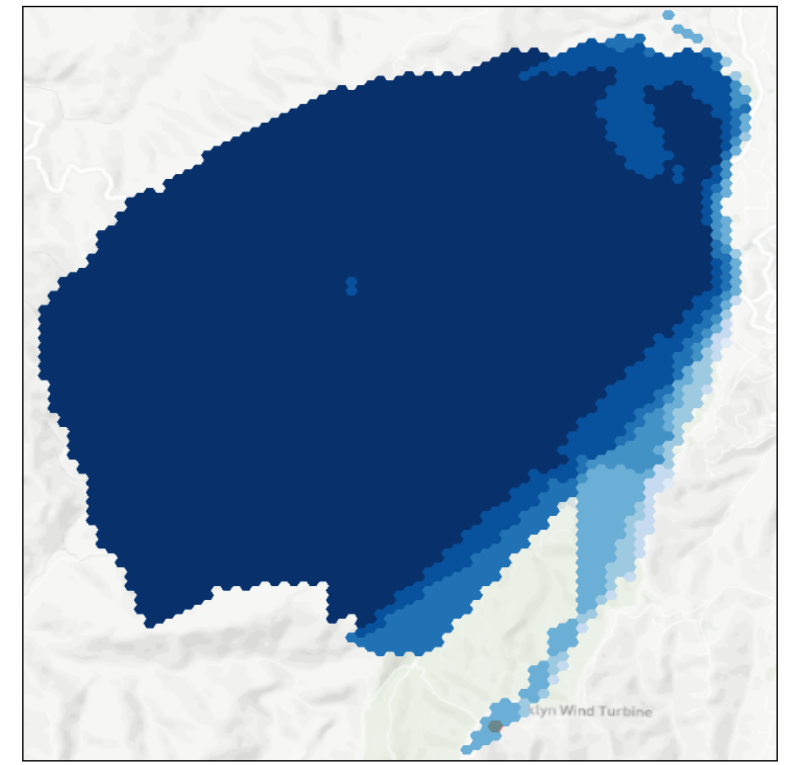

(b) Common Neighbourhood Name: Karori

Figure 4.12: Karori Neighbourhood Consensus using Unique (a) and Common (b) Names

By merging hexagons sharing the most common neighbourhood name, a set of Community Defined Neighbourhoods (CDNs) was produced (Figure 4.13). CDNs provide an alternative view into how participants collectively defined their neighbourhood boundaries. Overall, CDNs represent existing neighbourhoods in Wellington City well because most of neighbourhoods in the localities dataset are present in the group of CDNs. However, some existing neighbourhoods were not present, such as Strathmore and Southgate (excluded for not meeting the threshold of 5), and Vogeltown and Woodridge (excluded as bordering neighbourhoods received more submissions covering their areas). CDNs can also be used in comparisons to PNBs and official boundaries. 


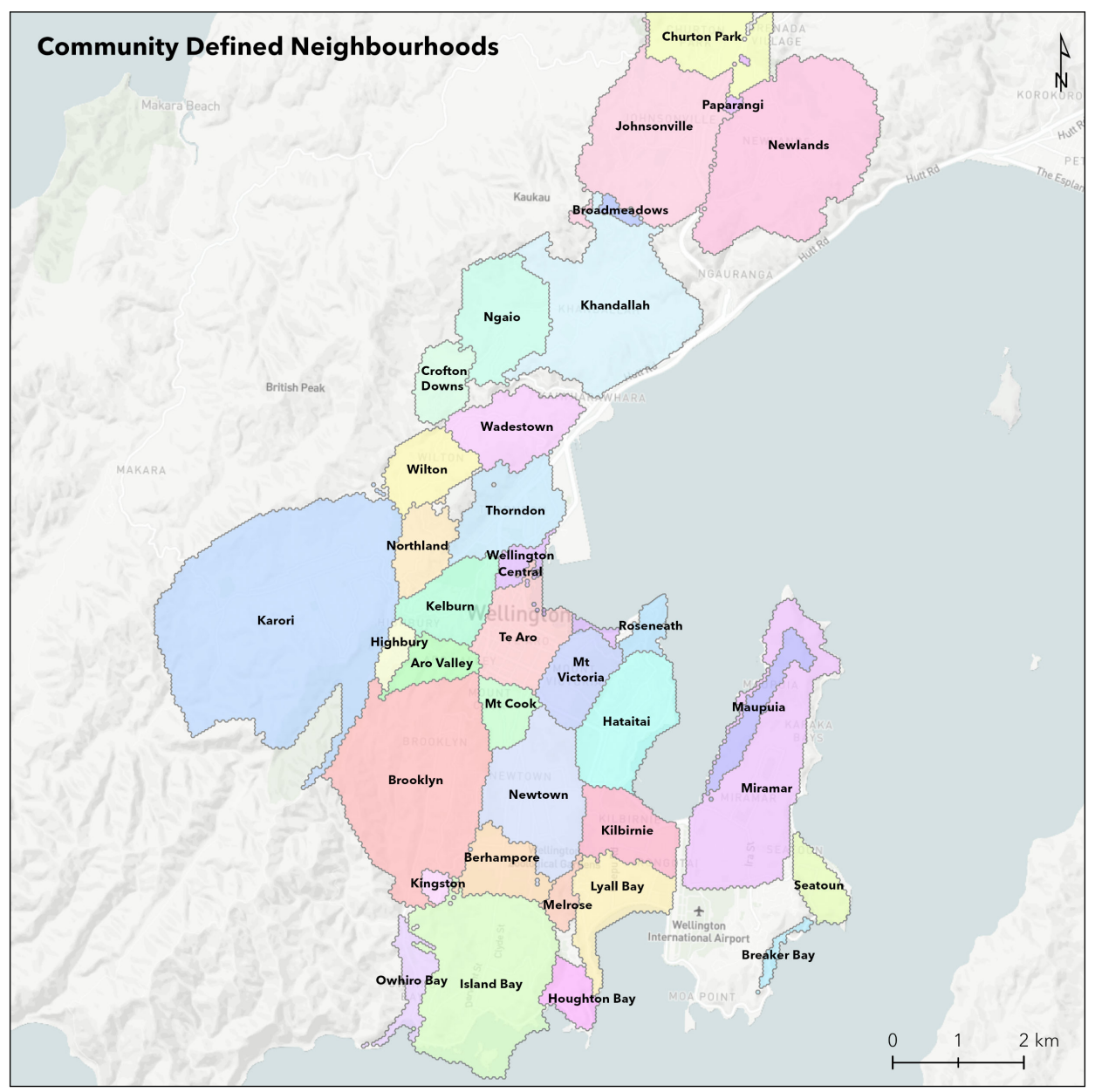

Figure 4.13: Community Defined Neighbourhoods

\subsubsection{Neighbourhood Connectivity}

Neighbourhoods are often represented by static, contiguous boundaries, with the only spatial interaction between neighbourhoods being the borders they share. However, this is not an accurate representation of how individuals' delineate their neighbourhoods, with boundaries often extending into areas of other neighbourhoods. The crowdsourced neighbourhood dataset provides the ability to explore how neighbourhoods connect to each other. Figure 4.14 shows neighbourhood connectivity for Wellington City. A connection between two neighbourhoods exists if a PNB of one neighbourhood intersected with a PNB from another neighbourhood (explained in Section 3.5.3). Neighbourhoods in and around Wellington's CBD had more connections to other neighbourhoods than those north of the CBD. PNBs received for the neighbourhood Tawa north of the CBD did not overlap with any other PNB in Wellington City and was disconnected from the neighbourhood connectivity model. 


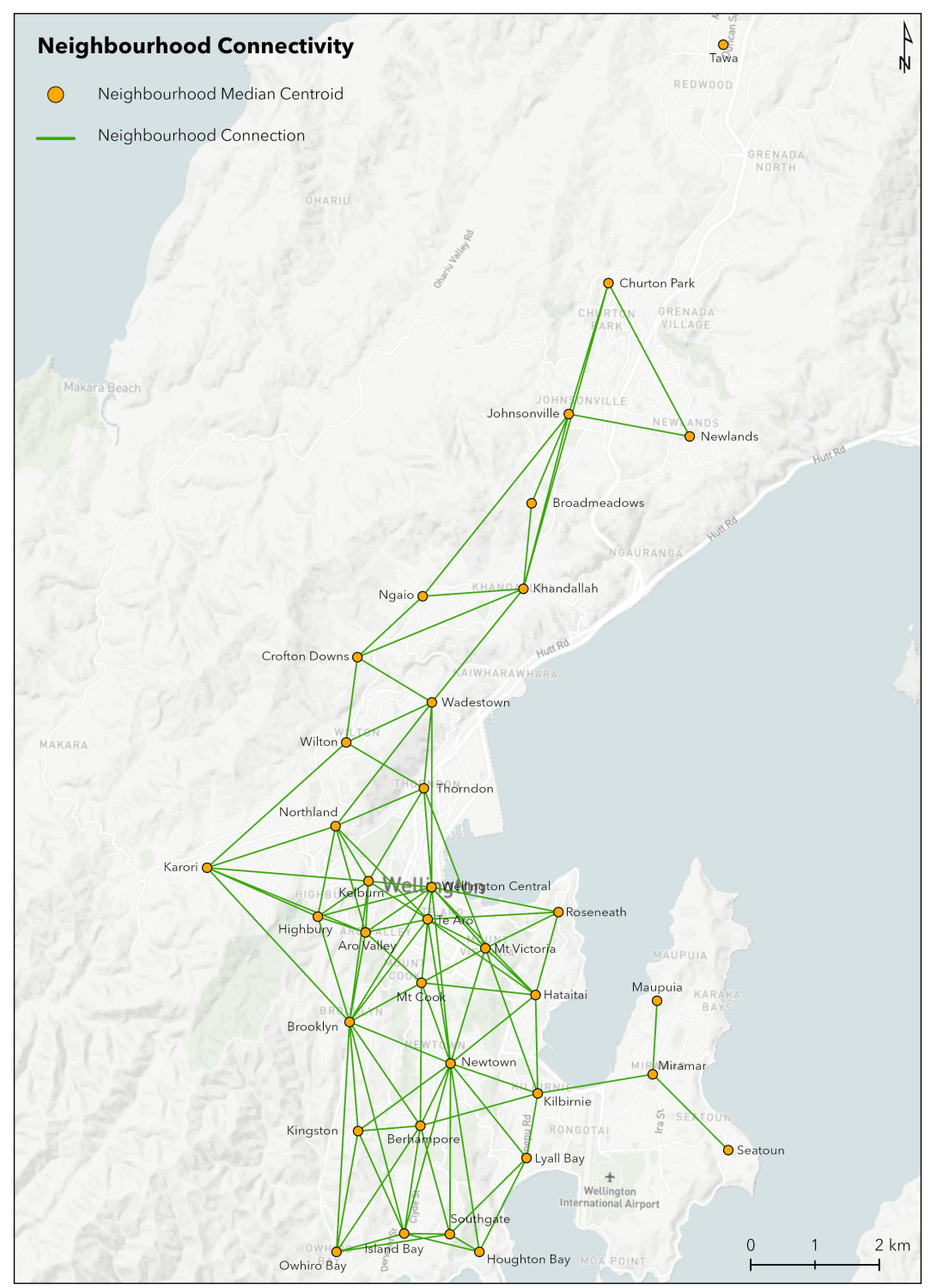

Figure 4.14: Neighbourhood Connectivity

Figure 4.14 does not paint an accurate picture of the scale of connectivity between neighbourhoods because the variety in sample sizes received for neighbourhoods was unaccounted for. Figure 4.15 presents neighbourhood connectivity weighted by the number of intersections between neighbourhoods. From visual inspection, we can observe neighbourhood connectivity is higher between neighbourhoods near Wellington's CBD than neighbourhoods far from the CBD. A strong southern corridor of connectivity running between the neighbourhoods of Te Aro, Mt Cook, Newtown, Berhampore, and Island Bay is also identifiable. This might be the result of a mostly straight, arterial road running between and connecting the neighbourhoods. Additionally, there are only minor elevation changes throughout this route when compared to neighbourhoods on surrounding hillsides. 
Lower connectivity was observed for neighbourhoods north of Wellington's CBD, such as Johnsonville, Broadmeadows, and Ngaio. This is likely due to their lower residential density and the fact that they are more spread out than neighbourhoods in and around Wellington's CBD. Neighbourhoods found in the Miramar peninsula east of the CBD also observed low connectivity. While most neighbourhoods were connected to multiple other neighbourhoods, Miramar only connected to one other neighbourhood not on the peninsula (Kilbirnie). This is perhaps the result of the Wellington Airport acting as a barrier between neighbourhoods and the primary access route to Miramar being a busy, state highway.

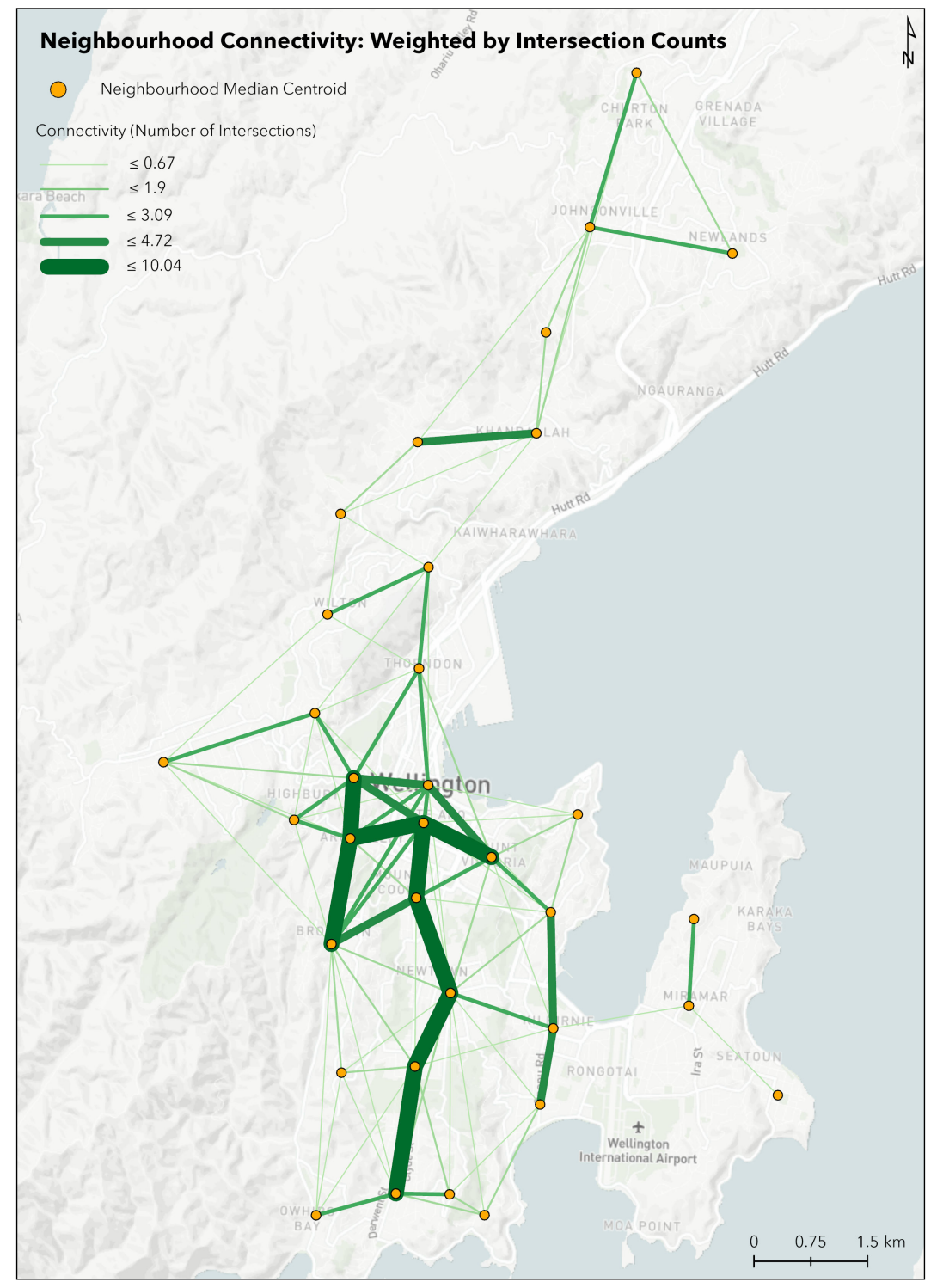

Figure 4.15: Neighbourhood Connectivity: Weighted by Number of Intersections

Neighbourhood connectivity weighted by mean intersection area between neighbourhoods is shown in Figure 4.16. Compared to connectivity weighted by number of intersections, connectivity be- 
tween most neighbourhoods was lower, especially in Wellington's CBD. The pronounced southern corridor observed earlier disappears when neighbourhood connectivity is weighted by mean intersection area indicating that while large amounts of PNBs between these neighbourhoods overlap, the mean intersection area between them was comparatively small.

An area of high neighbourhood connectivity made clear when weighted by mean intersection area can be observed between neighbourhoods on Wellington's Southern Coast (Owhiro Bay, Island Bay, Southgate, and Houghton Bay). For these neighbourhoods, the areas of intersection between overlapping PNBs were large perhaps because when travelling on the road between these neighbourhoods there is a lack of distinctive features marking the end of one neighbourhood or beginning of another.

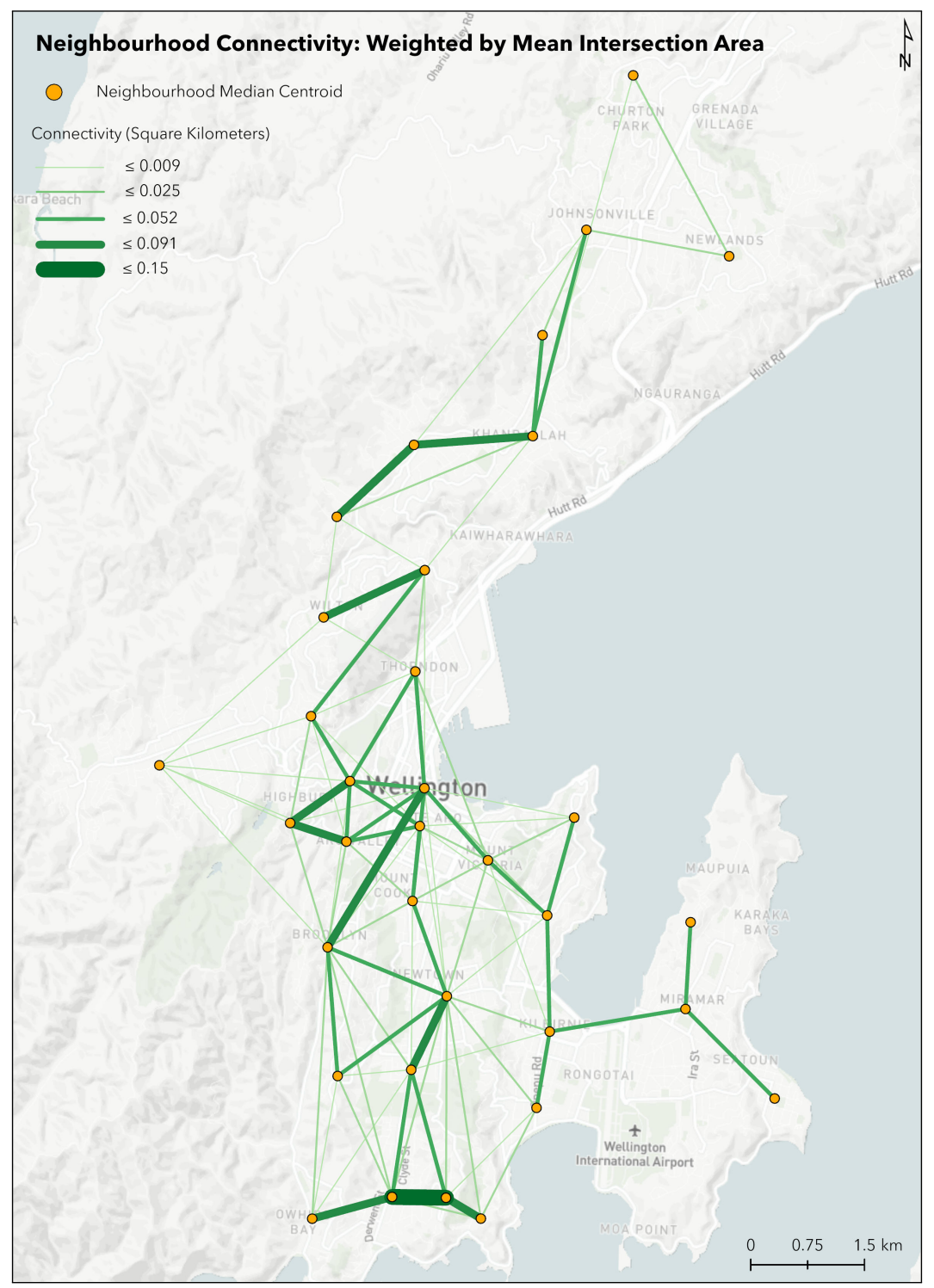

Figure 4.16: Neighbourhood Connectivity: Weighted by Intersection Area 
Two neighbourhoods with contrasting neighbourhood connectivity are shown in Figure 4.17. Karori (a) had low connectivity, only having connections to 6 other neighbourhoods all located to the east. The mean connectivity rating (weighted by mean intersection area) for connections between Karori and surrounding neighbourhoods observed was 0.0027. This implies neighbourhood borders between Karori and its connected neighbourhoods are firm as intersection areas were small. Karori's low connectivity is the result of a few factors. Apart from to the east, Karori is surrounded by mostly uninhabited, hilly terrain covered by thick bush. Additionally, Karori has poor accessibility as transport links to Karori wind up and around nearby ridgelines, or go through a short, narrow tunnel. From the neighbourhood connectivity model, it is clear Karori is unique because individuals mostly only travel to Karori rather than through it to reach another neighbourhood.

In comparison, Newtown had high neighbourhood connectivity (Figure 4.17(b)), with 13 connections to other neighbourhoods extending from all directions observed. A mean connectivity rating (weighted by mean intersection area) of 0.021 was observed for Newtown. Connectivity was higher for neighbourhoods to the west of Newtown (Mt Cook, Brooklyn, Kingston, and Berhampore) than any other direction. This indicates the borders between these neighbourhoods and Newtown are blurred as the overlapping areas of the PNBs are larger than other neighbourhoods connected to Newtown. While individuals may primarily travel to Karori, individuals commonly travel through Newtown to access Wellington's CBD or other surrounding neighbourhoods. The stark difference in neighbourhood connectivity observed between Karori and Newtown illustrates the problem of representing neighbourhoods as a group of fixed, contiguous boundaries. Additionally, it emphasises that neighbourhood geographies are complex, multi-faceted, and influenced by surrounding geographic contexts. 


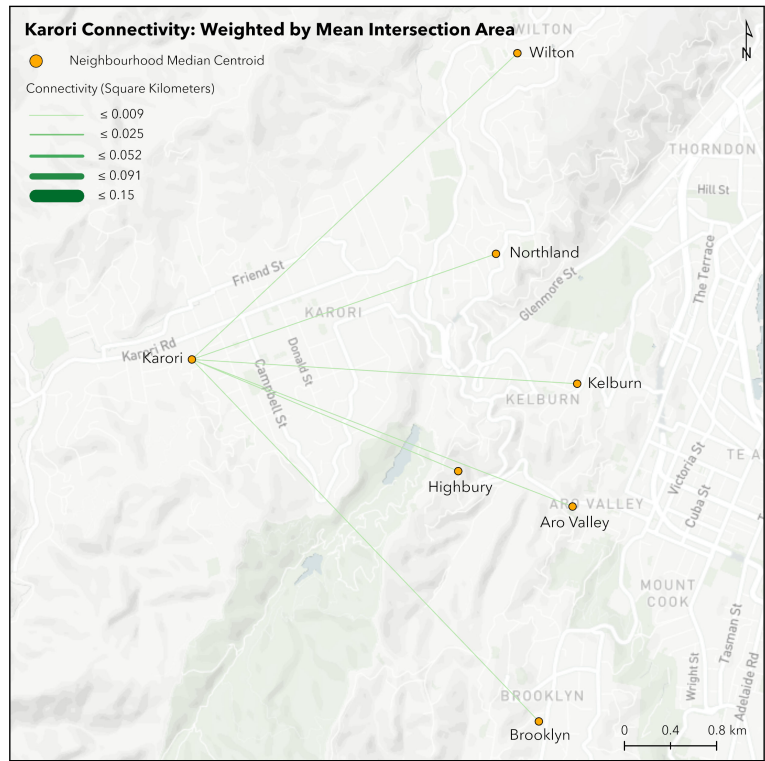

(a) Karori: Low Connectivity

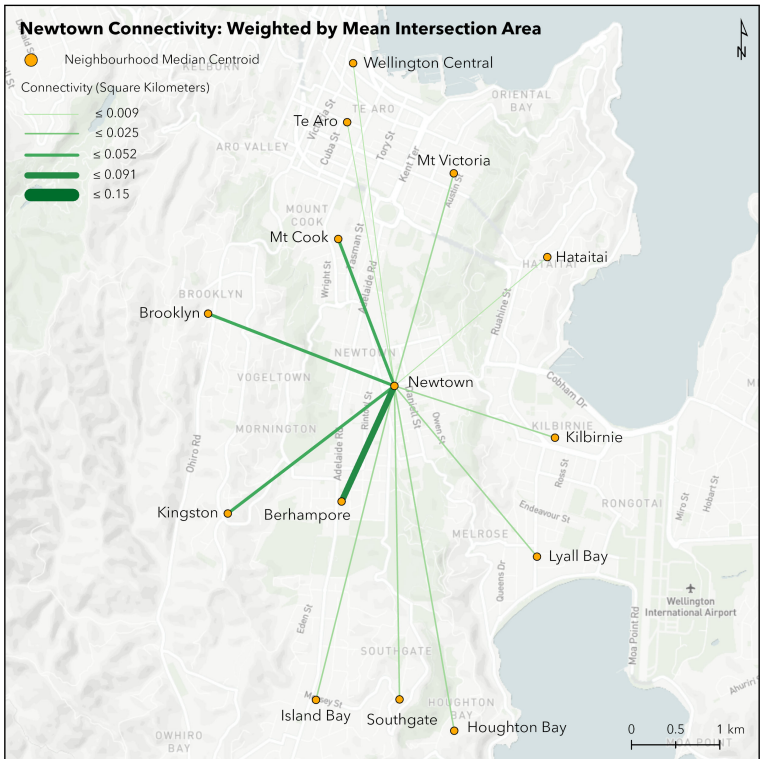

(b) Newtown: High Connectivity

Figure 4.17: Neighbourhood Connectivity Weighted by Interaction Area: Karori (a) and Newtown (b)

\subsubsection{Focal Point Clustering}

Neighbourhood consensus was also applied to Focal Points (FPs) through clustering measures. To investigate if the crowdsourced FPs were significantly clustered, average nearest neighbourhood analysis using Euclidean distances was performed. FPs were found to be highly significantly clustered, with a Z-Score of -46.47 observed. As the FPs were significantly clustered, density based clustering was then performed. The Density-based spatial clustering of applications with noise (DBSCAN) method was performed on FPs with a minimum threshold of 5 and search distance of 50 meters. From the 886 total FPs, 43.12\% (382) were clustered. Figure 4.18 shows the 28 FP clusters identified in Wellington City in red, along with neighbourhood shopping hubs. Shopping hubs were created by taking the median centroid of all relevant amenities in a neighbourhood and buffering it by 150 metres (explained in Section 3.5.3). Out of the 382 clustered FPs, 85.07\% (325) were in a shopping hub. One example of this effect can be observed for FPs received for Brooklyn (Figure 4.19). All 52 clustered FPs were within 50 metres from an amenity, where the average distance between non-clustered FPs and the nearest amenity was 400 metres. 


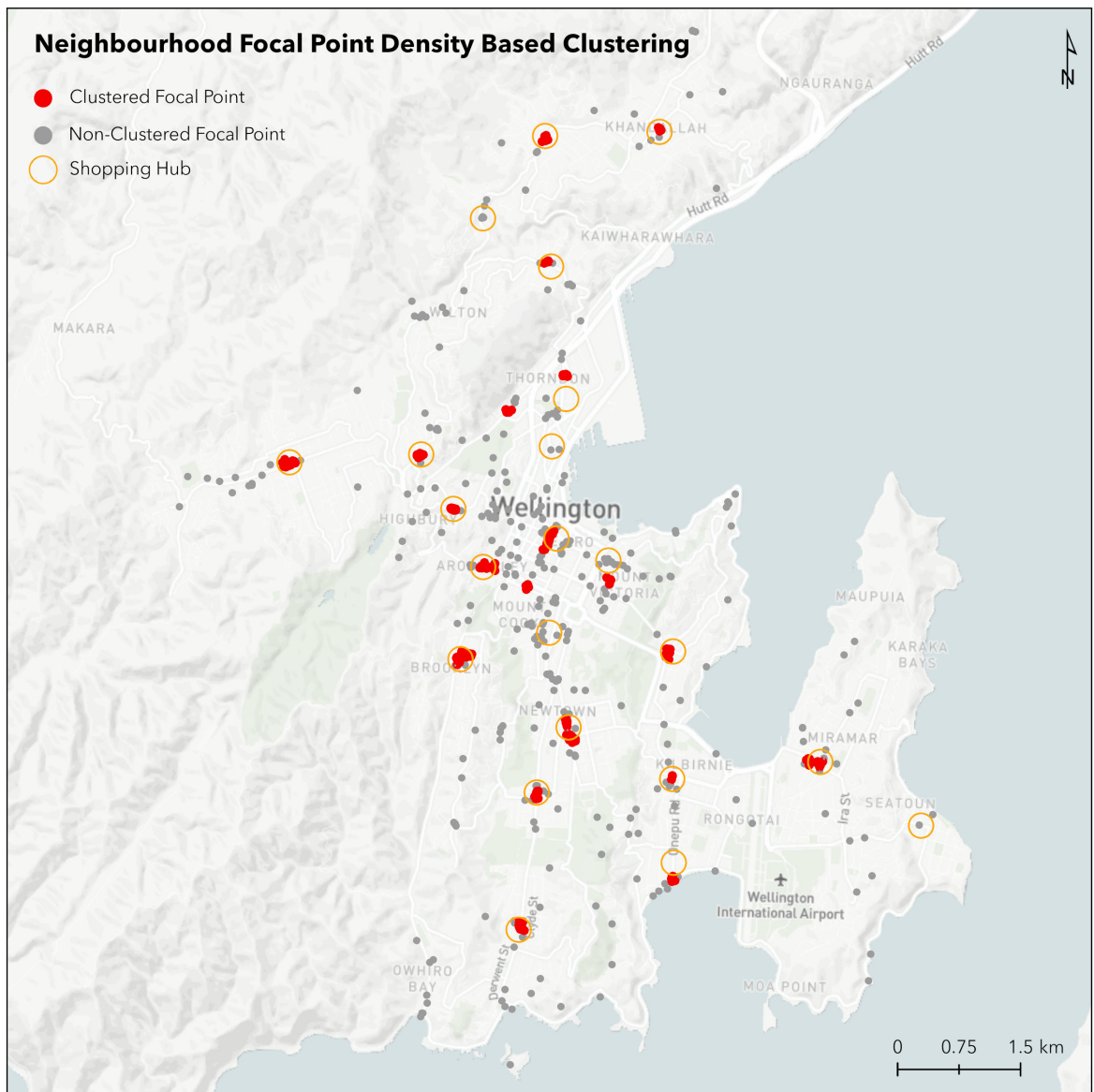

Figure 4.18: FP Density Based Clusters (DBSCAN)

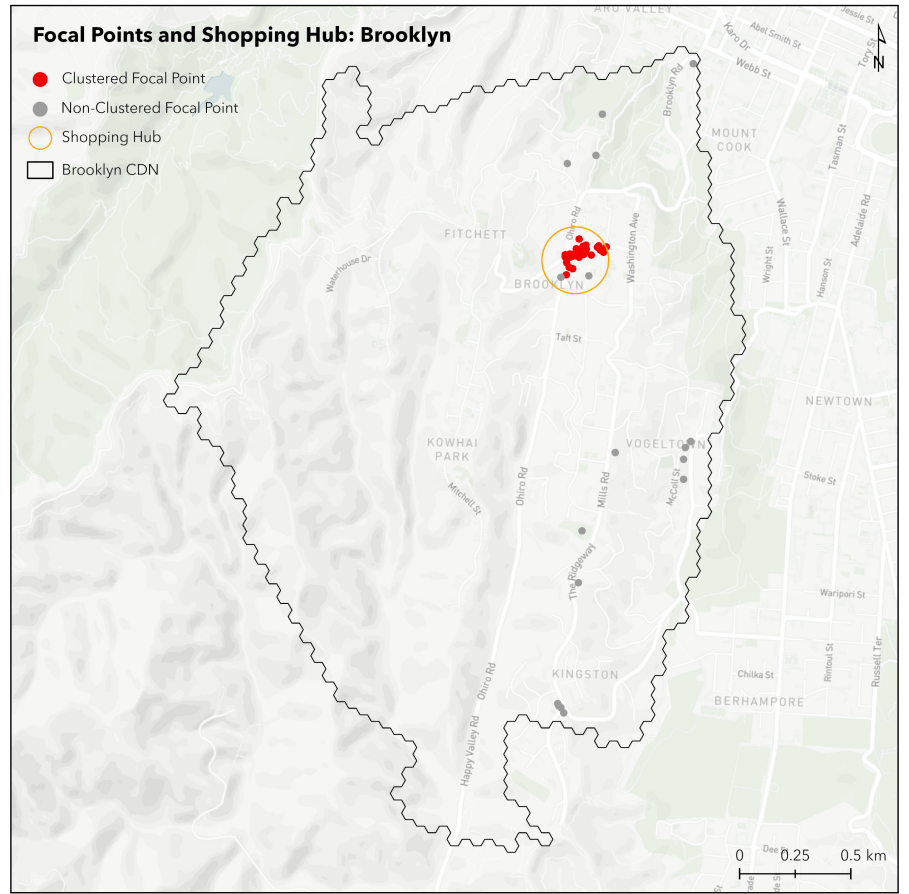

Figure 4.19: FPs and Shopping Hub: Brooklyn 
Shopping hubs were not the only location clustered FPs could be found. One example of a neighbourhood with a cluster of FPs not located in a shopping hub was Lyall Bay (Figure 4.20). Out of the total 17 FPs in Lyall Bay, neither any clustered or non-clustered FPs were found within the shopping hub. Instead, the main intersection and playground near the beach was where the 11 clustered FPs were located, and 6 non-clustered FPs were located on the shoreline. This is unsurprising as Lyall Bay is named after its popular beach that is the main feature of the neighbourhood.

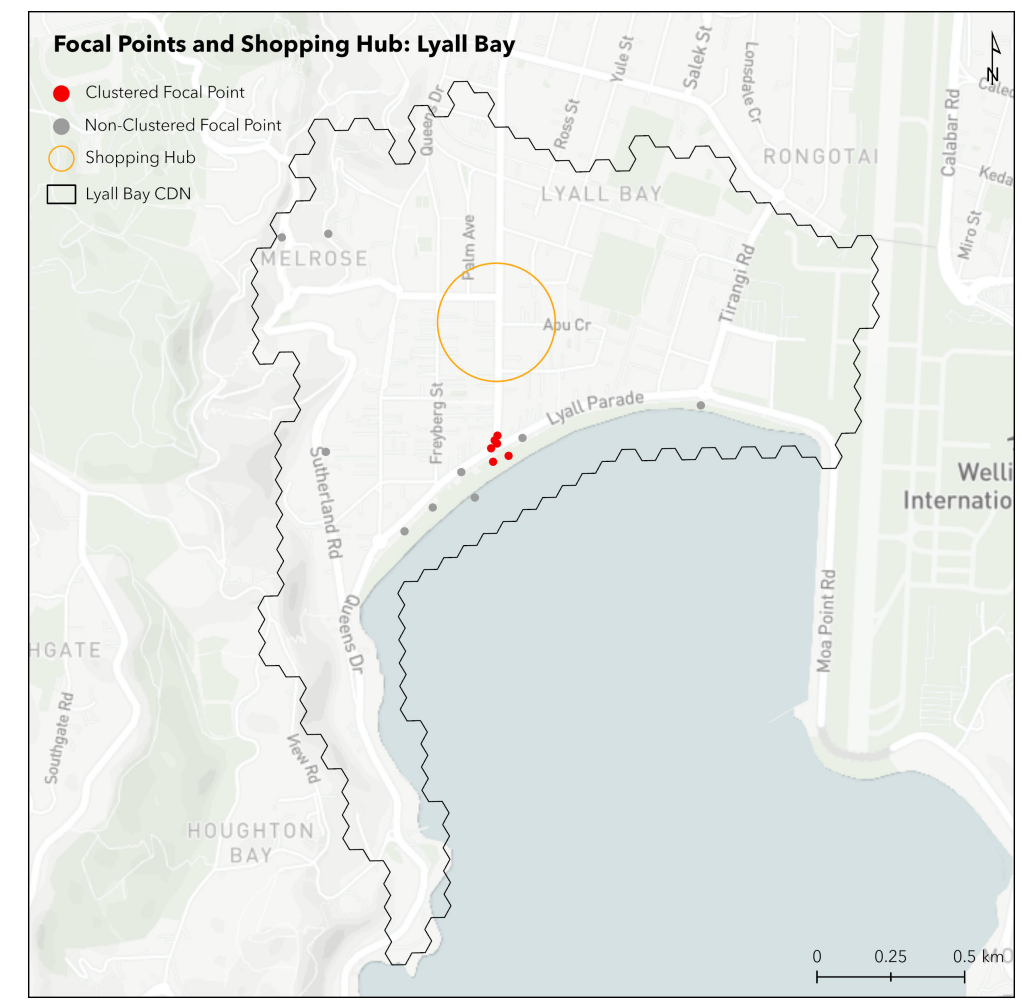

Figure 4.20: FPs and Shopping Hub: Lyall Bay

A spatial join between the grid of neighbourhood consensus hexagons and FPs was performed. Table 4.6 presents summary statistics of the results. 79 non-clustered FPs were excluded from the spatial join as they did not overlap with a hexagon. In hexagons measuring consensus uniquely, clustered FPs observed higher consensus than non-clustered FPs, with mean consensus values of 69\% and 57\% observed respectively. Both clustered and non-clustered FPs had higher consensus when joined with hexagons measuring consensus commonly, but a larger increase in consensus was observed for clustered FPs, increasing to $83 \%$. The difference may be the result of clustered FPs being found near neighbourhood shopping hubs which are mainly located in interior areas of neighbourhood with higher consensus. 


\begin{tabular}{|c|c|c|c|c|c|c|c|c|c|c|c|}
\hline & \multirow[b]{2}{*}{ Count } & \multicolumn{5}{|c|}{ Unique } & \multicolumn{5}{|c|}{ Common } \\
\hline & & Mean & Median & $\mathrm{SD}$ & Min & $\operatorname{Max}$ & Mean & Median & SD & Min & Max \\
\hline Total & 807 & $63 \%$ & $67 \%$ & $18 \%$ & $13 \%$ & $100 \%$ & $74 \%$ & $79 \%$ & $19 \%$ & $14 \%$ & $100 \%$ \\
\hline Clustered & 382 & $69 \%$ & $73 \%$ & $13 \%$ & $36 \%$ & $91 \%$ & $83 \%$ & $89 \%$ & $14 \%$ & $45 \%$ & $100 \%$ \\
\hline Non-Clustered & 425 & $57 \%$ & $55 \%$ & $19 \%$ & $13 \%$ & $100 \%$ & $66 \%$ & $67 \%$ & $20 \%$ & $14 \%$ & $100 \%$ \\
\hline
\end{tabular}

Table 4.6: Summary Statistics for Spatial Join Between FPs and Consensus Hexagons

Figure 4.21 shows FPs and consensus hexagons (common name) for Newtown. All clustered FPs were in the highest band of neighbourhood consensus, while non-clustered FPs were distributed across different consensus bands. This indicates FPs in internal areas of neighbourhoods tended to have higher consensus than external areas. Additionally, areas in neighbourhoods with high consensus were also more likely to contain the neighbourhood's shopping hub. This provides further evidence that the neighbourhood shopping hubs had an impact on participant's FPs.

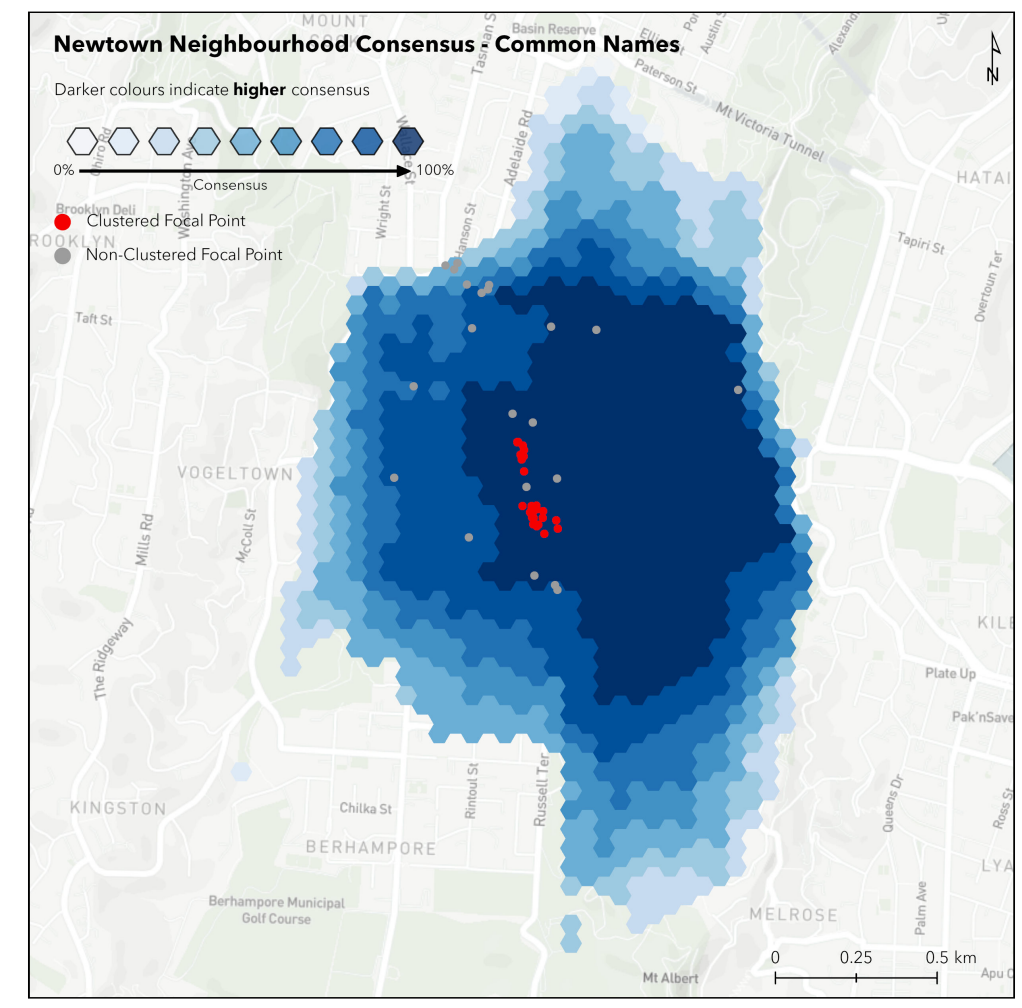

Figure 4.21: Neighbourhood Consensus (Common Name) and FPs for Newtown

A unique aspect of the crowdsourced neighbourhood dataset is its ability to explore neighbourhood consensus across an entire city. This section used consensus as a means to explore neighbourhood geographies in Wellington City through hexagon grids, connectivity models, and FP clustering. Individual neighbourhoods were provided as examples throughout the section to further illustrate the role of consensus. The methods used to explore neighbourhood consensus were made possible 
by the large sample size of overlapping PNBs across Wellington City. Exploring neighbourhood consensus is not possible using the fixed, contiguous boundaries frequently used to represent neighbourhoods.

\subsection{Comparisons to Official Boundaries}

Fixed, official boundaries, such as census units, are the most common representation of the extents of neighbourhoods and are used to present statistics and outcomes geographically. This is problematic as a "one size fits all" approach is applied that may not be appropriate to the study context and how the residents perceive their neighbourhood boundaries (Weiss et al., 2007). By understanding discrepancies between individuals' perceptions of their neighbourhoods and the official boundaries, improvements can be suggested so that official boundaries better reflect communities living in them. This section outlines results of comparisons made between participants' perceived neighbourhood boundaries (PNBs), Community Defined Neighbourhoods (CDNs) and official boundaries (Localities, Statistical Areas 2 (SA2s)).

\subsubsection{Neighbourhood Dimensions}

The same four neighbourhood dimensions (area, perimeter, compactness, and number of Vertices) analysed in Section 4.4 .2 were calculated for the comparison neighbourhood datasets. Summary statistics for area and perimeter are shown in Table 4.7. Both PNBs and CDNs were smaller than official boundaries. Mean areas of $1.93 \mathrm{~km}^{2}$ and $1.73 \mathrm{~km}^{2}$ were observed for PNBs and CDNs respectively, compared to $5.14 \mathrm{~km}^{2}$ and $3.72 \mathrm{~km}^{2}$ observed for localities and SA2s. However, median areas were not consistent with this trend. SA2s had a median area of $1.07 \mathrm{~km}^{2}$, which was only slightly larger than median areas of $1.02 \mathrm{~km}^{2}$ and $1.03 \mathrm{~km}^{2}$ observed for PNBs and CDNs. This indicates mean areas are heavily skewed by outliers, supported by SA2s having a max area of $177.54 \mathrm{~km}^{2}$ over five times the max area of PNBs $\left(29.11 \mathrm{~km}^{2}\right)$. Variation in area exists in both official neighbourhood boundaries and participants' boundaries, but it is much greater for official neighbourhood boundaries.

\begin{tabular}{|c|c|c|c|c|c|c|c|c|c|c|}
\hline & \multicolumn{5}{|c|}{ Area $\left(\mathrm{Km}^{2}\right)$} & \multicolumn{5}{|c|}{ Perimeter $(\mathrm{Km})$} \\
\hline & Mean & Median & $\mathrm{SD}$ & Min & Max & Mean & Median & $\mathrm{SD}$ & Min & Max \\
\hline PNBs & 1.92 & 1.02 & 2.94 & 0.002 & 29.11 & 5.32 & 4.59 & 3.36 & 0.17 & 24.63 \\
\hline $\mathrm{CDNs}$ & 1.73 & 1.03 & 2.10 & 0.003 & 10.65 & 7.58 & 6.32 & 5.0 & 0.20 & 22.36 \\
\hline Localities & 5.14 & 1.46 & 13.74 & 0.26 & 89.42 & 10.20 & 7.29 & 8.75 & 2.48 & 51.99 \\
\hline $\mathrm{SA} 2 \mathrm{~s}$ & 3.72 & 1.07 & 20.07 & 0.29 & 177.54 & 7.81 & 6.13 & 10.94 & 2.44 & 96.53 \\
\hline
\end{tabular}

Table 4.7: Summary Statistics for Area and Perimeter of Four Neighbourhood Datasets 
Table 4.8 shows summary statistics for compactness and number of vertices of the four neighbourhood datasets. PNBs were found to be much more compact than CDNs, localities, and SA2s with a mean compactness value of 0.64 being observed for PNBs, compared to 0.32, 0.35, and 0.39 being observed for CDNs, localities, and SA2s respectively. Median values of compactness also support this trend. This is likely the result of official boundaries having operational purposes, such as addressing for localities, or dissemination of geographic data for SA2s, leading to the boundaries following geographic features, such as roads and property boundaries. In comparison, participants tended to roughly delineate the area of what they considered to be their neighbourhood rather than meticulously following different geographic features resulting in a more compact and detailed neighbourhood boundary. Figure 4.22 shows a visual example of this for a PNB and locality boundary in Aro Valley.

\begin{tabular}{|c|c|c|c|c|c|c|c|c|c|c|}
\hline & \multicolumn{5}{|c|}{ Compactness } & \multicolumn{5}{|c|}{ Vertices } \\
\hline & Mean & Median & SD & Min & Max & Mean & Median & $\mathrm{SD}$ & Min & $\operatorname{Max}$ \\
\hline PNBs & 0.64 & 0.65 & 0.17 & 0.06 & 0.97 & 23.02 & 20 & 11.09 & 6 & 109 \\
\hline CDNs & 0.32 & 0.32 & 0.14 & 0.08 & 0.91 & 225.9 & 188 & 148.51 & 7 & 666 \\
\hline Localities & 0.35 & 0.36 & 0.12 & 0.1 & 0.58 & 401.5 & 316 & 337.29 & 92 & 1876 \\
\hline $\mathrm{SA} 2 \mathrm{~s}$ & 0.39 & 0.40 & 0.13 & 0.09 & 0.67 & 167.86 & 115 & 260.84 & 43 & 2326 \\
\hline
\end{tabular}

Table 4.8: Summary Statistics for Compactness and Vertices of Four Neighbourhood Datasets

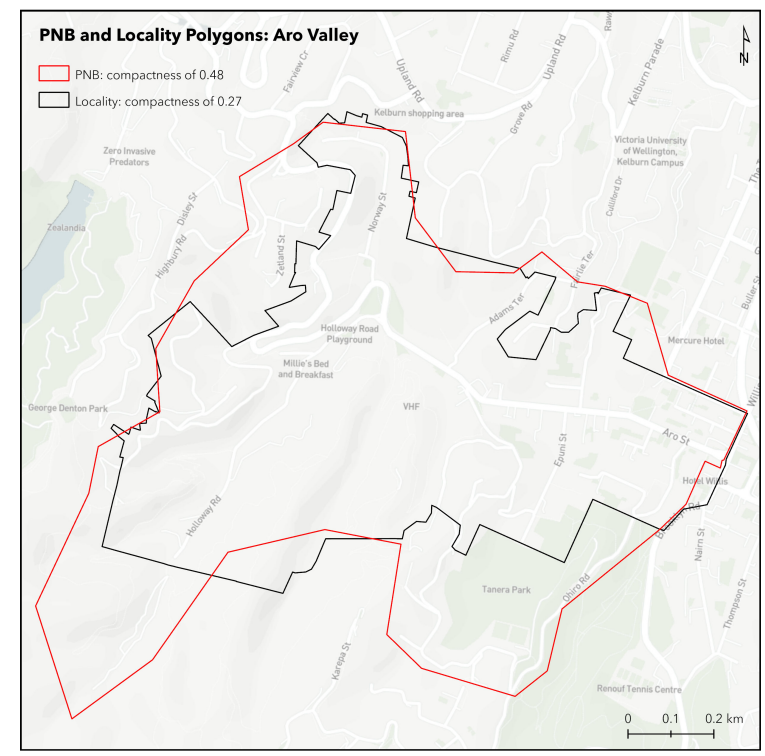

Figure 4.22: Example CDN and Locality Polygons for Aro Valley

Table 4.8 also shows summary statistics for the number of vertices in each of the four comparison datasets. On average, PNBs had much less vertices (23.02) than CDNs (225.9), localities (401.5), 
and SA2s (167.85). This is likely a result of the same reason discrepancy in compactness was observed. Official boundaries are much more detailed than PNBs to support operational purposes, resulting in more vertices in the boundaries. Additionally, participants were unlikely to be experienced with digitising and probably did not spent much time providing data. Both of these factors also resulted in simpler boundaries.

\subsubsection{Congruence}

Congruence was used to measure similarity between PNBs, CDNs, and official boundaries. As defined in Section 3.5.4, congruence is the intersection of two overlapping areas divided by the union of the same areas. Congruence values range from 0 to 1 , with a value of 0 meaning that two areas are completely dissimilar, and a value of 1 meaning that two areas are completely similar. Table 4.9 presents summary statistics of the congruence between the four neighbourhood datasets. It is of note that results in Table 4.9 only include congruence values for intersections between neighbourhood boundaries with the most overlap.

For PNBs, similar levels of congruence were observed between CDNs, localities, and SA2s, with mean congruence values of $0.38,0.36$, and 0.32 observed respectively (Table 4.9). This result is important as it shows participants' neighbourhood perceptions are generally very different from official boundaries, and there was a lot of variety in individual neighbourhood definitions. As CDNs were produced using levels of consensus from PNBs, higher congruence between them might have been expected. However, this was not the case, indicating CDNs are not better at collectively representing neighbourhoods than official boundaries. The highest congruence was observed between localities and SA2s, with a mean value of 0.43. Higher congruence between SA2s and localities was expected as they both use meshblocks ${ }^{1}$ as building blocks. However, large neighbourhoods are often separated into subsets (e.g. Newtown West, Newtown North, Newtown South) by SA2s, while localities kept large neighbourhoods singular (Figure 4.23).

\begin{tabular}{|c|c|c|c|c|c|c|c|c|c|c|c|c|c|c|c|c|c|c|c|c|}
\hline & \multicolumn{5}{|l|}{ PNB } & \multicolumn{5}{|l|}{$\mathrm{CDN}$} & \multicolumn{5}{|c|}{ Locality } & \multicolumn{5}{|l|}{$\mathrm{SA} 2$} \\
\hline & Mean & Median & SD & Min & Max & Mean & Median & SD & Min & Max & Mean & Median & $\mathrm{SD}$ & Min & Max & Mean & Median & SD & Min & Max \\
\hline PNB & - & - & - & - & - & 0.38 & 0.4 & 0.24 & 0.00006 & 0.88 & 0.36 & 0.36 & 0.23 & 0.00005 & 0.92 & 0.32 & 0.31 & 0.17 & 0.0015 & 0.86 \\
\hline CDN & 0.38 & 0.4 & 0.24 & 0.00006 & 0.88 & - & - & - & - & - & 0.43 & 0.49 & 0.26 & 0.007 & 0.85 & 0.33 & 0.29 & 0.2 & 0.013 & 0.77 \\
\hline Locality & 0.36 & 0.36 & 0.23 & 0.0012 & 0.92 & 0.43 & 0.49 & 0.26 & 0.007 & 0.85 & - & - & - & - & - & 0.43 & 0.42 & 0.28 & 0.003 & 0.98 \\
\hline SA2 & 0.32 & 0.31 & 0.17 & 0.0015 & 0.86 & 0.33 & 0.29 & 0.2 & 0.013 & 0.77 & 0.43 & 0.42 & 0.28 & 0.003 & 0.98 & - & - & - & - & - \\
\hline
\end{tabular}

Table 4.9: Summary Statistics for Congruence Between Four Comparison Datasets

\footnotetext{
${ }^{1}$ Smallest Statistical Unit used by Stats NZ
} 


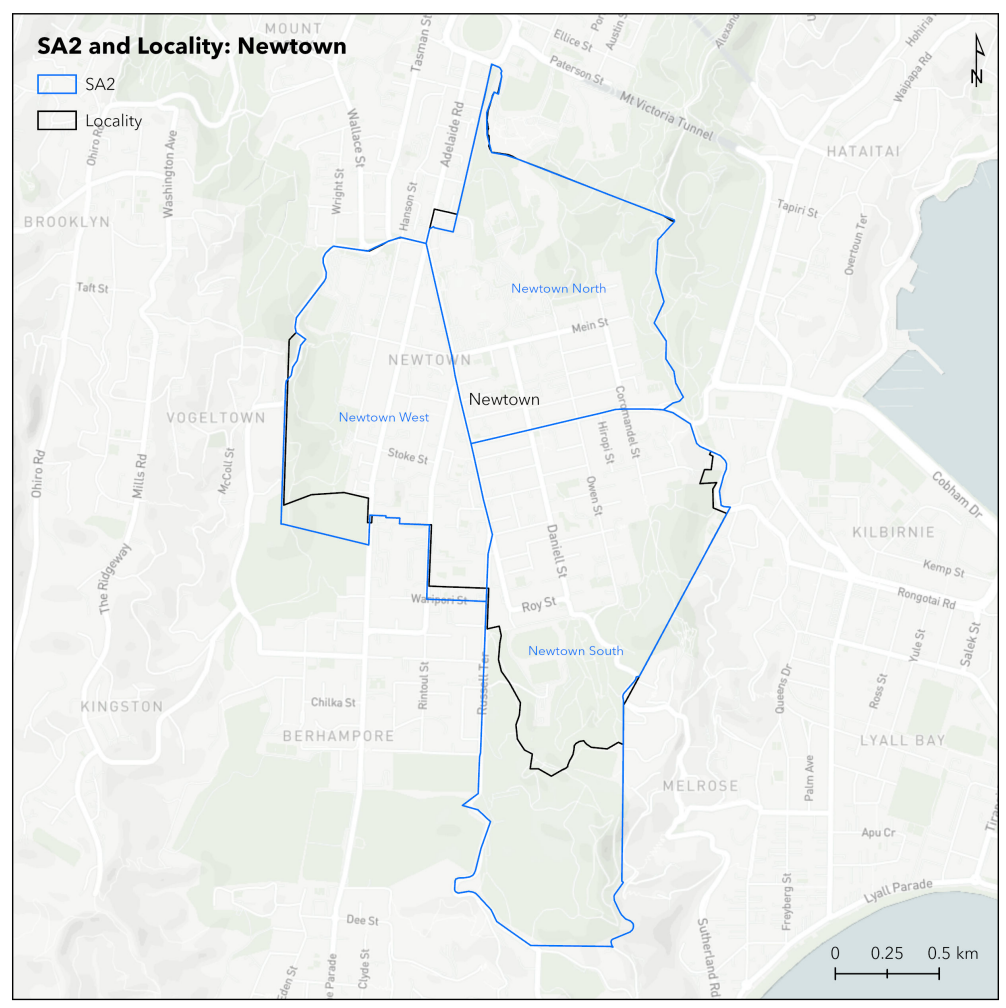

Figure 4.23: SA2 and Locality Boundaries for Newtown

Large variation in congruence values between each of the four comparison datasets was also observed (Table 4.9). The minimum congruence value between PNBs and localities was 0.0012 and the maximum was 0.92. These boundaries are shown in Figure 4.24. The lowest congruence value was observed because the PNB boundary was encompassed by the locality boundary and was much smaller, with areas of $0.0019 \mathrm{~km}^{2}$ and $15.4 \mathrm{~km}^{2}$ for the PNB and locality boundary respectively. This result indicates that extremely low congruence values occur when PNBs cover a small area within a much larger neighbourhood polygon. 23 PNBs had a congruence value less than 0.10 when compared to localities, and out of these $23 \mathrm{PNBs}, 15$ were classified as a street neighbourhood type. This supports the conclusion that extremely low congruence values (e.g. less than 0.1) between neighbourhoods are often caused by disparities in area rather than dissimilar boundaries. 


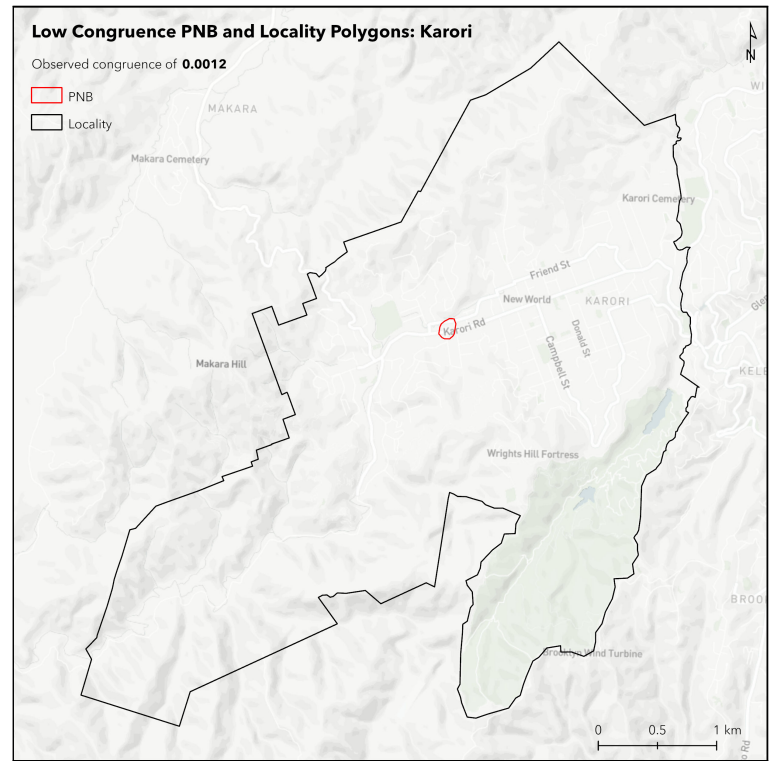

(a) Lowest Congruence (0.0012)

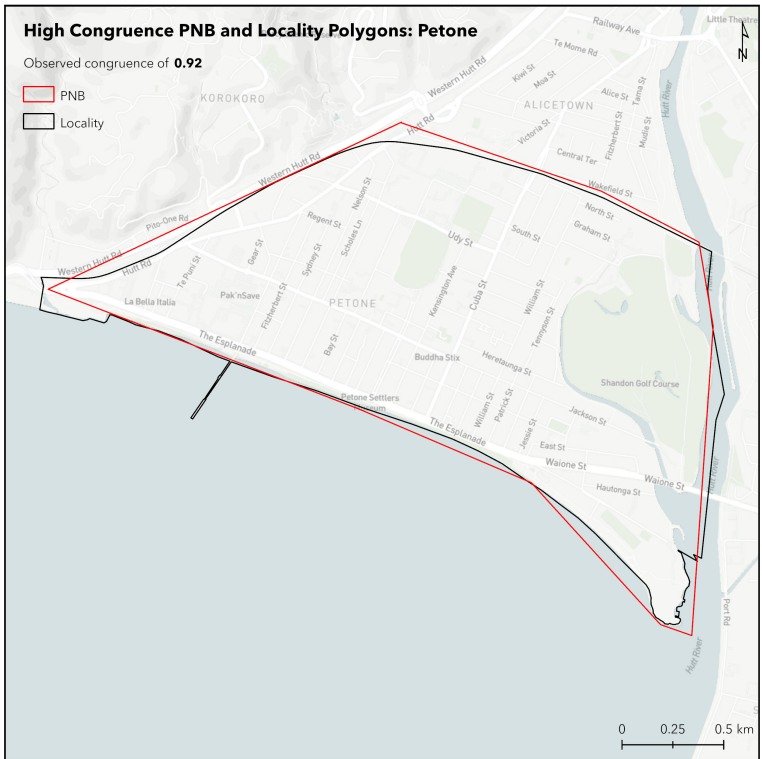

(b) Highest Congruence (0.92)

Figure 4.24: Lowest (a) and Highest (b) Congruence PNB and Locality Boundaries

The highest amount of congruence between a PNB and locality was observed in Petone (Figure 4.24, (b)). 7 participants provided submissions for Petone, with a mean congruence value between PNBs and localities of 0.65 observed, almost double the congruence observed between all PNBs and localities (0.36). Figure 4.25 shows the PNBs and locality polygons for Petone, along with the nearby motorway and train tracks. The physical geography of Petone likely influenced both the PNBs received for Petone and locality boundary to a larger degree than the influence of the small number of participants. From visual inspection, it is clear the shoreline in the south, river in the east, state highway in the west, and train tracks in the north all impacted boundaries of PNBs and localities in Petone. As a result, a high congruence value was observed. While performing analysis on the entire crowdsourced neighbourhood dataset has value, it ignores the fact that neighbourhoods are uniquely impacted by geographic features. Case studies of geographic features and their impact on neighbourhood perceptions is explored in the next chapter. 


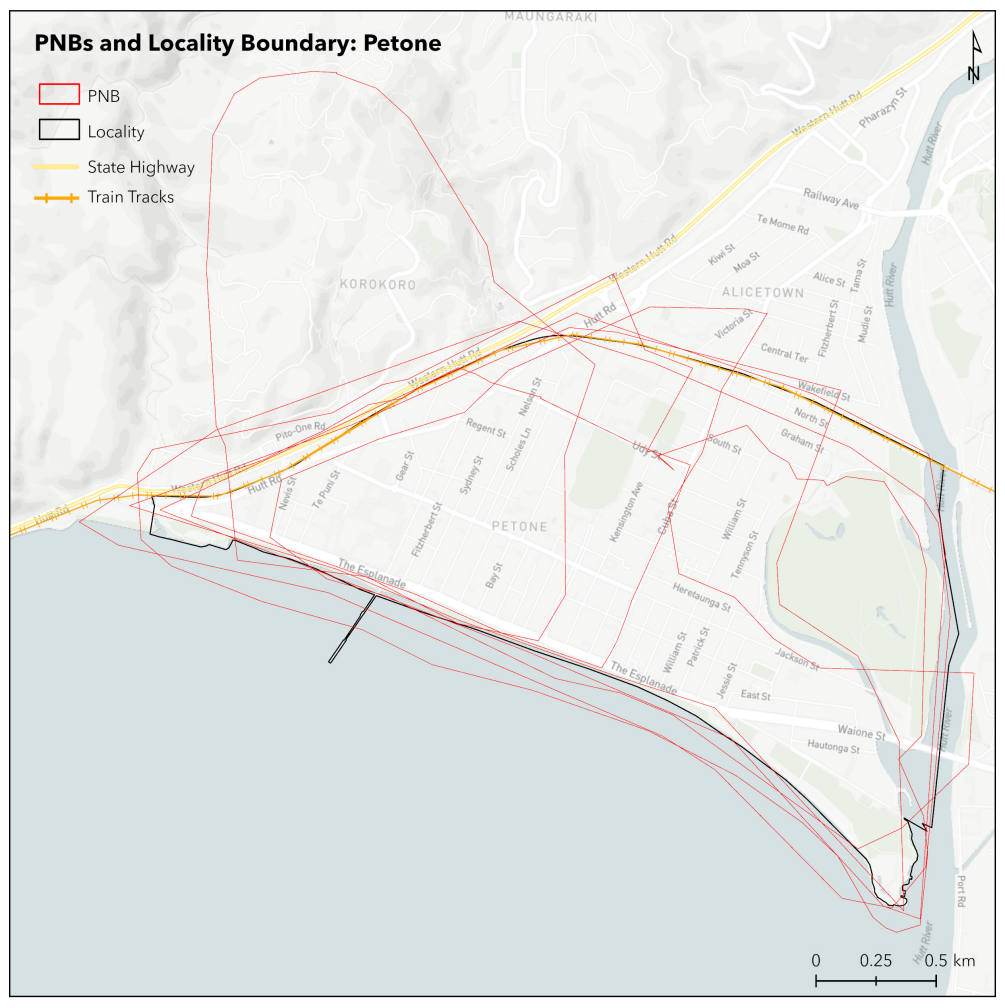

Figure 4.25: PNBs and Locality Boundary: Petone

\subsection{Summary}

This chapter outlined results of analysis performed on the entire crowdsourced neighbourhood dataset collected in Wellington, New Zealand. Linear regression between participant's personal characteristics and neighbourhood delineation revealed length of residence, neighbourhood type, and transport decisions significantly impacted PNBs in different ways. Interestingly, participants who drove daily delineated significantly larger neighbourhoods than participants who did not drive at all, and vice versa for walking. Neighbourhood consensus was used to investigate how neighbourhoods interact with each other spatially and provide a novel look into overlapping neighbourhood boundaries. Areas of high and low neighbourhood consensus were identified using hexagon grids, and models of neighbourhood connectivity indicated which of Wellington City's neighbourhoods had high and low connectivity. Density based clustering was also performed on FPs and found that neighbourhood shopping hubs were popular locations of FPs. Lastly, PNBs and official neighbourhood boundaries were compared. Similar areas were observed between PNBs and SA2s, but a larger congruence value was observed between PNBs and localities than SA2s. Findings from this chapter have implications for the first three research questions of this thesis, and for our understanding of interactions among Wellington City's neighbourhoods. 


\section{Chapter 5}

\section{Case Studies}

\section{$5.1 \quad$ Introduction}

Mental maps are personal interpretations of the environments we experience and interact with, and are used for various purposes, including navigation and orientation (Sulsters, 2005; Gould \& White, 1974). Five elements are influential in the formation of mental maps of urban areas: paths, edges, districts, nodes, and landmarks (Lynch, 1960). The crowdsourced neighbourhood delineations collected in Wellington City provide an opportunity to investigate the impact geographic features that function as one or more of Lynch's (1960) five elements have on neighbourhood perception.

In this chapter, case studies of geographic features are presented to explore how they impact neighbourhood perceptions. Each case study covered in this chapter was selected following visual inspection of the PNBs (Figures 4.1 and 4.2) and consensus hexagon grids (Figures 4.10 and 4.11), as well as using the author's local knowledge of Wellington City. A summary of the feature and its neighbourhood is initially given, followed by analysis and figures to show how the feature impacts neighbourhood perceptions. Lynch's (1960) five elements that inform mental maps of urban areas (Table 5.1) are used to categorise each feature. Two categories of geographic features are covered in this chapter: man-made, and natural. 


\begin{tabular}{lll}
\hline Element & Description & Examples \\
\hline Paths & Channels in which people travel. & Streets, footpaths, \\
& Arrange space and movement between space. & railway tracks, rivers, canals. \\
Edges & Real or perceived boundaries between areas. & Streets, walls, shorelines, rivers \\
& & \\
Districts & Two dimensional areas which we enter in and out of. & City CBDs, neighbourhoods, cultural districts \\
& Have common identifying features. & \\
Nodes & Large, focal points of areas which one can enter. & Plazas, town squares, shopping hubs \\
& &
\end{tabular}

Table 5.1: Lynch's (1960) Five Elements

\subsection{Man-made Features}

In urban areas, we rely on man-made features in our day-to-day lives. Man-made features, primarily roads, have also been shown to strongly influence PNBs (Minnery et al., 2009; Lohmann \& McMurran, 2009). Five man-made geographic features are used as case studies in this section: Cambridge and Kent Terrace, Cuba Street, the Brooklyn Wind Turbine, the Karori Tunnel, the Mt Victoria Lookout, and Wellington Airport. How each case study impacted data received from the crowdsourced neighbourhood survey is described, and are then fit into Lynch's (1960) five elements of urban mental maps based on their function.

\subsubsection{Cambridge and Kent Terraces}

Cambridge and Kent Terrace are one-way, multi-lane roads located on the outskirts of Wellington City's CBD (Figure 5.1). They are both busy, arterial routes used in over 5000 individuals' daily commute by car (Ford, Gerds, \& Prosee, 2017). Cambridge and Kent Terrace are also part of State Highway 1 connecting Wellington City to eastern neighbourhoods, such as Hataitai, Kilbirnie, and Miramar, and Wellington Airport. With multiple lanes, parking spaces, and greenery including trees and shrubs, Cambridge and Kent Terraces are found between two neighbourhoods: Te Aro to the west, and Mt Victoria to the east. 


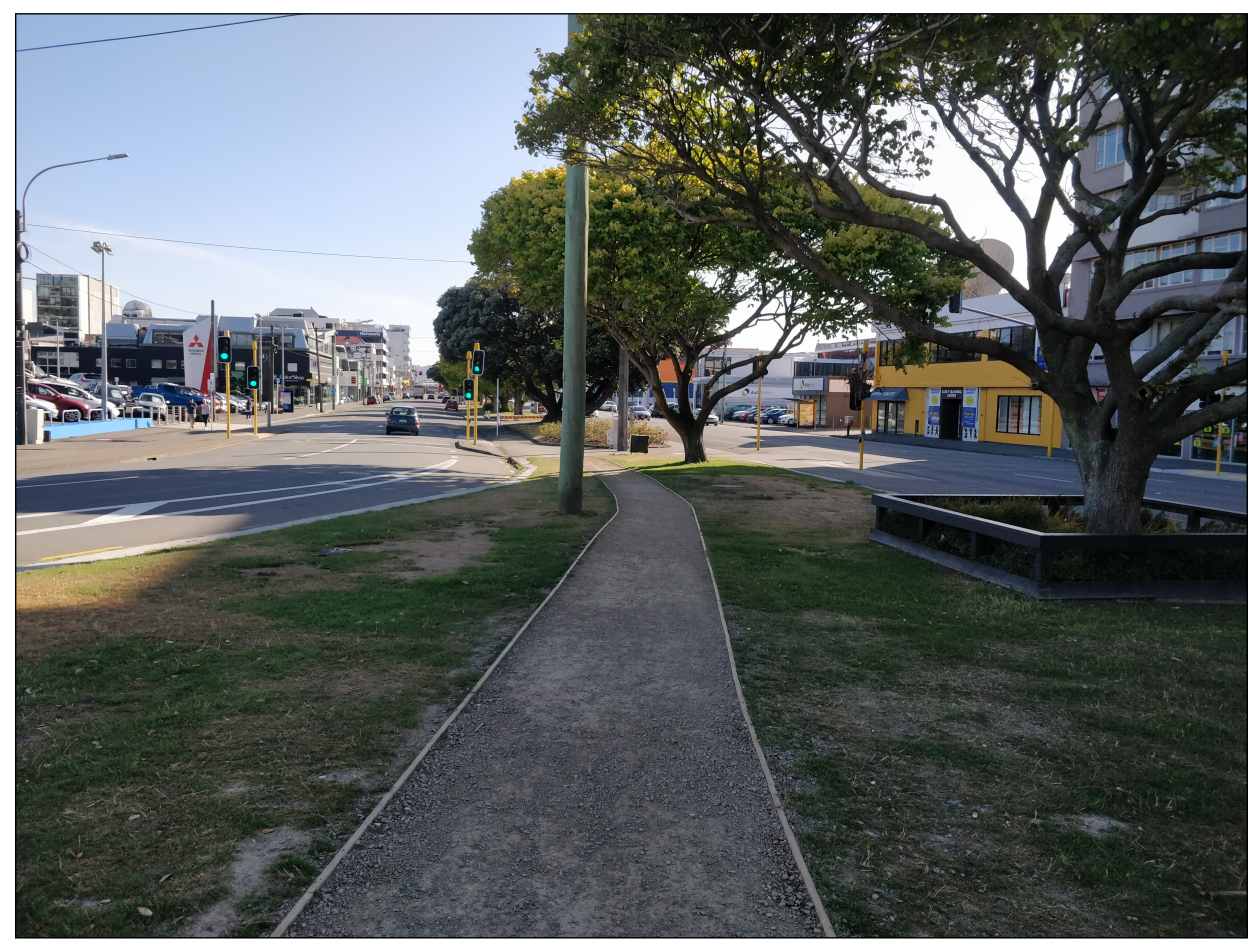

Figure 5.1: Cambridge and Kent Terrace. Credit: Author's Own

41 and 29 submissions were received for Te Aro and Mt Victoria respectively, shown in Figure 5.2. From visual inspection, we can observe that most PNBs received for Te Aro and Mt Victoria are guided by Cambridge and Kent Terrace in the west and east sides of each neighbourhood respectively. Just over a third (10) of PNBs received for Mt Victoria cross over both roads into Te Aro. We can also observe that Cambridge and Kent Terraces guided the western borders of Mt Victoria PNBs and eastern borders of Te Aro PNBs. The median proportion of PNB borders found in a 50 metre buffer of Cambridge and Kent Terrace was 23.59\% for Mt Victoria and 16.67\% for Te Aro (Figure 5.3). This indicates that the two roads were indicating that Cambridge and Kent Terraces functioned as an edge in neighbourhood perceptions. The stronger effect for Mt Victoria than Te Aro is likely the result of there being more variation in what was considered to be Wellington's CBD, as Te Aro represents part of Wellington's CBD. 


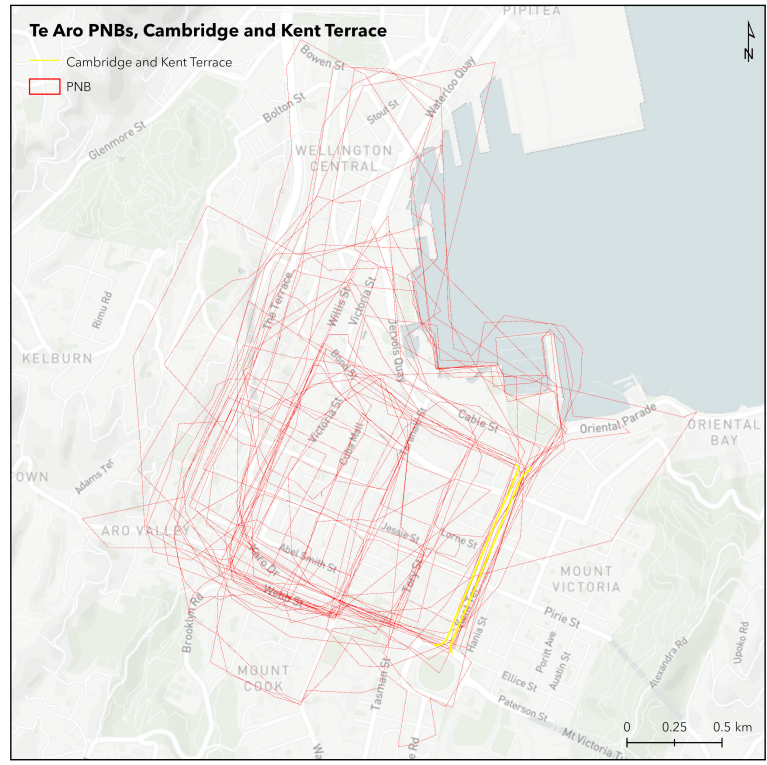

(a) Te Aro PNBs and Cambridge and Kent Terraces

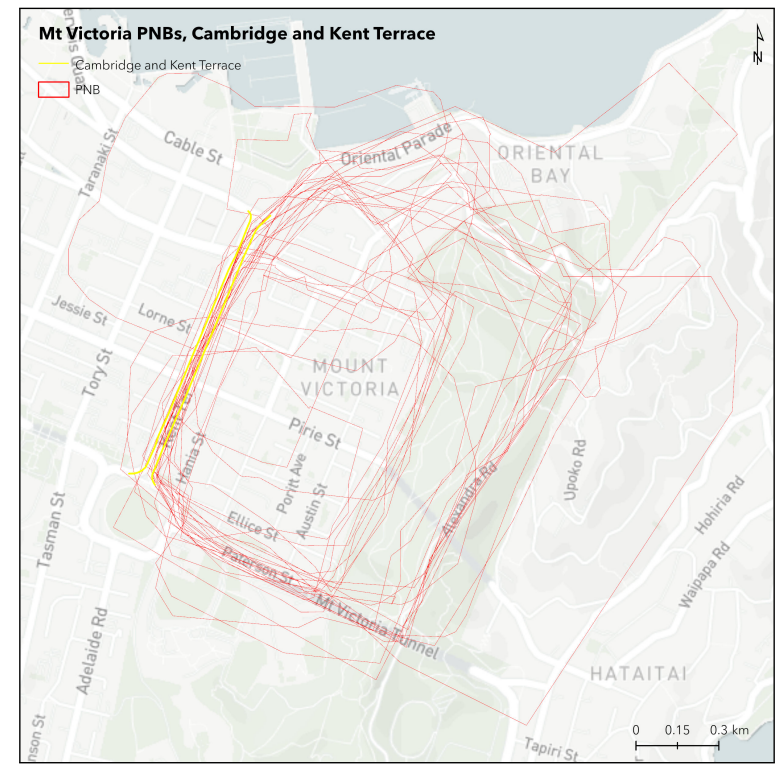

(b) Mt Victoria PNBs and Cambridge and Kent Terraces

Figure 5.2: Te Aro (a) and Mt Victoria (b) PNBs, and Cambridge and Kent Terraces

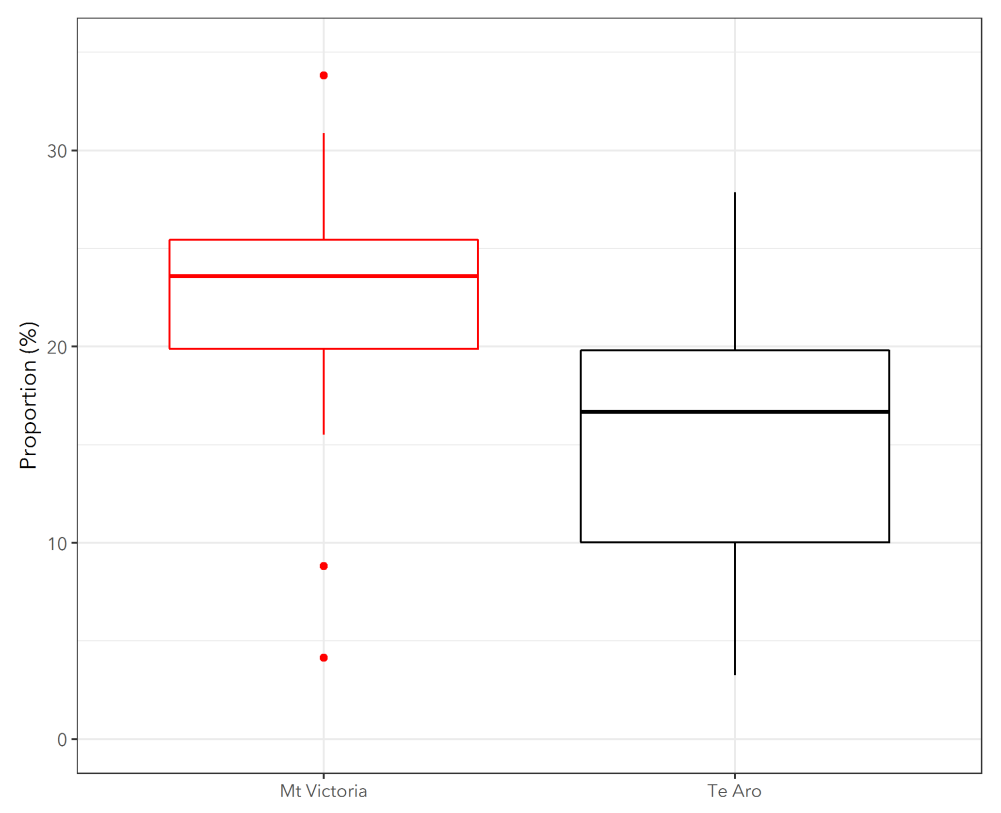

Figure 5.3: Proportion of Mt Victoria and Te Aro PNB Borders in a 50 metre Buffer of Cambridge and Kent Terraces

When overlaid with consensus hexagons of Te Aro and Mt Victoria, Cambridge and Kent Terraces are in a strip of low consensus between the two neighbourhoods (Figure 5.4). For all consensus hexagons intersecting Cambridge and Kent Terrace, a mean consensus percentage of $41.37 \%$ was 
observed. This is lower than the neighbourhood consensus for Te Aro and Mt Victoria, with a combined, mean consensus percentage of $58.41 \%$ observed for Mt Victoria and Te Aro. This change in consensus between Cambridge and Kent Terrace and the two neighbourhoods they border further supports the conclusion that roads function as edges in neighbourhood perceptions. We can also conclude that Cambridge and Kent Terrace function as paths, as they are arterial routes regularly used by Wellington City residents in transit.

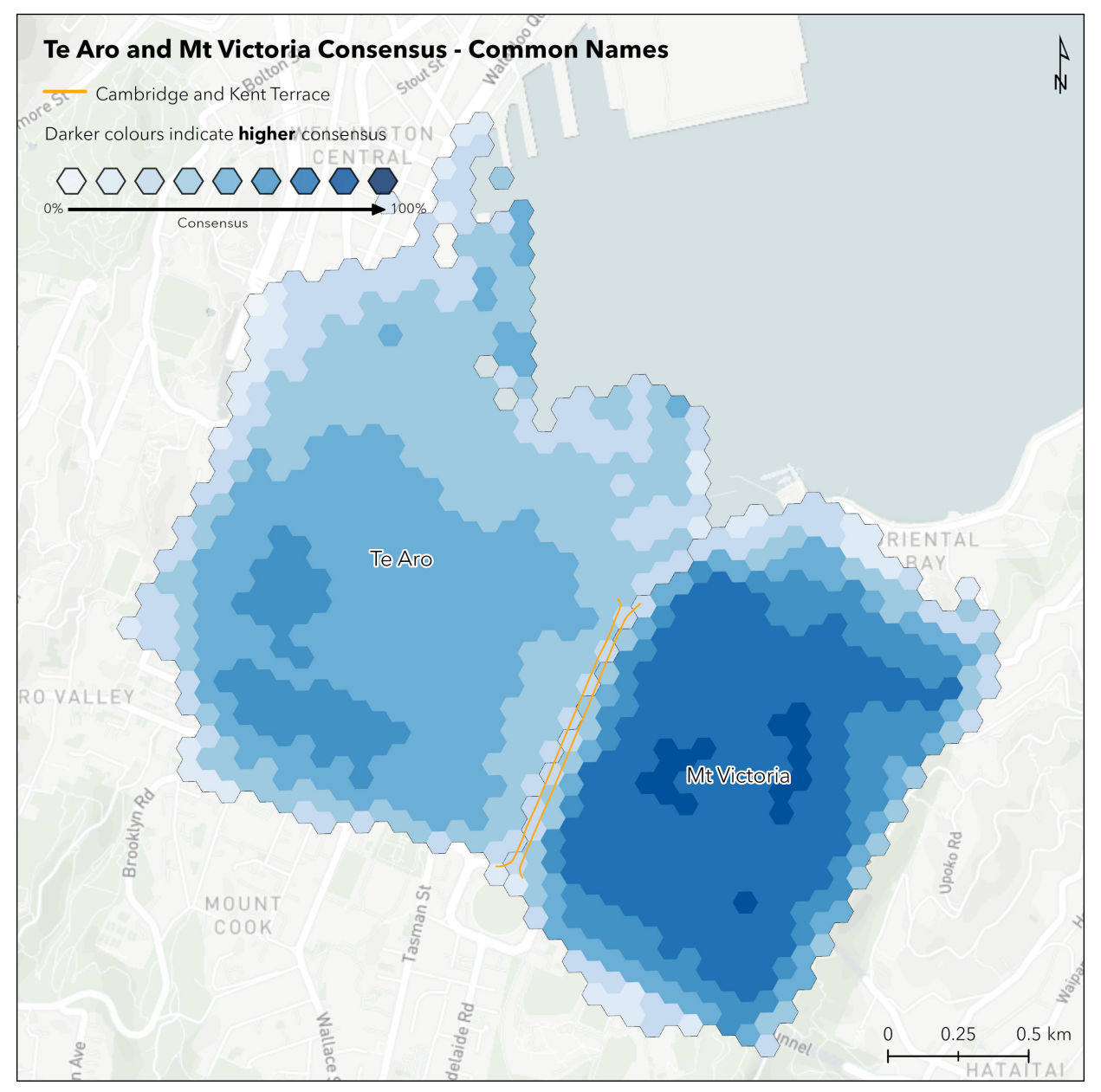

Figure 5.4: Cambridge and Kent Terrace, and Neighbourhood Consensus

\subsubsection{Cuba Street}

Home to Wellington's iconic Bucket Fountain (Figure 5.5), Cuba Street is an iconic street in Wellington's CBD known for its numerous cafes, restaurants, charity shops, music stores, and art galleries, among other things. Cuba Street is a narrow, two lane street 930 metres long with a 248 metre section accessible only to pedestrians. Visiting Cuba Street for somewhere to eat, shop, or socialise is a common attraction for tourists and residents of Wellington alike. Each year, a street festival called Cubadupa runs over a weekend in March hosting hundreds of music acts, 
performances, food and art stalls, among other activities. Cubadupa has been running since 2015, attracting thousands of visitors over the weekend period, and it has grown bigger and more popular since its inception ${ }^{1}$.

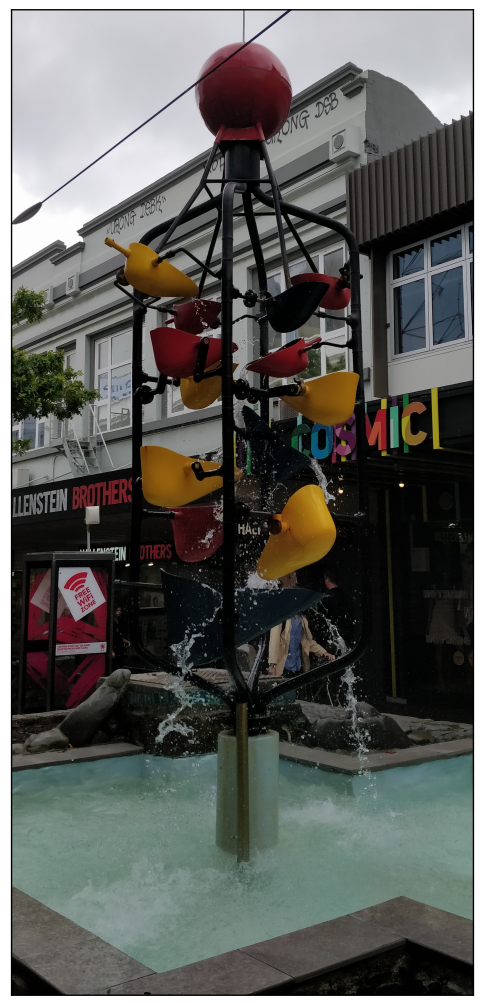

Figure 5.5: The Bucket Fountain in Action. Credit: Author's Own

Even though Cuba Street is not a neighbourhood in itself, 8 submissions were received containing the name Cuba during the crowdsourced neighbourhood survey. No other street in Wellington received more than one submission making Cuba Street a standout. These PNBs and FPs are shown in Figure 5.6. From visual inspection we can observe clear variation in the shapes of the PNBs, with only 1 PNB encompassing all of Cuba Street. This indicates that while Cuba Street was important to each of these 8 participants, different sections of it were relevant to different people. This may be the result of participants living nearby or having significant social hubs on the section of Cuba Street they included in their PNB. Unique names were observed for the 8 submissions (listed below) providing further support for this conclusion.

Upper Cuba, Cuba, Top of Cuba Street, Cubahood, Lower Cuba, Cuba Quarter, Cuba St, Wellington Central/Cuba Street

\footnotetext{
${ }^{1}$ https://www.cubadupa.co.nz/
} 


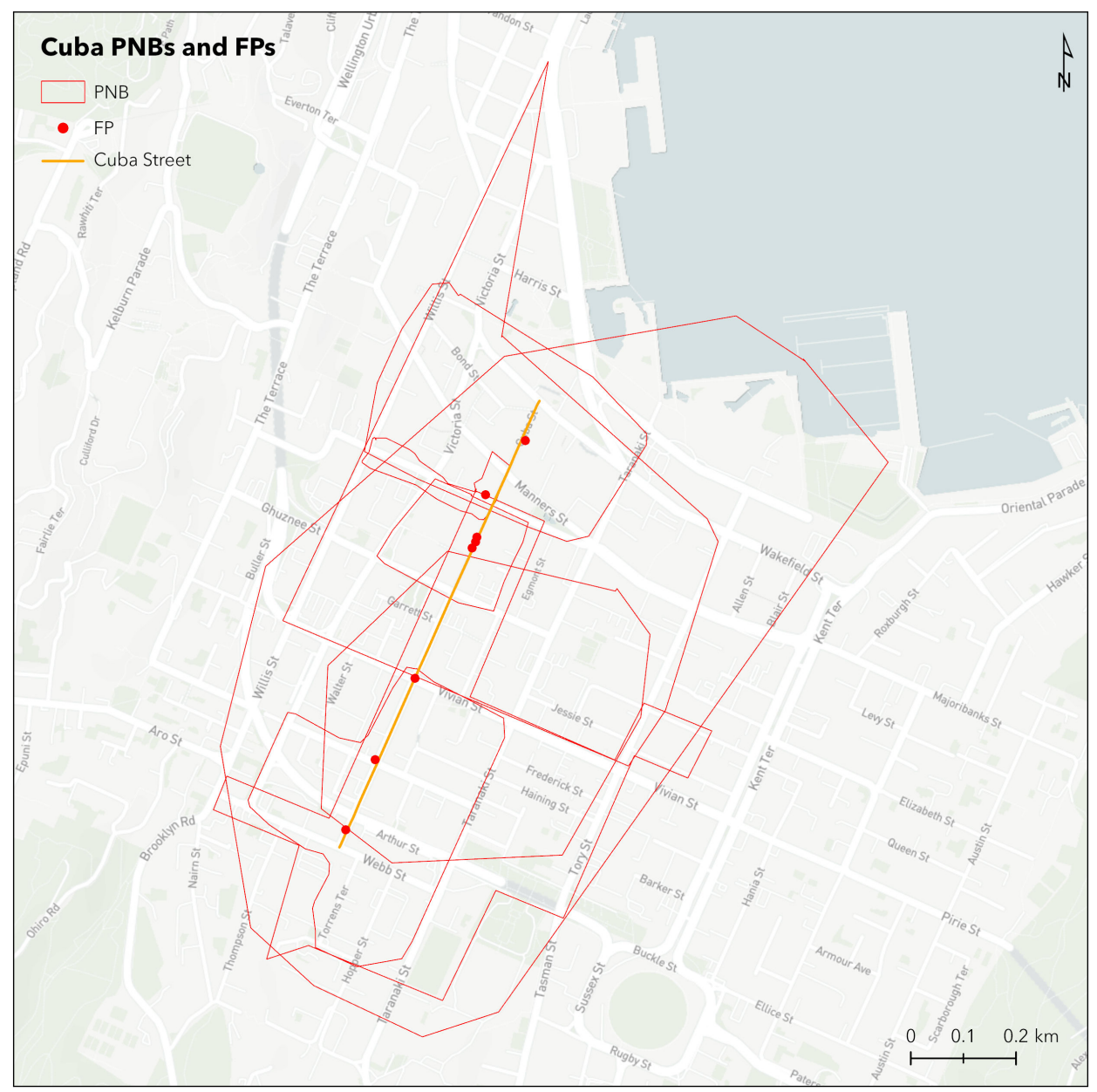

Figure 5.6: Cuba Street PNBs and FPs

40 FPs were located within 25 metres of Cuba Street. Out of these FPs, 8 were submissions received for Cuba Street, and 32 were submissions received for other neighbourhoods, mainly Te Aro and Wellington Central (Figure 5.7). Most of the FPs were clustered around section of Cuba Street at the northern end only accessible to pedestrians. This section is popular among tourists and residents alike, as they can walk around and enjoy Cuba Street's attractions without worrying about moving vehicles. This section of Cuba Street acts as a node in contributing to participants' neighbourhood perceptions (Lynch, 1960). This supports the conclusion that even though it is not considered to be an official neighbourhood, Cuba Street is a significant street in Wellington that impacted participants' neighbourhood perceptions. Additionally, Cuba Street could be considered the focus of Wellington's CBD. Cubadupa's annual occurrence supports this, as it the largest street festival in the city. 


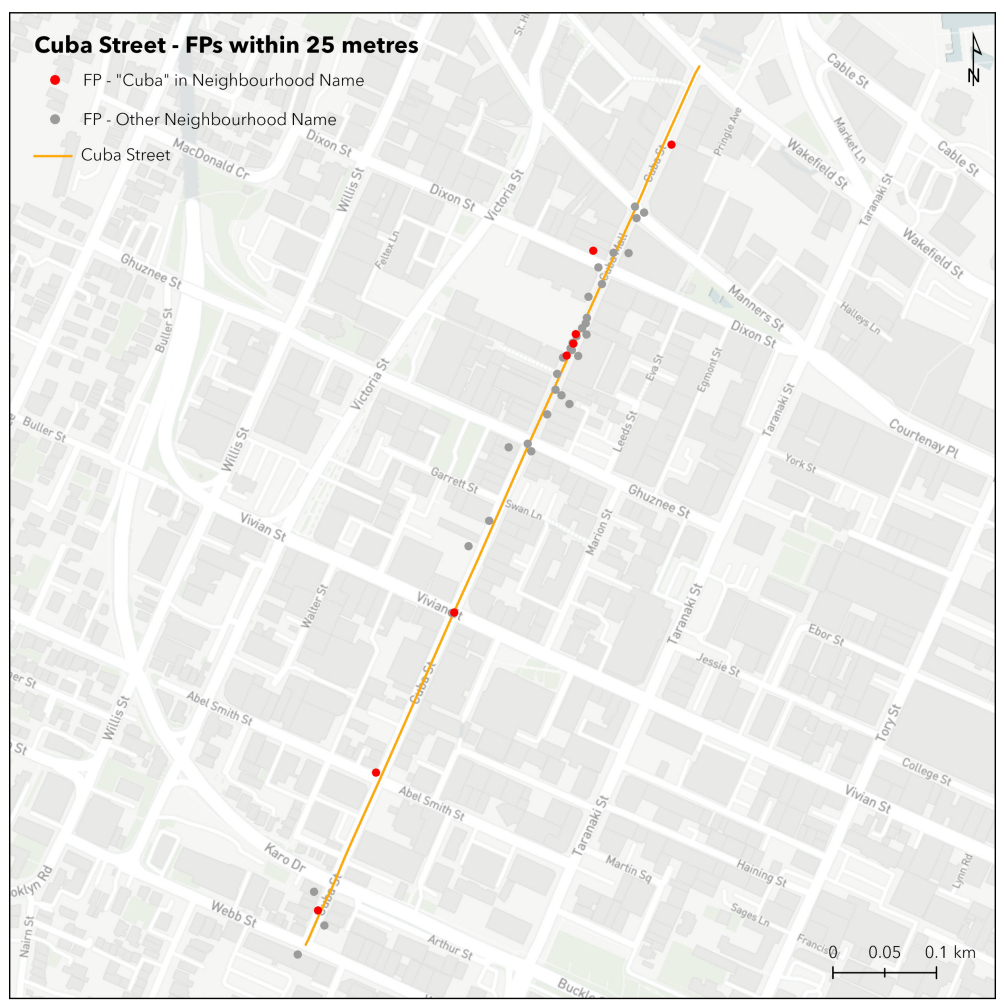

Figure 5.7: FPs within 25 metres of Cuba Street

\subsubsection{Brooklyn Wind Turbine}

The Brooklyn Wind Turbine is a significant fixture in Wellington's skyline located in the neighbourhood of Brooklyn (5.8 (a)). It stands 67 metres tall on top of a hill 299 metres above sea level. The wind turbine overlooks the rest of Brooklyn and some of wider Wellington, and can be seen from most locations in Brooklyn. Built in 1993, the wind turbine was used to test how well wind turbines performed in conditions in New Zealand ( Brooklyn Wind Turbine", n.d.). The site was chosen to take advantage of Wellington's strong wind patterns and gain large amounts of exposure being visible across the city. Today, the wind turbine is mainly a tourist attraction boasting incredible views over Wellington City, but still generates enough energy to power 110 homes in a year ("Brooklyn Wind Turbine", n.d.). Direction signs to the wind turbine are posted all the way along the main route to the wind turbine from the main intersection in Brooklyn (Figure 5.8 (b)). 


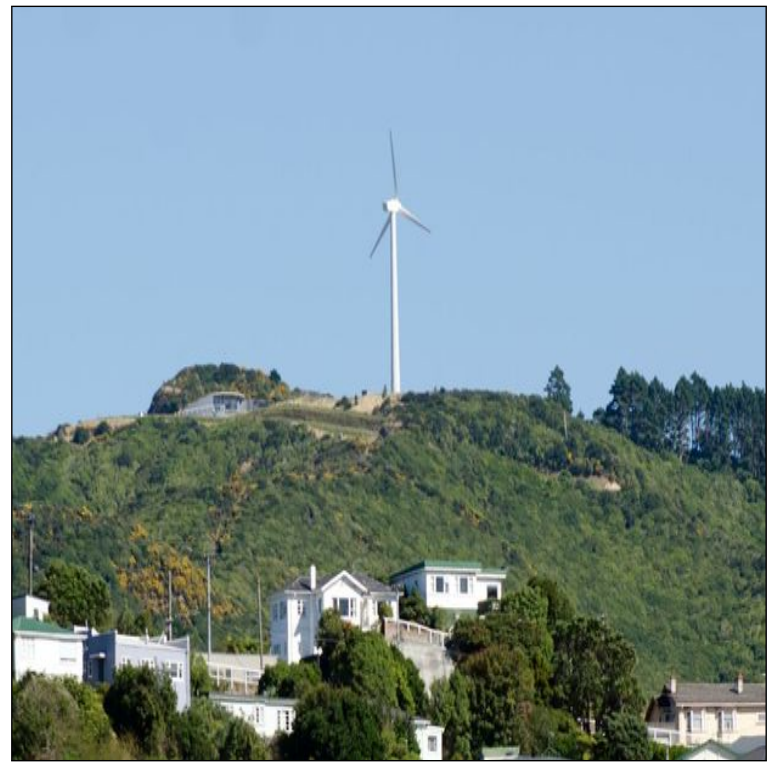

(a) Brooklyn Wind Turbine

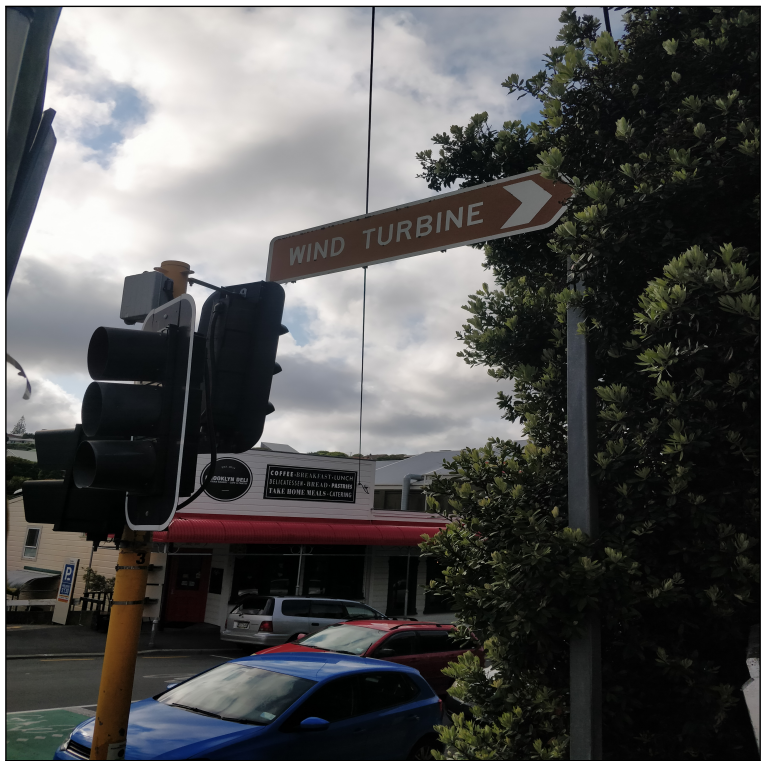

(b) Wind Turbine Sign

Figure 5.8: Brooklyn Wind Turbine (a) and Navigation Street Sign (b). Credit: Author's Own

As its name suggests, the Brooklyn Wind Turbine is located in the neighbourhood of Brooklyn, a large neighbourhood located about a 30 to 45-minute walk south of Wellington's CBD. Brooklyn sits on top of a hill 130 metres above sea level and has large elevation changes within the neighbourhood as streets wind up and around nearby ridgelines. In the crowdsourced neighbourhood dataset, 56 submissions were received for Brooklyn, with Figure 5.9 showing the PNBs and FPs as well as the location of the wind turbine. 


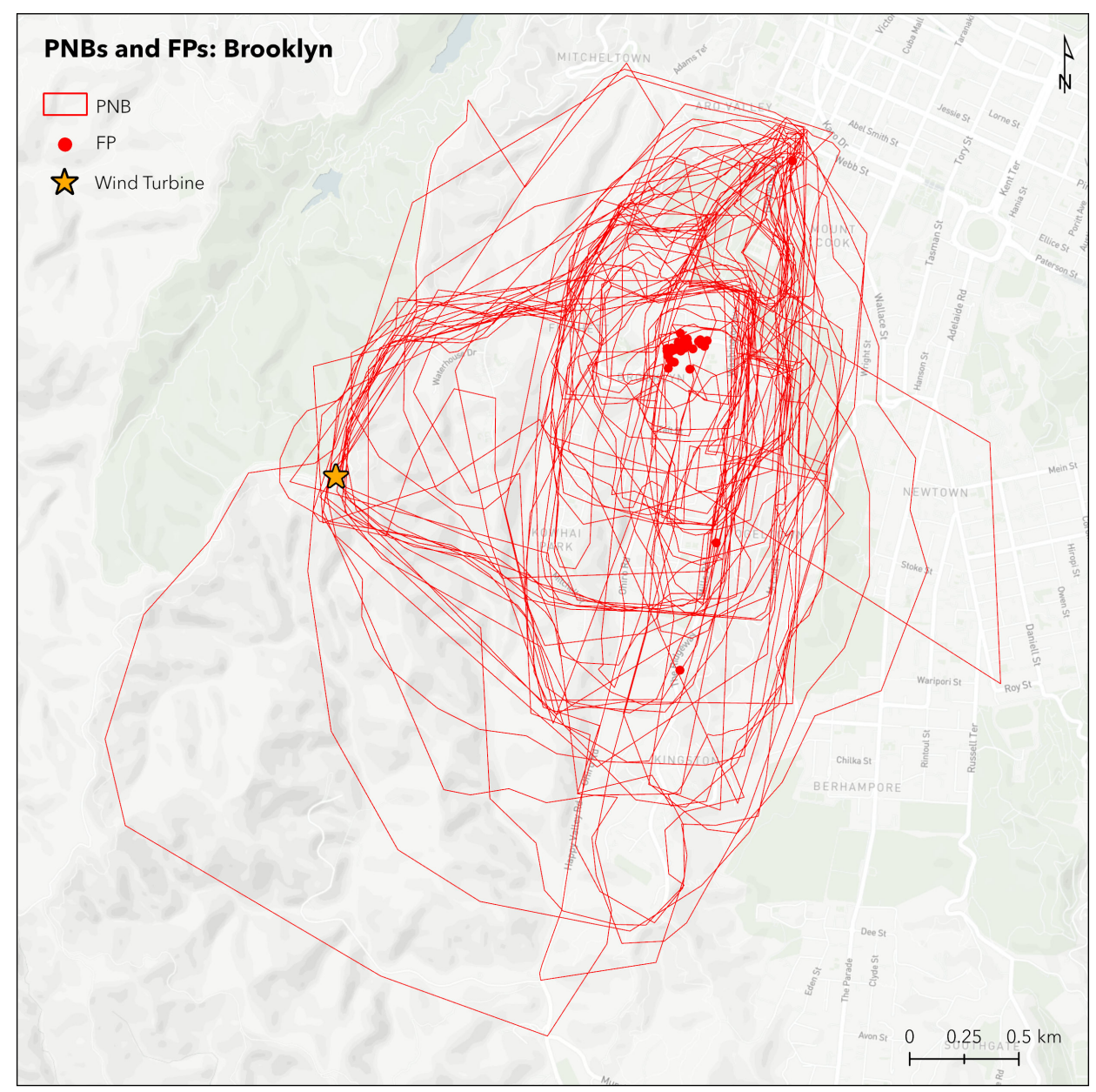

Figure 5.9: Brooklyn PNBs and FPs

The wind turbine is geographically separate from the rest of Brooklyn (Figure 5.10). The distance between the wind turbine and the main intersection in Brooklyn is $2.17 \mathrm{~km}$ in a straight line, and $3.15 \mathrm{~km}$ following the shortest road route. Between the main intersection in Brooklyn to the wind turbine, the elevation rises from 134 metres to 371 metres. Additionally, 80 metres of dense forest separates the wind turbine from the nearest residential area, making it accessible only by the road winding up around the hillside and walking tracks. 


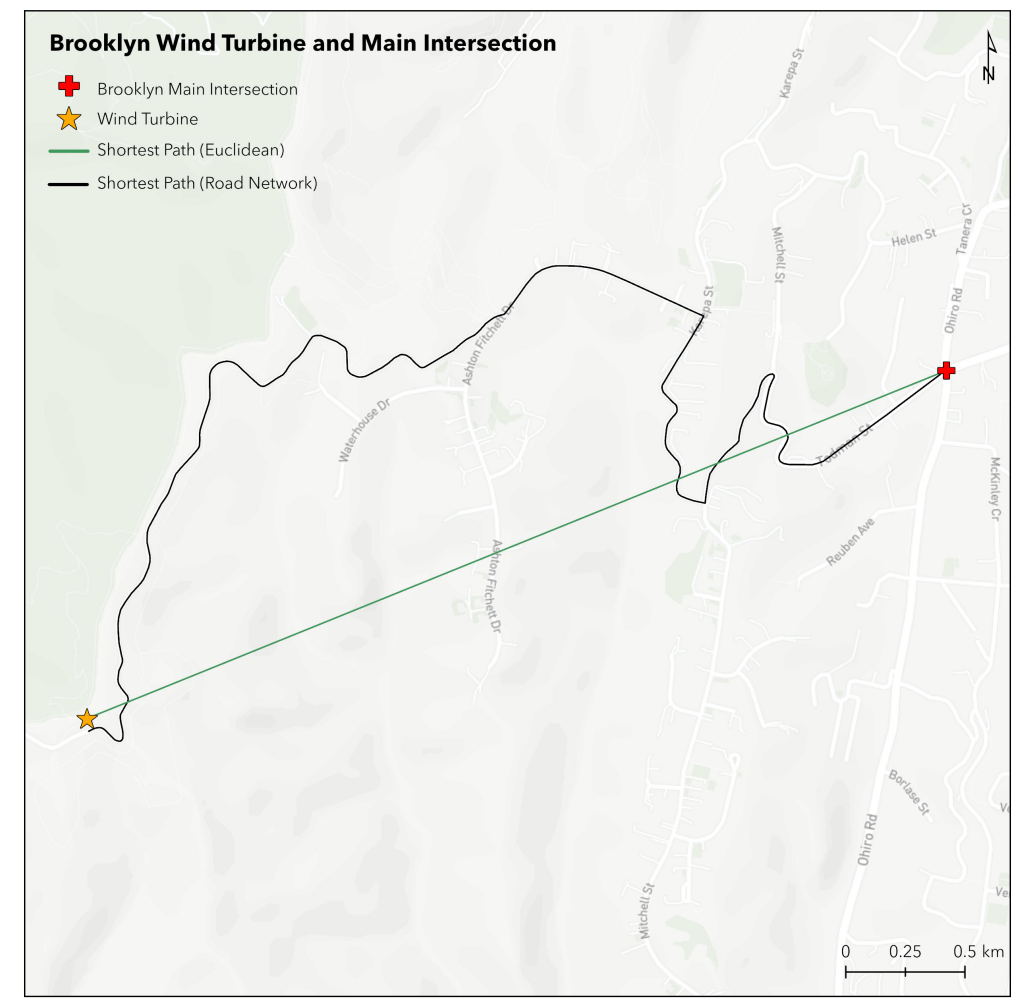

Figure 5.10: Distance Between Brooklyn Wind Turbine and Main Intersection

Of the total 56 submissions received for Brooklyn, just over a third (19) included the wind turbine in their PNB or had a PNB within 100 metres of the wind turbine. Figure 5.11 shows PNBs of participants that included the wind turbine (a) and PNBs of participants that did not (b). PNBs that included the wind turbine delineated larger areas covering the hills and ridgelines to the west of Brooklyn, while PNBs that excluded it delineated smaller, more compact areas in Brooklyn's residential areas. This indicates that even though the wind turbine is separated from the rest of Brooklyn by distance, elevation, and green space, it was still influential in determining how participants delineated their neighbourhood. Significant size differences were found between PNBs that included and excluded the wind turbine with mean areas of $3.67 \mathrm{~km}^{2}$ and $1.33 \mathrm{~km}^{2}$ observed respectively. While this may indicate that the wind turbine had a significant impact of PNBs, it is more likely the result of PNBs being necessarily larger to include the wind turbine as it is separate from Brooklyn's residential areas. The impact the wind turbine had on PNBs indicates that is functioned as a landmark in neighbourhood perceptions. It is a significant and memorable point of reference for residents of Brooklyn.

The name of the wind turbine containing the neighbourhood name Brooklyn may have had an effect on participants that included it in their PNB by providing a strong association between the wind turbine and the neighbourhood perceptions of residents of Brooklyn. If the wind turbine was known as the Wellington Wind Turbine, participants might have been less inclined to include it in their 
PNB. Unfortunately, this is difficult to test using the data collected. A complimentary qualitative survey to the crowdsourced neighbourhood survey may have been effective in understanding why participants included the wind turbine in the PNB.

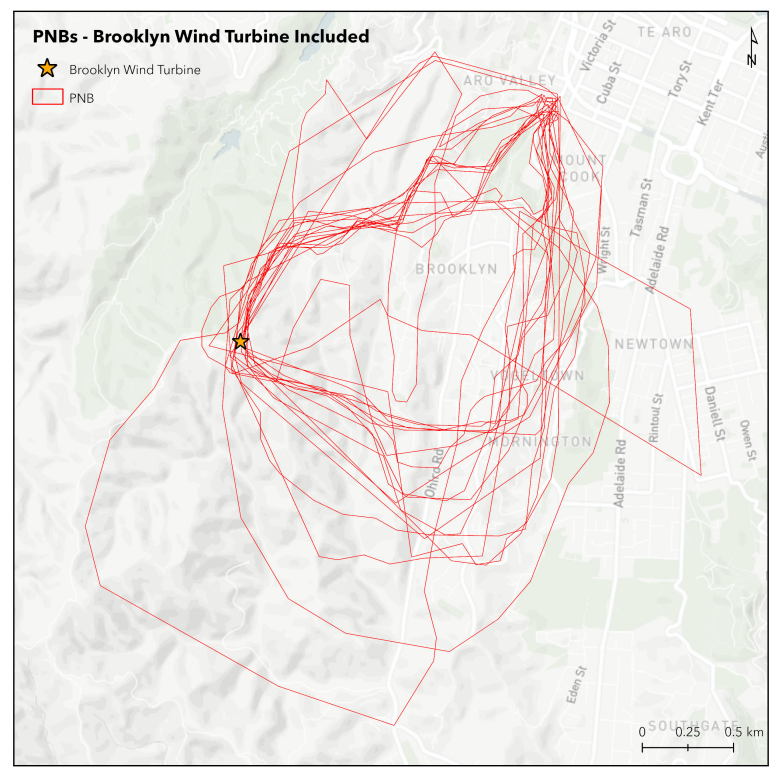

(a) Brooklyn PNBs - Wind Turbine Included

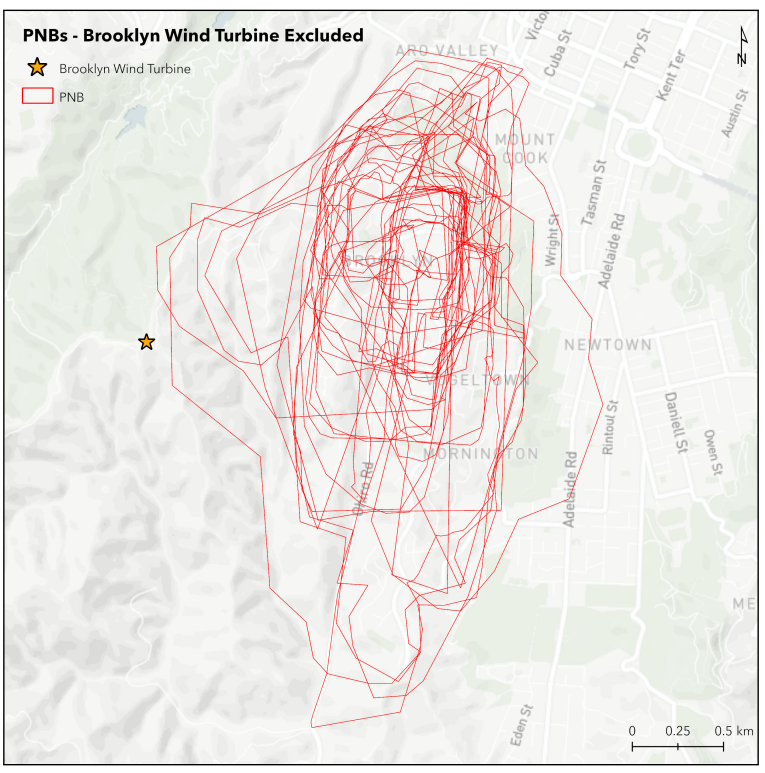

(b) Brooklyn PNBs - Wind Turbine Excluded

Figure 5.11: Brooklyn PNBs with (a) and without (b) the Wind Turbine included

\subsubsection{Karori Tunnel}

Tunnels are man-made features linking two separated areas. For the neighbourhood of Karori, the Karori Tunnel (Figure 5.12 is used in the main route to access the neighbourhood, with around 114,000 vehicles passing through the tunnel weekly ("Karori Tunnel", n.d.). Construction of the Karori Tunnel began in 1897 after access to Karori was considered poor and held the neighbourhood back due to a series of hills standing between it and the rest of Wellington City (O'Neil, 2015). The Karori Tunnel is 76 metres long, 7.71 metres high, and 5.8 metres wide, narrowly allowing cars, busses, and pedestrians to pass through it at the same time. The Karori Tunnel is important to Karori as it is on the main route to access the neighbourhood from Wellington's CBD. Other ways of accessing Karori either involve going through Aro Valley in the southwest or from Wilton in the east, but both are not as popular. 


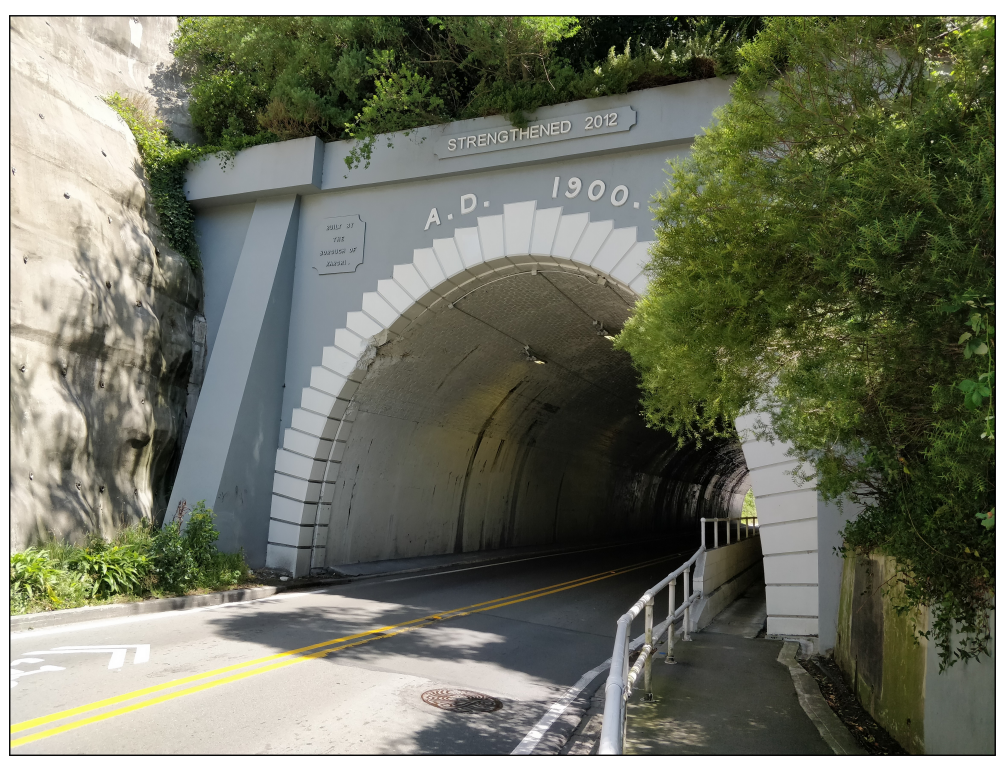

Figure 5.12: Eastern Entrance of the Karori Tunnel. Credit: Author's Own

The Karori Tunnel links Karori to the west and Kelburn to the east. Figure 5.13 shows the 34 and 41 PNBs received for Karori and Kelburn respectively and the Karori Tunnel. We can observe that the Karori Tunnel is a key point at which Karori ends and Kelburn begins, and vice versa. Only 7 out of 75 PNBs received for Karori and Kelburn include all of the Karori Tunnel. Rather, most of them end before or during the tunnel. Consequently, we can conclude that the Karori Tunnel functions as an edge, separating the two neighbourhoods. Tunnels are a unique geographic feature for neighbourhood mental maps as they provide a clear distinction between two neighbourhoods. Travelling through the Karori Tunnel, one begins in either Kelburn or Karori, and finishes in the other neighbourhood. 


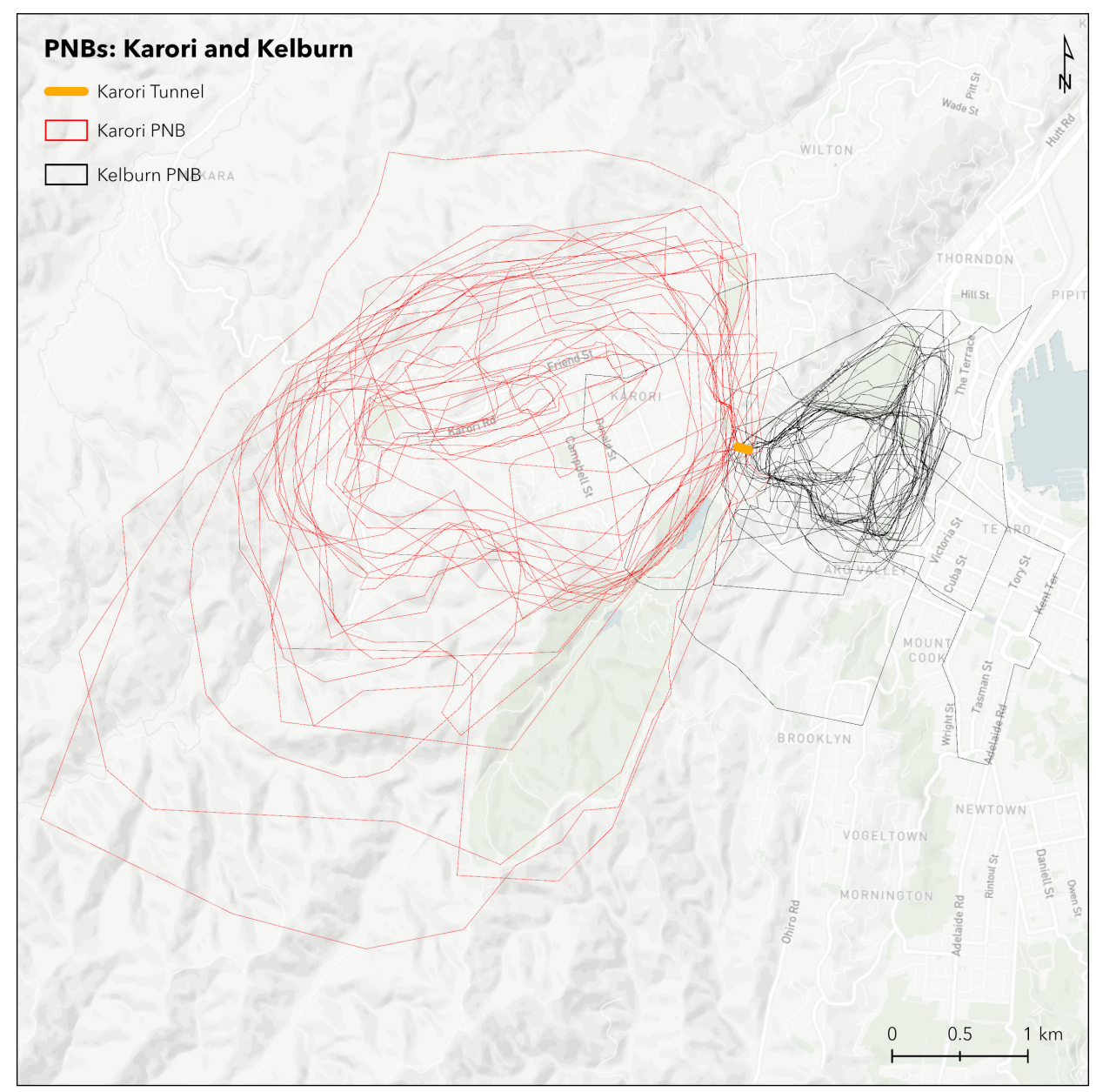

Figure 5.13: Karori and Kelburn PNBs

The Karori Tunnel also had an impact on neighbourhood consensus (Figure 5.14). The average consensus for hexagons intersecting the Karori Tunnel was lower than the consensus observed for Karori and Kelburn, with mean percentages of $45.62 \%, 93.18 \%$, and $63.45 \%$ observed respectively. Additionally, the Karori Tunnel is located on the CDN border between the two neighbourhoods, supporting the conclusion that Karori Tunnel functions as an edge separating the neighbourhood geographies of Karori and Kelburn. The Karori Tunnel is also a means for individuals to travel between Karori and Kelburn, connecting the two neighbourhoods that would be otherwise separated by a hill. Consequently, the Karori Tunnel also functions as a path regularly used in transit. 


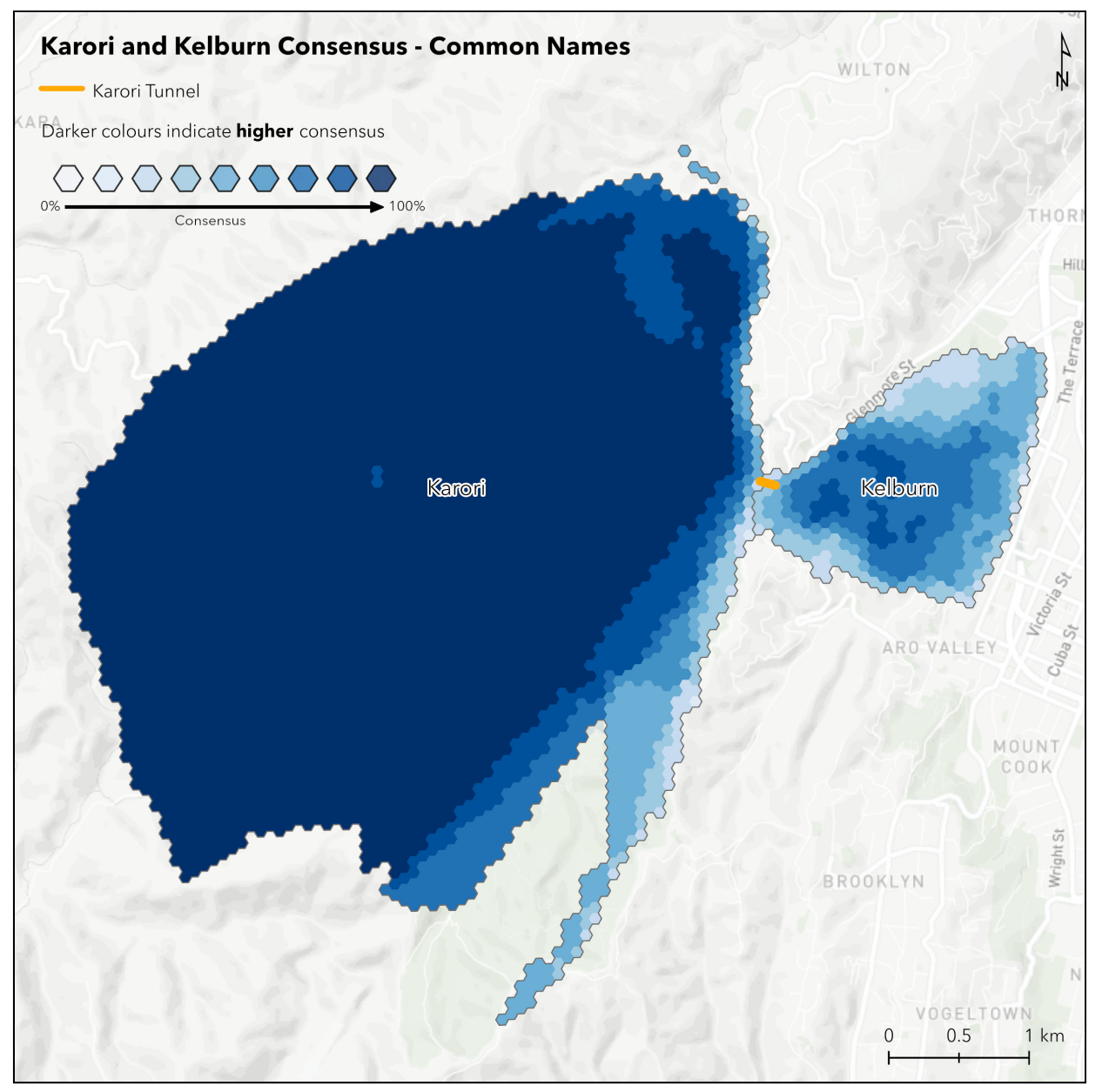

Figure 5.14: Karori and Kelburn Neighbourhood Consensus

\subsubsection{Mt Victoria Lookout}

The Mt Victoria Lookout is another notable geographic feature that sits on a hill above Wellington City. The lookout is a popular tourist location providing a 360 degree viewpoint of Wellington City and surrounding neighbourhoods (Figure 5.15(a)). It is located at the summit of Mount Victoria (the hill, not the neighbourhood) 196 metres above sea level. Green space part of Wellington's Town Belt ${ }^{2}$ surrounds the lookout, and separates the neighbourhoods of Mt Victoria, Roseneath, and Hataitai. Numerous walkways in the town belt and roads provide access to Mt Victoria lookout, with a direction sign to the lookout, shown in Figure 5.15 (b).

\footnotetext{
${ }^{2}$ Land set aside to be used as a public recreation ground for the residents of Wellington
} 


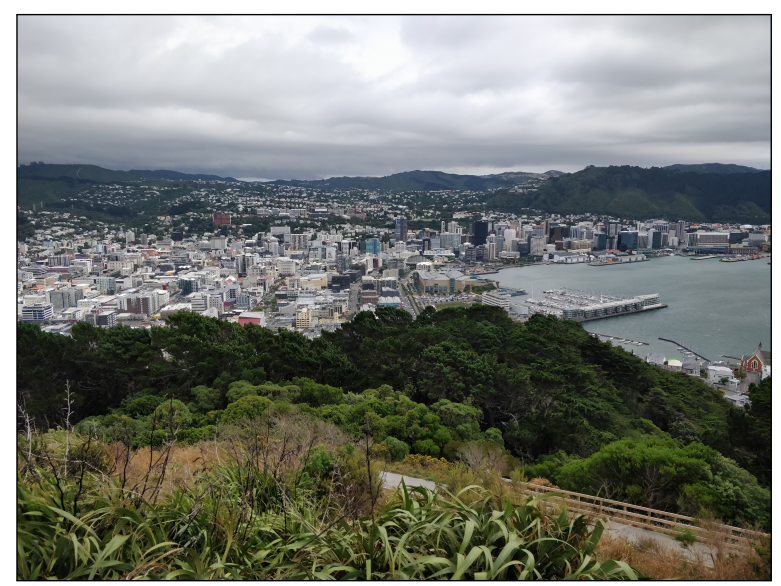

(a) Wellington's CBD seen from Mt Victoria Lookout

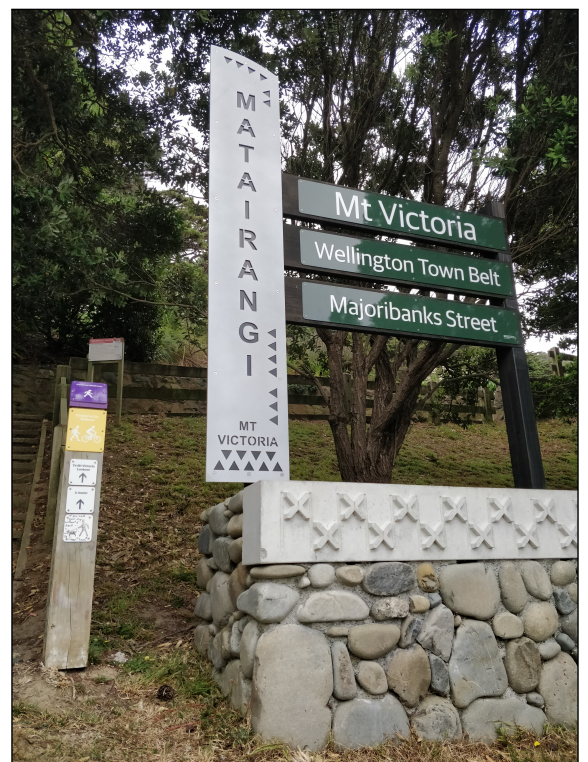

(b) Town Belt and Lookout Walkway Direction Signs

Figure 5.15: View from Mt Victoria Lookout (a) and Walkway Signs (b). Credit: Author's Own

The Mt Victoria lookout is primarily associated with the neighbourhood Mt Victoria which is a large neighbourhood located east of Wellington's CBD, but is also bordered by Roseneath to the northeast and Hataitai to the southeast. 29, 35, and 6 submissions were received for Mt Victoria, Hataitai, and Roseneath respectively, shown in Figure 5.16. The lookout was more important for neighbourhood perceptions of Mt Victoria, with $34.48 \%$ (10), 8.6\% (3) and 16.67\% (1) of PNBs received for Mt Victoria, Hataitai, and Roseneath respectively including the lookout. This difference is likely the result of the name association between Mt Victoria and the lookout, because similar levels of separation between the lookout and the three neighbourhoods exists. Additionally, 2 FPs received for Mt Victoria were found on top of or near the lookout. No FPs received for Hataitai and Roseneath were located nearby, providing further evidence for an association between neighbourhood delineations received for Mt Victoria and the lookout. Lynch (1960) defines landmarks as having at least one unique or memorable aspect. For participants with Mt Victoria submissions, the shared name between the lookout and their neighbourhood was memorable. 


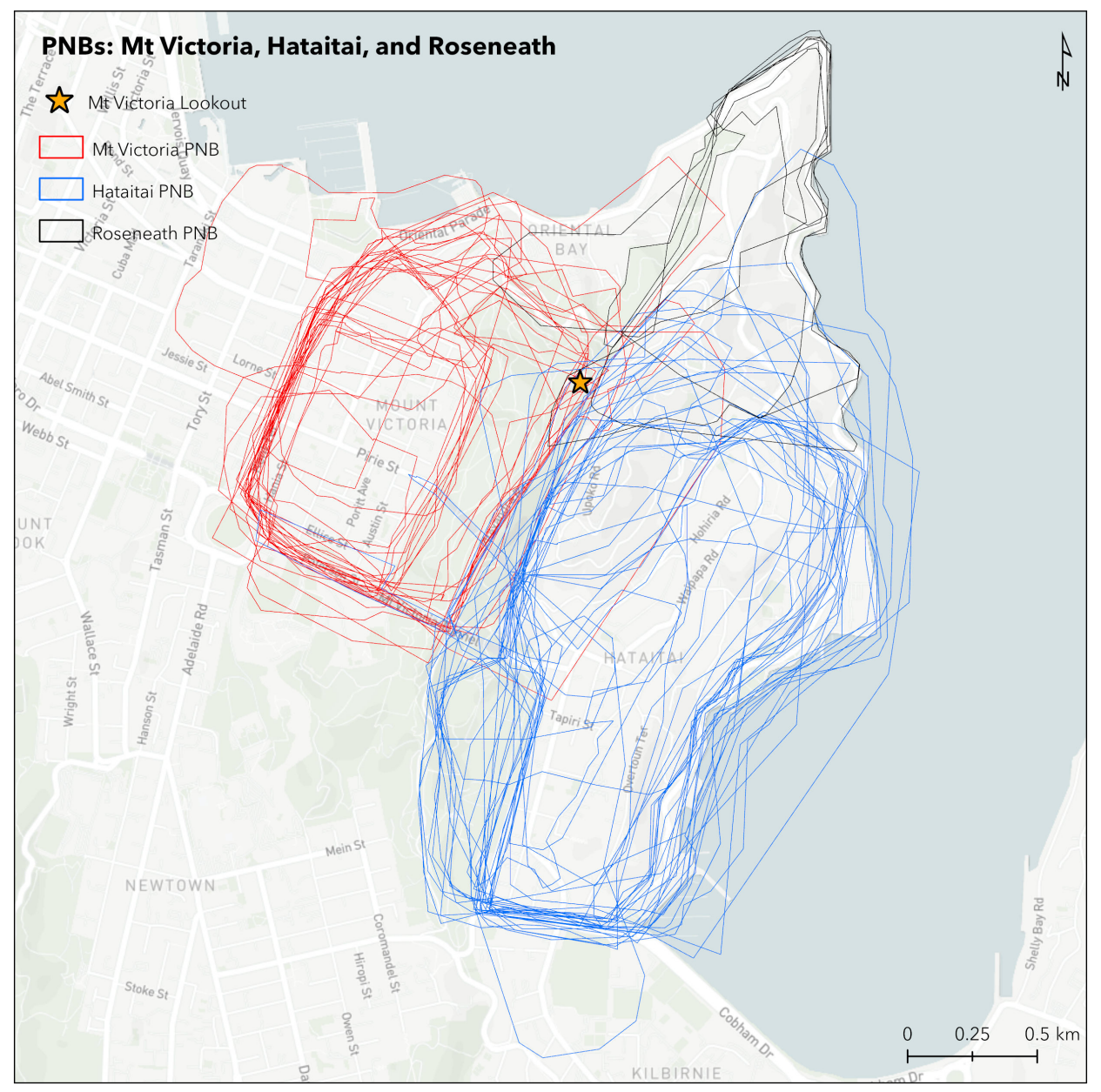

Figure 5.16: PNBs of Mt Victoria, Hataitai, and Roseneath

Just under half (14) of participants providing neighbourhood data for Mt Victoria included the lookout in their PNB or delineated their PNB within 100 metres of the lookout. Figure 5.17 shows PNBs that included (a) and excluded (b) include the Mt Victoria lookout. From visual inspection we can identify that PNBs including the lookout also included most of the town belt (green on the basemap), but PNBs excluding the lookout mostly followed the southern border of the town belt. PNBs including the lookout also had less variation among the boundaries than PNBs excluding the lookout. This may be because including the lookout resulted in participants delineating a larger, more robust area that they consider to be Mt Victoria, while excluding the lookout resulted in participants delineating smaller, rougher areas supporting the conclusion that the lookout impacted PNBs received for Mt Victoria. 


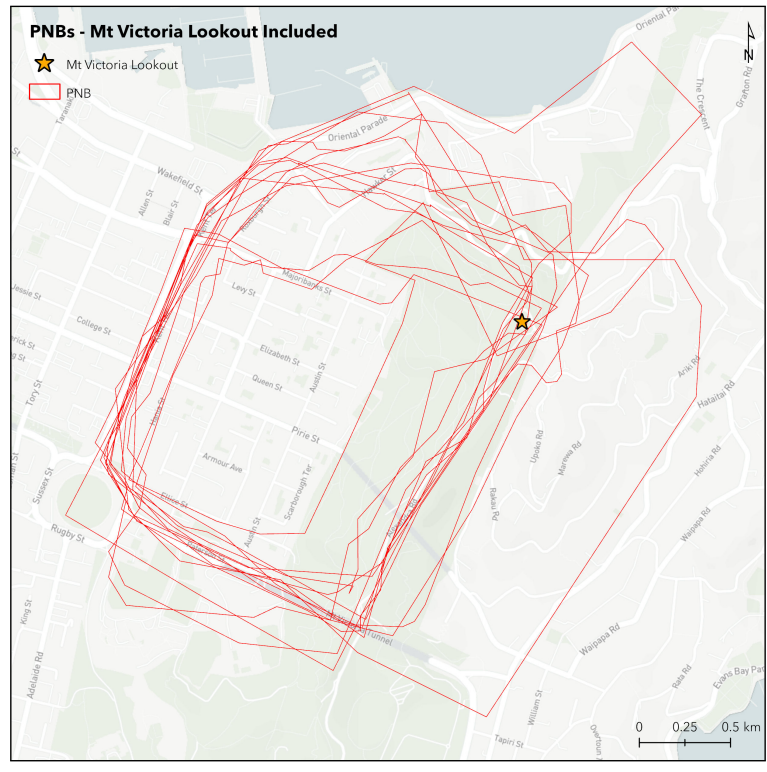

(a) Mt Victoria PNBs - Lookout Included

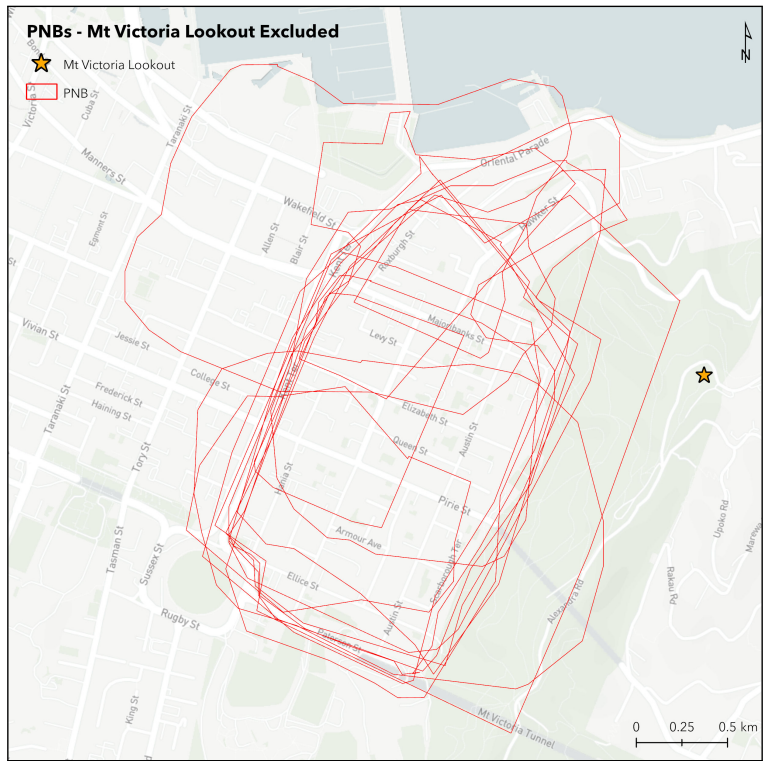

(b) Mt Victoria PNBs - Lookout Excluded

Figure 5.17: Mt Victoria PNBs with (a) and without (b) the Lookout included

Mt Victoria Lookout's clear impact on Mt Victoria PNBs indicates that for residents of Mt Victoria, the lookout functions as a landmark. The lookout affected Mt Victoria PNBs similarly to the Brooklyn Wind Turbine while not being as tall or imposing. The shared name between the lookout and Mt Victoria was influential because the lookout did not function as a landmark for residents of Hataitai and Roseneath.

\subsubsection{Wellington Airport}

Airports are another example of important man-made geographic features. Wellington Airport (Figure 5.18) is the only major airport in the Wellington region. The entire extent of the airport covers 110 hectares, with its single runway being $2.08 \mathrm{~km}$ long. Wellington Airport is located on an isthmus with the ocean to the north and south limiting development of the airport. Wellington Airport is the third busiest airport in New Zealand with 6,436,626 total passenger movements in a one-year period (Wellington International Airport, 2019). 


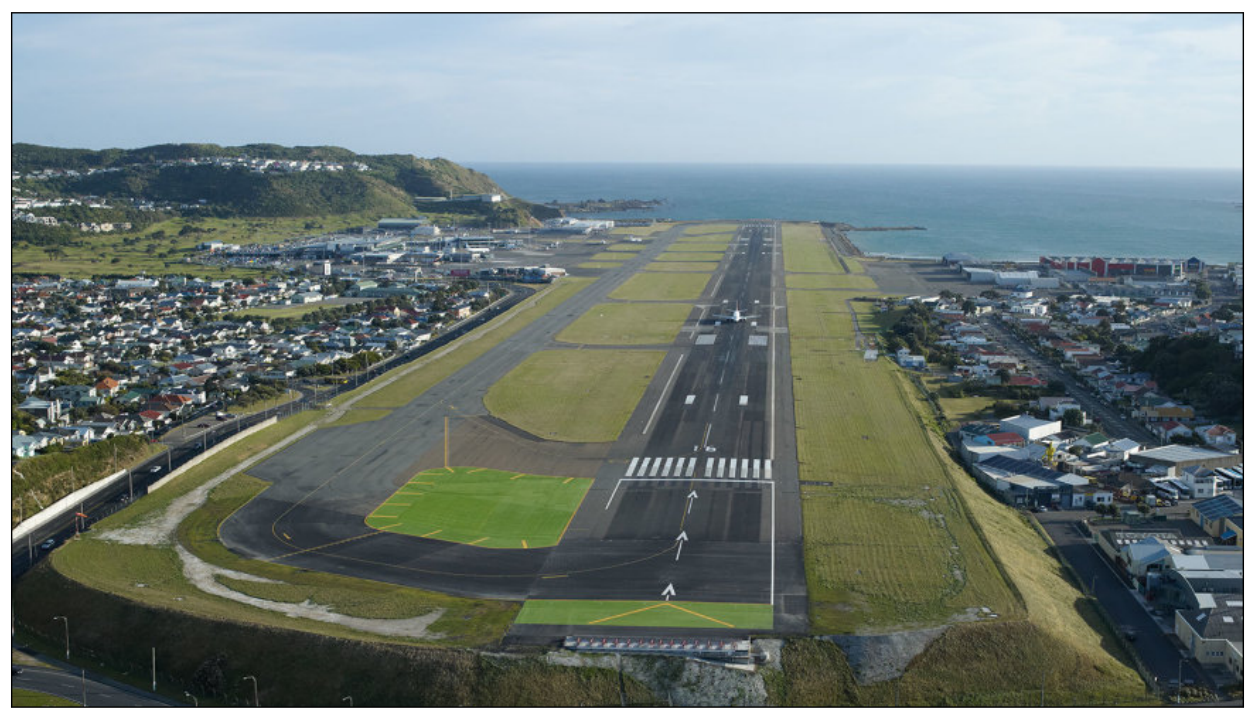

Figure 5.18: Wellington Airport. Credit: wellington.ultimate.org.nz

Wellington Airport is located east of Wellington's CBD, but, unlike other geographic features covered in this chapter, it is not considered part of any neighbourhood. Rather, it is nestled between four neighbourhoods: Kilbirnie and Lyall Bay to the west, and Miramar and Maupuia to the east (Figure 5.19). We can observe that the majority of PNBs received for the four neighbourhoods surrounding Wellington Airport did not extend into the airport's extent, but rather followed its boundary. Only 1 PNB crossed the entire extent of Wellington Airport. By separating Kilbirnie and Lyall from Miramar and Maupuia, Wellington Airport functions as an edge in participants' mental maps of their neighbourhoods. The impact Wellington Airport had on separating PNBs was more pronounced than that observed for Cambridge and Kent Terraces. This is likely a function of Wellington Airport being wider and covering a larger area than Cambridge and Kent Terraces, indicating that the size of the effect edges had on PNBs reflects the size of the respective geographic feature. 


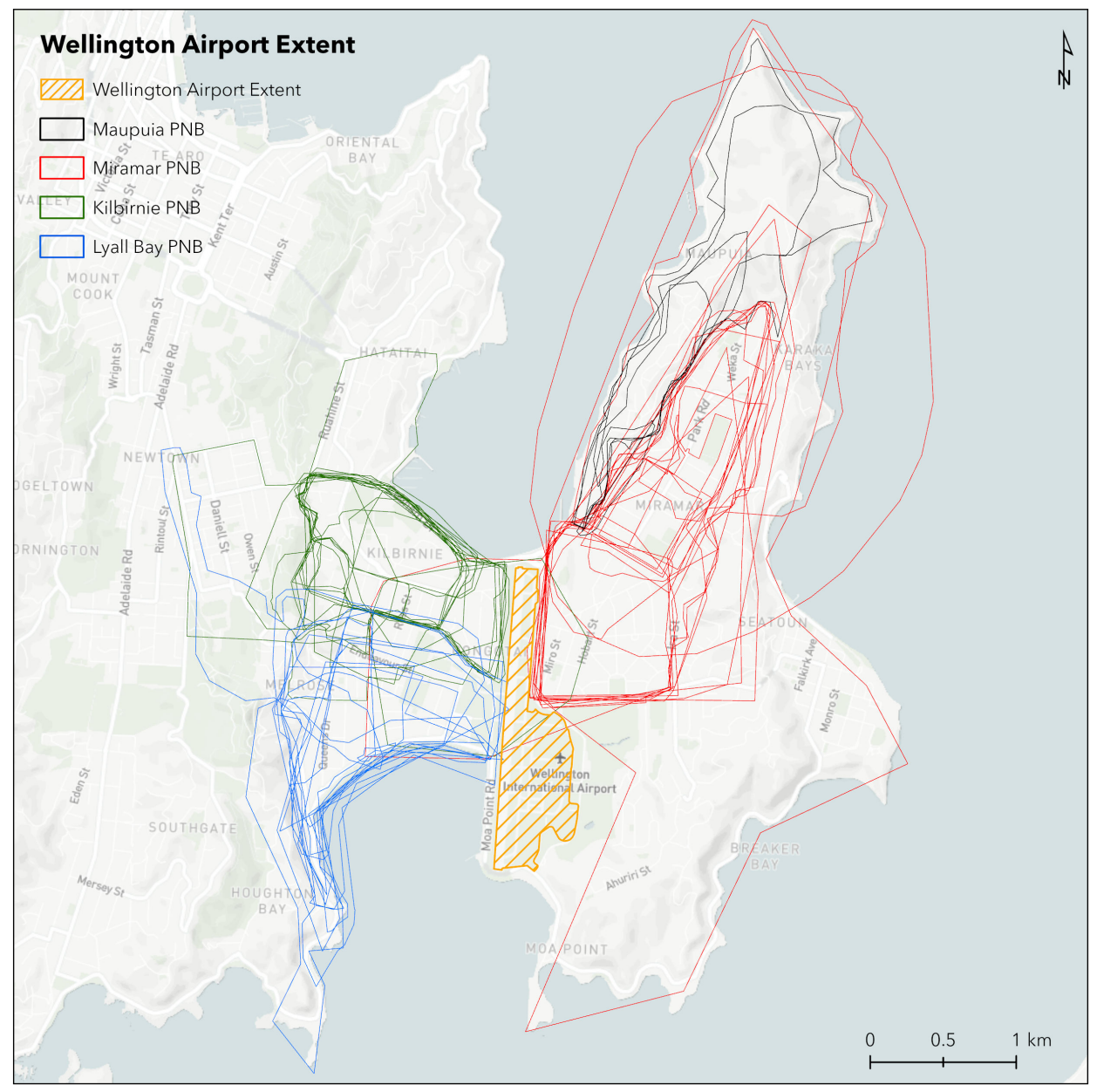

Figure 5.19: Wellington Airport Extent and Surrounding PNBs

Most of Wellington Airport's extent was one of the areas excluded from the hexagon grids in Section 4.3.2 due to not being covered by five or more PNBs (threshold value outlined in Section 3.5.3). Figure 5.20 shows Wellington Airport and consensus hexagons for the surrounding neighbourhoods. The exclusion of Wellington Airport from participants' PNBs was not likely the result of a lack of responses, as 58 responses were received for the four surrounding neighbourhoods. It was also not due to basemap biases either, as Wellington Airport was visible at most scales. Wellington Airport is a known and important location for most residents of Wellington City, being the only major airport in the region and has a well-defined, firm boundary. It is clear when an individual enters and leaves the airport. Additionally, the characteristics of Wellington Airport are distinct and different from surrounding neighbourhoods. This indicates that for neighbourhood perceptions, Wellington Airport acts as a district. The same effect can be assumed to occur for other city's major airports, although this cannot be tested in this thesis. 


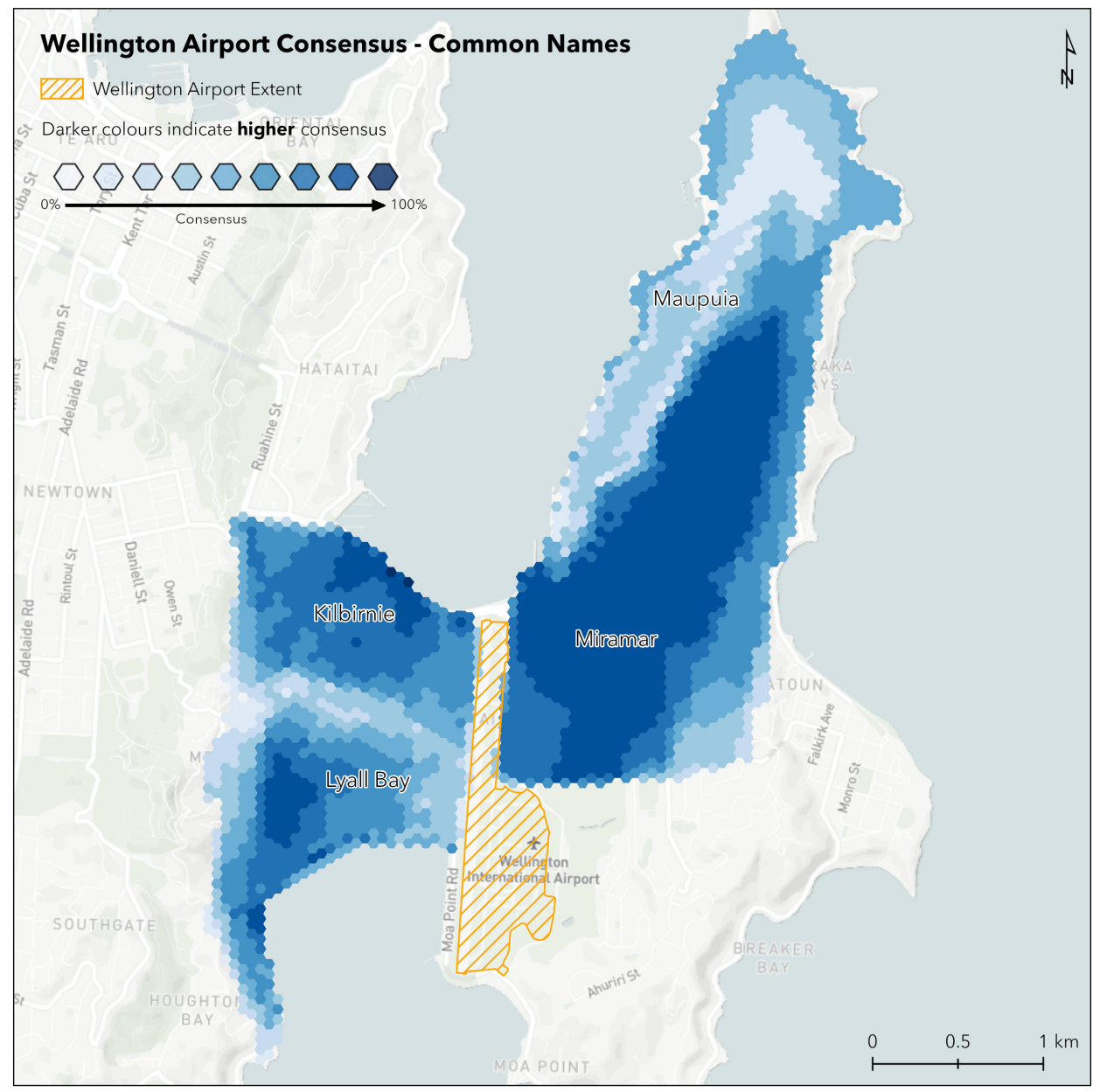

Figure 5.20: Wellington Airport and Surrounding Neighbourhood Consensus

\subsection{Natural Features}

When we consider Lynch's (1960) five elements that inform urban mental maps, natural features are common examples, even in urban areas dominated by man-made features. Case studies of green space, shorelines, and a river in Wellington City are given in this section to examine natural features' impact on neighbourhood perceptions.

\subsubsection{Wellington Botanic Gardens}

The Wellington Botanic Gardens are an example of a large area of green space that does not belong to or share a name with an existing neighbourhood. Covering 25 hectares, the Wellington Botanic Gardens (Figure 5.21) are northwest of Wellington's CBD. The botanic gardens are not considered part of any one neighbourhood, but are closely associated with the neighbourhood of Kelburn to the south. Winding trails run through the botanic gardens providing access to popular attractions, such as the succulent and rose gardens, native bush, playgrounds, and treehouse visitor centre. In 
the summer, a range of events are run in the gardens, such as live concerts and light shows.

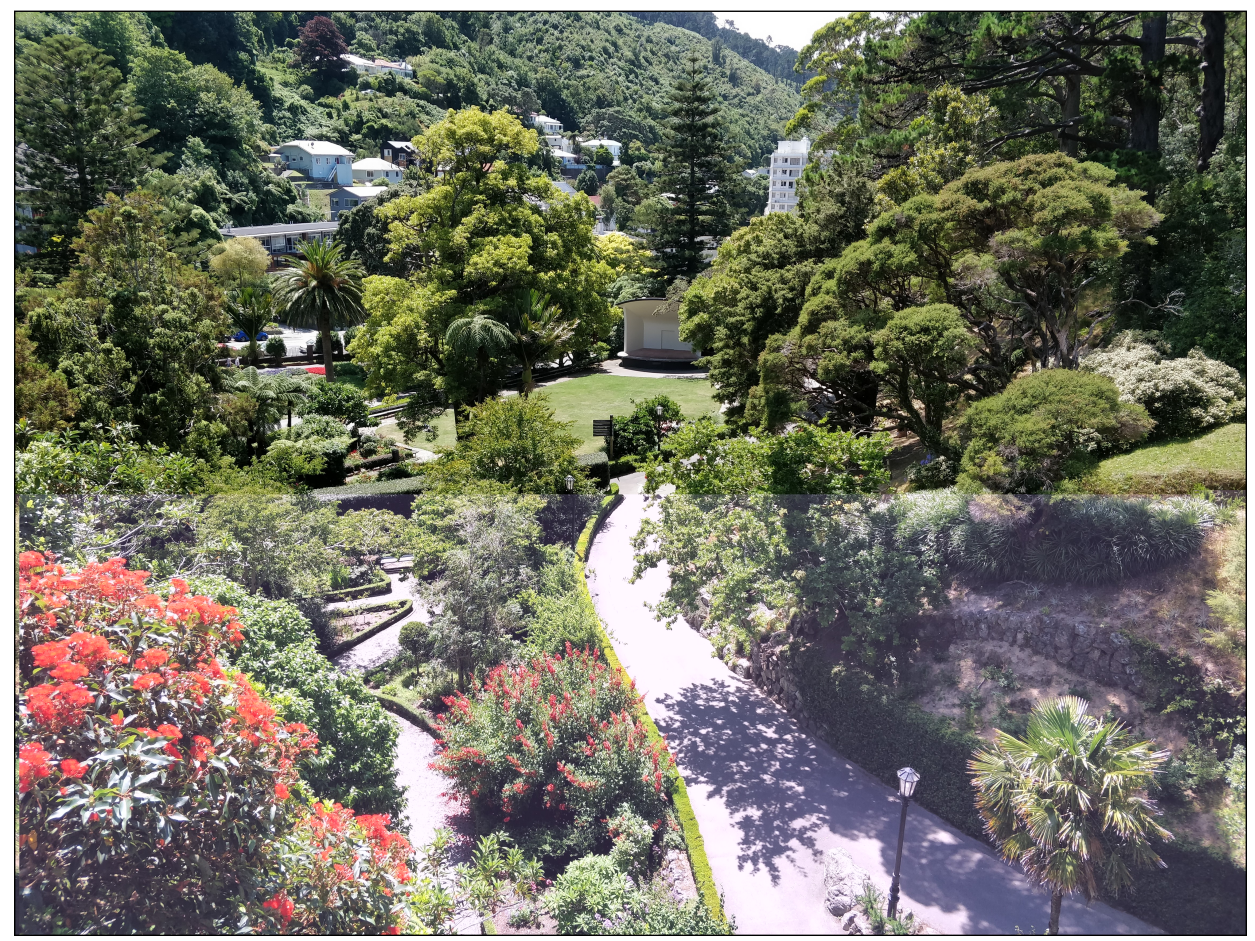

Figure 5.21: Wellington Botanic Gardens. Credit: Author's Own

28 submissions were received for Kelburn, shown in Figure 5.22 with the extent of the Wellington Botanic Gardens. Only 2 PNBs included the entire extent of the botanic gardens, with most including different sections or stopping at the botanic gardens' southern border. 10 participants delineated their PNB by following the southern border of the botanic gardens or extending their PNB into the botanic gardens a small amount. This indicates that borders of green space can function as edges in neighbourhood perceptions by forming a clear barrier between areas. None of the 28 FPs received for Kelburn were placed inside the botanic gardens, with most FPs located in the nearby Kelburn shopping hub or the Victoria University of Wellington campus. 


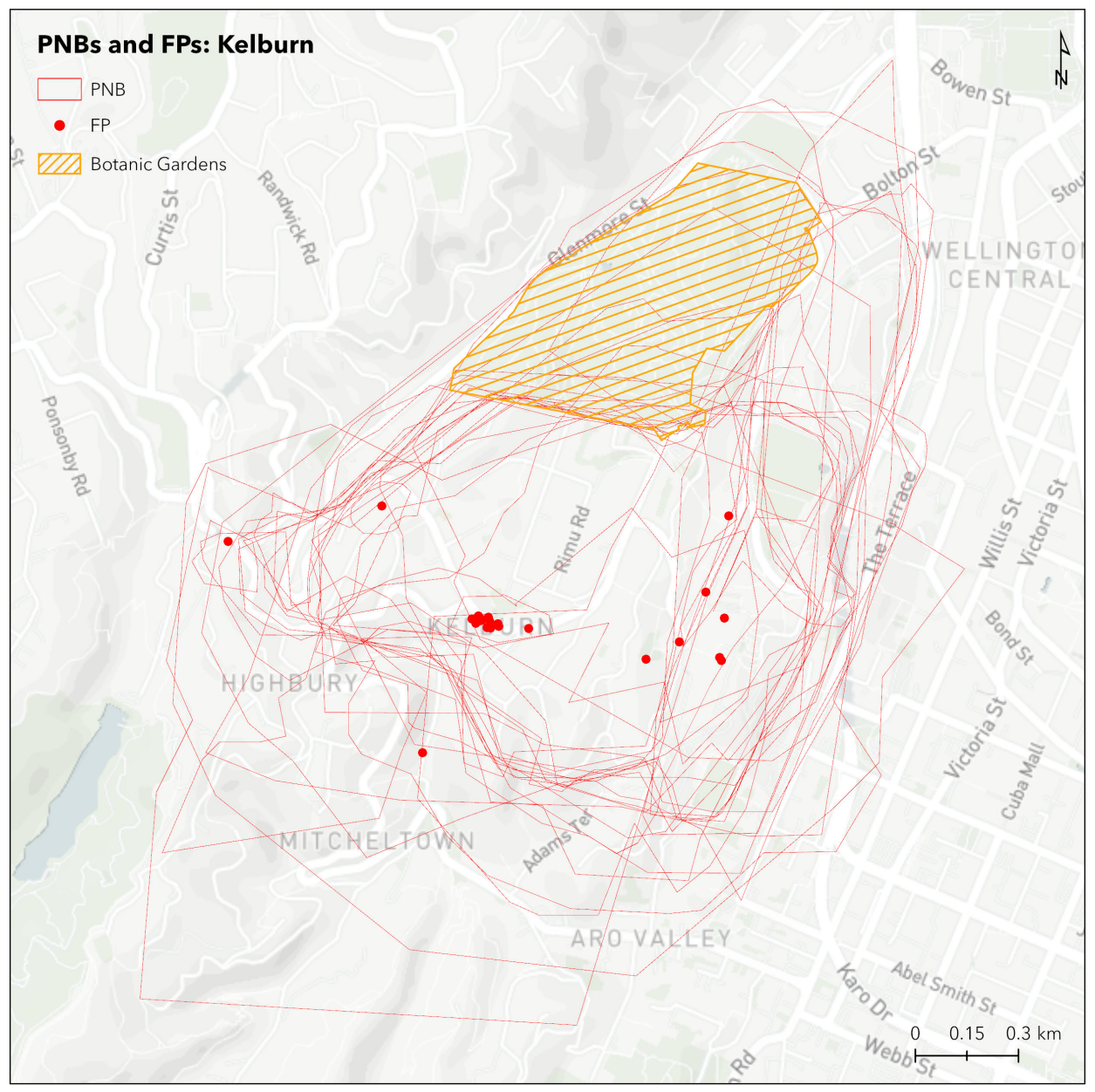

Figure 5.22: Kelburn PNBs and FPs

Green space covering large areas was also expected to have an impact on neighbourhood consensus. Figure 5.23 shows consensus for Kelburn and the Wellington Botanic Gardens using the common names method. We can observe that consensus is lower in the extent of the botanic gardens than the rest of Kelburn, with the drop beginning at the botanic gardens' southern border. Mean consensus percentages of $46.13 \%$ and $63.45 \%$ were respectively observed for the botanic gardens and Kelburn. The botanic gardens are a large area with common characteristics that individuals enter and exit, fitting Lynch's (1960) definition of a district. It is clear when an individual has entered the botanic gardens, as the environment changes significantly from residential streets to native bush and gardens. 


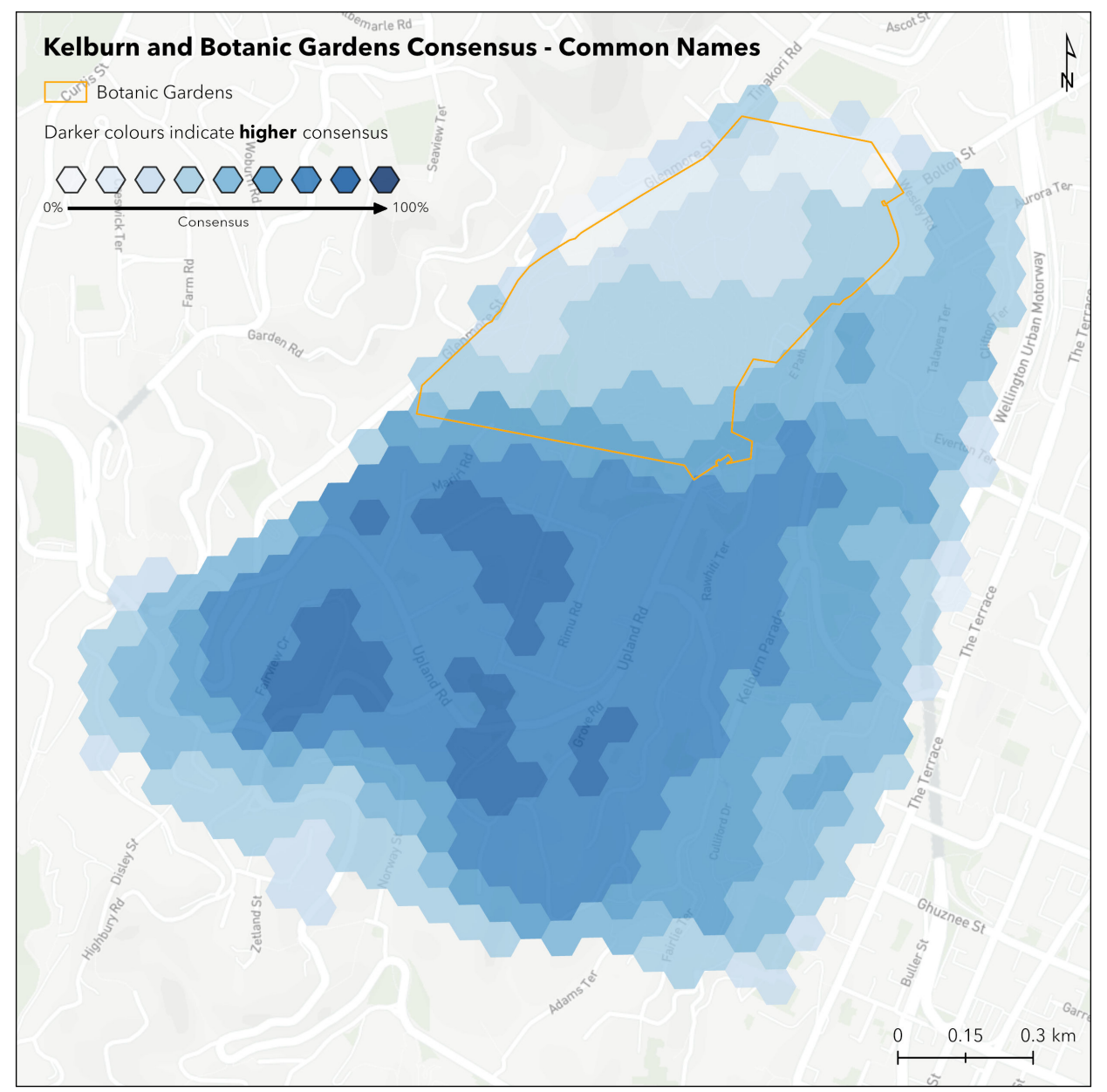

Figure 5.23: Kelburn and Botanic Gardens Consensus: Common Names

\subsubsection{Wakefield Park and the Green Belt}

Found between the neighbourhoods of Berhampore and Island Bay south of Wellington's CBD, Wakefield Park is a large area of green space containing four football fields (Figure 5.24). Wakefield Park is surrounded by Wellington's Green Belt on either side, adding to the area covered by green space between Berhampore and Island Bay. A main road (Adelaide Road) connecting Island Bay and Berhampore runs in between Wakefield Park to the east and the green belt to the west. Home to the Island Bay United football club, Wakefield Park regularly hosts football matches, training, and tournaments. The extents of Wakefield Park and the Green Belt are shown in Figure 5.25. with the park and the green belt covering 5.21 and 66.14 hectares respectively. 


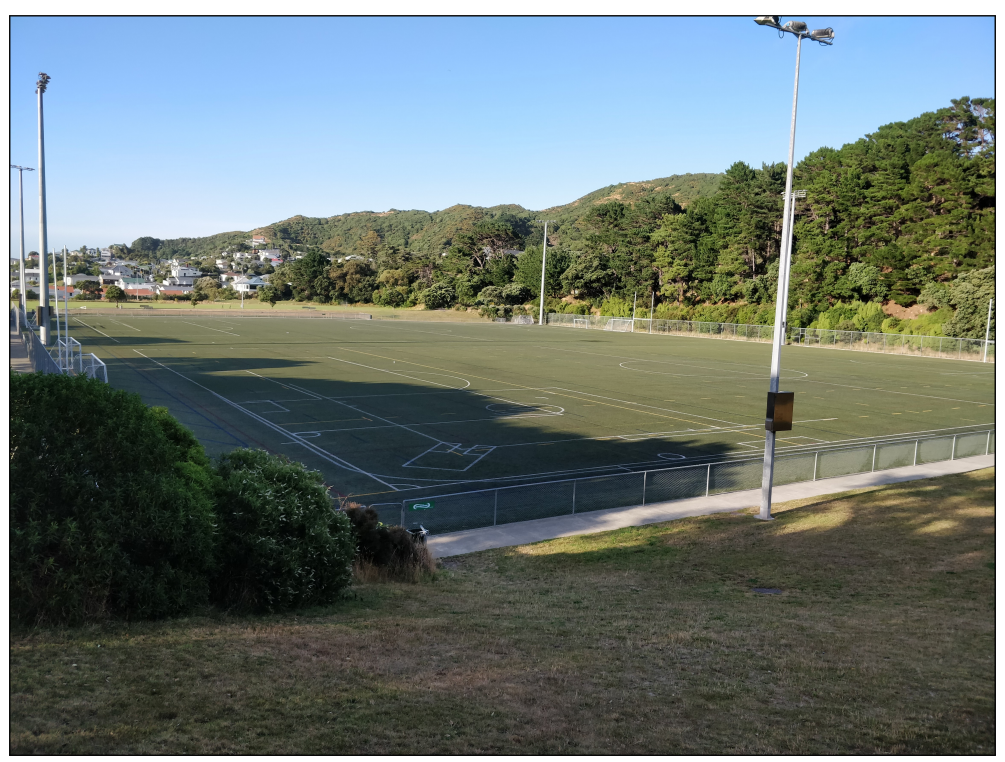

Figure 5.24: Wakefield Park. Credit: Author's Own

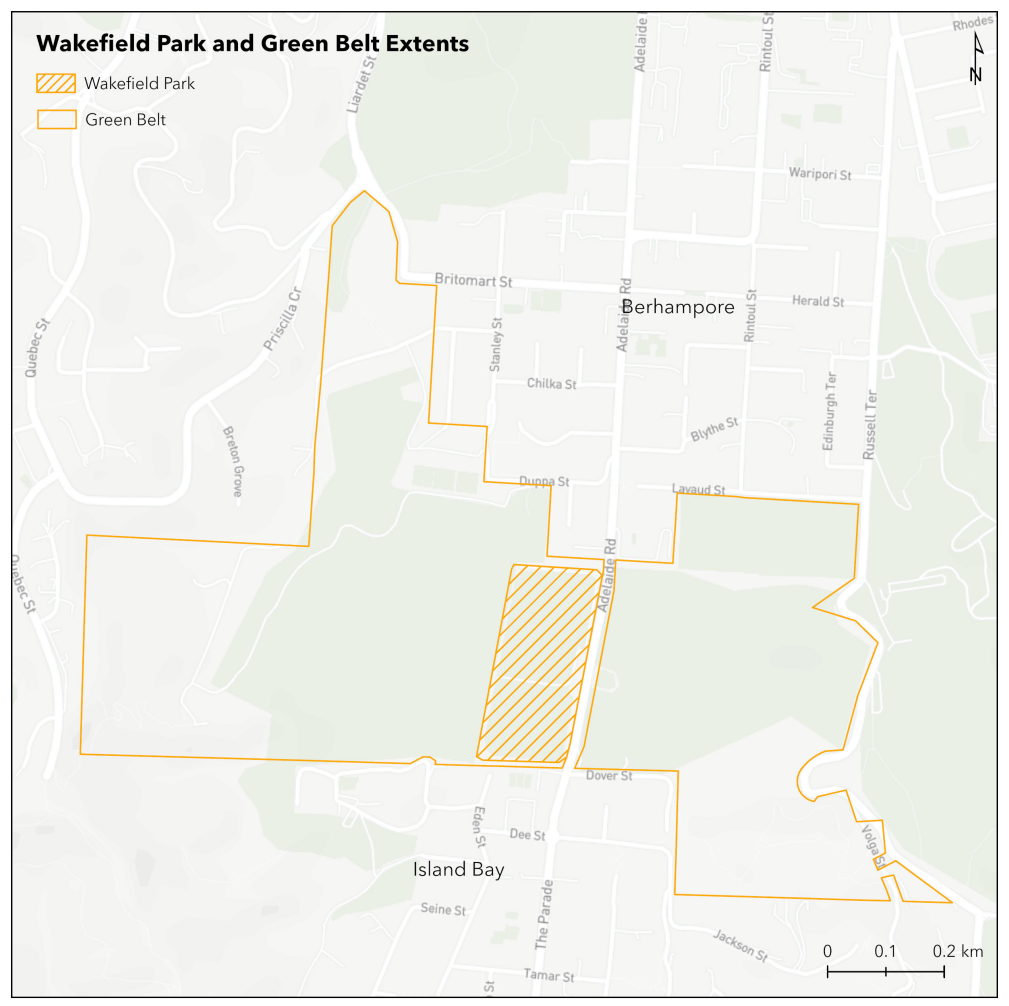

Figure 5.25: Extent of Wakefield Park and Green Belt

Island Bay and Berhampore received 32 and 19 submissions respectively, with Figure 5.26 showing their PNBs overlaid with Wakefield Park and the green belt. Only 3 PNBs received for Island Bay included all of Wakefield Park, with the majority of PNBs following the southern borders of Wakefield Park and the green belt. However, almost half of the PNBs (8) received for Berhampore 
included Wakefield Park. This effect is especially pronounced due to the sample size difference between the two neighbourhoods, indicating that Wakefield Park is more a part of Berhampore than of Island Bay. Island Bay has a stronger connection to Wakefield Park due to the Island Bay United football club using the park as a home ground making this result surprising. Consequently, we can conclude that green space functioned as different elements for neighbourhood perceptions of Island Bay and Berhampore. Wakefield Park and the green belt acted as an edge for Island Bay PNBs, but for Berhampore PNBs, they acted more like a district.

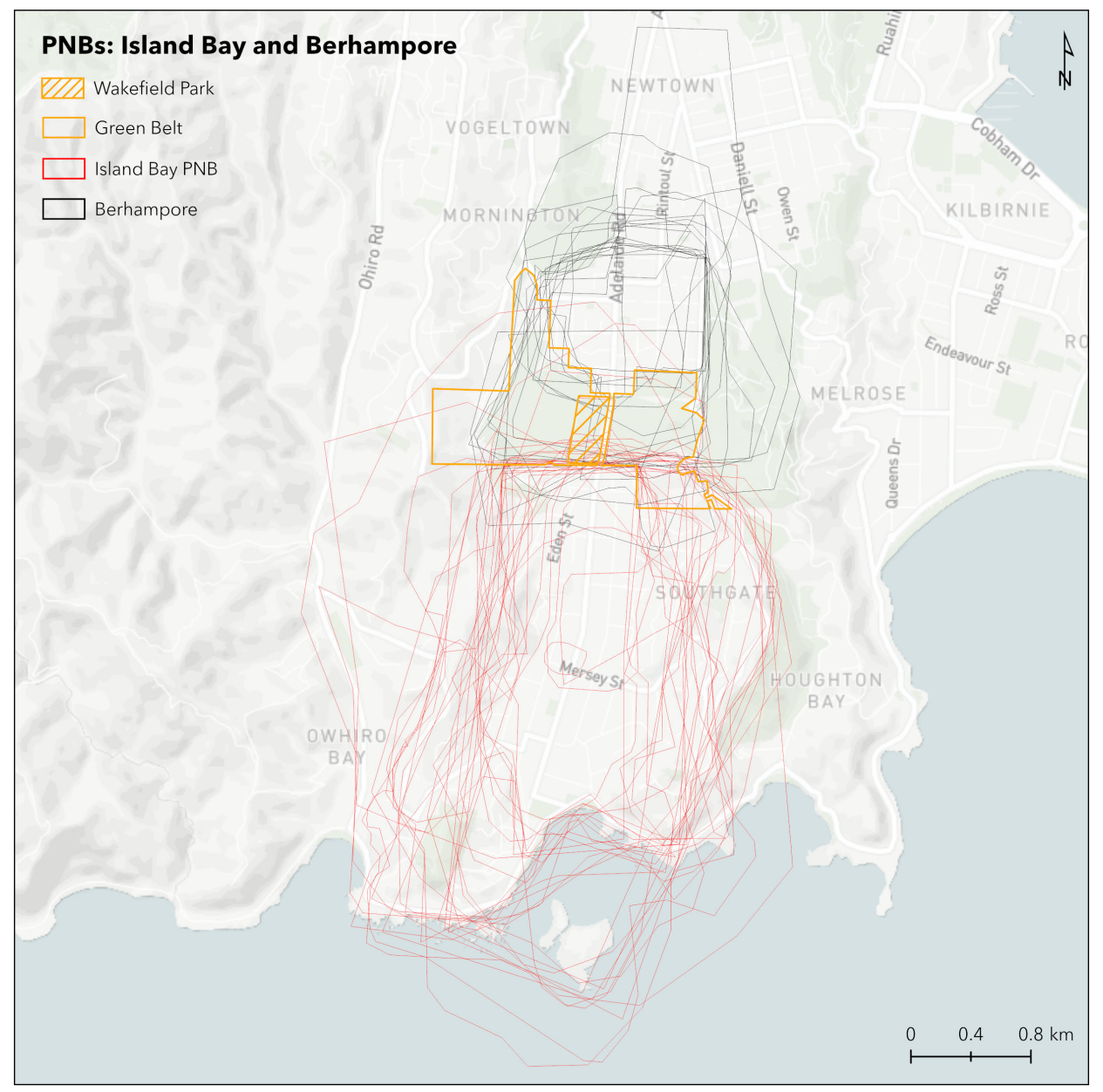

Figure 5.26: Island Bay and Berhampore PNBs Overlaid with Wakefield Park and Green Belt

Figure 5.27 shows consensus for Wakefield Park and the green belt using the common names method. We can observe that consensus falls at the north end of Island Bay where Wakefield Park and the green belt begin, and then increases moving into Berhampore. The average consensus for hexagons that intersected Wakefield Park was 53.64\% was lower than the average consensus observed for Island Bay and Berhampore (72.01\%). When compared to the consensus of hexagons that intersected with the extent of only the green belt, the average consensus for Wakefield Park only increases by $0.68 \%$ to $54.32 \%$ indicating that both the green belt and Wakefield Park had 
similar effects on neighbourhood consensus despite their different uses and sizes. This is a replication of what was observed for the Wellington Botanical Gardens, supporting the conclusion that green space of different sizes acts as contested areas between contiguous neighbourhoods.

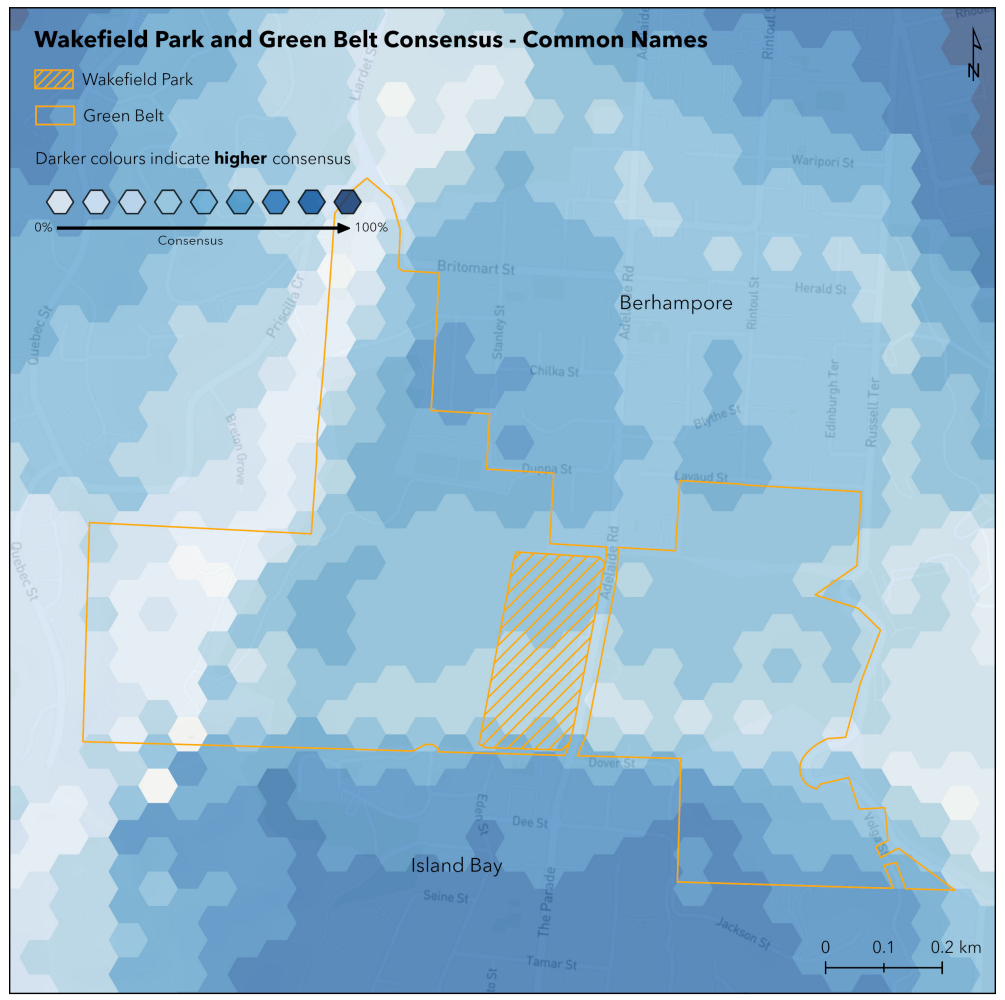

Figure 5.27: Wakefield Park Consensus

\subsubsection{Taputeranga Island}

Taputeranga Island has a different geographic context to the Brooklyn Wind Turbine and Mt Victoria Lookout, residing in the bay of Island Bay (Figure 5.28). Taputeranga Island is a small, uninhabited island covering only 3.2 hectares. The name Taputeranga is shared by the local Mara $\AA^{3}$ in Island Bay, and means a sacred rising in Māori. The island has been referred to by a variety of names in the past, such as Rat Island after the large number of rats and stoats that inhabit it, and Goat Island after a hermit that once lived on the island with goats ( The jewel that is Rat Island", 2009). The distance from Island Bay's shoreline to Taputeranga Island is 500 metres, but 1.98 kilometres separates the island from Island Bay's shopping hub. Being half a kilometre away from Island Bay's shoreline, Taputeranga Island can be accessed and explored through a short swim, kayak, or boat ride.

\footnotetext{
${ }^{3}$ Communal and Sacred Meeting Ground of Māori
} 


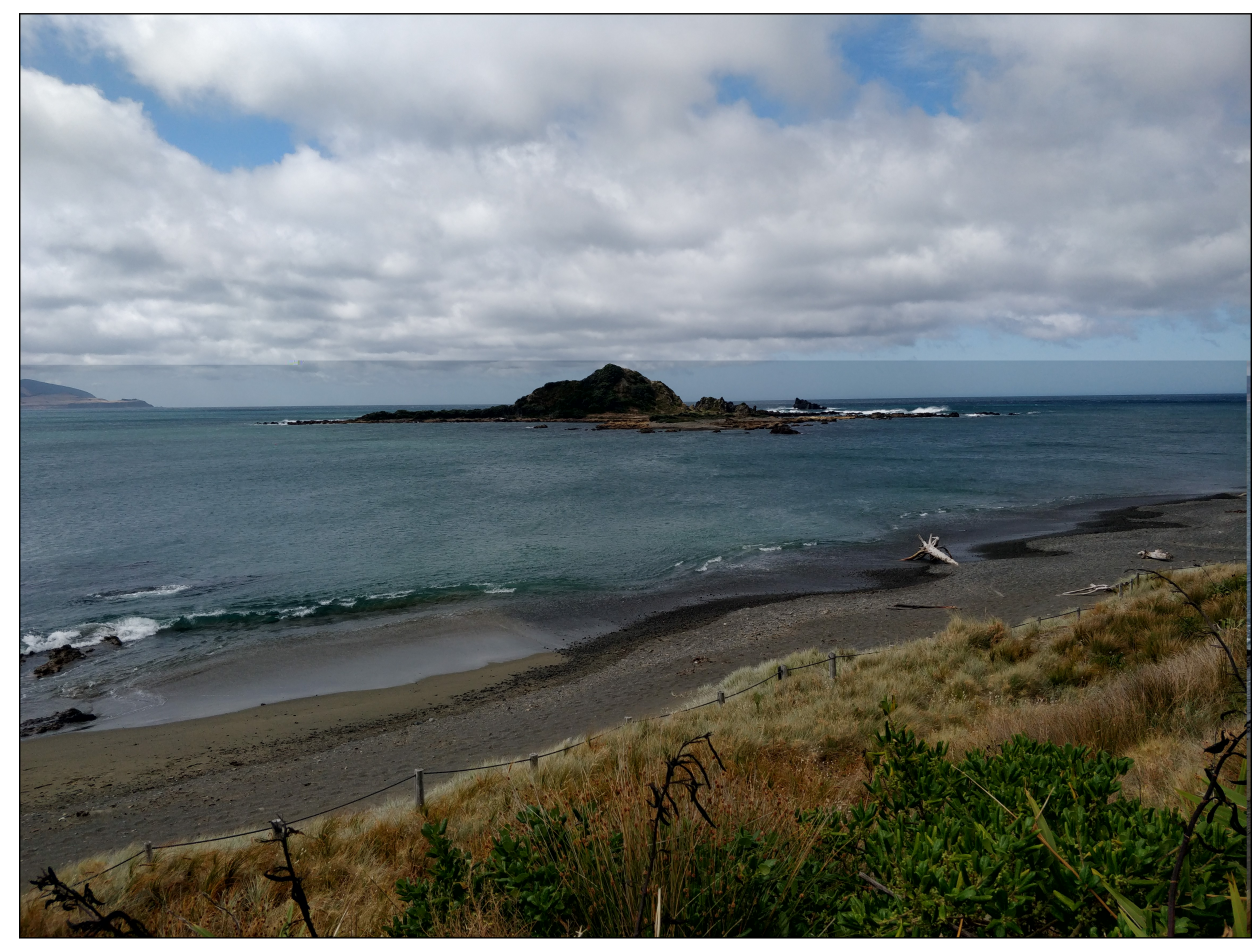

Figure 5.28: Taputeranga Island seen from Island Bay's Shoreline. Credit: Author's Own

Island Bay is a large, coastal neighbourhood with a prominent main street and shopping hub. Most of Island Bay is flat, apart from the hills in the east and west Island Bay that extends into. While Island Bay does not share Taputeranga Island's name, the neighbourhood's name is the result of the existence of Taputeranga Island in it's bay. Taputeranga Island can be seen from Island Bay's shoreline and hills in the east and west when looking towards the ocean. 33 responses were received for Island Bay, shown in Figure 5.29. 


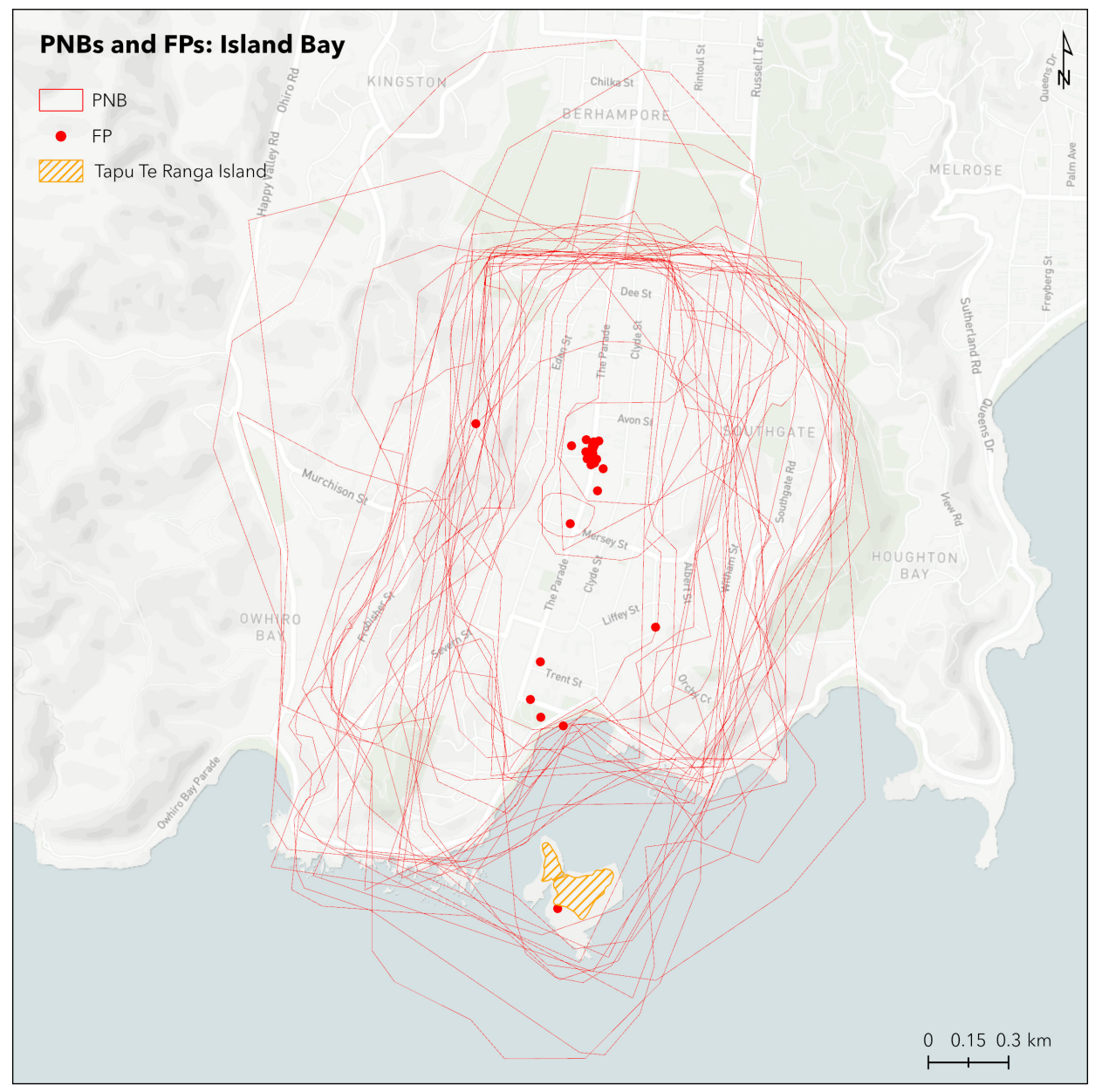

Figure 5.29: Island Bay PNBs and FPs

Even though 500 metres of water separates Island Bay from Taputeranga Island, the island still had an impact on participants' PNBs. Taputeranga Island was included by a third (11) of the PNBs received for Island Bay. Figure 5.30 shows PNBs that included (a) and excluded (b) Taputeranga Island. We can observe that PNBs that included Taputeranga Island extended further out into the ocean than PNBs that excluded it, roughly delineating what could be the extent of the bay of Island Bay. PNBs of participants that excluded Taputeranga Island roughly followed Island Bay's shoreline. This is another replication of the effect observed for the Brooklyn Wind Turbine and Mt Victoria Lookout, with Taputeranga Island causing a clear difference in PNBs observed for Island Bay. However, compared to the Brooklyn Wind Turbine and Mt Victoria Lookout, Taputeranga Island's name is not directly associated with Island Bay's name; only the island itself is. Additionally, one participant placed their FP on Taputeranga Island indicating Taputeranga Island was also seen as a viable FP despite its relative accessibility and lack of shopping hub. 


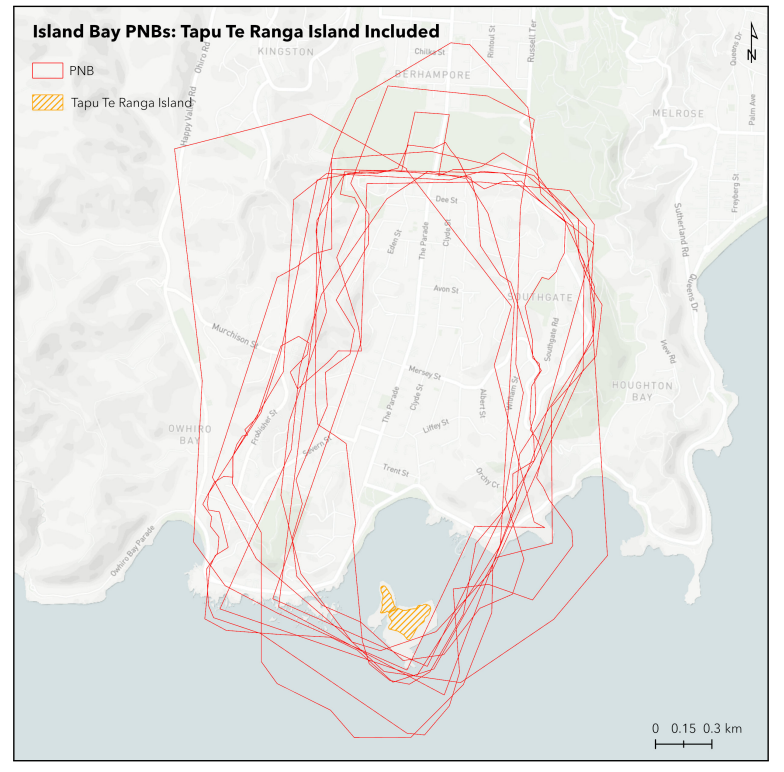

(a) Island Bay PNBs - Taputeranga Island Included

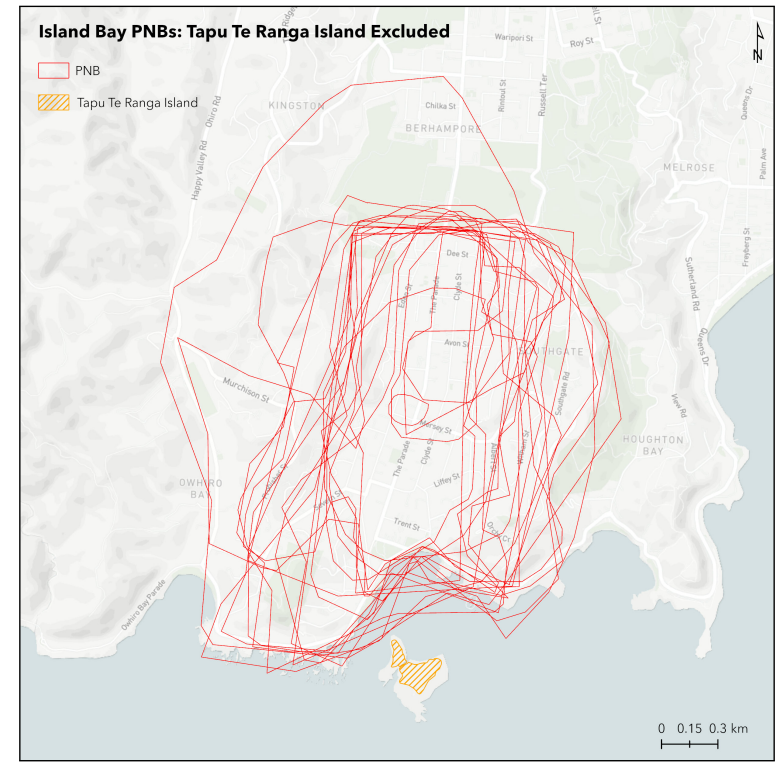

(b) Island Bay PNBs - Taputeranga Island Excluded

Figure 5.30: Island Bay PNBs with (a) and without (b) Taputeranga Island included

From the impact of PNBs received for Island Bay, it is clear that Taputeranga Island functioned as a landmark for these participants. The island is separated from the rest of the neighbourhood by hundreds of metres of water, can be observed from most points of Island Bay's shoreline, and has a strong association with Island Bay's name.

\subsubsection{Shorelines}

Edges are one of Lynch's (1960) five elements that inform mental maps of urban areas. Edges are continuous boundaries separating two areas. Being a coastal city with various types of shorelines, Wellington City is an excellent city to examine the impact of shorelines on individual's neighbourhood perceptions. Case studies of three neighbourhoods' shorelines will be given in this section: Lyall Bay, Petone, and Island Bay. It is hypothesised shorelines will function as edges by separating neighbourhood areas from the ocean.

\section{Lyall Bay}

Lyall Bay is a coastal neighbourhood east of Wellington's CBD. The main feature of Lyall Bay is its long, sandy beach popular for its surf and ability to walk dogs on (Figure 5.31). Lyall Bay's beach is 1.4 kilometres long, while the entire shoreline spans 4 kilometres extending to the airport runway to the east and Houghton Bay to the southwest. Numerous cafes are dotted along Lyall Bay's shoreline offering views of the beach and plane watching at Wellington Airport. 


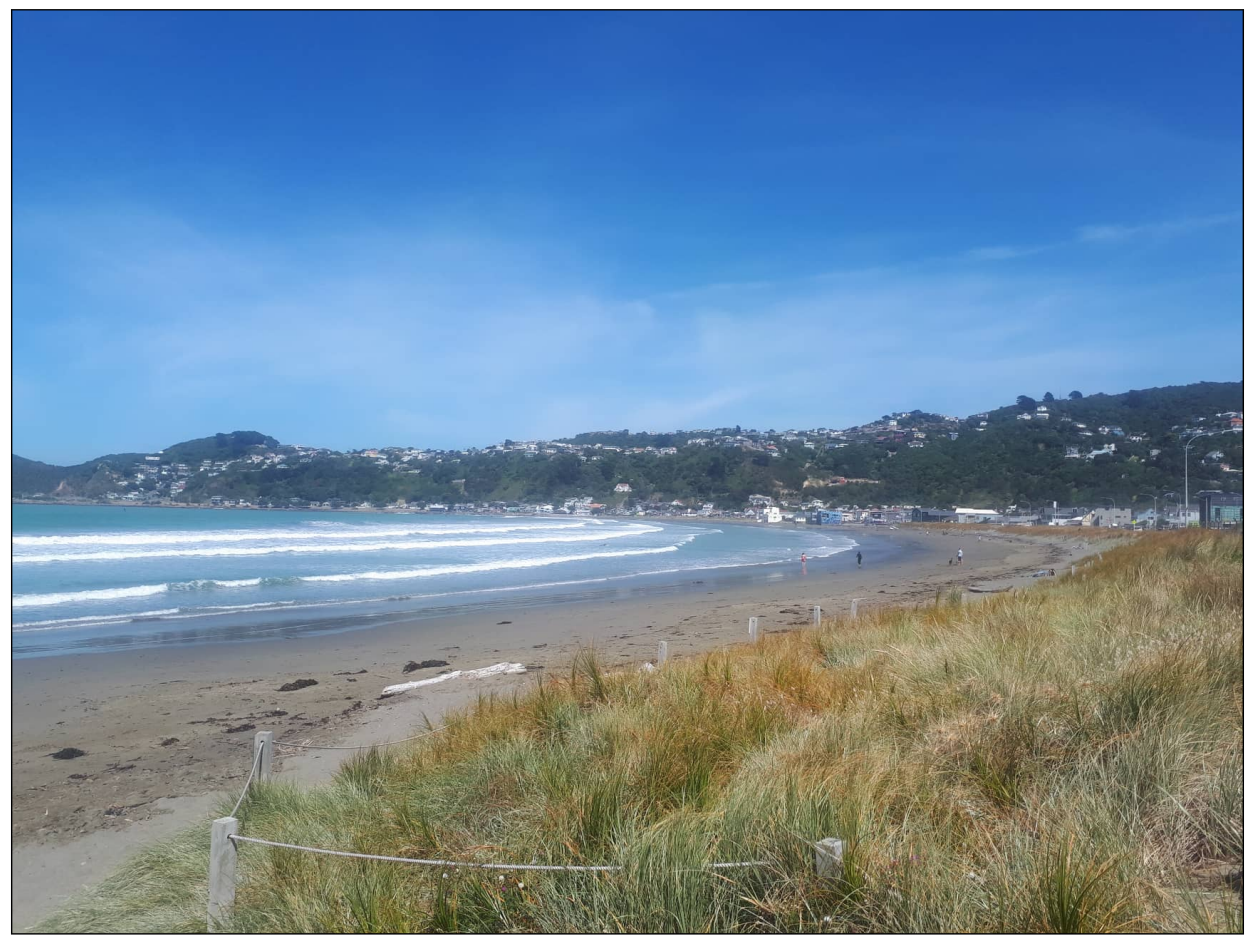

Figure 5.31: Lyall Bay Beach. Credit: Author's Own

15 submissions were received for Lyall Bay, shown in Figure 5.32, All PNBs received for Lyall Bay included the shoreline to some extent. The southern borders of most of Lyall Bay's PNBs were guided by the shoreline in part or in full. Rather than extending into the ocean, most PNBs followed the shoreline closely. This supports the conclusion that shorelines act as an edge by being a boundary for participants' neighbourhood delineations. However, rather than separating two neighbourhoods, Lyall Bay's shoreline separated it from the ocean. 


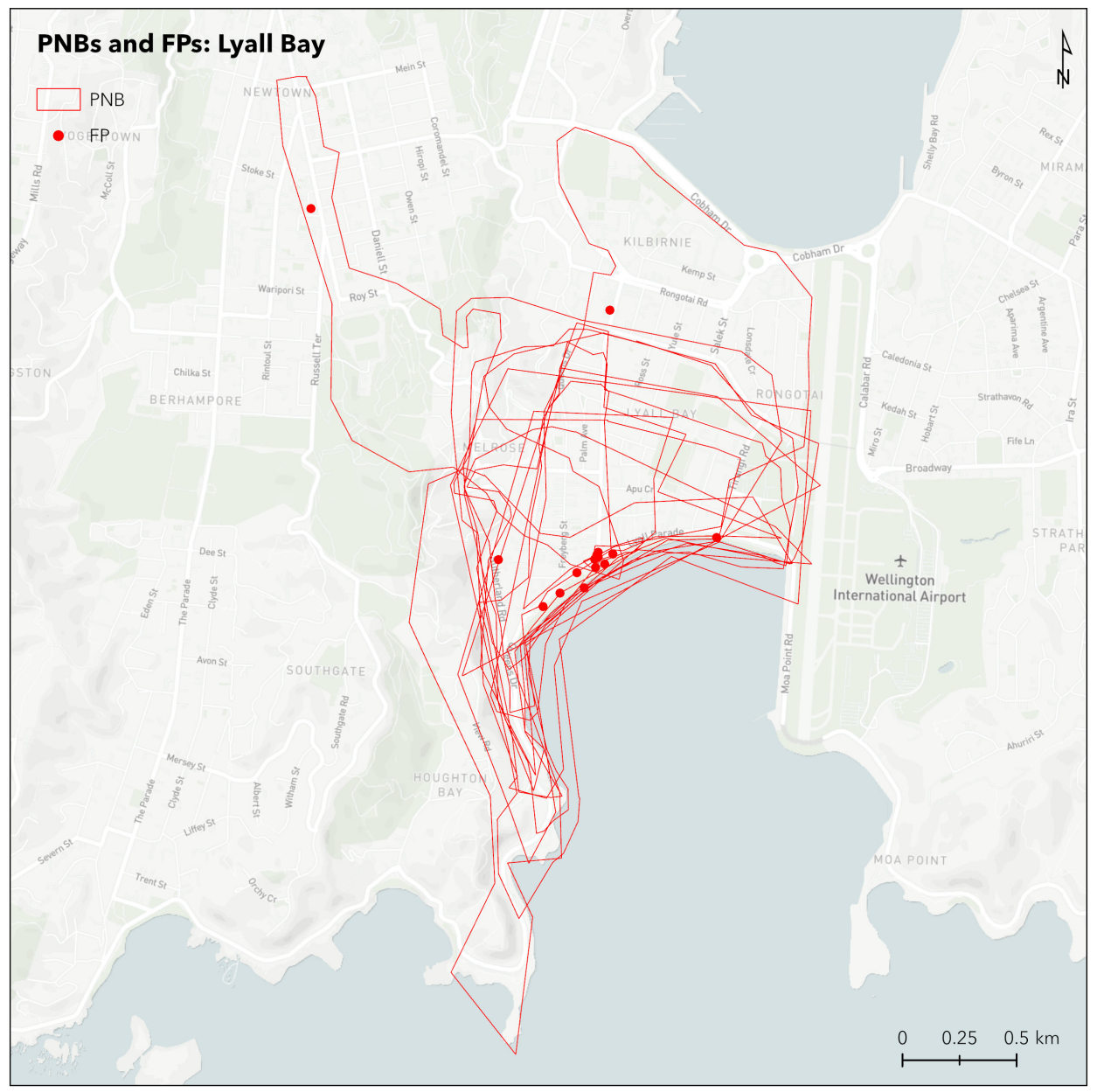

Figure 5.32: Lyall Bay PNBs and FPs

While Lyall Bay's shoreline impacted PNBs, it was also the focus of the neighbourhood for most participants. Out of the 15 submissions received for Lyall Bay, 12 participants placed their FPs on Lyall Bay's shoreline. While partly the result of Lyall Bay not having a significant shopping hub (Section 4.3.3), it reflects the importance of Lyall Bay's shoreline among participants. As a result, we can conclude that Lyall Bay's beach and shoreline functioned as a node in neighbourhood perceptions. The beach is a large, popular area individuals can can enter and walk around, and it is the focus of Lyall Bay.

\section{Petone}

North of Wellington's CBD, Petone is a large neighbourhood on the northern shore of Wellington harbour (Figure 5.33). Petone's shoreline runs for 3.6 kilometres, with much of it a sandy beach. Running parallel to almost the entire shoreline is a major road called the Esplanade, connecting Petone to the state highway to the west and the Hutt River to the east. A third of the way down the shoreline from the motorway lies the Petone wharf, which is used for recreational purposes and ferry trips. 


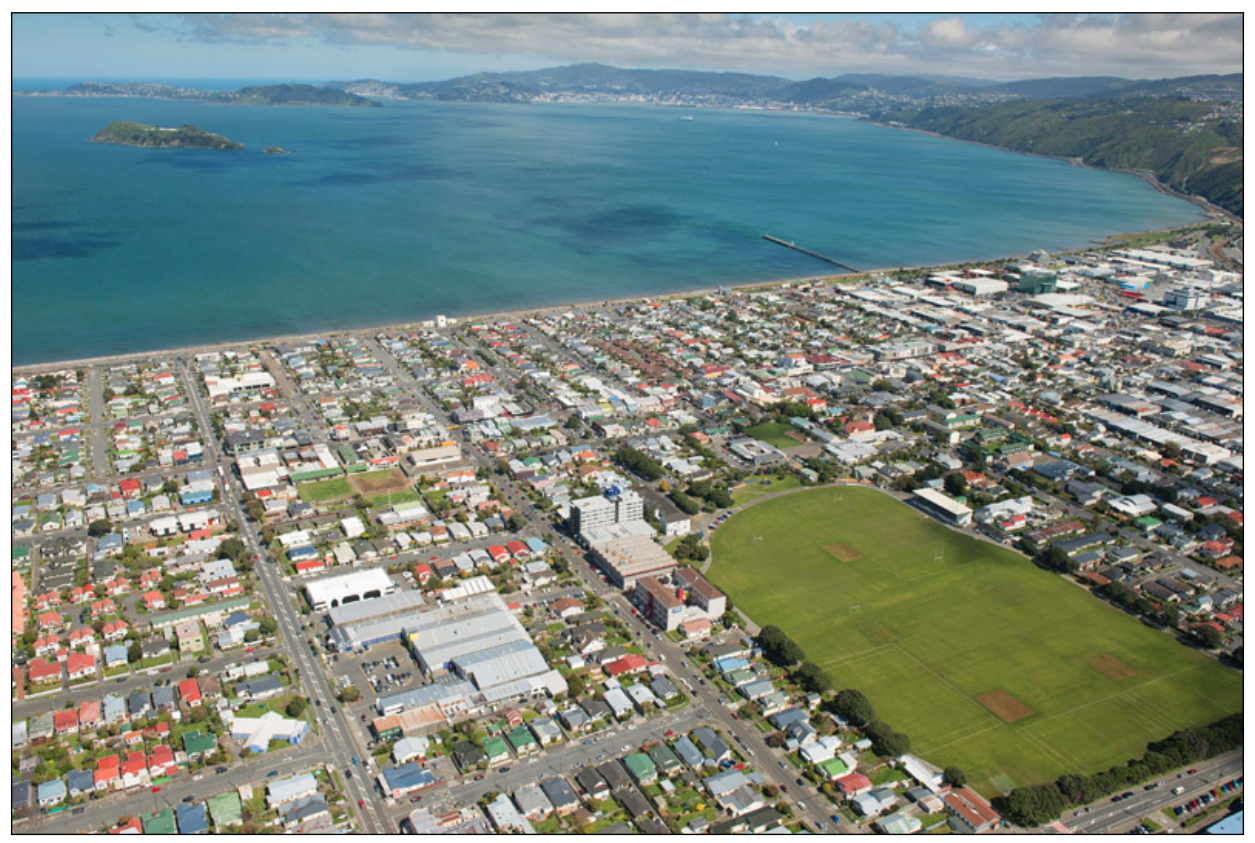

Figure 5.33: Petone seen from above. Credit: isenz.com

7 responses for Petone were received, shown in Figure 5.34; a smaller sample size than neighbourhoods described in other case studies. The combined effect of the shore and the Esplanade running parallel to it caused the southern borders of all the PNBs received to follow them to some extent. 5 PNBs covered all of Petone's shoreline, which is bordered by the state highway to the west and the Hutt River to the east. As a result, we can conclude that Petone's shoreline and the Esplanade both function as edges, as together they form a boundary between Petone and Wellington harbour. Compared to Lyall Bay, no FPs received for Petone were placed on or nearby the shoreline, likely due to Petone's shopping hub and main street, where 6 of the 7 FPs were placed. 


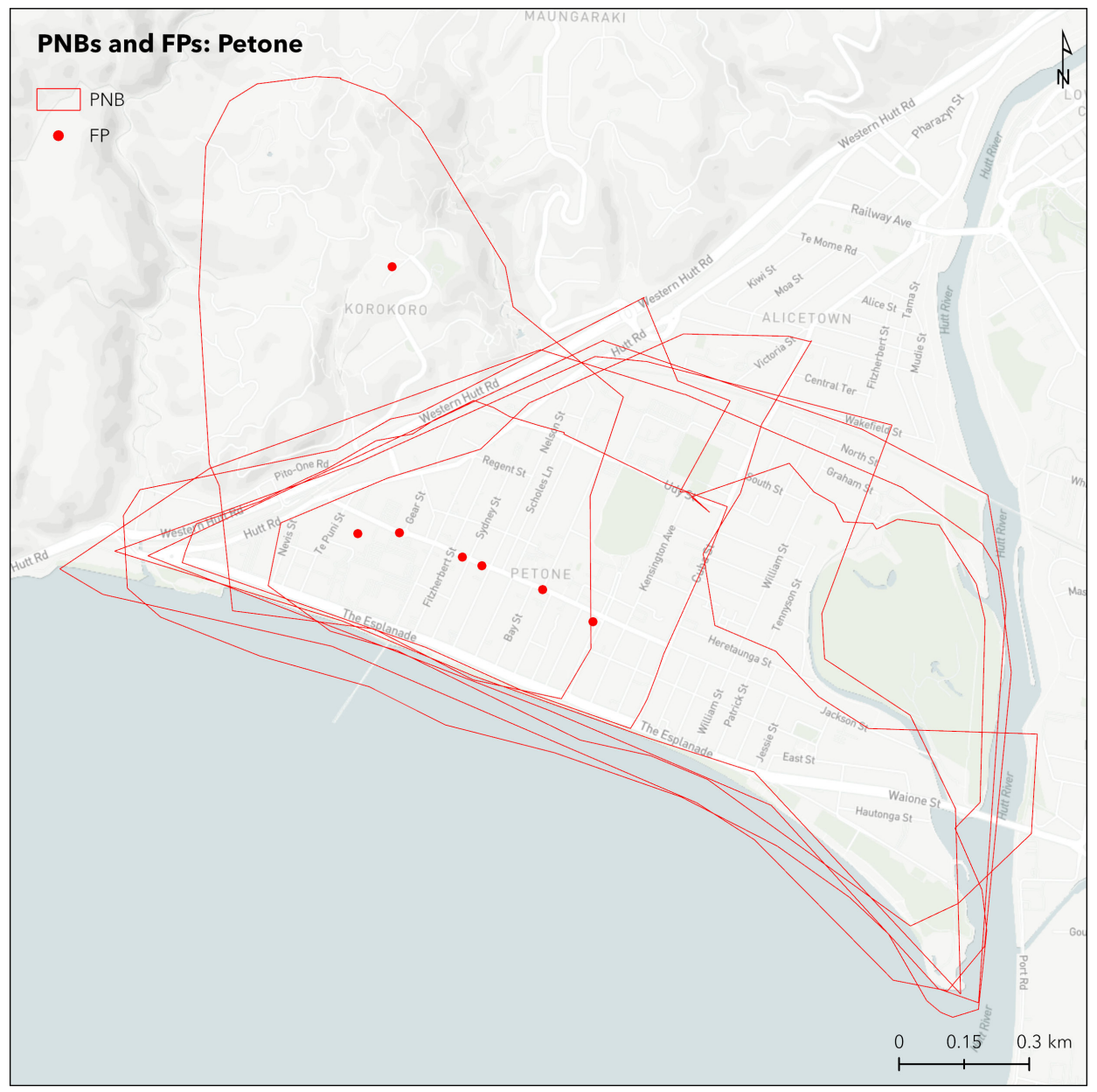

Figure 5.34: Petone PNBs and FPs

\section{Island Bay}

Another neighbourhood's shoreline with a different geographic context, but still impacted neighbourhood delineation was that of Island Bay's. Background on Island Bay has already been provided in Section 5.3 .3 for Taputeranga Island. The shoreline of Island Bay is 2.3 kilometres long, comprised mostly of rocky outcrops, while the beach is only 712 metres long and is sandy. As opposed to Lyall Bay, Island Bay is not known for its surfing or swimming due to large enough waves being obstructed by Taputeranga Island and one of the coldest water temperatures of beaches in Wellington.

Taputeranga Island impacted a third of Island Bay's PNBs, as they extended into the ocean to include the island (Figures 5.29 and 5.30). However, for the other two thirds of PNBs that excluded Taputeranga Island, the shoreline was influential with a similar effect observed to Lyall Bay and Petone. Most PNBs followed Island Bay's shoreline closely all the way to Owhiro Bay to the west and Houghton Bay to the east. Even in the presence of a significant landmark, Island Bay's shoreline functioned as an edge and influenced most participants' neighbourhood delineations. 


\subsubsection{Hutt River}

Wellington City is devoid of rivers, apart from the Hutt River which runs north of the city (Figure 5.35). The river flows from the Southern Tararua ranges for $56 \mathrm{~km}$ throughout the Hutt Valley, and deposits into the Wellington harbour east of Petone. A state highway runs alongside almost the entirety of the Hutt River, with bridges providing access to neighbourhoods the river blocks off. Figure 5.36 shows the relevant extents of the Hutt River and State Highway.

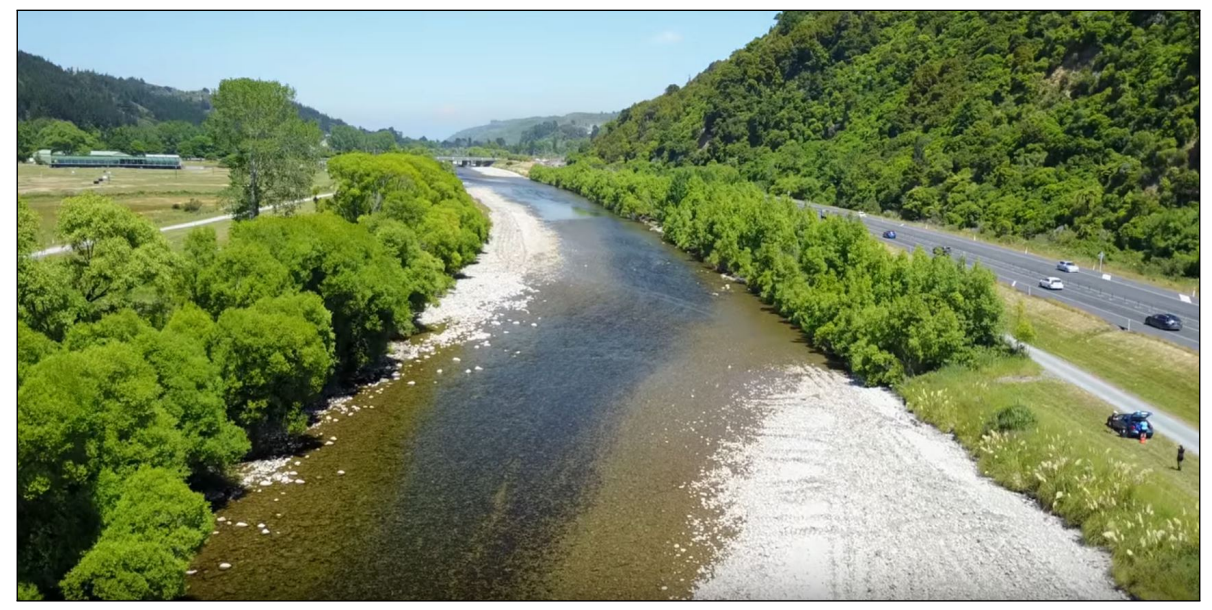

Figure 5.35: The Hutt River. Credit: Greater Wellington Regional Council

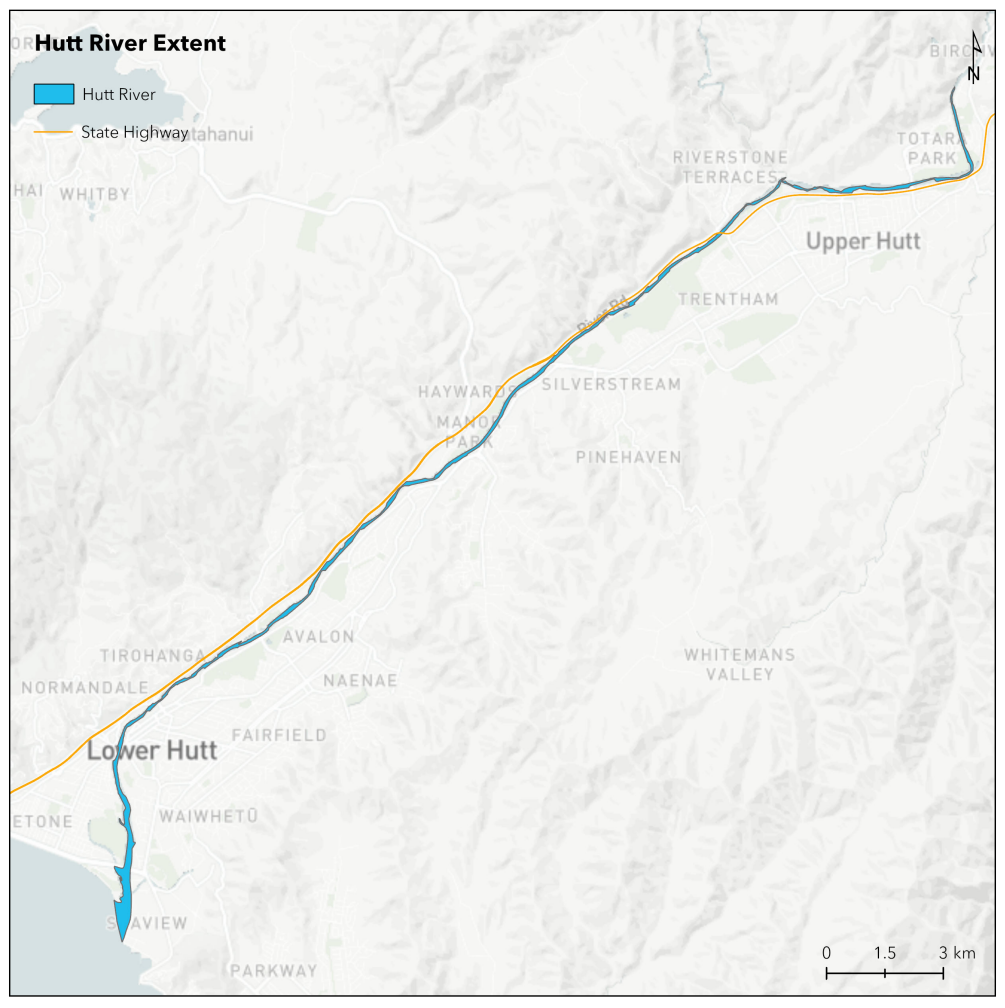

Figure 5.36: Extent of the Hutt River 
At the north end of the Hutt River, Totara Park is a small neighbourhood bordered by the Hutt River to the south and east. 10 submissions were received for Totara Park, shown in Figure 5.37. Totara Park is only accessible by car via a bridge to the south crossing the Hutt River from the adjacent highway. From visual inspection, we can observe that most PNBs received for Totara Park were influenced by the Hutt River to the south and the east, with only one PNB crossing the river entirely, and no PNBs extending into adjacent neighbourhoods across from the Hutt River. This supports the conclusion that the Hutt River functioned as an edge in neighbourhood perceptions by forming barriers between areas in individuals' mental maps (Lynch, 1960). A patch of green space is found prior to the Hutt River, as well as a state highway running parallel to it. The majority of PNBs extend past the green space and do not reach the state highway, indicating that for participants who provided data on Totara Park, the Hutt River was more influential than both green space and a highway.

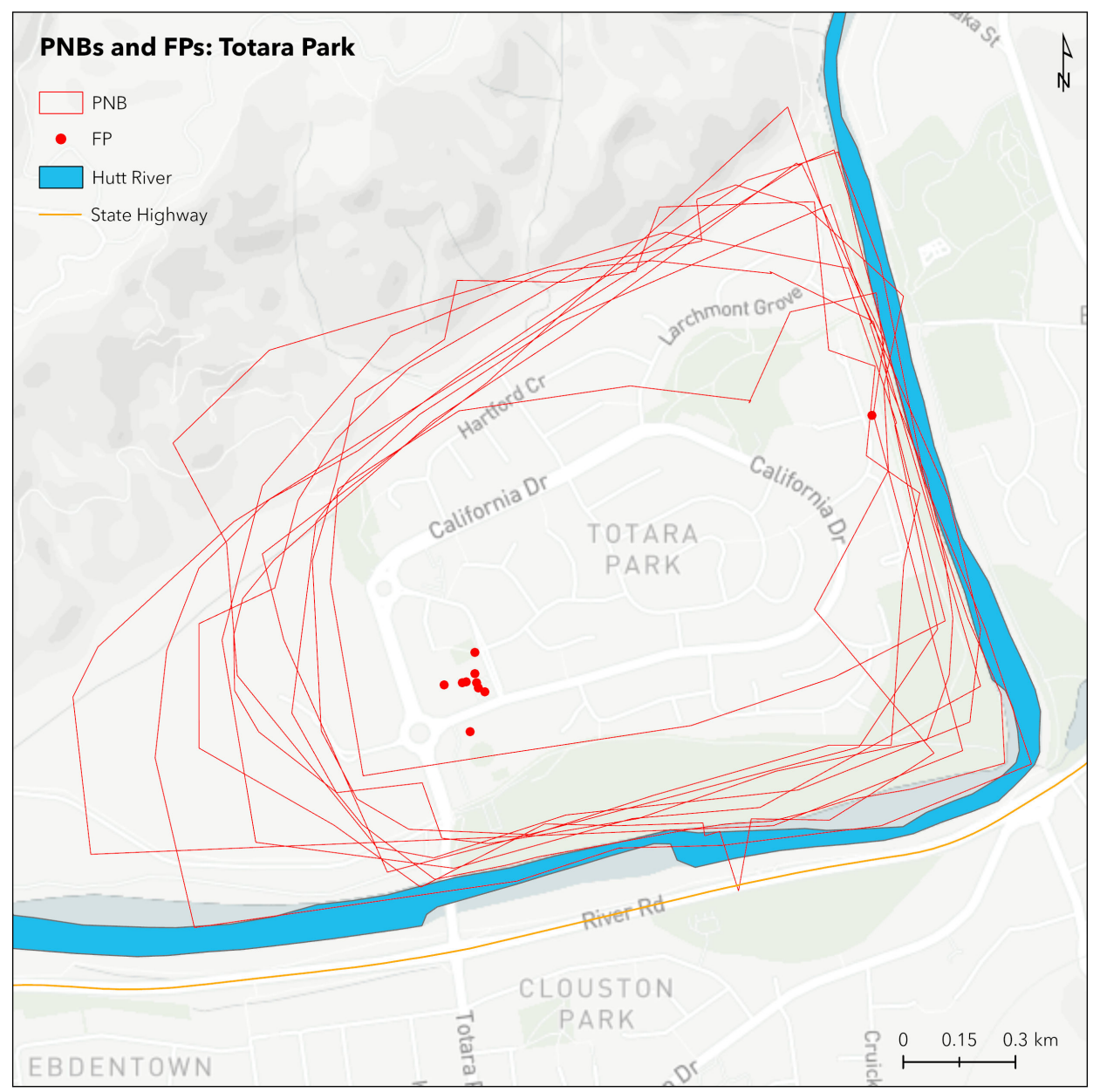

Figure 5.37: Totara Park PNBs and FPs

Neighbourhood consensus hexagons are shown for Totara Park in Figure 5.38. To the south of Totara Park where the Hutt River and State Highway lie, consensus falls. Consensus for the 
hexagons that intersected the Hutt River were lower than for the rest of Totara Park, with mean consensus percentages of $61.98 \%$ and $84.48 \%$ observed respectively. This is a replication of the effect observed for the Wellington Botanic Gardens, demonstrating that the Hutt River functioned as an edge for neighbourhood delineation.

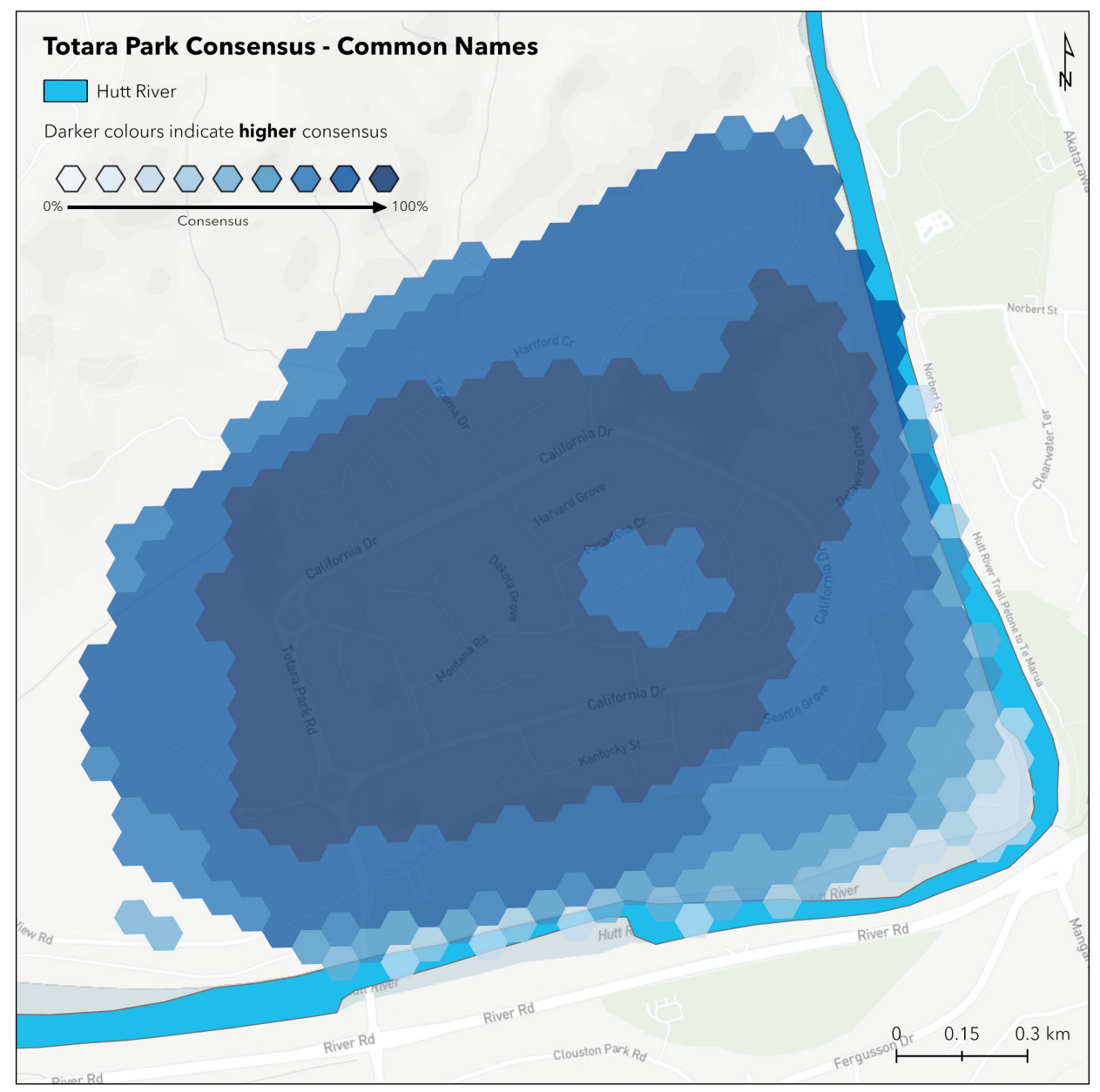

Figure 5.38: Totara Park Consensus

\subsection{Summary}

This chapter examined case studies of 13 different geographic features to examine how they fit into the five elements that inform mental maps outlined by Lynch (1960), and their on impact neighbourhood delineation. Table 5.2 lists Lynch's five elements and the fit for each geographic feature. The case studies covered in this chapter are only a snapshot of geographic features that could be used, with examples of others including canals, bridges, and lakes. Case studies of other geographic features would be made possible if the crowdsourced neighbourhood survey was run in another city with its own set of geographic features. 


\begin{tabular}{|ll|}
\hline Element & Geographic Feature \\
\hline Path & Cambridge \& Kent Terrace, Karori Tunnel \\
& \\
Edge & $\begin{array}{l}\text { Cambridge \& Kent Terrace, Karori Tunnel, Wellington Airport, } \\
\text { Botanic Gardens, Wakefield Park \& Green Belt, Lyall Bay, Petone, } \\
\text { Island Bay, Hutt River }\end{array}$ \\
District & Wellington Airport, Botanic Gardens, Wakefield Park \& Green Belt \\
Node & Cuba Street, Lyall Bay \\
Landmark & Brooklyn Wind Turbine, Mt Victoria Lookout, Taputeranga Island \\
\hline
\end{tabular}

Table 5.2: Case Studies and Lynch's (1960) Five Elements 


\section{Chapter 6}

\section{Discussion}

\subsection{Introduction}

This chapter discusses the outcomes of analysis performed on the neighbourhood delineations crowdsourced from residents of Wellington City. The impact of personal characteristics of neighbourhood delineation are examined and compared to existing literature. Conclusions about overlapping neighbourhood geographies are made based on the consensus hexagon grids and models of neighbourhood connectivity. Similarities and differences between crowdsourced neighbourhood delineations and official representations are discussed, and recommendations are made for official boundaries. The case studies of geographic features are reviewed using the framework of Lynch's (1960) five elements of urban mental maps. Finally, benefits and drawbacks of using a crowdsourcing approach to collect neighbourhood delineations are discussed, alongside implications for the localities dataset.

\subsection{Personal Characteristics}

Understanding how different demographics of individuals define their neighbourhood is important as it can explain variation in the wide variety of ways individuals perceive their neighbourhoods. Individuals' personal characteristics have been shown to impact neighbourhood delineations (Coulton et al., 2013; Charreire et al., 2016). Further exploration of relationships between individuals' personal characteristics and neighbourhood delineation is worthwhile as inconsistency exists in prior results, and some aspects of our lives are unexplored, like transport decisions. This section discusses the results of the statistical analysis exploring the impact of personal characteristics on the four neighbourhood dimensions (area, perimeter, compactness, and number of vertices). Length of residence in a neighbourhood, neighbourhood type, and transport decisions were all significantly associated with PNB area. 


\subsubsection{Overall Dataset}

The mean area of PNBs was $1.92 \mathrm{~km}^{2}$. This value is similar to Charreire et al. (2016) who surveyed 4,454 residents in 5 European cities and Coulton et al. (2013) who surveyed 6,224 residents from low income neighbourhoods in 10 US cities, with mean areas of $1.96 \mathrm{~km}^{2}$ and $2.33 \mathrm{~km}^{2}$ respectively observed. The median area of PNBs was $1.02 \mathrm{~km}^{2}$, almost half that of the mean area. Again, this is similar to both Charreire et al. (2016) and Coulton et al. (2013) who observed median area values of $0.71 \mathrm{~km}^{2}$ and $0.91 \mathrm{~km}^{2}$. Outliers of PNB area cause the mean to be highly skewed to the right. The minimum and maximum PNB areas in this thesis fell into a large size range of 0.002 and $29.11 \mathrm{~km}^{2}$, indicating that there is considerable variation in PNB area. Coulton et al. (2013) provided a definition for neighbourhood to participants, while this thesis and Charreire et al. (2016) did not. The lack of area difference between the two methodological choices leads to a conclusion a definition of neighbourhood is not required for research collecting PNBs and is unlikely to produce area differences, as high variation in PNB area has been observed for both cases.

\subsubsection{Age and Gender}

Prior research has established a relationship between age and PNB area, with younger individuals delineating smaller PNBs than older individuals (Guest \& Lee, 1984; Charreire et al., 2016; Coulton et al., 2013; Pebley \& Sastry, 2009). However, no significant relationship between age and any of the four neighbourhood dimensions was observed in this thesis. Summary statistics produced no clear trends between PNB area and age. While this may support the conclusion that age has no impact on PNB area among individuals in Wellington City, the lack of a relationship may be a caveat of the crowdsourcing methodology being an online survey and promotion methods attracting a younger sample of participants, with $54.13 \%$ of participants being under 30 years old (515). Older individuals were poorly represented, with participants over the age of 40 making up only $18.06 \%$ of the sample (160).

Inconsistency between gender and PNB area has been found in prior research. Guest and Lee (1984) and Charreire et al. (2016) have observed significant relationships, with women delineating

smaller PNBs than men. However, significant gender effects on PNB area were not observed observed in other studies (Coulton et al., 2013; Sastry et al., 2002; Kresek, 2018). In this thesis, gender did not have a significant effect on any of the four neighbourhood dimensions. This lack of significance was unlikely to be a result of a biased gender sample as large samples were captured for men (474) and women (391). Discrepancies among prior research of gender effects indicates that the impact gender has on PNB area is multi-faceted and requires further research. Additionally, it provides further support for the conclusion that methodological differences among studies surveying 
neighbourhood delineations may be impactful. A standardised method of doing so may see success in potentially producing consistent results.

\subsubsection{Neighbourhood Factors}

The link between length of residence in a neighbourhood and PNB area is mixed in prior research. Some studies have observed long-term residents delineate significantly larger PNBs than shortterm residents (Charreire et al., 2016; Coulton et al., 2013; Pebley \& Sastry, 2009). However, other studies have reported either a negative (Guest \& Lee, 1984) or non-significant (Haney \& Knowles, 1978; Kresek, 2018) relationship between length of residence and PNB area. This thesis observed a significant positive relationship between years lived in a neighbourhood and PNB area. Living in a neighbourhood for 6 to 10 years and 10 or more years were significantly associated with mean increases in PNB area of $0.305 \mathrm{~km}^{2}$ and $0.464 \mathrm{~km}^{2}$ respectively, compared to living in a neighbourhood for a year or less. Charreire et al. (2016) suggested this could be because individuals that have lived in a neighbourhood for longer have stronger ties to their neighbourhood and have had more time to explore and discover new locations in their neighbourhood. Consequently, the area they consider to be their neighbourhood grows. This conclusion is supported here and relates to the social and physical aspects of neighbourhood (Guest \& Lee, 1984; Kearns \& Parkinson, 2001). It also supports the conclusion that neighbourhood aspects are not independent; rather, they interact with and influence each other.

Neighbourhood type (explained in Section 3.5.1) provided insight into the different ways participants perceived their neighbourhoods. While a range neighbourhood types were received, 79.68\% of participants (706) had a neighbourhood type of single (e.g. Karori, Brooklyn, Mt Victoria). This demonstrates that the most common association between participants and their neighbourhood is with an existing, single neighbourhood. Subset, multiple, and street were also common neighbourhood types, showing that neighbourhood perceptions vary.

A significant relationship between neighbourhood type and PNB area was observed. Using the neighbourhood type of single as baseline, the neighbourhood types of subset and street resulted in significant decreases in PNB area of $0.584 \mathrm{~km}^{2}$ and $2.272 \mathrm{~km}^{2}$ respectively. This is unsurprising, because both of these neighbourhood types are smaller delineations than an entire, single neighbourhood. Conversely, the multiple neighbourhood type caused a significant increase in PNB area of $0.378 \mathrm{~km}^{2}$ compared to single neighbourhoods, $20 \%$ of the mean area observed for single neighbourhoods $\left(1.88 \mathrm{~km}^{2}\right)$. It was expected that multiple neighbourhoods would be substantially larger than single neighbourhoods, but the difference observed was smaller than anticipated. Participants with a neighbourhood type of multiple often demarcated the areas within two or more neighbourhoods important to them and that they have personal experiences with, rather than the 
entire extents of these neighbourhoods. Figure 6.1 shows this visually for two PNBs provided for Newtown/Berhampore with a neighbourhood type of multiple.

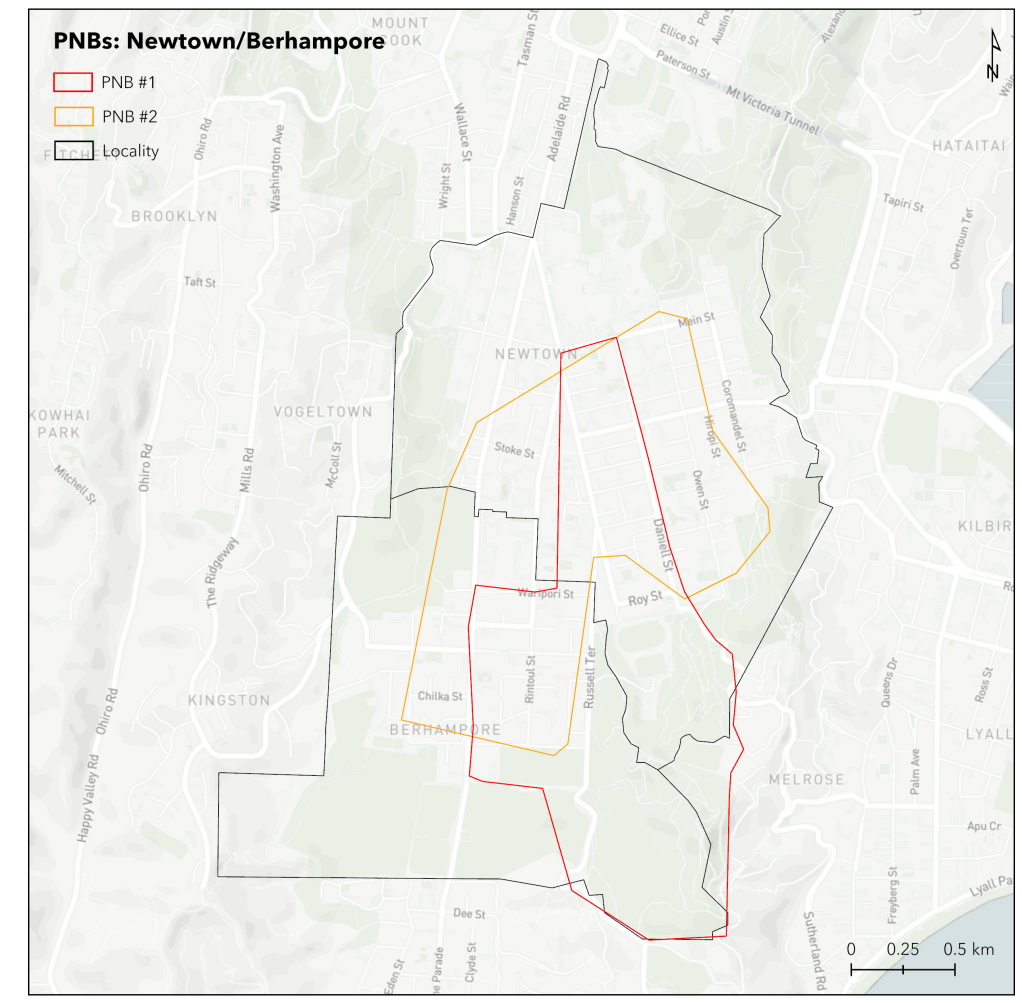

Figure 6.1: Multiple Type PNBs and Locality Boundaries: Newtown/Berhampore

The use of neighbourhood type to categorise neighbourhood delineations based on their given name is novel in research investigating definitions of neighbourhood boundaries. It allowed for effective categorisation of and direct comparisons to be made between the various ways participants delineated their neighbourhood. One prior study, Minnery et al. (2009), grouped PNBs into two categories based on visual inspection of the boundaries: abstract and road-based. This categorisation allowed for visual comparisons between the predominant ways in which participants demarcated their neighbourhood boundary. A combination of this thesis' use of neighbourhood type and the categorisation used by Minnery et al. (2009) would provide a deeper understanding of the different ways individuals perceive their neighbourhood boundaries.

\subsubsection{Transport}

The neighbourhoods we live in influence our transport decisions (Schwanen \& Mokhtarian, 2005; Chen et al., 2008), but the impact transport decisions have on neighbourhood delineation was unexplored in prior research. Car use was found to have a significant impact on PNB area. A mean increase of $0.605 \mathrm{~km}^{2}$ was observed for participants who used a car as a mode of transport daily, compared to participants who did not report car use. This difference is likely the result of 
whether participants lived inside or outside Wellington City. Shown visually in Figure 6.2, 66.53\% (138 out of 208) participants who reported daily car use provided neighbourhood data outside of Wellington City, and 95.88\% (186 out of 194) participants who reported no car use provided neighbourhood data inside Wellington City. Living outside of a city increases reliance on car use for transport (Ewing \& Cervero, 2010), and larger PNB areas have been observed for individuals living in areas of low residential density compared to high residential areas (Haney \& Knowles, 1978; Charreire et al., 2016). Consequently, PNBs observed outside of Wellington City have lower residential density and larger areas than PNBs inside Wellington City.

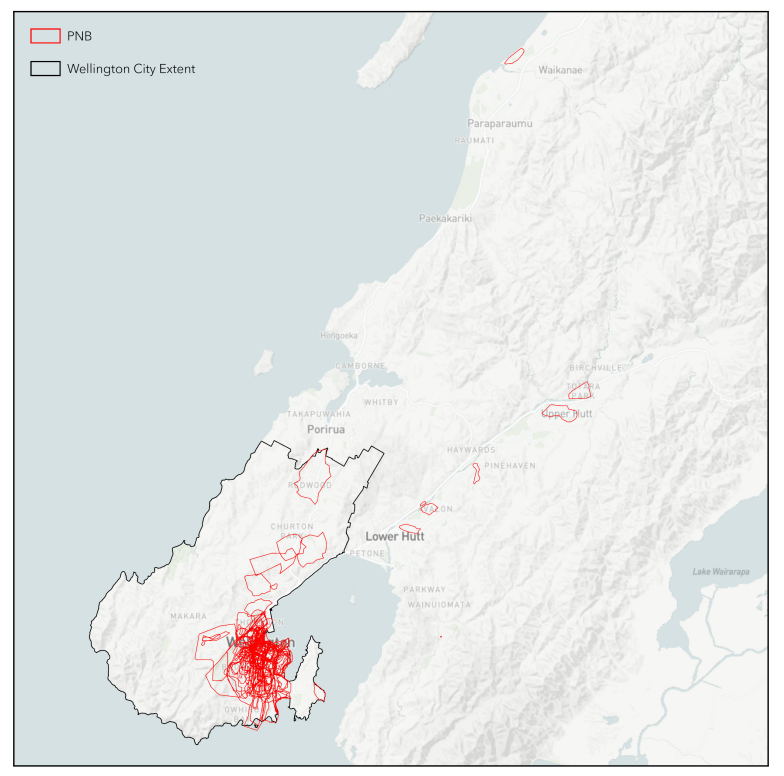

(a) Zero Days

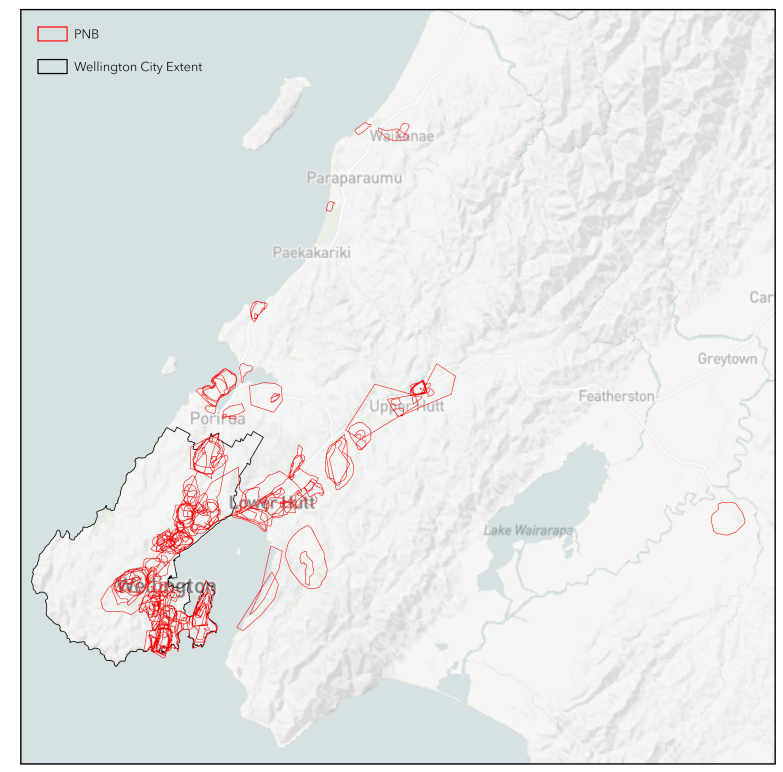

(b) Daily

Figure 6.2: Car Use in an Average Week PNBs: Zero Days (a) and Daily (b)

PNB area was also significantly impacted by participants' walking habits. Participants who walked daily observed a mean decrease of $0.388 \mathrm{~km}^{2}$ in PNB area than participants who did not walk at all. This finding was surprising, but is likely the result of three factors. First, overlap existed between participants who did not walk and drove daily (Figure 6.3). Second, individuals tend to depict themselves more positively for questions about certain personal aspects of their lives, such as exercise and eating habits (Dillman et al., 2014). Finally, the wording of the question about transport decisions in the questionnaire does not ask about duration of use. Shown in Appendix 1, the wording was:

"In an average week, how many days do you use the following modes of transport?"

It is likely participants interpreted the question to mean doing any type of walking and is likely to include walking to public transport or around their workplace rather than more substantial 
trips, e.g. commuting. $46.50 \%$ (412) of participants walked daily; almost double the number of participants who drove daily $(23.47 \%, 208)$. Future research could benefit from more explicit wording around transport decisions.

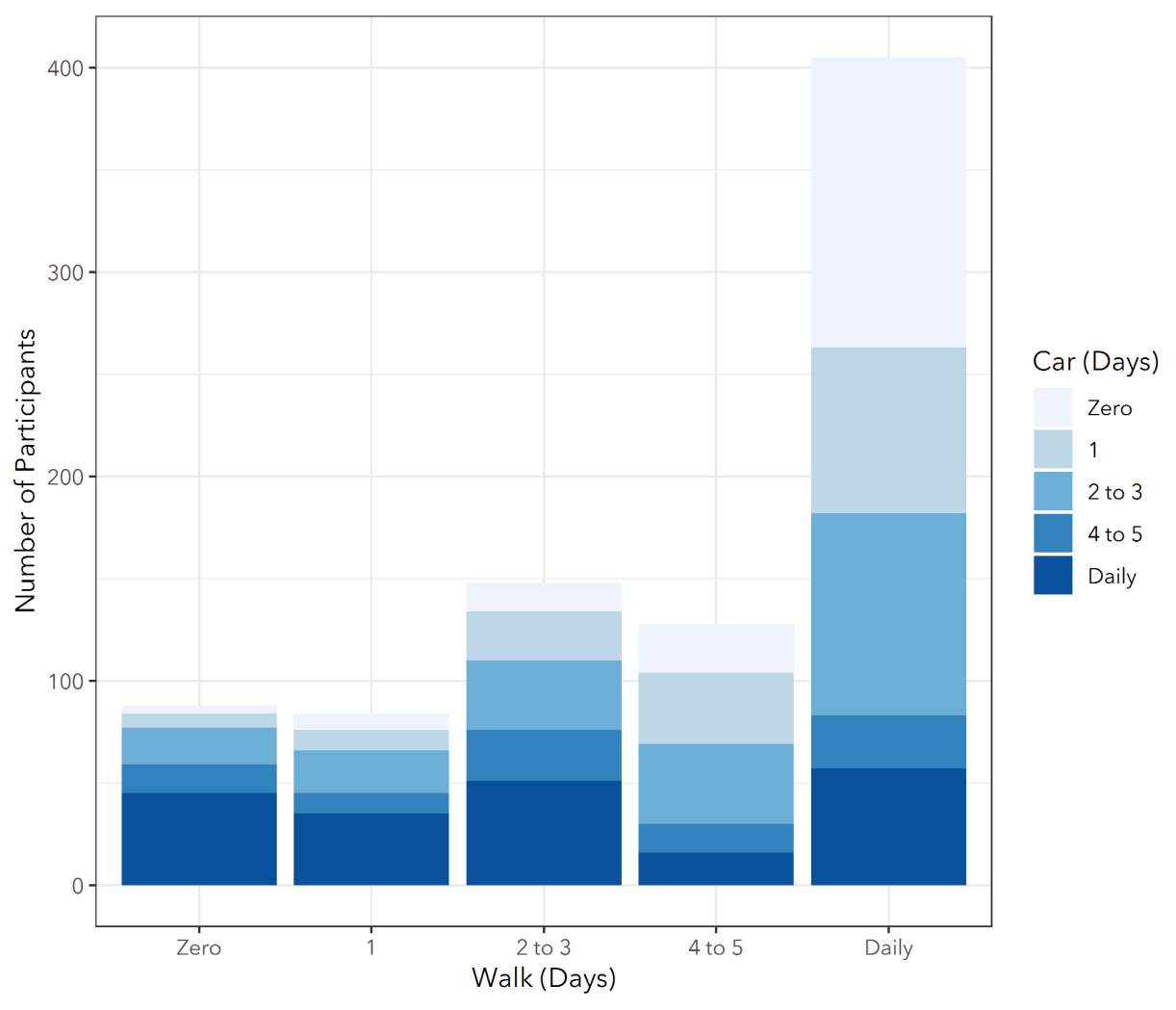

Figure 6.3: Number of Participants: Walk by Car Usage (Days)

\subsubsection{Suitability of Neighbourhood Dimensions}

Prior research investigating the relationship between personal characteristics and neighbourhood delineation focuses on PNB area (Coulton et al., 2013; Charreire et al., 2016; Pebley \& Sastry, 2009). The size of PNBs are directly comparable to other neighbourhood representations, such as census units and home buffers. Additionally, understanding area differences among personal characteristics can explain health outcomes, such as the number of primary healthcare resources included in an individual's neighbourhood (Vallée et al., 2015; Perchoux et al., 2016). An aim of the personal characteristic analysis was to test the suitability of three neighbourhood dimensions: perimeter, compactness, and number of vertices. Perimeter had potential to provide further context into compact PNBs with small areas, as a disparity between area and perimeter would exist. Compactness is a property of shapes commonly used to assess state gerrymandering in the USA (Polsby \& Poppper, 1991). Compactness was expected to highlight PNBs that follow geographic features closely, such as roads and property boundaries. The number of vertices in a PNB measured the complexity as well as participants put into demarcating their neighbourhood. 
PNB perimeter, compactness, and number of vertices were unable to provide any meaningful insight into neighbourhood delineation for most personal characteristics. A strong, positive correlation between PNB area and perimeter was found (0.89, Table 4.5) resulting in similar trends between area and perimeter being observed. Compactness and number of vertices had no significant impact and produced no trends for most personal characteristics. Consequently, perimeter, compactness, and the number of vertices are not recommended to be used in future research analysing relationships between personal characteristics and neighbourhood delineation. However, it is of note that perimeter, compactness, and number of vertices were useful in other case, such as comparisons between neighbourhood datasets, and investigating individual PNBs.

\section{Summary}

Certain personal characteristics were important for neighbourhood delineation. Significant relationships between PNB area and length of residence in a neighbourhood, neighbourhood type, walking, and car usage were observed. The findings add further inconsistency to research exploring relationships between personal characteristics and neighbourhood delineation, prompting a need for a standardised method of collecting neighbourhood delineations. PNB perimeter, compactness, and number of vertices were not insightful for understanding neighbourhood delineation.

\subsection{Neighbourhood Consensus}

Neighbourhood geographies are notoriously vague and difficult to define (Lupton, 2003). Prior research has analysed neighbourhood consensus in the context of individual, disconnected neighbourhoods using small sample sizes of PNBs (Coulton et al., 2001; Minnery et al., 2009). However, this approach does not present an accurate picture of neighbourhood consensus, nor does it capture interactions between bordering neighbourhoods. Overlapping PNBs received during the crowdsourced neighbourhood survey allowed for an exploration of neighbourhood consensus across Wellington City. This section discusses the outcomes of two measures of neighbourhood consensus: hexagon grids and models of neighbourhood connectivity. The outcomes discussed do not have obvious operational applications, but are nevertheless novel and interesting.

\subsubsection{Hexagon Grids}

In Section 4.3.1, Woodruff's (2017) method of measuring neighbourhood consensus was employed to produce hexagon grids of neighbourhood consensus. Areas of high and low neighbourhood consensus were observed, with different patterns observed for different neighbourhoods. Gradients of neighbourhood consensus occuring when moving away from the centre of a neighbourhood 
were identified. Interior, focal areas of neighbourhoods tended to observe higher neighbourhood consensus than external areas near neighbourhood boundaries. The method also gave a unique look into how bordering neighbourhoods interacted across Wellington City.

An interesting aspect of the neighbourhood consensus hexagon maps are the areas of dissensus between neighbourhoods. From these areas, trends and geographic features that impacted where individuals' consider to be the boundary between two bordering neighbourhoods were identified. Additionally, the hexagons form a raster-like grid which can be spatially joined to overlying features, such as land use plans, land cover, and population density units to identify relationships between features and neighbourhood consensus. In Section 4.3.3, this was done for FPs and provided further evidence for the relationship between FP locations and neighbourhood shopping hubs.

Methods of measuring neighbourhood consensus exists in prior research. Coulton et al. (2001) defined a neighbourhood common area as "the percent of each resident's map that overlapped the maps of at least 70\% of the other residents". In a replication of this method, Minnery et al. (2009) produced neighbourhood consensus at increasing bands of $10 \%$ percentiles. Both methods were applied to PNBs received for individual neighbourhoods. In comparison, this thesis' method was applicable to PNBs received for a group of contiguous neighbourhoods, providing an alternative perspective to complex neighbourhood geographies.

Two limitations exist for the neighbourhood consensus hexagon grids. First, a wide variety of neighbourhood names were observed, making measuring commonality in a neighbourhood difficult (described in Section 3.5.3). Two methods of interpreting the variety of neighbourhoods were used to account for this variation: Unique and Common names. Both methods were successful in representing neighbourhood consensus, but created different outputs for some neighbourhoods. A large disparity in consensus was observed between the two methods for some neighbourhoods, such as Karori (Figure 4.12). However, in other cases, such as Wellington's CBD, only minor consensus differences were observed. Second, the threshold of inclusion was 5 PNBs, resulting in the exclusion of some neighbourhoods with small amounts of PNBs from the hexagon grids, such as Strathmore, Vogeltown, and Mornington. A longer running survey of neighbourhood delineations explicitly promoted to underrepresented neighbourhoods may see success in addressing this limitation.

\subsubsection{Neighbourhood Connectivity}

The model of neighbourhood connectivity presented in Section 4.3.2 is a novel way of representing interactions between neighbourhoods. Weighting neighbourhood connectivity by intersection counts and mean intersection area represented interactions between neighbourhoods accurately and reduced the impact of small samples of PNBs received for some neighbourhoods. Both methods 
also painted different pictures of neighbourhood connectivity in Wellington City. Neighbourhoods with high and low connectivity to other neighbourhoods were able to be identified. Disconnected neighbourhoods were also observed, such as Tawa and neighbourhoods on the Miramar Peninsular.

Three factors appear to contribute to neighbourhood connectivity: transport links, elevation, and transit versus destination neighbourhoods. Neighbourhood connectivity observed for Karori (Figure 4.17 (a)) supports these factors. Karori has limited transport links being predominantly accessed through the Karori Tunnel and surrounded by hills, and it is not commonly used in transit to another neighbourhood. The strong, southern corridor of neighbourhood connectivity between Te Aro, Mt Cook, Newtown, Berhampore, and Island Bay (identified in Figure 4.15) also reflects this conclusion. These neighbourhoods are linked by a mostly flat, arterial route in the form of Adelaide Road commonly used in commute with regular bus services, and is cyclist friendly. Additionally, each of the neighbourhoods' sections of the southern corridor are all used in transit between each other, or to other nearby neighbourhoods.

\section{Summary}

Examining neighbourhood geographies using consensus measures provides a unique and fascinating look into how neighbourhoods interact. Areas of high and low consensus are identifiable using consensus hexagon grids. Neighbourhood connectivity measures are an interesting representation of bordering neighbourhoods and potentially has the ability to identify neighbourhoods with poor accessibility and transport links.

\subsection{Official Boundaries Comparisons}

Neighbourhoods are recognised as important for understanding relationships between our residential environments and health outcomes because they function as meaningful and easily comparable units of scale (Diez Roux, 2001). Official boundaries produced by government organisations, such as census units, are repeatedly used as proxies to represent neighbourhoods to examine geographic health outcomes, such as access to primary healthcare (Apparicio et al., 2008), supermarkets and convenience stores (Pearce et al., 2008), and alcohol, tobacco, and fast food retailers (Schneider \& Gruber, 2013). Understanding how official boundaries compare to PNBs is important as some health outcomes can be explained by differences in neighbourhood delineations rather than the underlying areas themselves (Vallée et al., 2015). This section will discuss the outcomes of comparisons made between the crowdsourced PNBs, community defined neighbourhoods (CDNs), localities, and statistical area 2 units (SA2s) in Section 4.4. Recommendations for how crowdsourced PNBs can be used to augment official boundaries to make them better reflect the communities living in them are also made. 


\subsubsection{Neighbourhood Dimensions}

Physical aspects of neighbourhood boundaries allow for comparisons between entire neighbourhood datasets. Four neighbourhood dimensions (area, perimeter, compactness, and number of vertices) were produced and compared between the comparison datasets: PNBs, CDNs, localities, and SA2s.

The area of all four neighbourhood datasets had very large ranges, from 0.002 to $29.11 \mathrm{~km}^{2}$ for CDNs (SD = 2.94), and 0.26 and $89.42 \mathrm{~km}^{2}$ for localities (SD = 13.74). Given this range and the clear presence of outliers of area, we focus on the median area for comparisons. Similar median areas were observed PNBs $\left(1.02 \mathrm{~km}^{2}\right)$, CDNs $\left(1.03 \mathrm{~km}^{2}\right)$, and SA2s $\left(1.07 \mathrm{~km}^{2}\right)$, but the median area of localities was slightly larger $\left(1.46 \mathrm{~km}^{2}\right)$. The findings here are both consistent and inconsistent with prior research. Coulton et al. (2001) found that on average, PNBs were of similar size to census units, which in this thesis, was replicated for PNBs and SA2s. However, Alidoust et al. (2017) found that the majority of participants delineated smaller neighbourhoods than the official neighbourhoods in which they resided, supported by the disparity between PNBs and localities. These findings suggest that SA2s are a more appropriate representation of neighbourhoods than localities and indicate that differences between how participants perceived their neighbourhoods and official boundaries continue to exist. By understanding these differences, official boundaries can be made to better reflect individuals' neighbourhood perceptions; subsequently improving the accuracy of presentations of geographic health outcomes.

Differences in the number of vertices was found between PNBs and the official boundaries of localities and SA2s, with mean values of 20, 401.5, and 167.86 observed respectively. PNBs were also considerably more compact than their official counterparts. The mean compactness of PNBs was 0.64, while localities and SA2s observed compactness values of 0.35 and 0.39 respectively. Figure 4.22 shows these differences for Aro Valley. Most participants delineated a rough area of what they considered to be their neighbourhood, while official boundaries are much more detailed and follow roads and parcel boundaries. Participants were also unlikely to be familiar with the digitising process. Even though the PNBs were less detailed than official representations, they still provided insight into the similarities of PNBs and official boundaries. In the example of Aro Valley (Figure 4.22), the PNB and locality boundaries cover roughly the same area indicating that for the participant, the locality is a suitable and more detailed representation of their neighbourhood.

It is important to note that SA2s are not the smallest census unit used by Stats NZ; meshblocks are $\AA^{1}$. SA2s were used as the census unit for comparisons because they are the closest representation to neighbourhoods in terms of scale, and each SA2 has a neighbourhood name (which meshblocks do not have).

\footnotetext{
${ }^{1}$ Smallest geographic unit for which statistical data is reported by Stats NZ
} 


\subsubsection{Congruence}

Congruence (defined in Section 3.5.4) measures the degree to which two areas correspond (Galster, 1986). Interestingly, while PNBs were more similar to SA2s than localities in terms of area, higher congruence was observed between PNBs and localities than SA2s with mean congruence values of 0.36 and 0.32 observed for localities and SA2s respectively. Localities could be considered a slightly better representation of PNBs using congruence measures, while from area comparisons SA2s may be preferred. This means deducing the suitability of a dataset of official boundaries by comparing them to PNBs based on a single indicator is problematic. Given the complex nature of PNBs, a range of factors are required to examine how representative official boundaries are of perceived neighbourhoods. CDNs were only slightly more similar to PNBs than official boundaries, with a mean congruence value of 0.38 . This indicates CDNs are not considerably better at representing neighbourhood perceptions than official boundaries.

The use of congruence did not come without limitations. PNBs often overlapped numerous official boundaries (Figure 3.14). If congruence was calculated using all intersections, outputs would be heavily skewed to the right as extremely low congruence scores from tiny intersection areas would be included. Consequently, congruence was only calculated between neighbourhood boundaries with the largest shared area. A second limitation is that measuring congruence between PNBs and entire official datasets does not capture the unique intricacies of PNBs. We would assume that a low congruence value between two neighbourhood boundaries indicates they have dissimilar borders, but this was not always true, such as in Figure 4.24 (a). Additionally, in the case of Figure 4.24 (a), extremely low congruence values between two boundaries are unclear and may not represent substantial differences between the two boundaries.

\subsubsection{Perspective for Official Boundaries}

Producing CDNs using the consensus hexagons was one method of representing contiguous neighbourhood boundaries based on collective PNBs. Overall, CDNs did a good job in representing neighbourhoods in Wellington City and were not completely dissimilar from localities. A key strength of producing CDNs is the ability to highlight areas of official neighbourhood boundaries that are unrepresentative of individuals' neighbourhood perceptions. An example of this is the corridor and large area to the west of Brooklyn that is part of the localities dataset, but not in CDNs (Figure 6.4). The area is roughly twice the size of the Brooklyn CDN alone, but was not included in any of the PNBs received for Brooklyn. This is one case of many where an official boundary poorly represents collective neighbourhood perceptions. It is of note that CDNs have several limitations and are not an adequate replacement for a dataset of official neighbourhood boundaries. Every CDN has a jagged edge which is the result of joining hexagons. Neighbour- 
hoods that received low sample sizes were not included in CDNs. Some CDNs have holes in them from where a hexagon did not receive 5 or more submissions or had more submissions received for another neighbourhood. A more refined method of production or further cleaning of CDNs is essential to produce a high quality, community defined dataset of neighbourhood boundaries.

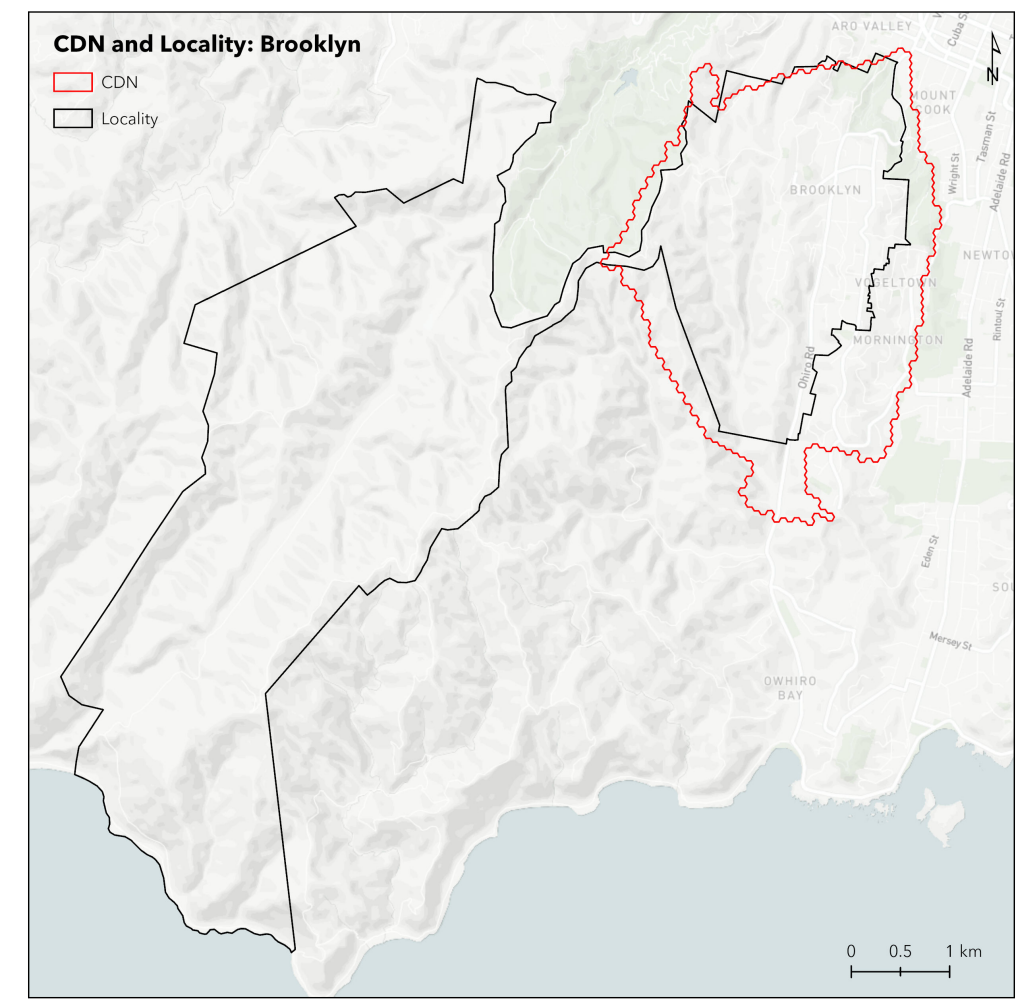

Figure 6.4: CDN and Locality Boundaries: Brooklyn

Crowdsourced neighbourhood delineations show promise as a supplementary source of neighbourhood delineations and to highlight areas of official boundaries that poorly represent how residents perceive their neighbourhoods. For operational uses of neighbourhood boundaries, such as reporting geographic health outcomes, this difference is significant as unrepresentative areas of official boundaries can result in biased outcomes (Spielman \& Yoo, 2009). Identified unrepresentative can be altered to better reflect the communities that live in them. It was also observed that official boundaries had low compactness and large numbers of vertices because they commonly followed geographic features, including roads and parcel boundaries. PNBs were also influenced by similar geographic features to an extent. Their impacts are discussed in the next section.

\section{Summary}

Crowdsourced neighbourhood boundaries differ greatly from official boundaries in some ways, but are similar in others. The sheer variety in which individuals define their neighbourhood is difficult to capture using a single set of static boundaries. By comparing PNBs and CDNs to official 
boundaries, unrepresentative areas can be identified and improved to better represent community perspectives and present geographic outcomes.

\subsection{Lynch's Five Elements}

Geographic features have been shown to be important for how individuals delineate their neighbourhoods (Minnery et al., 2009; Lohmann \& McMurran, 2009). Lynch's (1960) five elements that contribute to mental maps of urban areas were used to categorise case studies of geographic features. This section discusses geographic features' impact on neighbourhood delineations and considers limitations of using solely quantitative methods to explore complex relationships between geographic features and PNBs.

\subsubsection{Paths}

"Paths are the channels along which the observer customarily, occasionally, or potentially moves. They may be streets, walkways, transit lines, canals, railroads. For many people, these are the predominant elements in their image. People observe the city when moving through it, and along these paths the other environmental elements are arranged and related." (Lynch, 1960, p.47)

Of the five elements, identifying geographic features that functioned as paths in neighbourhood delineation was the most difficult because paths do not present themselves geographically. Rather, paths are used by individuals to navigate and move through their neighbourhoods, but not well applied to the neighbourhood delineations. It was common for participants to follow roads while drawing their PNB, but in these cases the road functions more like an edge by being a boundary for their neighbourhood. While it may have been likely that paths were used by participants to delineate their neighbourhoods, geographic features that functioned as paths were not easily identifiable using quantitative methods. Only Cambridge and Kent Terrace and the Karori Tunnel were found to function as paths. However, this identification was based on local knowledge and personal experiences rather than by analysis of the data. Cambridge and Kent Terrace are arterial routes used by thousands of Wellington residents in commute and day-to-day transit, and Karori Tunnel provides a main access route to Karori from Wellington's CBD.

Paths are recognised to be an influential element in neighbourhood perceptions through the use of qualitative methods. Through structured interviews, Lynch (1960) found paths to be the predominant element in individual's mental maps of urban areas and Alidoust et al. (2017) observed some participants used paths to demarcate their neighbourhood boundaries such that their neighbourhood ended at a busy road. Identifying paths and measuring their impact on neighbourhood 
delineation is not possible solely through quantitative analysis of individuals' neighbourhood delineations.

\subsubsection{Edges}

"Edges are the linear elements not used or considered as paths by the observed. They are the boundaries between two phases, linear breaks in continuity: shores, railroad cuts, edges of development, walls. They are lateral references rather than coordinate axes. Such edges may be barriers, more or less penetrable, which close one region off from another; or they may be seams, lines along which two regions are related and joined together." (Lynch, 1960, p. 47)

In mental maps of urban areas, edges separate one area from another. Out of Lynch's (1960) 5 elements, geographic features that function as edges were most commonly observed and easily identifiable among the case studies. Roads, a tunnel, an airport, green space, shorelines, and a river were all found to function as edges in neighbourhood delineations. The variety in types of geographic features that were found to function as edges reflects its prominence in impacting neighbourhood perceptions by separating an individual's neighbourhood boundary from external areas.

Most of the geographic features identified to function as edges were boundaries between two or more neighbourhoods. However, shorelines were boundaries between PNBs and another, significant geographic feature: the ocean. For coastal neighbourhoods, this indicates that the majority of residents do not consider the ocean to be part of their neighbourhood, except for PNBs of Island Bay impacted by Taputeranga Island (Section 5.3.3). This is an area where official neighbourhood boundaries are consistent with participants' neighbourhood perceptions. Both SA2s and localities of coastal neighbourhood follow shorelines and do not extend into the ocean, and a separate category of locality exists for bays, straits, and oceans.

While edges occur predominantly in the form of lines, three polygonal geographic features were also found to function as edges. The Wellington Botanic Gardens, Wakefield Park and the Green Belt, and the Wellington Airport all formed clear barriers between PNBs. The scale to which these features separated neighbourhoods was also larger than lines because the extent covered by them is larger. However, while polygonal geographic features separated neighbourhoods, their borders also separated neighbourhoods from themselves as they also functioned as districts.

\subsubsection{Districts}


"Districts are the medium-to-large sections of the city, conceived of as having two-dimensional extent, which the observed mentally enters "inside of," and which are recognizable as having some common, identifying character. Always identifiable from the inside, they are also used for exterior reference if visible from the outside." (Lynch, 1960, p. 47)

When we consider districts, we think of areas in a city that we are aware we enter, such as a city's CBD or cultural hub (Lynch, 1960). Districts are important in urban mental maps as they allow for us to break down a city into distinct areas. Neighbourhoods themselves could be considered districts if they have clear characteristics that differentiate them from areas of a city. Two geographic features found to function as districts in neighbourhood delineation were: Wellington Airport and the Wellington Botanic Gardens. Both are large areas with clear boundaries and common characteristics distinguishing them from surrounding areas.

The geographic features identified as districts had a clear impact on neighbourhood delineation and were identified because there was a clear trend of their exclusion from PNBs received for nearby neighbourhoods. In the official boundaries of localities and SA2s, Wellington Airport is included in the boundary of the neighbourhood Rongotai (Figure 6.5). Wellington Airport covers a large proportion of the official boundaries for Rongotai, making up $41.13 \%$ and $32.41 \%$ of the locality and SA2 boundaries respectively. However, based on the PNBs it is not considered a part of any neighbourhood and has no permanent residents. This presents the question of whether Wellington Airport should be included in the localities or SA2s dataset as its own, separate area, or at all. The common way of representing neighbourhood boundaries is using a set of fixed, contiguous boundaries without holes. For most neighbourhoods, this is appropriate. Yet, in some cases, as shown by Wellington Airport and its surrounding neighbourhoods in Figures 5.19 and 5.20, removing areas not considered to part of a substantial amount of individual's neighbourhood perceptions may be a more appropriate representation of neighbourhoods. 


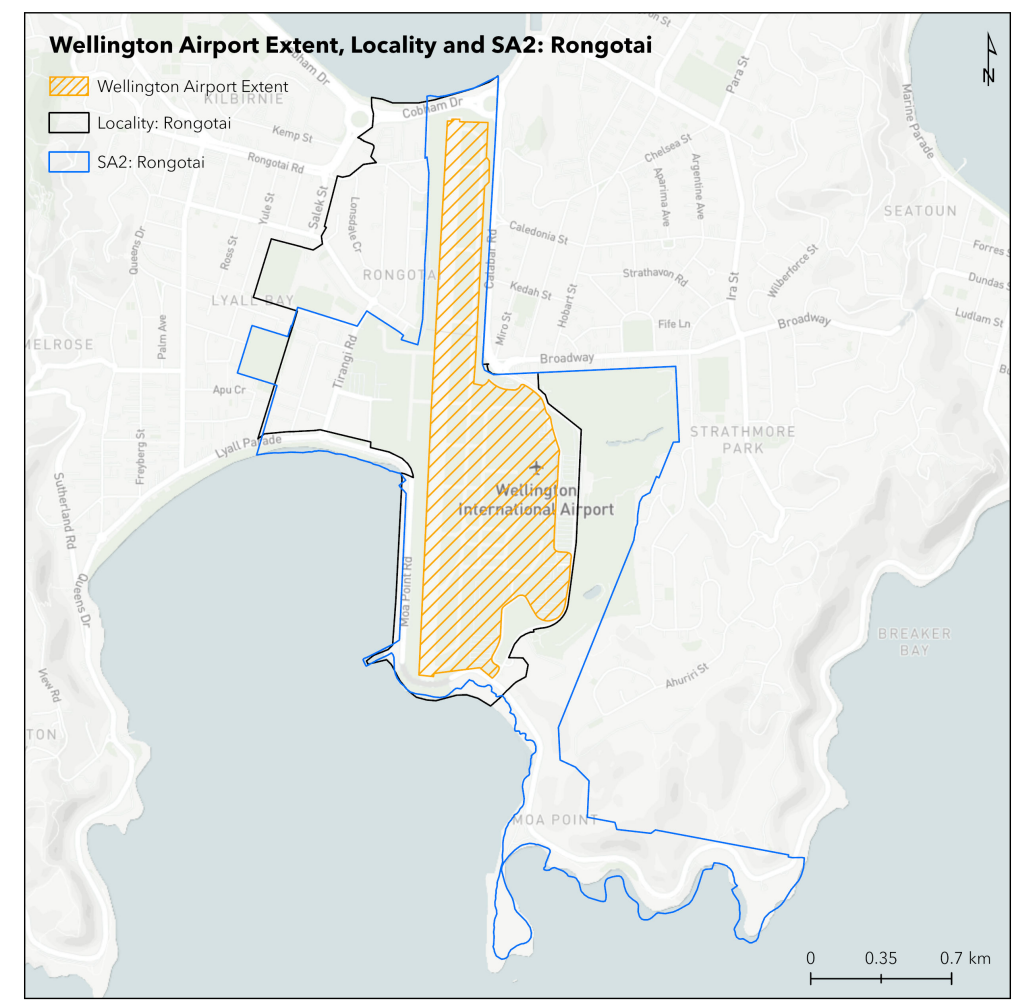

Figure 6.5: Wellington Airport Extent and Rongotai Locality and SA2 Boundaries

\subsubsection{Nodes}

"Nodes are points, the strategic spots in a city into which an observed can enter, and which are the intensive foci to and from which he is travelling. They may be primarily junctions, places, of a break in transportation, a crossing or convergence of paths, moments of shift from one structure to another. Or the nodes may be simply condensation of some use of physical character, as a street-corner hangout or an enclosed space." (Lynch, 1960, pp. 47-48)

In a survey of 54 older participants in Australia, Alidoust et al. (2017) found almost all participants used nodes in defining their neighbourhood boundaries, and that nodes were most the referred to out Lynch's (1960) five elements. Participants nodes were in a wide range of locations with different social and physical functions, such as socialising, shopping, and exercise. Furthermore, Alidoust et al. (2017) observed that the number and distribution of nodes was influenced by the type of neighbourhood participants lived in. To explore different locations which participants considered nodes of their neighbourhood, participants marked the focal point of their neighbourhood in the crowdsourced neighbourhood survey. No definition of focal point was given in the instructions. Due to this, it was hypothesised that variation would exist in where participants would place their neighbourhood FPs, but overall, FPs would be commonly found on or nearby neighbourhood shopping hubs. Shopping hubs are functional areas of neighbourhoods providing opportunities 
for social interaction, shopping, and to eat or drink (Figure 6.6). For some neighbourhoods, they contain the most accessible community resources, such as takeaways, convenience stores and dairies, schools, libraries, and GPs. They are also large, open areas which we enter in and out of, but have poorly defined boundaries.

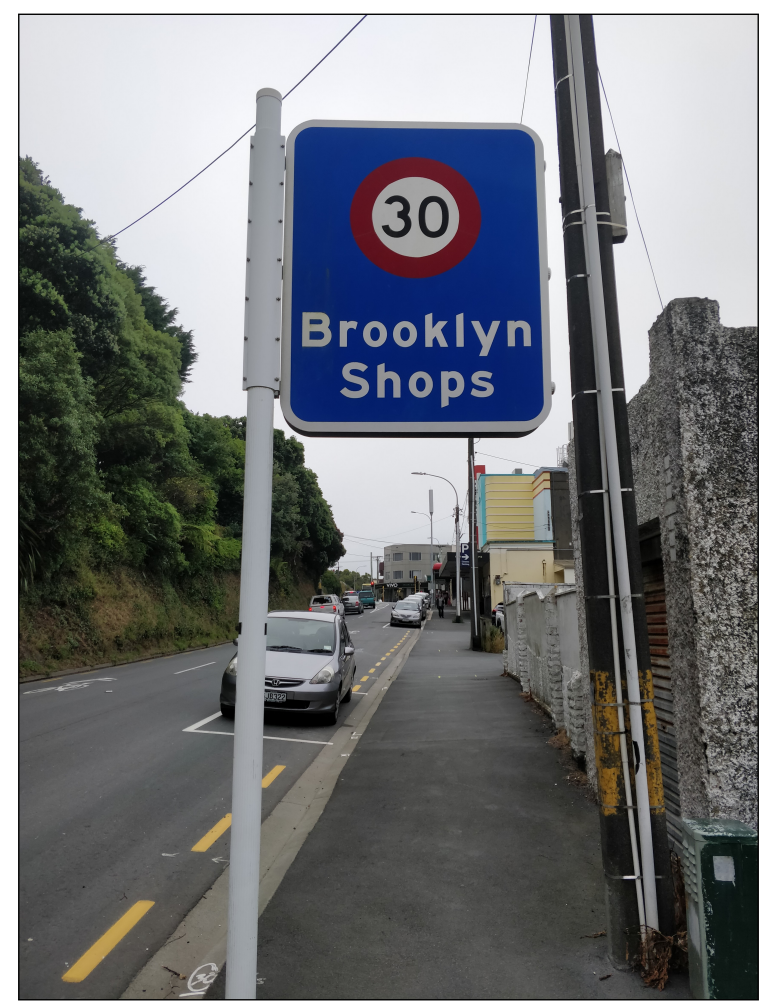

Figure 6.6: Traffic Sign showing Brooklyn Shops. Credit: Author's Own.

FPs were found to be highly significantly clustered and density based spatial clustering (DBSCAN method) was performed on them (Figure 4.18). 43.12\% (382) of the total FPs were clustered. From clustered FPs, common locations of nodes in neighbourhoods were inferred. The most popular locations of FPs were neighbourhood shopping hubs. 85.07\% (325) of clustered FPs were located inside a neighbourhood shopping hub (Figure 4.20). Consequently, the hypothesis of shopping hubs being a predominant location for participants' FPs was confirmed. This provides support for the conclusion that the main type of node observed for neighbourhoods was the shopping hub.

Not all neighbourhoods in Wellington City had a shopping hub. For these neighbourhoods, FPs were placed in a variety of locations, for example participants' homes, schools, and parks. This variation in observed FP locations supports the conclusion that individuals define their neighbourhoods in a range of ways. This conclusion has usually been made using PNBs (Coulton et al., 2001; Jenks \& Dempsey, 2007; Coulton et al., 2013), so replicating it using a different spatial component reinforces it. However, one exception was observed. If a neighbourhood without a shopping hub contained a significant, defining feature, such as what the neighbourhood was named after, 
FPs were drawn towards it. The example of Lyall Bay supports this conclusions (Section 4.3.3), because the majority of FPs received for Lyall Bay were on the beach.

Only two geographic features functioned as nodes in the Chapter 5. Cuba Street (Section 5.2.2) and Lyall Bay (Section 5.3.4). Cuba Street in particular almost functioned as an individual neighbourhood. By scaling up to the scale of Wellington City, the conclusion that Cuba Street is the main node of Wellington City can be drawn. Cuba Street being the location of the only street festival (Cubadupa) in Wellington's CBD also supports this conclusion. Most cities have a street or area that performs a similar role as Cuba Street. In New Zealand, Auckland has K Road, Christchurch has Cathedral Square (prior to the 2011 earthquake), and Dunedin has the Octagon. It could be assumed that these areas would also function as nodes for their respective cities. Streets like Cuba Street are important for cities as they provide substantial social and cultural value to residents.

\subsubsection{Landmarks}

"Landmarks are another type of point-reference, but in this case the observed does not enter within them, they are external. They are usually a rather simply defined physical object: building, sign, store, or mountain. Their use involves the singling out of one element from a host of possibilities. Some landmarks are distant ones, typically seen from many angles and distances, over the tops of smaller elements, and used as radial references. Such are isolated towers, golden domes, great hills. Other landmarks are primarily local, being visible in only restricted localities and from certain approaches. They are innumerable signs, store fronts, trees, doorknobs, and other urban derail, which fill in the image of most observers." (Lynch, 1960, p. 48)

The main role landmarks play in mental maps of urban areas is navigation (Lynch, 1960). Any feature that an individual uses to navigate the city is considered a landmark, as long as it cannot be entered by the observer. The geographic features found to function as landmarks in perceived neighbourhood delineation were all significant, global features because their impact on PNBs was clearly identifiable. The Brooklyn Wind Turbine, Mt Victoria Lookout, and Taputeranga Island all had clear impacts on neighbourhood delineations. Even though each landmark was geographically separate from the residential areas of the associated neighbourhood, the wind turbine, island, and lookout were respectively included in $33.93 \%, 33.33 \%$, and $34.48 \%$ of PNBs received for each associated neighbourhood.

An interesting aspect of landmarks is a name association between the landmark and its neighbourhood was required for it to impact neighbourhood perceptions. The Brooklyn Wind Turbine derives its named from the neighbourhood Brooklyn, Island Bay is named after the existence of 
Taputeranga Island. The Mt Victoria lookout was included in more PNBs received for Mt Victoria than bordering neighbourhoods Hataitai and Roseneath (Figure 5.16). Name associations between landmarks and neighbourhoods are important as a connection between the landmark and residents is facilitated, attributing importance to the landmark in neighbourhood perception.

In Lynch's (1960) definition of landmarks, he adds that any feature that an individual uses in their day-to-day navigation could be considered a landmark, such as a single shop, building, or sign. Smaller, personal landmarks were difficult to test using neighbourhood delineations because everyone has their own unique set of landmarks falling under this category that are almost impossible to distinguish among large samples of overlapping PNBs. As such, only global geographic features were found to function as landmarks.

\subsubsection{Limitations}

The approach used to categorise geographic features into Lynch's (1960) five elements has limitations. Neighbourhood geographies are complex and subjective making determining the extent to which geographic features impacted them difficult to discern using quantitative methods. One example of this is the case study of Lyall Bay's shoreline. From visual inspection it is clear that most PNBs received for Lyall Bay followed the shoreline (Figure 5.32), but determining this for all PNBs received for Lyall Bay quantitatively was troublesome. The extent to which PNBs followed the shoreline varied, with some extending over 200 metres into the ocean. A combination of quantitative and qualitative data collection and interpretation methods may see success in eliciting a more complete picture of how individuals perceive their neighbourhoods and what factors impact neighbourhood delineation (Kwan \& Ding, 2008). Talen and Shah (2007) and Alidoust et al. (2017) have both demonstrated effective use of a combination of quantitative and qualitative methods to collect and interpret neighbourhood perceptions. For future research crowdsourcing neighbourhood delineations, adding an optional supplementary qualitative survey asking what factors were important for how they delineated their neighbourhood would be valuable for furthering our understanding of complex neighbourhood geographies.

The base map used in the crowdsourced neighbourhood survey may have influenced participants' neighbourhood delineations. Base map biases are problematic for surveying mental maps as it can be difficult to distinguish if outcomes are the result of the study purpose or the base map used (Curtis et al., 2014). Additionally, a lack of commonality among the choice between using a base map at all, or the type of base map used (e.g. satellite imagery versus vector tile) produces replication issues for mental map research. An example of base map differences is shown in Figure 6.7. Cambridge and Kent Terrace (a) were wider and more distinct than other streets in Mt Victoria (b) at every scale. While this difference does reflect the significance of the geographic 
feature, neighbourhood delineations were likely impacted as a result.

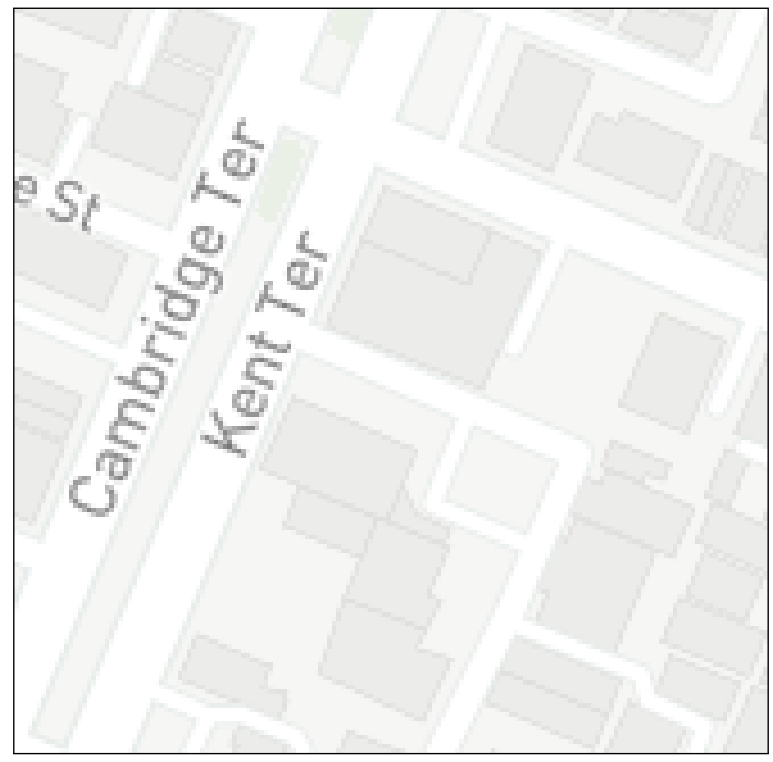

(a) Cambridge and Kent Terrace

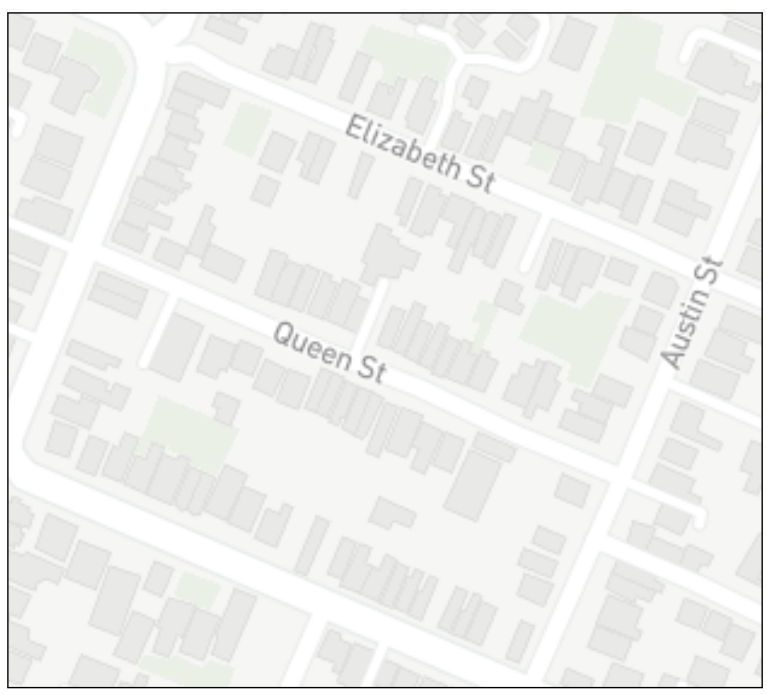

(b) Other Streets in Mt Victoria

Figure 6.7: Example Streets on the Neighbourhood Survey's Basemap (Same Scale)

\section{Summary}

A wide range of geographic features impacted neighbourhood perceptions by functioning as one or more of Lynch's (1960) five elements of urban mental maps. Paths, edges, districts, nodes, and landmarks were all represented, with edges being the most impactful on PNBs. Due to the complexity of perceived neighbourhood delineations, the impact of geographic features was difficult to determine using purely quantitative methods. A method integrating quantitative mapping and qualitative interviews would provide a more complete picture of how geographic features and perceived neighbourhood delineations interact.

\subsection{Viability of the Crowdsourcing Approach}

This thesis identified a gap in the literature where a crowdsourcing methodology could be used to collect neighbourhood delineations. Two methods of collecting neighbourhood delineations have been traditionally used: in-person surveys using paper maps (Jenks \& Dempsey, 2007; Lohmann \& McMurran, 2009; Alidoust et al., 2017) and large, stratified surveys using GIS software to collect neighbourhood responses (Coulton et al., 2011; Charreire et al., 2016; Chaix et al., 2012). In both cases, two issues were prominent: the amount of effort required to run the survey and undesirable sample sizes. Having seen success in Boston (Woodruff, 2017), a crowdsourcing methodology was used to attempt and remedy both issues. This section will describe the successes and drawbacks 
of the methodology, and its implications for the localities dataset.

\subsubsection{Neighbourhood Survey: Wellington City}

A total of 920 responses were received during the 3 months of the crowdsourced neighbourhood survey, with $96.30 \%$ (886) responses being valid. This demonstrates that neighbourhood delineations and personal characteristics can be collected rapidly, if effort is expended promoting and sharing the app used to collect responses. Even without a definition of neighbourhood or focal point provided, participants still readily understood and completed the data collection process. The quality of data received was high following data cleaning and had good geographic spread over Wellington City making it sufficient for analysis. The survey was also cheaper and simpler than traditional methods of collecting neighbourhood delineations. Additionally, the survey can be easily replicated in other cities or countries using a variant of the Wellyhoods app.

A demographically diverse range of participants completed the crowdsourced neighbourhood survey. Responses were received from sufficient sample sizes of participants with different ages, genders, neighbourhood types, and preferred modes of transport. This indicates that the crowdsourcing methodology was popular amongst a range of demographics, and was straightforward enough for participants with varying technical experience to complete the survey. One exception is that the majority of participants were younger than 30 (58.13\%). This was in part the result of internet surveys being more popular among younger participants (Dillman et al., 2014), but also the methods of promoting the app (posters at university campuses, social media) were more suited to receive responses from younger participants. For future research using a crowdsourcing methodology aiming to get a more representative spread of age groups, promotion methods focused on older individuals are required, such as promoting the app in retirement villages, commuter transport hubs, and forms of media more popular among older individuals.

The most common method of collecting neighbourhood delineations is to survey residents of a few individual neighbourhoods that meet specific criteria, such as low socioeconomic status or high urban density (Jenks \& Dempsey, 2007; Coulton et al., 2013; Charreire et al., 2016). By doing this, one can compare neighbourhood delineations based on the desired criteria. While this method is effective for answering specific hypotheses, it does not allow for the collection of neighbourhood delineations of overlapping, contiguous neighbourhood areas across a city. The crowdsourcing methodology used did provide this benefit, which resulted in a unique look into how perceived neighbourhood geographies interacted. 


\subsubsection{Drawbacks}

The crowdsourcing methodology contained drawbacks. As no incentive or reward was provided to participants for completing the survey, the crowdsourcing methodology was required to be straightforward, unobtrusive, and short to avoid deterring individuals from completing the survey and to encourage them to recommend it to friends and family. This was kept in mind throughout the questionnaire design process, and as a result concessions were made to reduce the likelihood of an individual refusing to partake. First, the number of questions included in the questionnaire was limited so as not to deter participants as shorter questionnaires have been shown to reduce response rates for online questionnaires by reducing the effort required to contribute (Edwards et al., 2009). Second, questions about potentially sensitive information, including ethnicity, income, and home and work addresses were excluded from the questionnaire. While this information was desired, it was considered to be excessively sensitive. If a financial incentive was able to be provided to participants, this problem would have been minimised (Katmada et al., 2016). Data quality was also lower than what would be expected from a traditional method. However, by performing data cleaning this problem was minimised. Only $3.70 \%$ (34) submissions were excluded from analysis.

Another drawback of using a crowdsourcing methodology is self-selection bias. Described in Section 2.3.5, self-selection bias refers to bias produced from participants who choose to contribute, rather than participants selected in a traditional survey (Heckman, 1979; Zhang \& Zhu, 2018). In the Wellyhoods app, no check was in place to ensure participants lived in the neighbourhood for which they provided data. Additionally, it was possible that individuals provided data for a single neighbourhood repeatedly or for multiple different neighbourhoods. Self-selection bias was problematic for neighbourhoods of different sizes, as small sample sizes were received for smaller neighbourhoods compared to large neighbourhoods. As a result, the smaller neighbourhoods were poorly represented in results, for example, Strathmore, Mornington, and Vogeltown, were excluded from neighbourhood consensus outputs because they did not receive enough submissions (5) to meet the inclusion threshold. These neighbourhoods are still important to the residents that live in them, but due low sample size due to self-selection bias meant they were not represented in outputs.

\subsubsection{Implications for Localities}

The crowdsourcing methodology has implications for official neighbourhood datasets, specifically localities. Localities are the closest representation to official neighbourhood boundaries in New Zealand and are maintained and produced by Fire and Emergency New Zealand (FENZ). Localities in Wellington City are shown in Figure 3.12. Currently, if a member of the public, government organisation, or council wanted to propose a change to the localities dataset, they are required to 
fill out an official change request form (Figure 6.8). FENZ will then assess the request and decide whether to implement it. Examples of past changes include creating new localities, altering the boundaries of existing localities, and renaming localities.

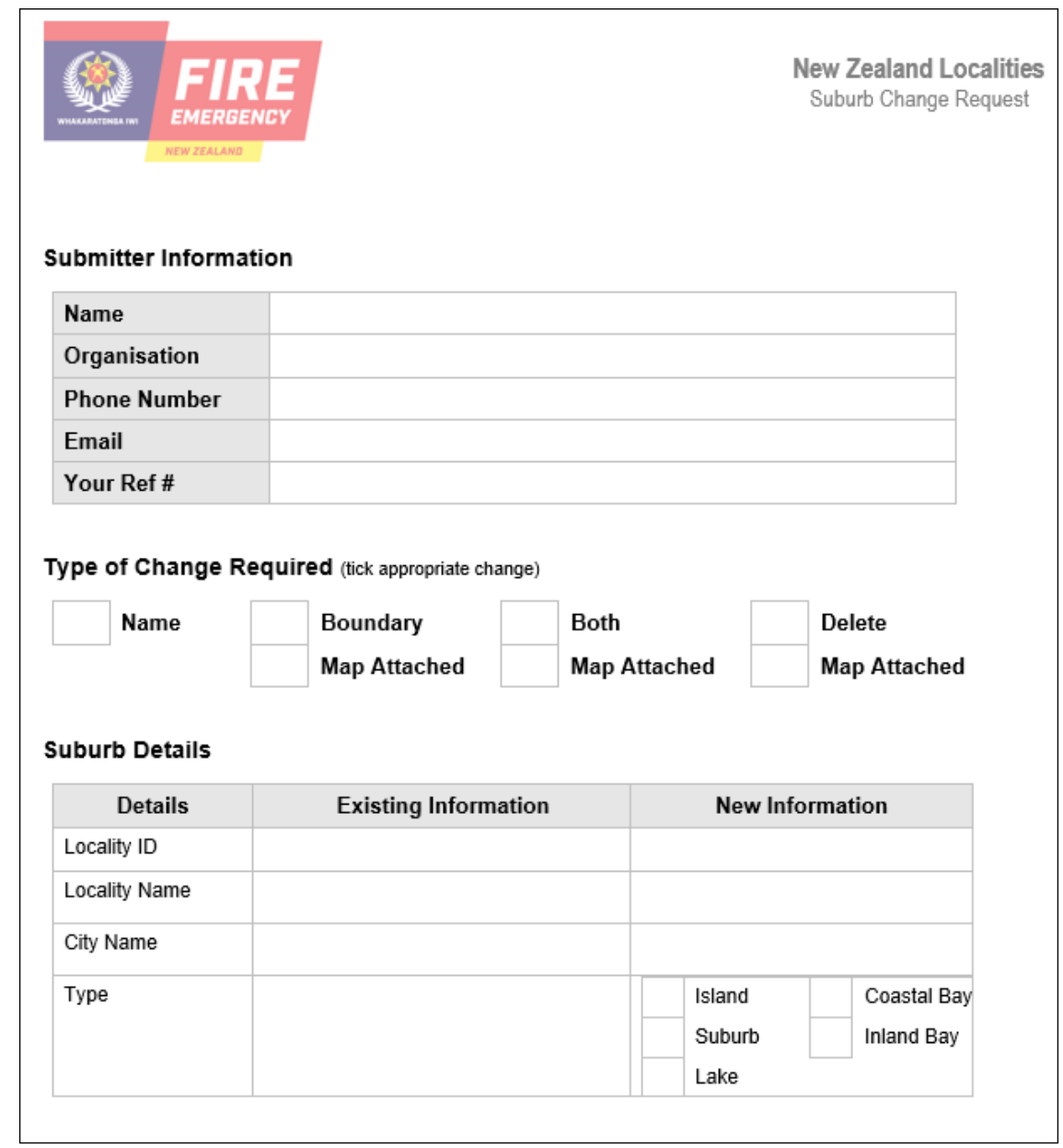

Figure 6.8: Localities Change Request Document. Credit: Fire and Emergency New Zealand

FENZ's document allows for change requests to attach a map which is simple for individuals and organisations with GIS capabilities, but for the general public this is not likely to be the case. Rather than replace the change request document, an adjusted version of the Wellyhoods app could support this approach. By adding an interactive mapping element with demonstrated success in crowdsourcing neighbourhood delineations, individuals without GIS capabilities would be able to make change requests without their request being misinterpreted. Additionally, with enough promotion of the localities dataset and ability to make change requests using a easy to use app, FENZ could collect enough responses to add a community-driven element to the localities dataset which is the most official representation of New Zealand's neighbourhood boundaries. 


\section{Summary}

The crowdsourcing methodology was successful in collecting a large sample of perceived neighbourhood delineations from a variety of participants demographics and neighbourhoods. Drawbacks step from self-selection bias, restrictions on questionnaire design, and lower data quality than would be expected from a traditional survey. An extension of the app developed can potentially be a supplementary source of community driven data and feedback for the localities dataset.

\subsection{Summary}

The methodology of this thesis sought to investigate the effectiveness of a crowdsourcing approach for surveying residents about their neighbourhood. While containing limitations, the methodology demonstrated that a crowdsourcing approach can effectively sample neighbourhood delineations from a large sample of residents with less effort than traditional methods. Implications for official datasets of neighbourhood boundaries were discussed, such as the ability for community perspectives to highlight unrepresentative areas, and using a crowdsourcing survey tool to supplement traditional methods.

Individual's perception of physical aspects of their neighbourhoods contribute insight into Wellington City's urban environment. Neighbourhood consensus provides a unique and insightful perspective of complex neighbourhood geographies. Factors that influence ways individuals delineate their neighbourhoods were explored. Personal characteristics impacted neighbourhood perceptions, but the relationships were nuanced. Using Lynch's (1960) five elements of urban mental maps successfully provided a framework to categorise geographic features and explore their influence on

neighbourhood delineations. Lacking a formal and agreed upon definition, physical aspects of neighbourhoods will continue to be difficult to interpret quantitatively. 


\section{Chapter 7}

\section{Conclusion}

When we consider the physical aspect of neighbourhoods, a set of static, contiguous boundaries is the most common representation. In reality, we all have personal relationships and experiences with our neighbourhoods resulting in physical boundaries of neighbourhoods being complex, subjective, and ever-changing. Individuals can provide a unique perspective of the physical aspects of their neighbourhood. Capturing these perspectives through traditional methods is time consuming and commonly results in small sample sizes received for individual, isolated neighbourhoods. This thesis found that a crowdsourcing approach was successful in collecting a large sample of perceived neighbourhood delineations from a variety of neighbourhoods and participant demographics across a city. In comparison to traditional methods of surveying neighbourhood delineations from residents, limited effort was required to employ a crowdsourcing approach that can also be easily replicated in other locations or used to survey different physical aspects of neighbourhoods.

\subsection{Answering the Research Questions}

This thesis posed five research questions. Summaries of methods used to address and key findings of each the research questions are given below.

\section{How do personal characteristics impact neighbourhood delineation?}

Four linear regression models were fit testing relationships between participant's personal characteristics and neighbourhood dimensions of PNB area, perimeter, compactness, and number of vertices (Section 4.2). Out of participant's personal characteristics, length of residence, neighbourhood type, and transport decisions of walking and car use significantly impacted PNB area. No significant relationships were observed between age, gender, children, transport decisions of cycling and public transport and PNB area. This adds further inconsistency to the body of research examining similar relationships and prompts the need for a standardised method of surveying neighbourhood boundaries. 
Consistent with prior research, only PNB area was insightful in examining relationships between personal characteristics and perceived neighbourhood delineation. PNB perimeter, compactness, and number of vertices did not provide useful insight. For future research examining similar relationships, either only exploring PNB area or other neighbourhood dimensions than perimeter, compactness, or number of vertices may be worthwhile.

\section{What can collective individual neighbourhood definitions tell us about complex neighbourhood geographies?}

Representing neighbourhoods using static, contiguous boundaries does not capture the subjectivity and complexity of individuals' perceptions of their neighbourhoods. Doing so with consensus measures was one way of exploring how groups of participants collectively perceived their neighbourhood. Two approaches that utilised large sample sizes of overlapping PNBs were used to examine neighbourhood consensus: consensus hexagon maps and models of neighbourhood connectivity (Sections 4.3.1 and 4.3.2). Areas of high and low neighbourhood consensus were identified using hexagon maps, with areas that cause dissensus between neighbourhoods being of interest. Neighbourhood connectivity was a novel way of representing neighbourhood geographies using overlapping PNBs, and when weighted by either number of intersections or mean intersection area can identify neighbourhoods with high and low neighbourhood connectivity, such as Newtown and Karori (Figure 4.17). Unfortunately, the measures of neighbourhood consensus used had limited operational benefits, but rather were more interesting visualisations of collective neighbourhood geographies.

\section{How do crowdsourced neighbourhood boundaries compare to official boundaries?}

Official boundaries are commonly used to represent neighbourhoods in the dissemination of geographic health outcomes. They are the most accessible neighbourhood boundaries and are easily comparable between studies, but are limited by problems that produce bias, such as the MAUP, UGCoP, and local trap. As such, it is important that they are context appropriate and representative of the communities that live in them. Understanding discrepancies between official boundaries and individuals' perceptions of their neighbourhoods can be used to improve official boundaries and subsequently reduce bias in geographic health outcomes.

In Section 4.4, PNBs, Community Defined Neighbourhoods (CDNs), Localities, and Statistical Areas 2 (SA2s) in Wellington City were compared using four neighbourhood dimensions: area, perimeter, compactness, and number of vertices. Congruence was also used to compare shared areas of the four neighbourhood datasets. Large amounts of variation in area were observed for all four neighbourhood datasets, prompting the need to make size comparisons using median values. PNBs were most similar to SA2s in terms of area, with a similar median value. However, 
a higher congruence value was observed between PNBs and localities than between PNBs and SA2s. Both of these observations indicated that using a single measure to identify the most appropriate official boundary to represent PNBs is problematic. Overall, it was made clear that the sheer amount of variation in participants' PNBs is impossible to capture using a single set of neighbourhood boundaries. One way PNBs can be used to make official boundaries more representative of communities living in them is by identifying unrepresentative areas in official boundaries.

\section{What impact do geographic features have on neighbourhood perceptions?}

A framework using Lynch's (1960) five elements that contribute to mental maps of urban areas was used to interpret relationships between geographic features and perceived neighbourhood delineation. In Chapter 5, 13 case studies of man-made and natural geographic features in Wellington City were provided. Paths, edges, districts, nodes, and landmarks were all represented and impacted neighbourhood perceptions in a variety of ways. However, given the complexity and subjectivity of perceived neighbourhood delineations, testing relationships using purely quantitative methods was difficult and relied on visual observations at times. An approach combining qualitative and quantitative methods was identified as a way to create a more complete picture of how geographic features impact neighbourhood perceptions.

Neighbourhood Focal Points (FPs) were examined using Lynch's (1960) definition of nodes: large accessible areas that serve as the focus of a neighbourhood, district, or city. Following density-based clustering of FPs, neighbourhood shopping hubs were found to be the most common location for clustered FPs (Section 4.3.3). For neighbourhoods without a shopping hub, nodes were identified in various locations, such as home addresses and schools, but also a neighbourhood's defining feature, such as the shoreline for Lyall Bay. Cuba Street was also identified as a node of Wellington City's CBD due to its significance for some participants.

\section{Is a crowdsourcing methodology viable for collecting neighbourhood delineations?}

Through promotion and ease of use of the Wellyhoods app, the crowdsourcing approach successfully achieved a large sample of participants from a range of Wellington City's neighbourhoods and participant demographics. 920 responses were received during the 3 month data collection period. Data quality was generally high, with only 3.7\% (32) responses excluded leaving 886 crowdsourced neighbourhood delineations for analysis. A clear advantage to traditional approaches of collecting neighbourhood perceptions was the comparative ease of implementing the crowdsourcing approach, as well as the ability to easily replicate for other locations.

The success of the crowdsourcing approach has implications for the way change requests are made to the localities dataset. The document used (Figure 6.8) is antiquated and limited by its lack of a 
mapping component. While unable to completely replace the existing approach, success could be seen by supplementing it with a variant of the Wellyhoods app to provide an interactive, geographic element and allow individuals without GIS capabilities to make meaningful requests.

\subsection{Future Research Directions}

The success of a crowdsourcing approach used to collect neighbourhood delineations opens avenues for future research. It is often difficult to understand why participants delineated their neighbourhood in the way that they did. Neighbourhood geographies are complex and multi-faceted meaning inferences made from using PNBs in analyses could be flawed at times (Lupton, 2003). Combining qualitative and quantitative methods of recording perceived neighbourhoods would address this problem. Integrating qualitative data with PNBs has been used to construct comprehensive depictions of perceived neighbourhood geographies (Talen \& Shah, 2007; Alidoust et al., 2017). Adding an optional supplementary survey asking what factors contributed to participant's neighbourhood delineations could result in a detailed examination of neighbourhood geographies from a large number of individuals reachable through a crowdsourcing approach.

Manually drawing a neighbourhood boundary is only one way of capturing PNBs. The Wellyhoods app used to survey neighbourhood delineations could be extended to collect PNBs through a variety of methods, such as:

- "Mark five points you consider to be inside your neighbourhood, and five points outside your neighbourhood". A neighbourhood area could be inferred using these points.

- "Choose hexagons you are 100\% confident are inside your neighbourhood, and 50\% confident are inside your neighbourhood". Grouping the hexagons would form two PNBs of $100 \%$ and $50 \%$ confidence.

- "Select the streets that form the boundary of your neighbourhood". A participant's PNB could be interpreted as area covered by the chosen streets.

While this approach would likely result in a smaller sample size because of the increased effort required to contribute, the data produced might provide a unique view into how individuals perceive their neighbourhood in a range of ways. Comparisons between the different methods of recording neighbourhood boundaries could be made and ranked based on how accurately they represent neighbourhood geographies.

Collecting participants' home addresses using a crowdsourcing approach would be valuable and open new avenues for exploration. Financial incentives may be required to motivate participants to 
provide their home address (Katmada et al., 2016), otherwise a less aggregated option of recording home address, such as selecting a $100 \mathrm{~m}^{2}$ raster cell containing home address, may see success. Buffers of home addresses have been used to represent neighbourhoods adding another neighbourhood representation to compare with (Minnery et al., 2009; Charreire et al., 2016; Perchoux et al., 2016). Comparing distances between FPs, home addresses, and PNB centroids (fixed and population weighted) could provide insight into internal neighbourhood perceptions. Additionally, a relationship between these distances and personal characteristics related to mobility, such as age, car access, and transport decisions, may be observed.

In this thesis, comparisons between PNBs and official boundaries were only made using the four neighbourhood dimensions (Section 4.4.1) and congruence (Section 4.4.2). Official boundaries which take the form of static grids of polygons are the predominant spatial unit in which geographic outcomes are presented, but these do not capture the different ways in which individuals perceive their neighbourhood boundaries (Lupton 2003; Coulton et al., 2013). Further comparisons between PNBs and official boundaries could be performed based on personal health outcomes, such as accessibility of primary healthcare (Apparicio et al., 2008), supermarkets and convenience stores (Pearce et al., 2008), and alcohol, tobacco, and fast food retailers (Schneider \& Gruber, 2013). Differences observed could highlight areas where official boundaries poorly reflect personal health outcomes for participants who provided neighbourhood boundaries,further illustrating the limitations of representing neighbourhoods as a fixed grid of polygons.

\subsection{Final Remarks}

Neighbourhood geographies are complex, subjective, and ever-changing. To that effect, surveying individuals' perceptions of their neighbourhoods is fundamental to further our understanding into the different ways individuals perceive their neighbourhoods. This thesis has demonstrated that crowdsourcing neighbourhood delineations is an effective approach to achieve a large sample size of diverse responses with minimal effort. Crowdsourced neighbourhood delineations provide unique insight collective neighbourhood definitions, highlight unrepresentative areas of official boundaries, and allow for a deep exploration of the relationships between neighbourhood perceptions, our personal characteristics, and features of urban environments. It is important for research on perceived neighbourhood geographies to continue, as the sheer variety of ways in which individuals experience and perceive their neighbourhoods makes defining neighbourhoods operationally and physically persistently difficult. 


\section{References}

Alidoust, S., Bosman, C., Holden, G., Shearer, H., \& Shutter, L. (2017). The spatial dimensions of neighbourhood: how older people define it. Journal of Urban Design, 22(5), 547-567. https://doi.org/10.1080/13574809.2017.1336057

Alivand, M., \& Hochmair, H. (2013). Extracting scenic routes from VGI data sources. Proceedings of the Second ACM SIGSPATIAL International Workshop on Crowdsourced and Volunteered Geographic Information - GEOCROWD 13, 23-30. https://doi.org/10.1145/2534732.2534743

Anselin, L., \& Williams, S. (2016). Digital neighborhoods. Journal of Urbanism: International Research on Placemaking and Urban Sustainability, 9(4), 305-328. https://doi.org/10.1080/17549175.2015.1080752

Apparicio, P., Abdelmajid, M., Riva, M., \& Shearmur, R. (2008). Comparing alternative approaches to measuring the geographical accessibility of urban health services: Distance types and aggregation-error issues. International journal of health geographics, $7(1), 7$. https://doi.org/10.1186/1476-072X-7-7

Ballatore, A., \& De Sabbata, S. (2018, June). Charting the geographies of crowdsourced information in Greater London. In The Annual International Conference on Geographic Information Science (pp. 149-168). Springer, Cham.

Basiri, A., Haklay, M., Foody, G., \& Mooney, P. (2019). Crowdsourced geospatial data quality: challenges and future directions. International Journal of Geographical Information Science, 33(8), 1588-1593. https://doi.org/10.1080/13658816.2019.1593422

Bastin, L., Schade, S., \& Mooney, P. (2018). Volunteered Metadata, and Metadata on VGI: Challenges and Current Practices. In Mobile Information Systems Leveraging Volunteered Geographic Information for Earth Observation (pp. 151-172). Springer International Publishing. https://doi.org/10.1007/978-3-319-70878-2_8

Bethlehem, J. (2008). How accurate are self-selection web surveys?. Statistics Netherlands Discussion paper, (08014). 
Bishr, M., \& Janowicz, K. (2010, September). Can we Trust Information? - The Case of Volunteered Geographic Information. In Towards Digital Earth Search Discover and Share Geospatial Data Workshop at Future Internet Symposium, volume (Vol. 640).

Black, J. L., \& Macinko, J. (2008). Neighborhoods and obesity. Nutrition Reviews, 66(1), 2-20. https://doi.org/10.1111/j.1753-4887.2007.00001.x

Bonney, R., Cooper, C. B., Dickinson, J., Kelling, S., Phillips, T., Rosenberg, K. V., \& Shirk, J. (2009). Citizen Science: A Developing Tool for Expanding Science Knowledge and Scientific Literacy. BioScience, 59(11), 977-984. https://doi.org/10.1525/bio.2009.59.11.9

Brabham, D. C. (2013). Crowdsourcing. MIT Press.

Brindley, P., Goulding, J., Wilson, M. L. (2018). Generating vague neighbourhoods through data mining of passive web data. International Journal of Geographical Information Science, 32(3), 498-523. https://doi.org/10.1080/13658816.2017.1400549

Brooklyn Wind Turbine. (n.d.). Meridian. Retrieved March 12, 2020, from https://www. meridianenergy.co.nz/who-we-are/our-power-stations/wind/brooklyn

Brown, G. G. (2012). An empirical evaluation of the spatial accuracy of public participation GIS (PPGIS) data. Applied Geography, 34, 289-294. https://doi.org/10.1016/j.apgeog.2011.12.004

Brown, G. G., \& Reed, P. (2009). Public participation GIS: a new method for use in national forest planning. Forest science, 55(2), 166-182.

Bugs, G. (2012, June). Assessment of online PPGIS study cases in urban planning. In International Conference on Computational Science and Its Applications (pp. 477-490). Springer, Berlin, Heidelberg.

Campbell, E., Henly, J. R., Elliott, D. S., \& Irwin, K. (2009). Subjective Constructions of Neighborhood Boundaries: Lessons from a Qualitative Study of Four Neighborhoods. Journal of Urban Affairs, 31(4), 461-490. https://doi.org/10.1111/j.1467-9906.2009.00450.x

Cavallo, S., Lynch, J., \& Scull, P. (2014). The Digital Divide in Citizen-Initiated Government Contacts: A GIS Approach. Journal of Urban Technology, 21(4), 77-93. https://doi.org/10.1080/10630732.2014.942167

Chaix, B., Kestens, Y., Perchoux, C., Karusisi, N., Merlo, J., \& Labadi, K. (2012). An Interactive Mapping Tool to Assess Individual Mobility Patterns in Neighborhood Studies. American Journal of Preventive Medicine, 43(4), 440-450. https://doi.org/10.1016/j.amepre.2012.06.026 
Charreire, H., Feuillet, T., Roda, C., Mackenbach, J. D., Compernolle, S., Glonti, K., ... \& De Bourdeaudhuij, I. (2016). Self-defined residential neighbourhoods: size variations and correlates across five European urban regions. Obesity Reviews, 17, 9-18. https://doi.org/10.1111/obr.12380

Chen, C., Gong, H., \& Paaswell, R. (2008). Role of the built environment on mode choice decisions: additional evidence on the impact of density. Transportation, 35(3), 285-299.

Clapp, J. M., \& Wang, Y. (2006). Defining neighborhood boundaries: Are census tracts obsolete? Journal of Urban Economics, 59(2), 259-284. https://doi.org/10.1016/j.jue.2005.10.003

Clougherty, J. E., \& Kubzansky, L. D. (2009). A framework for examining social stress and susceptibility to air pollution in respiratory health. Environmental health perspectives, 117(9), 1351-1358. https://doi.org/10.1289/ehp.0900612

Conrow, L., Wentz, E., Nelson, T., \& Pettit, C. (2018). Comparing spatial patterns of crowdsourced and conventional bicycling datasets. Applied Geography, 92, 21-30. https://doi.org/10.1016/j.apgeog.2018.01.009

Coulton, C. J., Jennings, M. Z., \& Chan, T. (2013). How Big is My Neighborhood? Individual and Contextual Effects on Perceptions of Neighborhood Scale. American Journal of Community Psychology, 51(12), 140-150. https://doi.org/10.1007/s10464-012-9550-6

Coulton, C. J., Korbin, J., Chan, T., \& Su, M. (2001). Mapping Residents Perceptions of Neighborhood Boundaries: A Methodological Note. American Journal of Community Psychology, 29(2), 371-383. https://doi.org/10.1023/A:1010303419034

Coulton, C., Chan, T., \& Mikelbank, K. (2011). Finding Place in Community Change Initiatives: Using GIS to Uncover Resident Perceptions of their Neighborhoods. Journal of Community Practice, 19(1), 10-28. https://doi.org/10.1080/10705422.2011.550258

Crawford, T. W., Pitts, S. B. J., McGuirt, J. T., Keyserling, T. C., \& Ammerman, A. S. (2014). Conceptualizing and comparing neighborhood and activity space measures for food environment research. Health $\&$ Place, 30, 215-225. https://doi.org/10.1016/j.healthplace.2014.09.007

Cummins, S. (2007). Commentary: Investigating neighbourhood effects on health-avoiding the Local Trap. International Journal of Epidemiology, 36(2), 355-357. https://doi.org/10.1093/ije/dym033

Curtis, J. W., Shiau, E., Lowery, B., Sloane, D., Hennigan, K., \& Curtis, A. (2014). The Prospects and Problems of Integrating Sketch Maps with Geographic Information Systems to Understand Environmental Perception: A Case Study of Mapping Youth Fear in Los Angeles Gang Neighborhoods. Environment and Planning B: Planning and Design, 41(2), 251-271. https://doi.org/10.1068/b38151 
Diez Roux, A. V. (2001). Investigating Neighborhood and Area Effects on Health. American Journal of Public Health, 91 (11), 1783-1789. https://doi.org/10.2105/AJPH.91.11.1783

Dillman, D. A., Smyth, J. D., \& Christian, L. M. (2014). Internet, phone, mail, and mixed-mode surveys: the tailored design method. John Wiley \& Sons.

Dorn, H., Törnros, T., \& Zipf, A. (2015). Quality Evaluation of VGI Using Authoritative DataA Comparison with Land Use Data in Southern Germany. ISPRS International Journal of GeoInformation, 4 (3), 1657-1671. https://doi.org/10.3390/ijgi4031657

Duncan, D. T., Kawachi, I., Subramanian, S. V., Aldstadt, J., Melly, S. J., \& Williams, D. R. (2014). Examination of how neighborhood definition influences measurements of youths' access to tobacco retailers: a methodological note on spatial misclassification. American journal of epidemiology, $179(3), 373-381$.

Edwards, P. J., Roberts, I., Clarke, M. J., DiGuiseppi, C., Wentz, R., Kwan, I., ... \& Pratap, S. (2009). Methods to increase response to postal and electronic questionnaires. Cochrane database of systematic reviews, (3). https://doi.org/10.1002/14651858.MR000008.pub4

Elwood, S. (2006). Negotiating Knowledge Production: The Everyday Inclusions, Exclusions, and Contradictions of Participatory GIS Research. The Professional Geographer, 58(2), 197-208. https://doi.org/10.1111/j.1467-9272.2006.00526.x

Ewing, R., \& Cervero, R. (2010). Travel and the built environment: A meta-analysis. Journal of the American planning association, 76 (3), 265-294. https://doi.org/10.1080/01944361003766766

Farber, S., Morang, M. Z., \& Widener, M. J. (2014). Temporal variability in transit-based accessibility to supermarkets. Applied Geography, 53, 149-159. https://doi.org/10.1016/j.apgeog.2014.06.012

Flanagin, A. J., \& Metzger, M. J. (2008). The credibility of volunteered geographic information. GeoJournal, 72(34), 137-148. https://doi.org/10.1007/s10708-008-9188-y

Flowerdew, R., Manley, D. J., \& Sabel, C. E. (2008). Neighbourhood effects on health: Does it matter where you draw the boundaries? Social Science \& Medicine, 66(6), 1241-1255. https://doi.org/10.1016/j.socscimed.2007.11.042

Ford, A., Gerds, C., \& Prosee, S. (2017). Data Report. Let's Get Wellington Moving. Retrieved March 12, 2020, from https://lgwm.nz/assets/Uploads/LGWM-Data-Report.pdf.

Forrest, R., \& Kearns, A. (2001). Social Cohesion, Social Capital and the Neighbourhood. Urban Studies, 38(12), 2125-2143. https://doi.org/10.1080/00420980120087081 
Galster, G. (2001). On the Nature of Neighbourhood. Urban Studies, 38(12), 2111-2124. https://doi.org/10.1080/00420980120087072

Galster, G. (1986). What is neighbourhood? An externality-space approach. International Journal of Urban and Regional Research, 10(20), 243-263.

Golledge, R. G. (1997). Spatial behavior: A geographic perspective. Guilford Press.

Goodchild, M. F. (2007). Citizens as sensors: the world of volunteered geography. GeoJournal, $69(4)$, 211-221. https://doi.org/10.1007/s10708-007-9111-y

Goodchild, M. F., \& Li, L. (2012). Assuring the quality of volunteered geographic information. Spatial Statistics, 1, 110-120. https://doi.org/10.1016/j.spasta.2012.03.002

Gould, P., \& White, R. (1974). Mental Maps. Routledge.

Great Kererū Count. (2018). The Great Kererū Count 2018. Retrieved March 12, 2020, from https://www.greatkererucount.nz/

Guest, A. M., \& Lee, B. A. (1984). How urbanites define their neighborhoods. Population and Environment, 7(1), 32-56. https://doi.org/10.1007/BF01257471

Haklay, M. (2010). How Good is Volunteered Geographical Information? A Comparative Study of OpenStreetMap and Ordnance Survey Datasets. Environment and Planning B: Planning and Design, 37(4), 682-703. https://doi.org/10.1068/b35097

Haklay, M. (2013). Citizen Science and Volunteered Geographic Information: Overview and Typology of Participation. Crowdsourcing Geographic Knowledge: Volunteered Geographic Information (VGI) in Theory and Practice, 9789400745, 105-122. https://doi.org/10.1007/978-94-007-4587$2+7$

Haklay, M. (2016). Why is participation inequality important?. Ubiquity Press.

Haklay, M, \& Tobón, C. (2003). Usability evaluation and PPGIS: towards a user-centred design approach. International Journal of Geographical Information Science, 17(6), 577-592. https://doi.org/10.1080/1365881031000114107

Haney, W. G., \& Knowles, E. S. (1978). Perception of neighborhoods by city and suburban residents. Human Ecology, 6(2), 201-214. https://doi.org/10.1007/BF00889095

Harris, R., Sleight, P., \& Webber, R. (2005). Geodemographics, GIS and neighbourhood targeting (Vol. 8). John Wiley \& Sons. 
Hecht, B., \& Stephens, M. (2014, May). A tale of cities: Urban biases in volunteered geographic information. In Eighth International AAAI Conference on Weblogs and Social Media.

Heckman, J. J. (1977). Sample selection bias as a specification error (with an application to the estimation of labor supply functions (No. w0172). National Bureau of Economic Research.

Heipke, C. (2010). Crowdsourcing geospatial data. ISPRS Journal of Photogrammetry and Remote Sensing, 65(6), 550-557. https://doi.org/10.1016/j.isprsjprs.2010.06.005

Horton, F. E., \& Reynolds, D. R. (1971). Effects of Urban Spatial Structure on Individual Behavior. Economic Geography, 47(1), 36. https://doi.org/10.2307/143224

Jenkins, A., Croitoru, A., Crooks, A. T., \& Stefanidis, A. (2016). Crowdsourcing a Collective Sense of Place. PloS one, 11(4). https://doi.org/10.1371/journal.pone.0152932

Jenks, M., \& Dempsey, N. (2007). Defining the neighbourhood: Challenges for empirical research. Town Planning Review, 78(2), 153-177. https://doi.org/10.3828/tpr.78.2.4

Jones, M., \& Pebley, A. R. (2014). Redefining Neighborhoods Using Common Destinations: Social Characteristics of Activity Spaces and Home Census Tracts Compared. Demography, 51 (3), 727752. https://doi.org/10.1007/s13524-014-0283-Z

Kalantari, M., Rajabifard, A., Olfat, H., \& Williamson, I. (2014). Geospatial Metadata 2.0 An approach for Volunteered Geographic Information. Computers, Environment and Urban Systems, 48, 35-48. https://doi.org/10.1016/j.compenvurbsys.2014.06.005

Karori Tunnel. (n.d.). Wellington City Council. Retrieved March 12, 2020, from https://wellington. govt.nz/your-council/projects/karori-tunnel

Katmada, A., Satsiou, A., \& Kompatsiaris, I. (2016, September). Incentive mechanisms for crowdsourcing platforms. In International Conference on Internet Science (Vol. 9934, pp. 3-18). Springer International Publishing. https://doi.org/10.1007/978-3-319-45982-0_1

Kawachi, I., \& Berkman, L. F. (Eds.). (2003). Neighborhoods and health. Oxford University Press.

Kearns, A., \& Parkinson, M. (2001). The Significance of Neighbourhood. Urban Studies, 38(12), 2103-2110. https://doi.org/10.1080/00420980120087063

Knigge, L., \& Cope, M. (2006). Grounded Visualization: Integrating the Analysis of Qualitative and Quantitative Data through Grounded Theory and Visualization. Environment and Planning A: Economy and Space, 38(11), 2021-2037. https://doi.org/10.1068/a37327 
Kresek, K. (2018). Are perceived neighborhoods palimpsests? Analyzing self-defined neighborhoods in the context of historical redlining (Honors Thesis, University of Colorado Boulder, Boulder, USA). Retrieved March 12, 2020, from https://scholar.colorado.edu/concern/undergraduate_ honors_theses/qb98mf962

Kwan, M. P. (2004). Gis methods in timegeographic research: geocomputation and geovisualization of human activity patterns. Geografiska Annaler: Series B, Human Geography, 86(4), 267-280. https://doi.org/10.1111/j.0435-3684.2004.00167.x

Kwan, M. P. (20012). The Uncertain Geographic Context Problem. Annals of the Association of American Geographers, 102(5), 958-968. https://doi.org/10.1080/00045608.2012.687349

Kwan, M. P., \& Ding, G. (2008). Geo-narrative: Extending geographic information systems for narrative analysis in qualitative and mixed-method research. The Professional Geographer, 60(4), 443-465. https://doi.org/10.1080/00330120802211752

Lohmann, A., \& McMurran, G. (2009). Resident-Defined Neighborhood Mapping: Using GIS to Analyze Phenomenological Neighborhoods. Journal of Prevention 6 Intervention in the Community, 37(1), 66-81. https://doi.org/10.1080/10852350802498714

Lupton, R. (2003). Neighbourhood effects: can we measure them and does it matter? LSE STICERD Research Paper No. CASE073.

Lynch, K. (1960). The Image of the City. Cambridge: MIT Press.

Meng, Y., \& Malczewski, J. (2010). Web-PPGIS usability and public engagement: a case study in Canmore, Alberta, Canada. URISA Journal, 22(1), 55.

Minnery, J., Knight, J., Byrne, J., \& Spencer, J. (2009). Bounding Neighbourhoods: How Do Residents Do It? Planning Practice 8 Research, 24(4), 471-493. https://doi.org/10.1080/02697450903327170

Montello, D. R., Goodchild, M. F., Gottsegen, J., \& Fohl, P. (2003). Wheres Downtown?: Behavioral Methods for Determining Referents of Vague Spatial Queries. Spatial Cognition 83 Computation, 3(23), 185-204. https://doi.org/10.1080/13875868.2003.9683761

Mooney, P., Olteanu-Raimond, A. M., Touya, G., Juul, N., Alvanides, S., \& Kerle, N. (2017). Considerations of privacy, ethics and legal issues in volunteered geographic information. In Mapping and the citizen sensor (pp. 119-136). London: Ubiquity Press. https://doi.org/10.5334/bbf

Mujahid, M. S., \& Roux, A. V. D. (2010). Neighborhood factors in health. In Handbook of behavioral medicine (pp. 341-354). Springer, New York, NY. 
Neis, P., \& Zipf, A. (2012). Analyzing the Contributor Activity of a Volunteered Geographic Information Project - The Case of OpenStreetMap. ISPRS International Journal of Geo-Information, 1(2), 146-165. https://doi.org/10.3390/ijgi1020146

Nielsen, J. (2006). The 90-9-1 rule for participation inequality in social media and online communities.

Noy, C. (2008). Sampling knowledge: The hermeneutics of snowball sampling in qualitative research. International Journal of social research methodology, 11(4), 327-344. https://doi.org/10.1080/13645570701401305

O’Neil, A. (2015). Karori tunnel brought residents and riches from Wellington - 150 years of news. Dominion Post. Retrieved March 12, 2020, from https://www.stuff.co.nz/dominion-post/news/ 69592758/karori-tunnel-brought-residents-and-riches-from-wellington---150-years-of-news

Openshaw, S. (1981). The modifiable areal unit problem. Quantitative geography: A British view, 60-69.

Orford, S., \& Leigh, C. (2014). The Relationship between Self-reported Definitions of Urban Neighbourhood and Respondent Characteristics: A Study of Cardiff, UK. Urban Studies, 51 (9), 18911908. https://doi.org/10.1177/0042098013499795

Papadopoulou, C. A., \& Giaoutzi, M. (2014). Crowdsourcing as a tool for knowledge acquisition in spatial planning. Future internet, 6(1), 109-125. https://doi.org/10.3390/fi6010109

Pebley, A., \& Sastry, N. (2009). Our place: perceived neighborhood size and names in Los Angeles. UCLA CCPR Population Working Papers.

Pearce, J. (2006). Neighbourhoods and health: a GIS approach to measuring community resource accessibility. Journal of Epidemiology \&6 Community Health, 60(5), 389-395. https://doi.org/10.1136/jech.2005.043281

Pearce, J., Hiscock, R., Blakely, T., \& Witten, K. (2008). The contextual effects of neighbourhood access to supermarkets and convenience stores on individual fruit and vegetable consumption. Journal of Epidemiology \& Community Health, 62(3), 198-201. https://doi.org/10.1136/jech.2006.059196

Perchoux, C., Chaix, B., Brondeel, R., \& Kestens, Y. (2016). Residential buffer, perceived neighborhood, and individual activity space: New refinements in the definition of exposure areas The RECORD Cohort Study. Health \& Place, 40, 116-122. https://doi.org/10.1016/j.healthplace.2016.05.004 
Polsby, D. D., \& Popper, R. D. (1991). The third criterion: Compactness as a procedural safeguard against partisan gerrymandering. Yale Law \& Policy Review, 9(2), 301-353. https://doi.org/10.2139/ssrn.2936284

Purcell, M., \& Brown, J. C. (2005). Against the local trap: scale and the study of environment and development. Progress in Development Studies, 5(4), 279-297. https://doi.org/10.1191/1464993405ps122oa

Richardson, E. A., \& Mitchell, R. (2010). Gender differences in relationships between urban green space and health in the United Kingdom. Social science \& medicine, 71(3), 568-575. https://doi.org/10.1016/j.socscimed.2010.04.015

Robinson, A. I., \& Oreskovic, N. M. (2013). Comparing self-identified and census-defined neighborhoods among adolescents using GPS and accelerometer. International Journal of Health Geographics, 12(1), 57. https://doi.org/10.1186/1476-072X-12-57

Santos, S. M., Chor, D., \& Werneck, G. (2010). Demarcation of local neighborhoods to study relations between contextual factors and health. International Journal of Health Geographics, 9(1), 34. https://doi.org/10.1186/1476-072X-9-34

Sastry, N., Pebley, A. R., \& Zonta, M. (2002). Neighborhood definitions and the spatial dimension of daily life in Los Angeles.

Schlossberg, M., \& Shuford, E. (2005). Delineating "public" and "participation" in PPGIS.

Schmidt, M., Klettner, S., \& Steinmann, R. (2013, August). Barriers for contributing to VGI projects. In Proc. ICC (Vol. 13).

Schneider, S., \& Gruber, J. (2013). Neighbourhood deprivation and outlet density for tobacco, alcohol and fast food: first hints of obesogenic and addictive environments in Germany. Public Health Nutrition, 16(7), 1168-1177. https://doi.org/10.1017/S1368980012003321

Schwanen, T., \& Mokhtarian, P. L. (2005). What affects commute mode choice: neighborhood physical structure or preferences toward neighborhoods? Journal of Transport Geography, 13(1), 83-99. https://doi.org/10.1016/j.jtrangeo.2004.11.001

See, L., Mooney, P., Foody, G., Bastin, L., Comber, A., Estima, J., ... \& Liu, H. Y. (2016). Crowdsourcing, Citizen Science or Volunteered Geographic Information? The Current State of Crowdsourced Geographic Information. ISPRS International Journal of Geo-Information, 5(5), 55. https://doi.org/10.3390/ijgi5050055 
Severinsen, J., de Róiste, M., Reitsma, F., \& Hartato, E. (2019). VGTrust: measuring trust for volunteered geographic information. International Journal of Geographical Information Science, $33(8), 1683-1701$.

Sieber, R. (2006). Public Participation Geographic Information Systems: A Literature Review and Framework. Annals of the Association of American Geographers, 96(3), 491-507. https://doi.org/10.1111/j.1467-8306.2006.00702.x

Silvertown, J. (2009). A new dawn for citizen science. Trends in Ecology EG Evolution, 24 (9), 467-471. https://doi.org/10.1016/j.tree.2009.03.017

Singleton, A. D., \& Spielman, S. E. (2014). The Past, Present, and Future of Geodemographic Research in the United States and United Kingdom. The Professional Geographer, 66(4), 558567. https://doi.org/10.1080/00330124.2013.848764

Spielman, S. E., \& Yoo, E. (2009). The spatial dimensions of neighborhood effects. Social Science E Medicine, 68(6), 1098-1105. https://doi.org/10.1016/j.socscimed.2008.12.048

Statistics New Zealand. (2013). 2013 Census usually resident population counts. Retrieved March 12, 2020, from https://www.stats.govt.nz/information-releases/ 2013-census-usually-resident-population-counts

Stewart, T., Duncan, S., Chaix, B., Kestens, Y., Schipperijn, J., \& Schofield, G. (2015). A novel assessment of adolescent mobility: a pilot study. International Journal of Behavioral Nutrition and Physical Activity, 12(1), 18. https://doi.org/10.1186/s12966-015-0176-6

Sui, D., Elwood, S., \& Goodchild, M. (2013). Crowdsourcing geographic Knowledge: Volunteered geographic information (VGI) in theory and practice. Crowdsourcing Geographic Knowledge: Volunteered Geographic Information (VGI) in Theory and Practice, 9789400745(September), 1-396. http://doi.org/10.1007/978-94-007-4587-2

Sulsters, W. A. (2005, October). Mental mapping, viewing the urban landscapes of the mind. In International conference 'Doing, thinking, feeling home: the mental geography of residential environments', Delft, The Netherlands, October 14-15, 2005. Delft University of Technology, OTB Research Institute for the Built Environment.

Tailor, T. D., Choudhury, K. R., Tong, B. C., Christensen, J. D., Sosa, J. A., \& Rubin, G. D. (2019). Geographic access to CT for lung cancer screening: a census tract-level analysis of cigarette smoking in the United States and driving distance to a CT facility. Journal of the American College of Radiology, 16(1), 15-23. https://doi.org/10.1016/j.jacr.2018.07.007 
Talen, E., \& Shah, S. (2007). Neighborhood Evaluation Using GIS: An Exploratory Study. Environment and Behavior, 39(5), 583-615. https://doi.org/10.1177/0013916506292332

Tan, W., Liu, D., \& Bishu, R. (2009). Web evaluation: Heuristic evaluation vs. user testing. International Journal of Industrial Ergonomics, 39(4), 621-627. https://doi.org/10.1016/j.ergon.2008.02.012

Thatcher, J. (2014). Big data, big questions - Living on fumes: Digital footprints, data fumes, and the limitations of spatial big data. International Journal of Communication, 8, 19.

The jewel that is Rat Island. (2009). Dominion Post. Retrieved March 12, 2020, from http://www.stuff.co.nz/dominion-post/news/local-papers/the-wellingtonian/812466/ The-jewel-that-is-Rat-Island

Vallée, J., Le Roux, G., Chaix, B., Kestens, Y., \& Chauvin, P. (2015). The constant size neighbourhood trap in accessibility and health studies. Urban Studies, 52(2), 338-357. https://doi.org/10.1177/0042098014528393

Weiss, L., Ompad, D., Galea, S., \& Vlahov, D. (2007). Defining Neighborhood Boundaries for Urban Health Research. American Journal of Preventive Medicine, 32(6), S154-S159. https://doi.org/10.1016/j.amepre.2007.02.034

Wellington Airport. (2019). Market Report. Retrieved March 12, 2020, from https://www. wellingtonairport.co.nz/documents/3139/08_November_2019.pdf

Woodruff, A. (2017). Official unofficial neighbourhoods, 2017. Retrieved March 12, 2020, from https: //bostonography.com/2017/official-unofficial-neighborhoods-2017/

Zhang, G., \& Zhu, A.-X. (2018). The representativeness and spatial bias of volunteered geographic information: a review. Annals of GIS, $24(3)$, 151-162. https://doi.org/10.1080/19475683.2018.1501607

Zhao, J., \& Exeter, D. J. (2016). Developing intermediate zones for analysing the social geography of Auckland, New Zealand. New Zealand Geographer, 72(1), 14-27. https://doi.org/10.1111/nzg.12110

Zook, M., Graham, M., Shelton, T., \& Gorman, S. (2010). Volunteered Geographic Information and Crowdsourcing Disaster Relief: A Case Study of the Haitian Earthquake. World Medical \& Health Policy, 2(2), 6-32. https://doi.org/10.2202/1948-4682.1069 


\section{Appendix 1: Questionnaire}

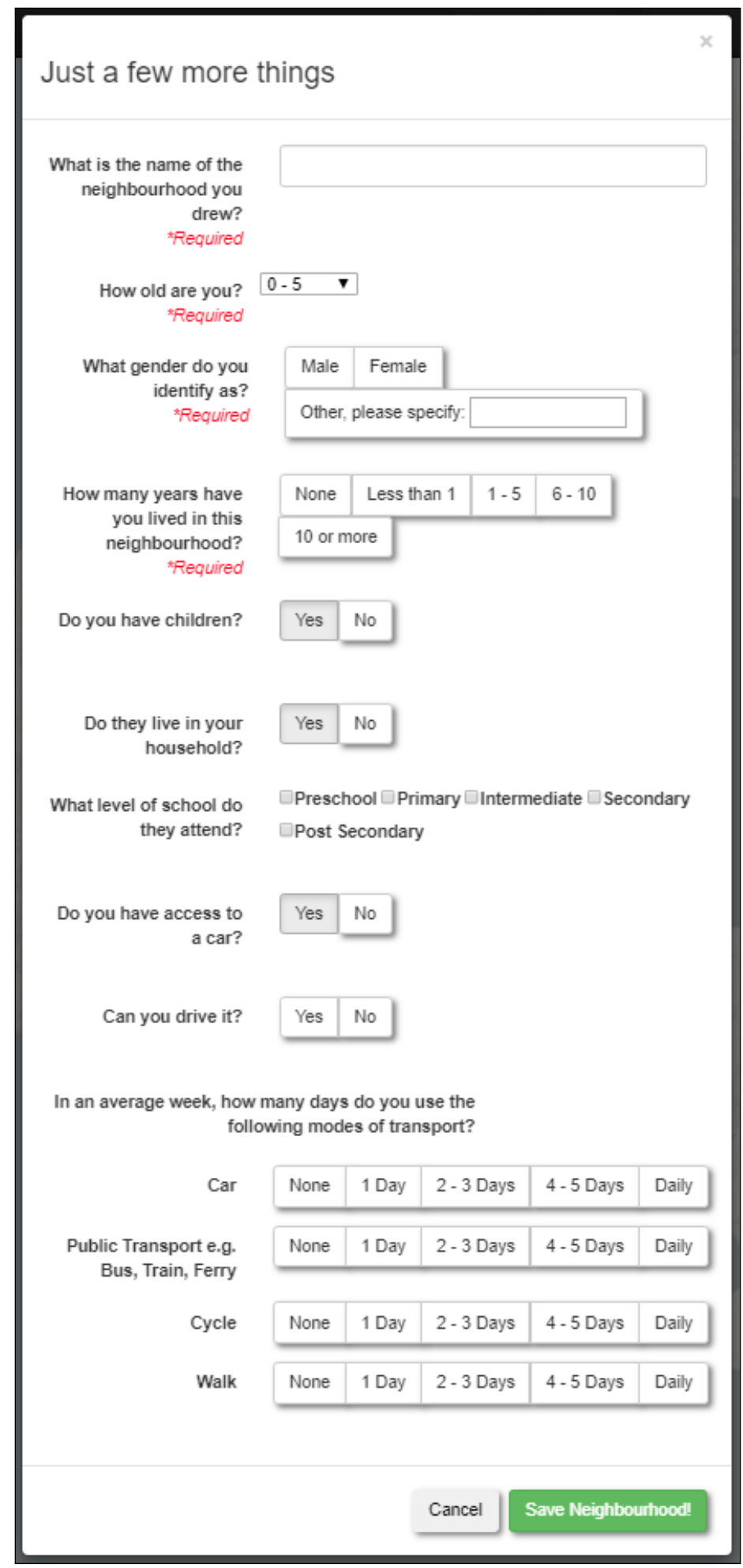




\section{Appendix 2: Results of Linear Regression Models}

\begin{tabular}{|c|c|c|c|c|c|c|c|c|c|c|c|c|c|}
\hline & \multirow[b]{2}{*}{ term } & \multicolumn{3}{|c|}{ Area $\left(\mathrm{Km}^{2}\right)$} & \multicolumn{3}{|c|}{ Perimeter $(\mathrm{Km})$} & \multicolumn{3}{|c|}{ Compactness } & \multicolumn{3}{|l|}{ Vertices } \\
\hline & & Estimate & Std Error & T Statistic & Estimate & Std Error & T Statistic & Estimate & Std Error & T Statistic & Estimate & Std Error & T Statistic \\
\hline & Intercept & -0.194 & 0.278 & -0.696 & 1.355 & 0.140 & $9.684^{* * *}$ & 0.696 & 0.039 & $17.839^{* * *}$ & 2.818 & 0.103 & $27.470^{* * *}$ \\
\hline \multirow[t]{6}{*}{ Age } & 11 to 20 & & & & & & & & & & & & \\
\hline & 21 to 30 & -0.095 & 0.128 & -0.738 & -0.038 & 0.064 & -0.587 & -0.011 & 0.018 & -0.585 & 0.047 & 0.047 & 1.002 \\
\hline & 31 to 40 & -0.015 & 0.158 & -0.092 & -0.016 & 0.079 & -0.205 & 0.013 & 0.022 & 0.565 & 0.003 & 0.058 & 0.048 \\
\hline & 41 to 50 & -0.265 & 0.190 & -1.394 & -0.137 & 0.096 & -1.432 & 0.019 & 0.027 & 0.729 & 0.070 & 0.070 & 1.002 \\
\hline & 51 to 60 & -0.380 & 0.263 & -1.445 & -0.219 & 0.132 & -1.656 & 0.035 & 0.037 & 0.954 & 0.031 & 0.097 & 0.316 \\
\hline & $60+$ & 0.019 & 0.344 & 0.055 & -0.009 & 0.173 & -0.054 & 0.023 & 0.048 & 0.470 & 0.196 & 0.127 & 1.548 \\
\hline \multirow[t]{3}{*}{ Gender } & Male & & & & & & & & & & & & \\
\hline & Female & 0.062 & 0.086 & 0.718 & 0.034 & 0.043 & 0.787 & 0.003 & 0.012 & 0.244 & -0.033 & 0.032 & -1.041 \\
\hline & Other & 0.130 & 0.340 & 0.381 & 0.028 & 0.171 & 0.163 & 0.050 & 0.048 & 1.047 & -0.039 & 0.125 & -0.308 \\
\hline \multirow[t]{4}{*}{ Years Lived } & Less than one & & & & & & & & & & & & \\
\hline & One to Five & 0.077 & 0.109 & 0.705 & 0.052 & 0.055 & 0.952 & -0.017 & 0.015 & -1.124 & 0.029 & 0.040 & 0.730 \\
\hline & Six to Ten & 0.305 & 0.154 & $1.988^{*}$ & 0.164 & 0.077 & $2.127^{*}$ & -0.014 & 0.022 & -0.665 & 0.058 & 0.057 & 1.030 \\
\hline & Ten or more & 0.464 & 0.132 & $3.500^{* * *}$ & 0.219 & 0.067 & $3.294^{* *}$ & 0.010 & 0.019 & 0.547 & 0.019 & 0.049 & 0.381 \\
\hline \multirow[t]{5}{*}{ Neighbourhood Type } & Single & & & & & & & & & & & & \\
\hline & Subset & -0.584 & 0.197 & $-2.957^{* *}$ & -0.263 & 0.099 & $-2.650^{* *}$ & -0.039 & 0.028 & -1.405 & -0.013 & 0.073 & -0.180 \\
\hline & Multiple & 0.378 & 0.172 & $2.196^{*}$ & 0.299 & 0.087 & $3.460^{* * *}$ & -0.112 & 0.024 & $-4.656^{* * *}$ & 0.132 & 0.063 & $2.081^{*}$ \\
\hline & Street & -2.272 & 0.181 & $-12.522^{* * *}$ & -1.116 & 0.091 & $-12.220^{* * *}$ & -0.006 & 0.025 & -0.232 & -0.174 & 0.067 & $-2.594^{* *}$ \\
\hline & Other & -0.811 & 0.216 & $-3.755^{* * *}$ & -0.395 & 0.109 & $-3.638^{* * *}$ & -0.001 & 0.030 & -0.025 & -0.006 & 0.080 & -0.080 \\
\hline \multirow[t]{2}{*}{ Children } & Yes & & & & & & & & & & & & \\
\hline & No & -0.114 & 0.126 & -0.902 & -0.046 & 0.064 & -0.729 & -0.009 & 0.018 & -0.498 & 0.032 & 0.047 & 0.682 \\
\hline \multirow[t]{2}{*}{ Car Access } & Yes & & & & & & & & & & & & \\
\hline & No & 0.289 & 0.147 & 1.962 & 0.153 & 0.074 & $2.065^{*}$ & -0.010 & 0.021 & -0.477 & 0.114 & 0.054 & $2.103^{*}$ \\
\hline \multirow[t]{5}{*}{ Car } & Zero & & & & & & & & & & & & \\
\hline & One & 0.156 & 0.153 & 1.019 & 0.074 & 0.077 & 0.960 & 0.004 & 0.021 & 0.191 & 0.120 & 0.056 & $2.124^{*}$ \\
\hline & Two to Three & 0.279 & 0.168 & 1.659 & 0.147 & 0.085 & 1.740 . & -0.005 & 0.024 & -0.202 & 0.091 & 0.062 & 1.469 \\
\hline & Four to Five & 0.419 & 0.204 & $2.054^{*}$ & 0.238 & 0.103 & $2.323^{*}$ & -0.035 & 0.029 & -1.206 & 0.113 & 0.075 & 1.502 \\
\hline & Daily & 0.605 & 0.181 & $3.347^{* * *}$ & 0.311 & 0.091 & $3.426^{* * *}$ & -0.012 & 0.025 & -0.481 & 0.032 & 0.067 & 0.484 \\
\hline \multirow[t]{5}{*}{ Public Transport } & Zero & & & & & & & & & & & & \\
\hline & One & 0.006 & 0.124 & 0.046 & 0.000 & 0.063 & -0.001 & 0.006 & 0.017 & 0.355 & 0.028 & 0.046 & 0.610 \\
\hline & Two to Three & 0.190 & 0.128 & 1.479 & 0.074 & 0.065 & 1.153 & 0.013 & 0.018 & 0.724 & 0.075 & 0.047 & 1.591 \\
\hline & Four to Five & 0.242 & 0.124 & 1.955 & 0.109 & 0.062 & 1.752 . & 0.013 & 0.017 & 0.736 & 0.012 & 0.046 & 0.266 \\
\hline & Daily & 0.270 & 0.157 & 1.717 & 0.132 & 0.079 & 1.666 . & 0.003 & 0.022 & 0.121 & 0.053 & 0.058 & 0.914 \\
\hline \multirow[t]{5}{*}{ Cycle } & Zero & & & & & & & & & & & & \\
\hline & One & 0.282 & 0.165 & 1.712 & 0.090 & 0.083 & 1.079 & 0.054 & 0.023 & $2.313^{*}$ & -0.018 & 0.061 & -0.299 \\
\hline & Two to Three & 0.348 & 0.155 & $2.243^{*}$ & 0.189 & 0.078 & $2.416^{*}$ & -0.015 & 0.022 & -0.693 & 0.098 & 0.057 & 1.712 \\
\hline & Four to Five & -0.053 & 0.257 & -0.208 & -0.014 & 0.129 & -0.110 & -0.016 & 0.036 & -0.449 & 0.063 & 0.095 & 0.661 \\
\hline & Daily & -0.524 & 0.256 & $-2.042^{*}$ & -0.188 & 0.129 & -1.455 & -0.081 & 0.036 & $-2.247^{*}$ & 0.036 & 0.095 & 0.379 \\
\hline \multirow[t]{5}{*}{ Walk } & Zero & & & & & & & & & & & & \\
\hline & One & -0.161 & 0.182 & -0.888 & -0.054 & 0.091 & -0.591 & -0.026 & 0.026 & -1.019 & 0.017 & 0.067 & 0.254 \\
\hline & Two to Three & -0.156 & 0.161 & -0.971 & -0.037 & 0.081 & -0.456 & -0.042 & 0.023 & -1.875 & -0.002 & 0.059 & -0.028 \\
\hline & Four to Five & -0.180 & 0.172 & -1.048 & -0.051 & 0.087 & -0.591 & -0.042 & 0.024 & -1.739 & 0.067 & 0.063 & 1.056 \\
\hline & Daily & -0.388 & 0.149 & $-2.603^{* *}$ & -0.152 & 0.075 & $-2.032^{*}$ & -0.045 & 0.021 & $-2.163^{*}$ & 0.021 & 0.055 & 0.379 \\
\hline
\end{tabular}

$$
.=\mathrm{p}<0.10,{ }^{*}=\mathrm{p}<0.05,{ }^{* *}=\mathrm{p}<0.01,{ }^{* * *}=\mathrm{p}<0.001
$$

